Exergy Analysis in Industrial Food Processing

Filippos K. Zisopoulos

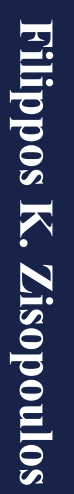

ชัต

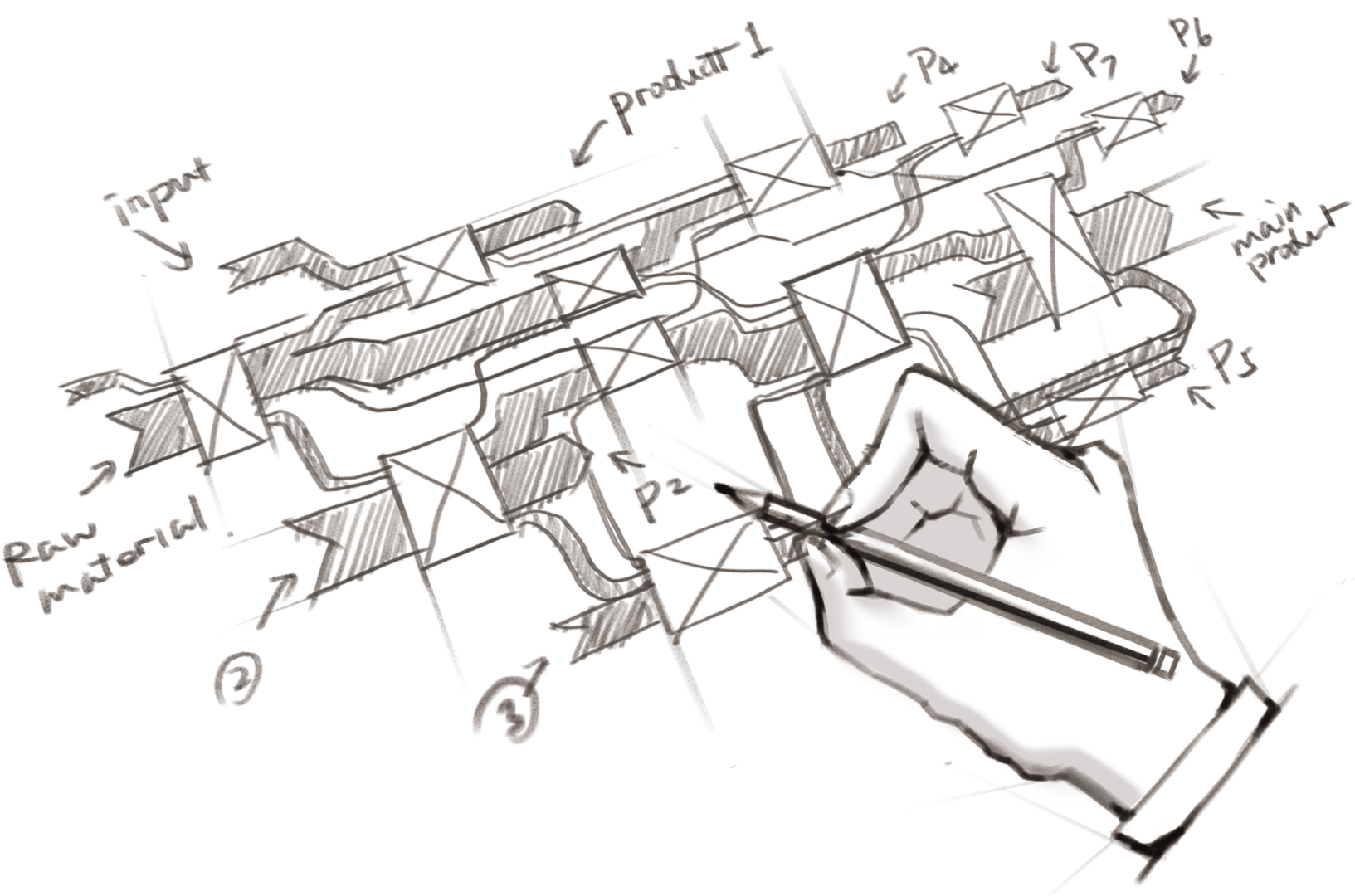




\section{Exergy analysis in}

\section{industrial food processing}

Filippos K. Zisopoulos 


\section{Thesis committee}

\section{Promotor}

Prof. Dr R.M. Boom

Professor of Food Process Engineering

Wageningen University

\section{Co-promotor}

Prof. Dr A.J. van der Goot

Personal chair at Food Process Engineering

Wageningen University

\section{Other members}

Prof. Dr M.A.J.S. van Boekel, Wageningen University

Prof. Dr J.H. Bitter, Wageningen University

Dr C. Pénicaud, INRA, Thiverval Grignon, France

Prof. Dr E. Zondervan, University of Bremen, Germany

This research was conducted under the auspices of the Graduate School VLAG (Advanced studies in Food Technology, Agrobiotechnology, Nutrition and Health Sciences). 


\title{
Exergy analysis in
}

\section{industrial food processing}

\author{
Filippos K. Zisopoulos
}

\author{
Thesis \\ submitted in fulfilment of the requirements for the degree of doctor \\ at Wageningen University \\ by the authority of the Rector Magnificus \\ Prof. Dr A.P.J. Mol, \\ in the presence of the \\ Thesis Committee appointed by the Academic Board \\ to be defended in public \\ on Wednesday 7 September 2016 \\ at 11 a.m. in the Aula.
}


Filippos K. Zisopoulos

Exergy Analysis in Industrial Food Processing 229 pages.

$\mathrm{PhD}$ thesis, Wageningen University, Wageningen, NL (2016)

With references, with summary in English

ISBN 978-94-6257-832-6

DOI $10.18174 / 383689$ 
"A journey of a thousand miles begins with a single step." Laozi, ancient Chinese philosopher and writer 


\section{Table of contents}

\section{Chapter 1}

\section{Introduction}

The purpose and objectives of industrial food production .............................. 2

The sustainable design of industrial food production chains............................. 3

Resource efficiency within the context of exergy ......................................... 6

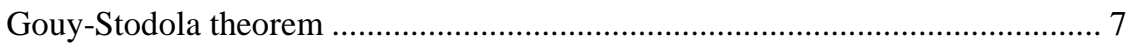

Why should the food industry use exergy analysis?................................... 8

Connecting exergy analysis with food process engineering ......................... 10

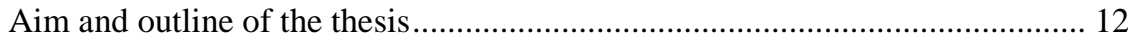

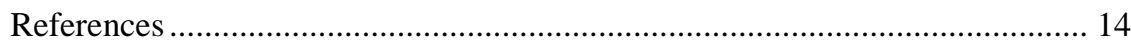

\section{Chapter 2}

\section{The use of exergetic indicators in the food industry - A review}

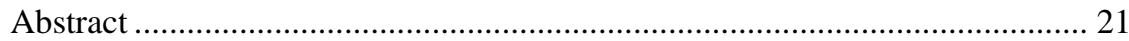

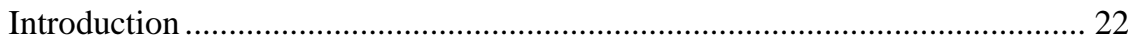

Applications of exergy analysis in the food industry .................................. 26

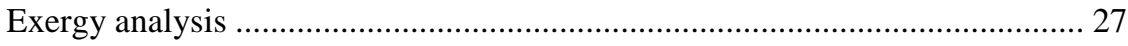

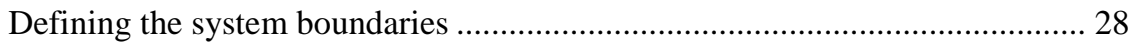

Defining the environment of reference..................................................... 28

Defining the relevant forms of exergy .......................................................... 29

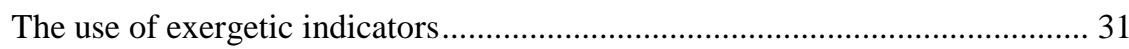

Communicating the results of an exergy analysis ........................................ 39

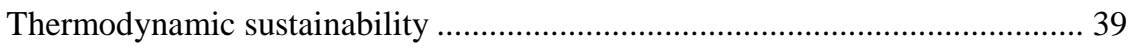


Current challenges and future trends in designing sustainable food chains ...... 41

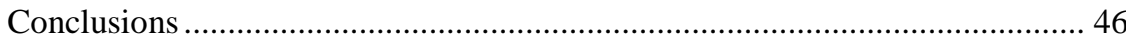

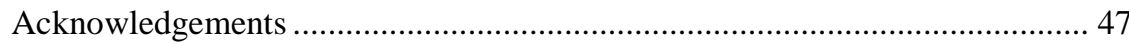

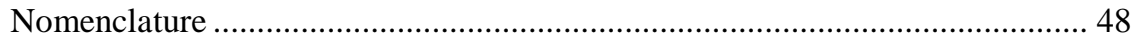

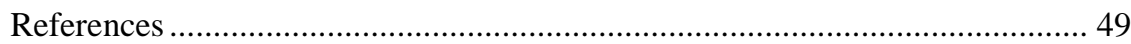

\section{Chapter 3}

Exergetic comparison of food waste valorization in industrial bread production

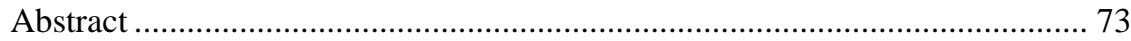

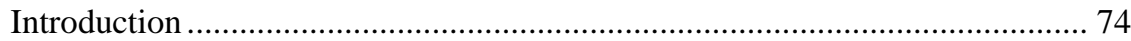

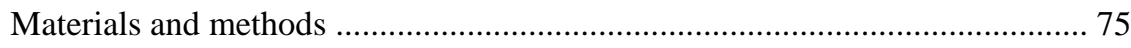

General description of the industrial bread production chains ...................... 75

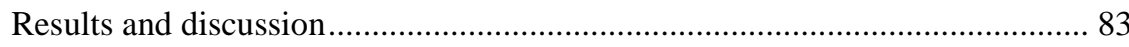

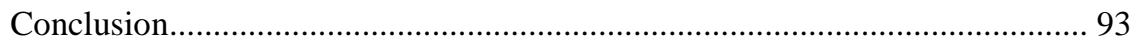

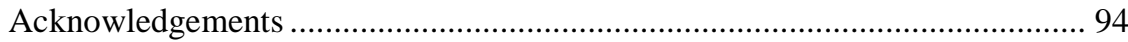

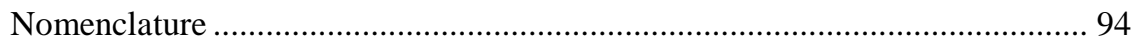

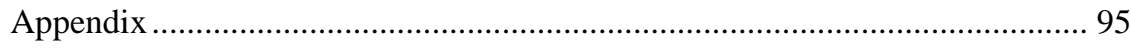

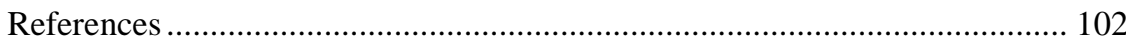

\section{Chapter 4}

\section{A resource efficiency assessment of the industrial mushroom production chain: The influence of data variability}

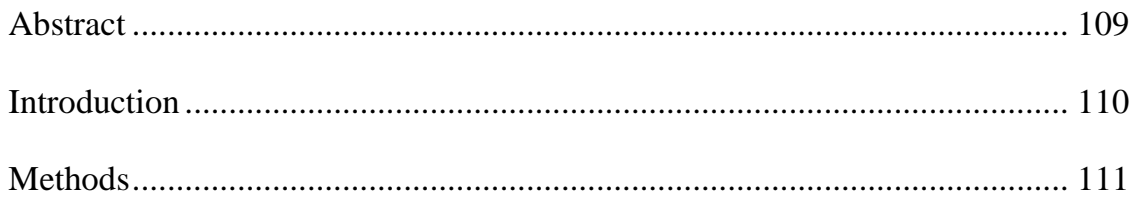




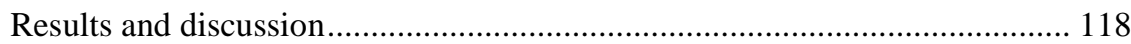

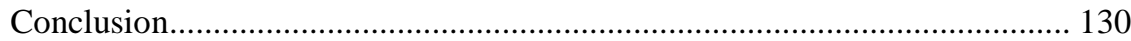

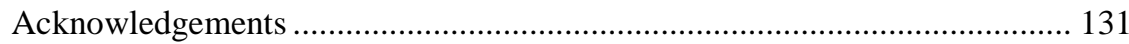

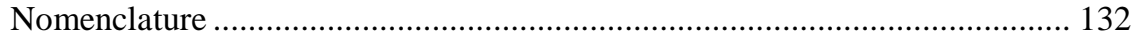

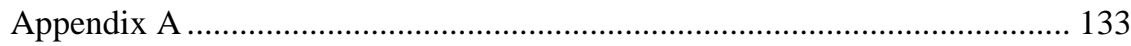

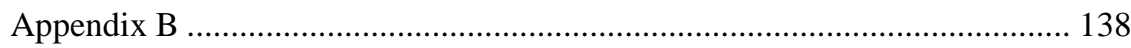

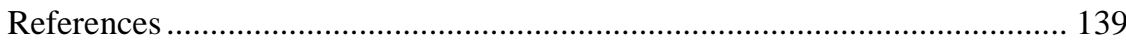

\section{Chapter 5}

\section{Thermodynamic efficiency analysis of a conceptual drying} process: Towards resource use efficiency in the food industry

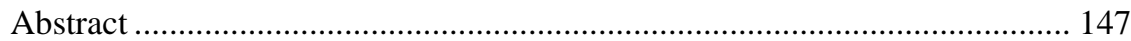

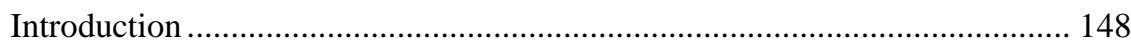

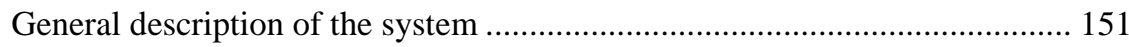

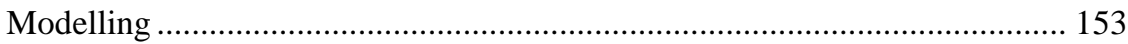

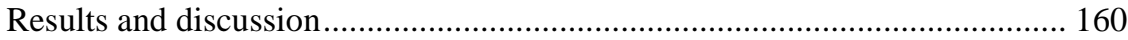

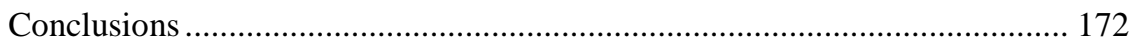

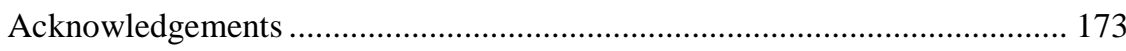

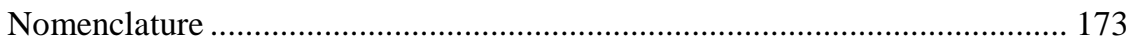

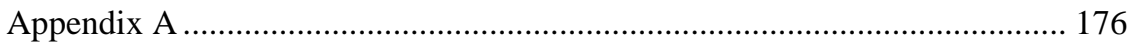

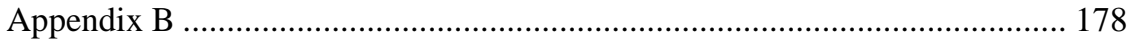

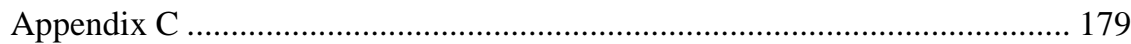

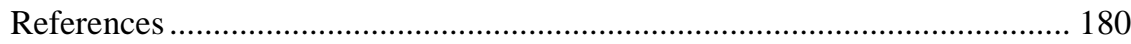




\section{Chapter 6}

\section{General discussion}

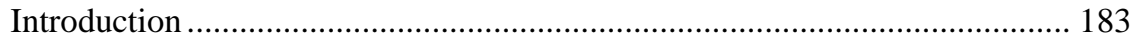

Methodological aspects of exergy analysis ............................................ 184

Consequences for the design of industrial food production chains ................ 200

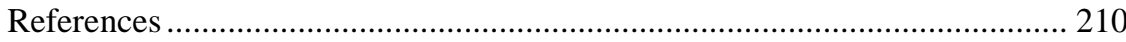

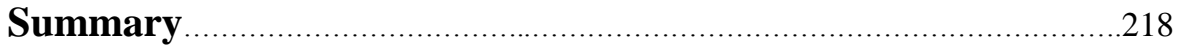

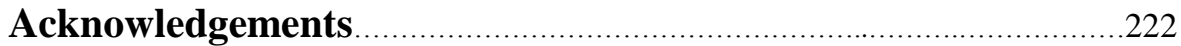

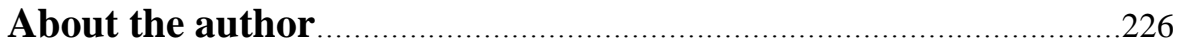

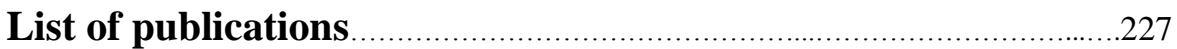

Overview of completed training activities...............................228 



\title{
Chapter 1
}

\author{
Introduction
}




\section{The purpose and objectives of industrial food production}

Industrial food production chains transform agricultural commodities into a vast diversity of food products and ingredients that are supplied to different markets. They can be very complex, connecting the primary sector with the food processing industry and the distribution sector [1]. A food production chain can be considered as a sequence of processes, either in series or in parallel, that induce physico- or biochemical transformations in agricultural raw materials to make them edible, safe, nutritious, and stable.

Food process engineering science has been used traditionally for the design of processes that lead to the creation of stable food products but its focus is integrating with the design of products themselves in the recent decades [2]. Therefore, the purpose of food process engineering science is to develop industrial food production chains that allow the manufacturing of desirable, healthy, shelf-stable, transportable, and profitable food products, and it is characterized by three main objectives (Figure 1) $[3,4]$. The first objective is the identification of all relevant phenomena that are necessary for food processing (e.g. phase changes, changes in physical and nutritional properties, changes in quality aspects, etc.). The second objective is the process system design (e.g. formulating the appropriate composition for obtaining pre-specified sensory profiles in the final product, identifying the optimal timetemperature combinations, etc.). The third objective is the optimal control of the designed process (e.g. maintenance of appropriate temperature and humidity levels, correction of $\mathrm{pH}$, etc.).

So far, the focus of food process engineering science was on designing individual processing steps rather than complete food production chains from raw materials to final products in an efficient manner. The large diversity in the physical and biochemical phenomena occurring during processing, and the lack of flexibility of most food processes in coping with changes in the properties of agricultural raw materials are some of the main reasons that make food process design complex [5]. Clearly, designing industrial food production chains is not a trivial task. 


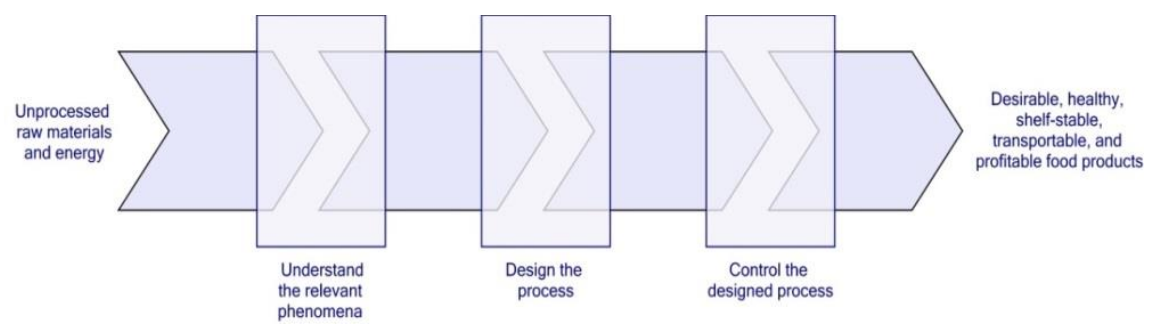

Figure 1. The purpose and the inherent objectives of food process engineering adapted by [3] and [4].

\section{The sustainable design of industrial food production chains}

A number of advancements have been made in the methodology for process design mainly in the chemical industry, which could also inspire the food industry. For example, process synthesis can be used for the systematic or even automatized selection of the "best" flowsheet of processes, even when limited information is available [6], while conceptual process design can assist in the design of cost-, and energy-effective processes [7].

A new approach for designing sustainable chemical processes is bio-refinery design which, unfortunately still translates into high capital investments and processing costs [8]. Additional design challenges include: a) the increased complexity due to environmental constraints and objectives to be optimized, b) the consideration of the whole supply chain (including the delivery and the disposal of the products), and c) the multiple sources of uncertainty (e.g. in the inventory of the assessment, in the demand and the market prices, etc.) [9].

Similar arguments hold for the design of industrial food production chains where foods are produced on a global scale to meet customer demands at a minimum cost, and where there is still a considerable improvement potential for the efficient utilization of raw materials, energy inputs, and side-streams. Important aspects that have been stressed are: the production of nutritious and healthy food, the communication of transparency and responsibility towards the consumers [10], and the promotion of industrial collaboration between and within organizations and 
companies to implement material waste recycling, energy cascading, and renewable energy use [11].

The interest in improving the sustainability of industrial food production chains is growing. There are numerous global initiatives for enhancing the awareness of both consumers and stakeholders in reducing food losses and food wasted along and across food networks $[12,13]$. This is partly borne from a cost perspective, but is also related to the awareness that with the future population of the Earth, we will not be able to sustain our current food production and consumption patterns, without making much better use of our resources.

New concepts emerge for value creation from food waste and biomass, for example by the extraction of valuable bio-active components using green technologies (e.g. microwave-assisted extraction, bio- and chemo-enzymatic conversions, cascade separations etc.) [14], or by biofuels production through hydrolysis [15] and biocatalysis [16]. This creates a different perspective on the whole chain, now not just for production of a single food component, but more and more oriented towards total use of a raw material for a range of products, including food ingredients, non-food, bio-based components, and biofuels.

Customizable conceptual models have been developed to help policy-makers and industry managers in identifying and monitoring locations in the food network where surpluses of food are generated and which could be reused depending on their "degree of recoverability" [17]. However, the usefulness of these models depends to a great extent on the structure of the network. On a societal level, it is not yet clear how to create the right incentives to convert our current industrial system towards one that would actively strive for total and efficient use of our resources.

Water and energy management methodologies and technologies are also encountered more frequently in the food industry. For example, Ruini et al. [18] estimated the water footprint of a pasta production food company where they identified the cultivation of wheat as the main contributor, and stressed the importance of considering virtual water fluxes involved in the complete chain. 
Ridoutt et al. [19] studied the water footprint of the Australian mango industry and they stressed that the food waste reduction along the mango chain could have a positive impact on freshwater savings that could be even greater than other water use efficiency measures. Muller et al. [20] proposed an energy management method for food production factories, which combines a multi-linear regression model for obtaining a holistic view of the energy consumption (top-down approach) with a thermodynamic assessment of the most energy-influential processes (bottom-up approach). Raghu Ram and Banerjee [21] showed that the thermodynamic performance of a sugar production factory could be improved considerably by adding a fifth evaporator stage. Becker et al. [22] compared the pros and cons of two different integration methods of a heat pump in a cheese production factory where, amongst others, they considered the easiness of implementation, investment costs, and energetic efficiency. Zhelev and Zheleva [23] developed a method for minimizing water and energy requirements, and for identifying trade-offs between these two objectives through a combined water and thermal pinch analysis. Evidently, the efforts in intensifying waste and energy reduction are becoming more popular in the food industry.

Traditionally, the focus of the food industry was on the production of safe and inexpensive food ingredients and products which is however characterised by the simultaneous generation of side-streams at the expense of considerable amounts of energy and raw materials. A modern way of designing food production chains is shifting from optimizing individual processes to formulating new products with desirable properties for consumers. In the future, the design methodology will shift towards bio-refinery and energy and material cascading concepts where wastestreams will be seen as valuable side-streams. Ultimately, sustainability will become the leading criterion for designing industrial food production chains to which the use of exergy-based methodologies will provide foundations for their objective assessment. 


\section{Resource efficiency within the context of exergy}

Sustainability generally considers economic, social and environmental aspects. This thesis is restricted to assessing the environmental performance of industrial food production chains in terms of resource efficiency. Here, resource efficiency is quantified with the concept of exergy, in which all material and energy flows attain values of usefulness, with the same unit (Joule), relative to a defined environment of reference. Exergy is the maximum amount of useful work that is embedded in the materials and energy resources, relative to the environment of reference, and which is obtained by the biological growth on the fields and farms, and is modified during the conversion process of one form of energy into another.

The essence of resource efficiency is reflected in the following definitions according to the Oxford dictionary [24]:

Resource: "A stock or supply of ... assets that can be drawn on by a person or organization in order to function effectively"

Efficiency: "(Of a system or machine) achieving maximum productivity with minimum wasted effort or expense"

Therefore, an industrial food production chain is resource efficient within the context of exergy when it achieves the highest utilizable output exergy (e.g. a portfolio of food products and/or services) with the lowest possible exergy losses and exergy investment drawn from the environment when producing food products.

The need for the use of objective sustainability assessment tools such as exergy analysis, is stressed by various authors [25-32]. The concept of exergy has been widely explored by the global scientific community with applications ranging from economics, where exergy was proposed as a "factor of production" that is equally important to labor and capital $[33,34]$, to the health assessment of ecosystems whose state and adaptation could be reflected in their structural exergy (ability to accept and utilize external fluxes of exergy) [35]. 


\section{Gouy-Stodola theorem}

To demonstrate the usefulness of exergy in estimating the utilizable work of a stream we analyse the conversion of thermal energy into work by a conceptual simple heat engine (Figure 2). Following the first law of thermodynamics, the total energy in an isolated system is constant, and the maximum work $W_{\max }$ obtained is:

$$
W_{\max }=Q_{H}-Q_{C}
$$

where $Q_{H}$, and $Q_{C}$, are the thermal energies of the hot source of temperature $T_{H}$, and the cold sink of temperature $T_{C}$, respectively.

The first law efficiency $\eta_{I}$ (also known as the Carnot efficiency) of the process is:

$$
\eta_{I}=\frac{W_{\max }}{Q_{H}}=\frac{Q_{H}-Q_{C}}{Q_{H}}=\frac{T_{H}-T_{C}}{T_{H}}=1-\frac{T_{C}}{T_{H}}
$$

This energy efficiency shows the upper bound of work that could be obtained by the heat engine in ideal conditions when operating at a particular temperature difference.

In exergy analysis, the actual useful work of a hot (or cold) stream is evaluated relative to a particular environment of reference of a temperature $T_{o}$. A "theoretical" heat engine between the streams and the environment is assumed to calculate the useful work from the difference between the thermal exergy of the hot $\left(B_{H}\right)$ and the cold $\left(B_{C}\right)$ stream:

$$
W_{\text {useful }}=B_{H}-B_{C}=\left(1-\frac{T_{o}}{T_{H}}\right) Q_{H}-\left(1-\frac{T_{o}}{T_{C}}\right) Q_{C}=Q_{H}-Q_{C}-T_{0} \frac{Q_{H}}{T_{H}}+T_{0} \frac{Q_{C}}{T_{C}}
$$

The ratio of thermal energy over temperature is entropy, and therefore:

$$
\begin{gathered}
W_{\text {useful }}=Q_{H}-Q_{C}-T_{o}\left(S_{H}-S_{C}\right) \\
W_{\text {useful }}=\Delta Q-T_{o} \Delta S \\
W_{\text {useful }}=W_{\text {max }}-B_{\text {destroyed }}
\end{gathered}
$$




$$
B_{\text {destroyed }}=T_{o} \Delta S
$$

This relation is known as the Gouy-Stodola relation that links exergy destruction (i.e. dissipation of thermal energy) to a change in entropy. Thermal gradients constitute only one type of the sources of exergy destruction. Differences in concentration, and pressure, for example, can also contribute to the production of irreversibility.

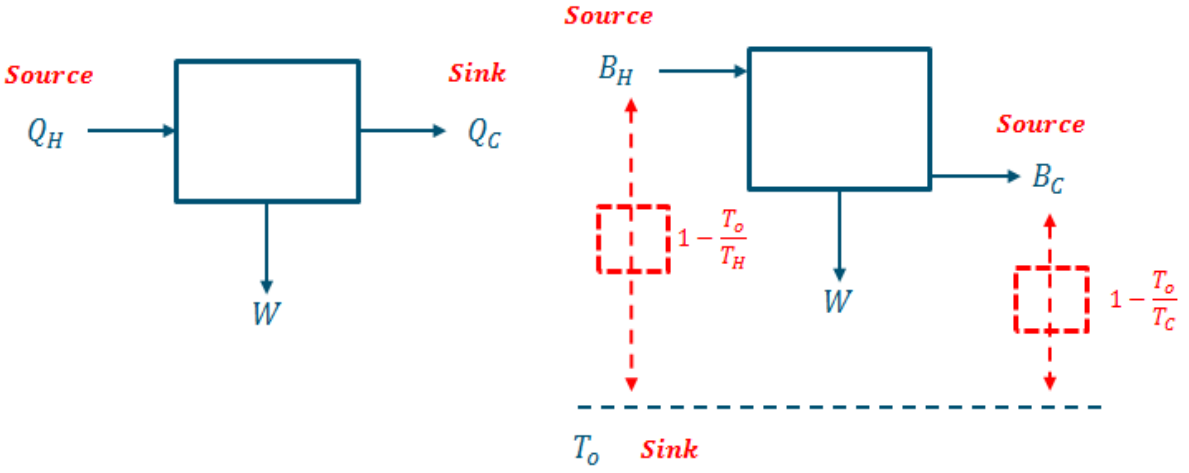

Figure 2. Conceptual heat engine where, left: energy analysis, and right: exergy analysis, are applied.

\section{Why should the food industry use exergy analysis?}

The usefulness of assessing industrial food production chains by exergy analysis can be summarized in four aspects:

- The first reason is that the method allows the identification of the minimum requirements of a process or even a complete food production chain, in terms of exergy destruction. In other words, we can estimate the minimum thermodynamic cost for producing a food product, which sets an absolute minimum of the use of resources for a particular activity. 
- Secondly, because we can identify the exact location, nature and size of any additional inefficiencies in the process that lead to exergy wasted (e.g. waste heat), and which could theoretically be reused because of its unexploited exergy content. In an exergy analysis all waste streams (including food losses and food waste as defined by Gustavsson et al. [12]) can be considered as side-streams that contain useful chemical, and potentially physical exergy that could be reused somewhere else in the system theoretically. In this thesis, the waste streams of a food production chain are distinguished as the raw materials, intermediate products, final products, emissions, and waste heat streams that are discarded to the environment for various reasons (e.g. quality aspects, spoilage, mismanagement etc.) without being used.

- Thirdly, because we can assess complete networks and sequences of processes, from raw materials to final products, to identify locations along the chain where considerable amounts of exergy are destroyed and/or wasted. Since exergy is a universal concept, it can be applied on any level and sub-level. This makes it suitable for the analysis of very complex systems.

- Fourthly, because exergy is a state variable, we can easily use it to compare whether a modification in a process design, or a different configuration of a set of processes will be beneficial for the thermodynamic sustainability of the overall system studied. For this we do not need detailed information of the actual workings of a system, as long as we know the inputs and outputs on the correct level of detail. 
By understanding how industrial food production chains perform exergetically, their eco-efficient design will be facilitated without the unnecessary degradation and depletion of natural resources. Food production chains that are well thought in their design, and focus, amongst others, on simplicity and adaptability in a constantly changing environment, will be of lasting value.

\section{Connecting exergy analysis with food process engineering}

For a better understanding of the type of research questions that can be addressed by exergy analysis in the field of food engineering, one has to place both individual scientific disciplines under a conceptual scheme to see how they can be connected. Becher proposed a scheme that identifies two main dimensions, each one with their respective set of properties $[36,37]$. The first dimension is the cognitive dimension, which can be described by the properties of "rigidity" (hard versus soft science) and "purity" (pure versus applied science). The second dimension is the social dimension, which is characterized by the properties of "similarity" (convergent versus divergent science) and "ecology" (urban versus rural science ${ }^{1}$ ). For example, Tranfield and Starkey [36] used these dimensions to map management and which they identified as a soft, applied, divergent and rural science. These dimensions are adapted in this thesis for our purposes to capture the aspects that describe both food process engineering and exergy analysis. The cognitive dimension is here described by "purity" and "reasoning" (inductive versus deductive), and the social dimension is described by "similarity" and "structure" (centralized versus distributive).

Figure 3 shows the position of food process engineering, and exergy analysis on the conceptual map described by a dimensional scheme adapted by Becher. Food process engineering can be categorized as an inductive, applied, convergent, and centralized scientific field. Firstly, because it is based on observations and measures to identify patterns and regularities which can be used to formulate tentative hypotheses, and ultimately, lead to general conclusions and theories (inductive science). Secondly, because it is prone to a number of external factors, e.g. changes

\footnotetext{
${ }^{1}$ The urban and rural properties are meant to describe qualitatively the density and distribution of scientific efforts within a scientific field.
} 
in policies and regulations, and, therefore, it is non-cumulative in terms of linear and logical development of academic agendas (applied science). Thirdly, because it follows cohesiveness in ideology within the scientific community (convergent science). Finally, because research lines in general seem to focus in similar and well known "research highways", even though food process engineering covers a vast spectrum of food types and processes (centralized science).

Exergy analysis on the other hand, can be seen as a deductive, pure, convergent, and distributed scientific field. Firstly, because exergy is a concept based on fundamental thermodynamics (deductive science). Secondly, because it is continuously extended methodologically by the scientific community in a logically linear, and cumulative manner (pure science). Thirdly, because it is very cohesive in its principles and ideology even though it is used by scientists that are interested in various applications ranging from chemical engineering (e.g. [38]) to medical applications (e.g. [39]) (convergent science). Lastly, since exergy is used in different fields it has a low people-to-problem ratio leading to a large distribution of scientific efforts between all research groups (distributed science).

Clearly, food process engineering and exergy analysis have to be bridged in a coherent and clear way if theory-relevant research questions are to be coupled with practice-driven applications. These type of questions can be posed in a broad sense, for example:

- Can we assess industrial food production chains by exergy analysis?

- Can we understand food processes as thermodynamic engines?

- What is the exergy investment required to produce food on an industrial scale?

- How much exergy requires the production of a unit of food product?

- What are the main types of exergy losses in industrial food production chains? And where and why do exergy inefficiencies occur?

- (How) can we improve the sustainability of industrial food production chains by using the concept of exergy? 

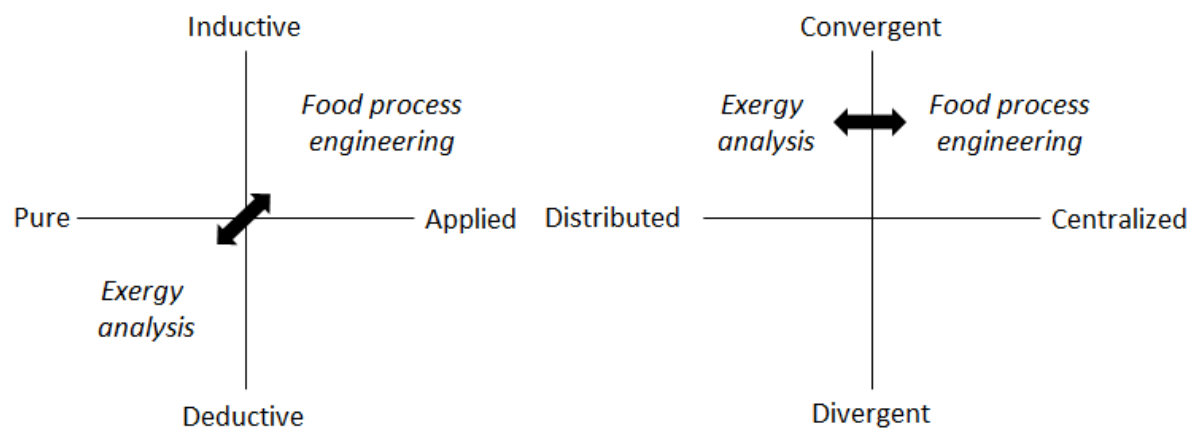

Figure 3. Left: The cognitive and, right: the social dimensions of exergy analysis and food engineering, where each dimension is characterized by its corresponding properties (adapted by Becher [37]).

\section{Aim and outline of the thesis}

Bridging the fields exergy and food engineering science is the overarching goal that this thesis contributes to. Since the methodological and ontological differences are not trivial, the aim of this thesis is specified to obtaining at least partial answers to the questions given above for specific cases, and from this formulate general rules for designing resource (exergy) efficient industrial food production chains by identifying exergy-inefficient processes, and understanding the reasons of their occurrence.

A conceptual scheme of the thesis outline is shown in Figure 4. Case studies of industrial food production chains and processes are assessed exergetically. Economic and social aspects, even though important, are out of the scope. The main focus is twofold: First, on understanding why and where exergy is destroyed and wasted along industrial food production chains. Secondly, on understanding how to design industrial food production chains in an exergy-efficient manner. 


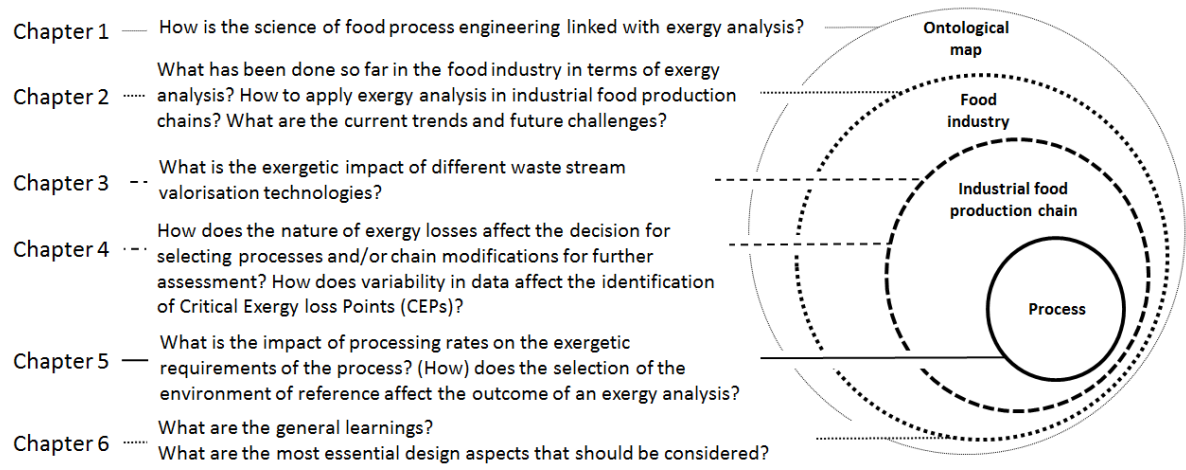

Figure 4. Conceptual outline of the thesis.

Chapter 2 is a literature review on the use of exergetic indicators in the food industry. The food processes that have been extensively assessed by exergy analysis are identified, and the challenges of applying exergy analysis in the food industry, as well as potential future trends, are discussed.

Chapter 3 demonstrates the application of exergy analysis on an industrial bread production chain. The conventional bread production technology (where bread is wasted at the retailer) is compared, firstly, to a par-baking technology (where bread waste is avoided by baking on demand), and, secondly, to a fermented breadcrumb technology (where the bread waste is reworked into a new product of equally good quality). The results of this case are provided as input for a developed multi-criteria decision making model by Banasik et al. [40] where economic aspects are also considered.

Chapter 4 demonstrates the impact of data variability on the identification of Critical Exergy loss Points (CEPs) in an industrial mushroom production chain. Furthermore, it is shown that any decision regarding chain improvement should be based on the nature of exergy losses (which can be either physical or chemical exergy). The results of this case are provided as input for a developed multi-criteria decision making model by Banasik et al. [41] where economic aspects are also considered. 
Chapter 5 aims at understanding the effects of processing rates on the exergetic requirements of a spray drying process. A conventional drying model is presented to describe the impact of utilizing air of different qualities on the thermodynamic performance of a conceptual convective drying process of a lactose solution.

Chapter 6 gives a general discussion on the main learning points of the cases studied. The learnings are used to formulate general design rules. Moreover, additional implications of using the exergy concept are discussed, and an outlook on future directions for the implementation of exergy-based methodologies is given.

\section{References}

[1] Bukeviciute L, Dierx A, Ilzkovitz F. European economy, The functioning of the food supply chain and its effect on food prices in the European Union. In: European Commission. Brussels: Economic and Financial Affairs; 2009.

[2] Boom RM, Janssen AEM, Alfen NKV. Food Engineering. Encyclopedia of Agriculture and Food Systems. Oxford: Academic Press; 2014. p. 154-66.

[3] Trystram G. Modelling of food and food processes. Journal of Food Engineering. 2012;110(2):269-77.

[4] Bowser TJ. Chapter 21 - Food Processing Facility Design. In: Kutz M, editor. Handbook of Farm, Dairy and Food Machinery Engineering (Second Edition). San Diego: Academic Press; 2013. p. 571-97.

[5] Clark JP. Food process design. In: Barbosa-Cãjnovas GV, editor. Encyclopedia of Life Support Systems (EOLSS). Paris, France: Eolss Publishers; 2006.

[6] Westerberg AW. Synthesis in engineering design. Computers \& Chemical Engineering. 1989;13(4-5):365-76.

[7] Harmsen GJ. Industrial best practices of conceptual process design. Chemical Engineering and Processing: Process Intensification. 2004;43(5):671-5. 
[8] Yuan Z, Chen B, Gani R. Applications of process synthesis: Moving from conventional chemical processes towards biorefinery processes. Computers \& Chemical Engineering. 2013;49(0):217-29.

[9] Nikolopoulou A, Ierapetritou MG. Optimal design of sustainable chemical processes and supply chains: A review. Computers \& Chemical Engineering. 2012;44:94-103.

[10] Lazarides HN. Food Processing Technology in a Sustainable Food Supply Chain. Procedia Food Science. 2011;1(0):1918-23.

[11] Zhelev TK. The conceptual design approach-A process integration approach on the move. Resources, Conservation and Recycling. 2007;50(2):143-57.

[12] Gustavsson J, Cederberg C, Sonesson U, Otterdijk Rv, Meybeck A. Global food losses and food waste - Extent, causes and prevention. Food and Agriculture Organization of the United Nations; 2011. p. 37.

[13] FAO. Global initiative on food loss and waste reduction. 2014.

[14] Luque R, Clark JH. Valorisation of food residues: waste to wealth using green chemical technologies. Sustainable Chemical Processes. 2013;1(10).

[15] Karmee SK, Lin CSK. Valorisation of food waste to biofuel: current trends and technological challenges. Sustainable Chemical Processes. 2014;2(22).

[16] Mukherjee J, Gupta MN. Biocatalysis for biomass valorization. Sustainable Chemical Processes. 2015;3(7).

[17] Garrone P, Melacini M, Perego A. Opening the black box of food waste reduction. Food Policy. 2014;46(0):129-39.

[18] Ruini L, Marino M, Pignatelli S, Laio F, Ridolfi L. Water footprint of a largesized food company: The case of Barilla pasta production. Water Resources and Industry. 2013;1-2(0):7-24. 
[19] Ridoutt BG, Juliano P, Sanguansri P, Sellahewa J. The water footprint of food waste: case study of fresh mango in Australia. Journal of Cleaner Production. 2010;18(16-17):1714-21.

[20] Muller DCA, Marechal FMA, Wolewinski T, Roux PJ. An energy management method for the food industry. Applied Thermal Engineering. 2007;27(16):2677-86.

[21] Raghu Ram J, Banerjee R. Energy and cogeneration targeting for a sugar factory. Applied Thermal Engineering. 2003;23(12):1567-75.

[22] Becker H, Vuillermoz A, Maréchal F. Heat pump integration in a cheese factory. Applied Thermal Engineering. 2012;43(0):118-27.

[23] Zhelev TK, Zheleva SR. Combined pinch analysis for more efficient energy and water resources management in beverage industry. In: Almorza D, Brebbia CA, Sales D, Popov V, editors. Waste Management and the Environment. Ashurst Lodge, Southampton, SO40 744, UK: WIT Press; 2002

[24] Oxford dictionaries. www.oxforddictionaries.com. 2016.

[25] Wall G, Gong M. On exergy and sustainable development-Part 1: Conditions and concepts. Exergy, An International Journal. 2001;1(3):128-45.

[26] Gong M, Wall G. On exergy and sustainable development-Part 2: Indicators and methods. Exergy, An International Journal. 2001;1(4):217-33.

[27] Dincer I, Rosen MA. Chapter 5 - Applications of exergy in industry. In: Ibrahim D, Marc AR, editors. Exergy (Second Edition): Elsevier; 2013. p. 75-82.

[28] Cornelissen RL. Thermodynamics and sustainable development: The use of exergy analysis and the reduction of irreversibility. Enschede, The Netherlands: University of Twente, 1997. 
[29] Rosen MA, Dincer I, Kanoglu M. Role of exergy in increasing efficiency and sustainability and reducing environmental impact. Energy Policy. 2008;36(1):12837.

[30] Hepbasli A. A key review on exergetic analysis and assessment of renewable energy resources for a sustainable future. Renewable and Sustainable Energy Reviews. 2008;12:593-661.

[31] Zvolinschi A, Kjelstrup S, Bolland O, van der Kooi HJ. Exergy Sustainability Indicators as a Tool in Industrial Ecology. Journal of Industrial Ecology. 2007;11(4):85-98.

[32] Stougie L. Exergy and Sustainability - Insights into the value of exergy analysis in sustainability assessment of technological systems: TU Delft, 2014

[33] Ayres RU, Ayres LW, Martinás K. Eco-thermodynamics: exergy and life cycle analysis. In: Centre for the Management fo Environmental Resources I, editor. Fontainebleau, France1996.

[34] Ayres RU. Eco-thermodynamics: economics and the second law. Ecological Economics. 1998;26(2):189-209.

[35] Silow EA, Mokry AV. Exergy as a Tool for Ecosystem Health Assessment. Entropy. 2010;12(4):902-25.

[36] Tranfield D, Starkey K. The Nature, Social Organization and Promotion of Management Research: Towards Policy. British Journal of Management. 1998;9(4):341-53.

[37] Becher A. Academic tribes and territories: Intellectual enquiry and the cultures of dicsiplines: The Society for Research into Higher Education and the Open University Press, 1989.

[38] Sorin M, Lambert J, Paris J. Exergy Flows Analysis in Chemical Reactors. Chemical Engineering Research and Design. 1998;76(3):389-95. 
[39] Lucia U. Molecular refrigerators: a new approach in anti-cancer therapy. OA Medical Hypothesis. 2013;1(1):9.

[40] Banasik A, Kanellopoulos A, Claassen GDH, Bloemhof-Ruwaard JM, van der Vorst JGAJ. Assessing alternative production options for eco-efficient food supply chains using multi-objective optimization. Annals of Operations Research. 2016:122 .

[41] Banasik A, Kanellopoulos A, Claassen GDH, Bloemhof-Ruwaard J, van der Vorst JGAJ. Closing loops in agricultural supply chains using multi-objective optimization: a case study of an industrial mushroom supply chain. (submitted). 


\section{Chapter 2}

\section{The use of exergetic indicators in the food industry - A review}

Published as:

Zisopoulos F. K., Rossier-Miranda F.J., van der Goot A.J., Boom R.M. (2015). The use of exergetic indicators in the food industry - A Review. Critical Reviews in Food Science and Nutrition. 


\begin{abstract}
Sustainability assessment will become more relevant for the food industry in the years to come. Analysis based on exergy including the use of exergetic indicators and Grassmann diagrams is a useful tool for the quantitative and qualitative assessment of the efficiency of industrial food chains. In this paper, we review the methodology of exergy analysis and the exergetic indicators that are most appropriate for use in the food industry. The challenges of applying exergy analysis in industrial food chains and the specific features that food processes are also discussed.
\end{abstract}

Keywords: Sustainability; food industry; exergy analysis 


\section{Introduction}

The global population will reach 9.6 billion by 2050 [1]. The economic prosperity of a big part of the population is also expected to increase, leading to more affluent diet patterns that support a very demanding food system in terms of natural resources [2]. It is estimated that the current demand for phytomass production will at least double, but with the probability of attaining only $80 \%$ or less of the total theoretical potential yield due to competing claims in land usage, while a number of other reasons like the increasing frequency of extreme climatic phenomena, and water and phosphorus scarcity will also worsen the situation [3]. As a result, there will be a strong pressure on natural resources, energy, and food. Thus, efficient and complete use of our resources will be of utmost importance.

The main challenges the food industry will face are the need for better agricultural and post-harvest handling practices, for more efficient food production that uses less energy and water, and for minimizing food wastage throughout the complete food chain [4]. The total amount of raw materials, water, and energy required along a food chain can be substantial depending on the type of food product produced [5]. Food waste generation is also considerable since about a third of all the food produced globally is lost within the various steps in the food supply chain. About $7 \%^{1}$ of this loss is due to industrial processing (Figure 1) which seems small, but this wasted food still translates into prodigal expenditure of energy, water, fertilizer and land use, all spent in vain.

\footnotetext{
${ }^{1}$ Calculated by using data of the report of Gustavsson et al. [6] where the production volumes and the percentage of expected losses occurring at the processing and packaging sector for each commodity group per region, were considered for the estimation of the processing and packaging food losses (in million tonnes).
} 


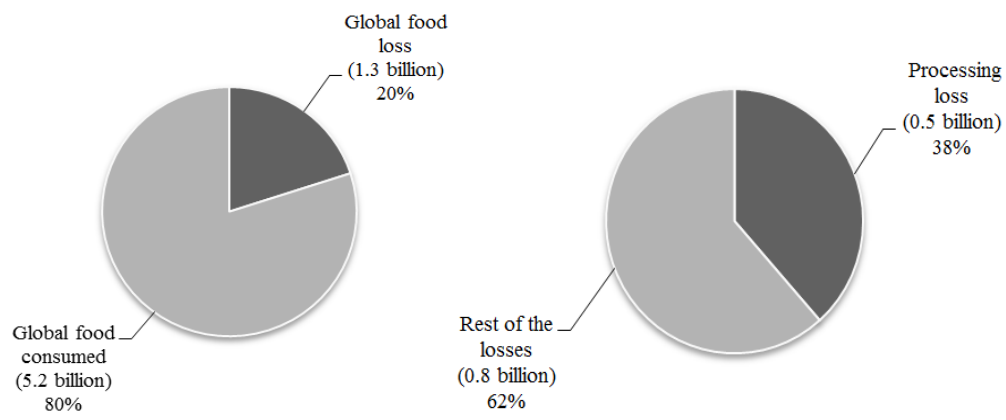

Figure 1. Left: Global food losses in relation to the total global food production. Right: Food processing losses in relation to the total global food losses. The values used for the estimations were adapted from the report of Gustavsson et al. [6].

Many efforts have been undertaken to improve the sustainability of the food industry and a number of positive developments can be observed. For example, Lee and Okos [7] evaluated successfully different food processing systems that use less water and energy, while Alamilla-Beltran et al. [8] identified emerging food processing technologies with promising applications such as electroporation, plasma processing, pulsed electric fields, and radiofrequency heating, amongst others. However, the practical implementation of sustainable improvements in the food industry is hindered by the vast product diversity, the specific and limited production times, and the large distribution areas [9]. Nevertheless, the need to produce food both effectively and efficiently will become even more profound because the continuation of unsustainable processing practices will contribute to the irreversible depletion of Earth's natural resources. Several methodologies have been proposed for assessing and improving the sustainability of various processes and products such as mass flow analysis (MFA) (also known as material throughput analysis), energy analysis (EA), life cycle assessment (LCA), Cradle-to-Cradle design (C2C), and pinch analysis amidst others [10-16]. 
Clearly, there is no shortage of sustainability assessment methods. Yet, the most challenging task for the scientific community is to agree on useful and operational criteria that can connect resource consumption with the generated services appropriately [17].

Currently, energy is the most common term the food industry used to understand process and system performance or efficiency. According to Wall [18], energy should be considered as an indestructible quantity that is conserved in every closed process. Upon transformation of one energy form to another, part of its initial quality is destroyed (irreversibly lost) leading to a lower, degraded quality [19]. The concept of energy quality has been described by Van Gool [20] as the possibility of energy exchange between a donating and an accepting stream. This possibility was defined by Cornelissen [21] as the "maximum work potential of a material or of a form of energy in relation to its environment", and it is known as available work or exergy, a term which was originally given by Rant and his co-workers [22] after the

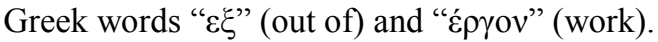

Now, consensus amongst many authors from different scientific fields develops in using exergy analysis (ExA) as an objective methodology for assessing the efficiency and hence sustainability of processes and systems, because it is based on the first and second law of thermodynamics, considering both the quantity and the quality of material and energy streams simultaneously without having to resort to subjective weighing factors ([23]; [24]; [25]; [26]; [27]; [28]; [29]; [19]; [30]; [31]). The advantages of using ExA over other assessment methods have been discussed in detail by various authors, e.g. $[17,32]$. The basic principles, the general definitions and the differences between energy and exergy have been discussed by Dincer and Cengel [33] and Dincer [27].

BoroumandJazi et al. [34] reviewed the applications of ExA in various industrial sectors in different countries. Luis [35] focused on the chemical industry and showed that most of the ExA publications relate to the energy and thermodynamicsrelated fields. According to Dincer and Rosen [32], ExA seems to be applied mainly 
by European companies and one of the reasons could be their longer-term viewpoints on sustainability. The potential use of ExA in the food industry has been demonstrated by Apaiah et al. [36], and now the interest in research in this field is rapidly growing (Figure 2.a). However, the number of publications focusing on the food industry in relation to the total number of publications and to the chemical industry, as shown by Luis [35], is still small, indicating a need for identifying relevant research questions that can better couple ExA to food science and technology (Figure 2.b).

Therefore, the aim of this review is to evaluate the usefulness of $E x A$ as a sustainability assessment tool, to summarize the most commonly used exergetic indicators and their application in the food industry to identify particular features food processes and chains have, and to identify possible future directions for further research.

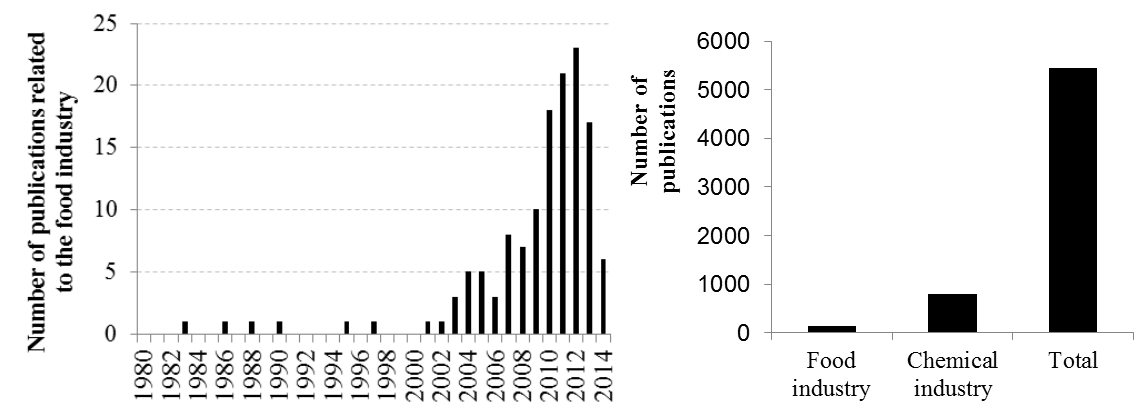

Figure 2.a Number of published papers related to exergy analysis applied in the food industry. The results are obtained after the comparison of 134 publications to the best of the authors knowledge. Figure 2.b Total number of exergy analysis publications related to the chemical industry as shown by Luis [35], and to the food industry. 


\section{Applications of exergy analysis in the food industry}

Most food process related publications using ExA focus on drying technologies $(66 \%)$, followed by food chains having wider boundaries (10\%), and heating/pasteurization processes (6\%) (Figure 3.a). The remaining studies deal with other processes such as heating, evaporating, and chilling, and some of them consider whole countries including the agricultural sector (societal chains). The main drying technologies studied are related to general aspects of drying (17\%) but innovative drying methods such as solar drying (19\%) and the use of heat pump drying (16\%) receive growing attention as well (Figure 3.b). Solar drying case studies have been reviewed by Panwar et al. [37] and mathematical models for thin or thick layer solar drying have been discussed by Bennamoun [38]. El-Sebaii and Shalaby [39] described the different types of solar dryers used in the drying of agricultural products. Heat pump drying systems were summarized by Colak and Hepbasli [40], while Bruttini et al. [41] suggested operational policies for exergetically sustainable freeze drying of pharmaceutical products. Dincer and Sahin [42] proposed an exergetic model for the design of thermodynamically efficient moist solid drying operations, while the energetic and exergetic efficiencies as well as general sustainability aspects of dryers have been discussed by Dincer [43]. The reason that drying receives more attention is undoubtedly because it is one of the most energy demanding processes due to the high latent heat of vaporization of water, and the inefficient use of energy in case of spray drying [44]. Most of the publications studied (62\%) focus on practical applications of ExA, either on experimental rigs or larger scale equipment, while about a third of them (30\%) relate to modelling of food processes or chains, and the rest $(8 \%)$ are literature reviews that do not focus on the food industry but discuss relevant processing technologies (e.g. drying). Grassmann diagrams were used in about $17 \%$ of the publications to represent exergy flows, an aspect that can be important for communicating visually the results of ExA to non-expert stakeholders. 

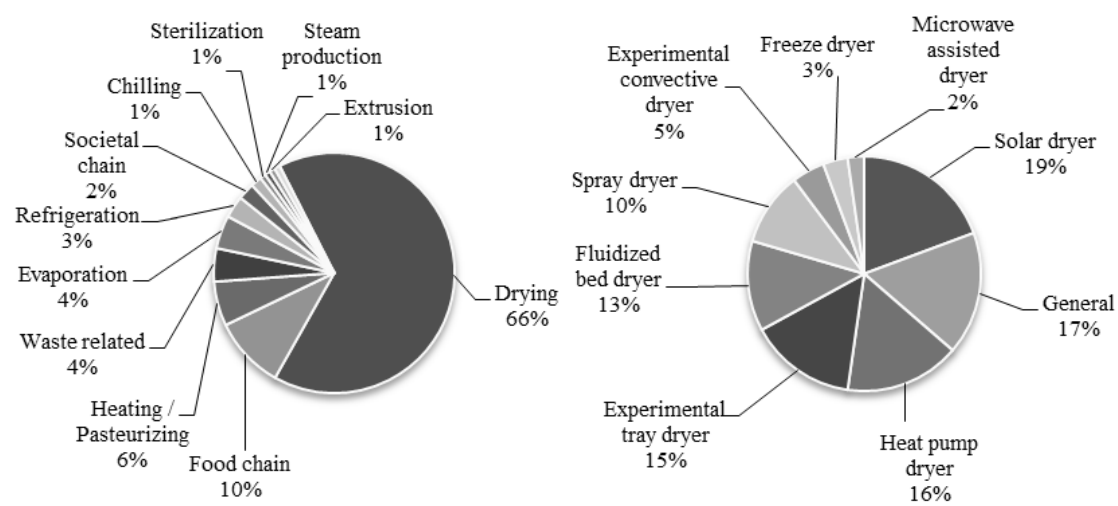

Figure 3. Publications of ExA applied in the food industry which show: figure 3.a the main type of processes researched, and, figure 3.b the main drying technologies researched. The results are obtained after the comparison of 134 publications to the best of the authors' knowledge.

\section{Exergy analysis}

ExA identifies parts within a system where most of the exergy is wasted and/or destroyed, and it can help to understand better the reasons that causes those inefficiencies [45]. A typical stepwise procedure to conduct a general ExA is described by Dincer and Rosen [28]. The procedure for applying the exergy analysis methodology in industrial food chains is proposed as follows:

1. Define the system boundaries of the food process or chain including all crucial steps;

2. Determine an environment of reference, which should reflect local environmental conditions;

3. Conduct a mass flow analysis, an energy analysis, and an exergy analysis using only the most relevant forms of exergy to construct Grassmann diagrams;

4. Define and calculate thermodynamic indicators; 
5. Interpret the results;

6. Propose and assess potential modifications/improvements;

7. Communicate the results.

\section{Defining the system boundaries}

The choice of system boundaries for the evaluation of different food processes or chains is an important step because it considerably affects the outcome of the analysis as shown by Seckin et al. [46]. Stanek and Gazda [47] argued that the system boundaries should be extended when renewable resources are included in the analysis, to account for the origin (extraction) of the natural resource. The use of broad system boundaries will give a more detailed overview of the analysed chains, but it can lead to extensive calculations and excessive use of assumptions that complicate the analysis. On the other hand, the use of tighter system boundaries will simplify the analysis but it will also omit the identification of the impact of potentially relevant "external" processes.

\section{Defining the environment of reference}

To calculate the available work of each stream, an environment of reference has to be selected. Several reference environment models have been developed and these are discussed by Dincer and Rosen [28] who mentioned that one of the most commonly used ones is the natural-environment-subsystem model. In this model, the environmental temperature is adjusted to match the local geographical conditions of the system under study. This approach is used in many of the publications studied in this review. In cases where psychrometric processes or pressure differences are relevant, the humidity of the ambient air and the pressure of the reference environment should be considered as well.

For example, Figure 4.a shows how the chemical exergy of $1 \mathrm{~kg}$ air changes with increasing its moisture fraction at constant environmental moisture content and at different environmental temperatures $(\mathrm{K})$, while Figure 4.b shows how the total exergy of $1 \mathrm{~kg}$ of air changes with increasing both its moisture fraction and its 
temperature at constant environmental moisture and environmental temperature. This shows that the selection of a particular environment of reference will influence the outcome of an ExA of, for example, a drying process, since the exergetic contents of all relevant streams and the exergetic efficiencies in the analysed system are calculated in relation to this environment.
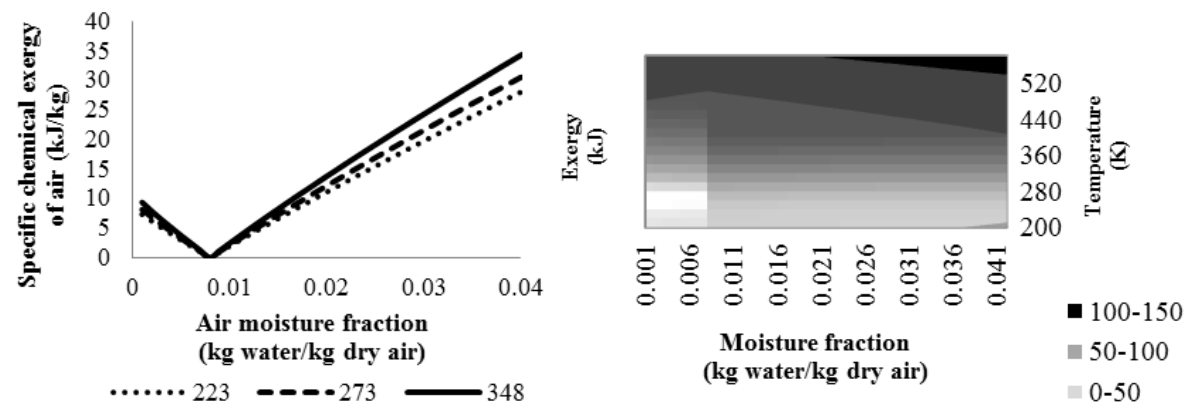

Figure 4.a Chemical exergy of $1 \mathrm{~kg}$ of moist air as a function of its moisture content at a constant environmental moisture content $(0.008 \mathrm{~kg}$ water $/ \mathrm{kg}$ dry air $)$ and at different environmental temperatures. Figure 4.b Contour plot of the total exergy of $1 \mathrm{~kg}$ of moist air as a function of its moisture content ( $\mathrm{kg}$ water/ $\mathrm{kg}$ dry air) and its temperature $(\mathrm{K})$ at constant environmental moisture content $(0.008 \mathrm{~kg}$ water $/ \mathrm{kg}$ dry air) and at constant environmental temperature (298 K).

\section{Defining the relevant forms of exergy}

The most relevant relations for conducting an ExA are shown in Table 1. It is common practice to consider only the relevant forms of exergy involved in the process, which are classified into three main categories: the physical, the chemical, and the mixing exergy. The total exergetic content of a stream is the sum of all of those exergies. The physical exergy can be further categorized into thermal, pressure, kinetic, potential, and electrical exergy, of which the three latter ones are fully convertible into work meaning that they are equal to their corresponding energies. The chemical exergy, according to Dincer and Rosen [48], "represents the maximum work extractable from a system at the pressure and temperature of the reference environment [non equilibrium state] as it changes to a system with the 
same composition, pressure and temperature as the reference environment [equilibrium or dead state]". Therefore, the chemical exergy of the stream can be calculated by knowing the chemical composition of a mass stream, expressed in mass fractions, and the specific chemical exergy of each component, which values can be found in literature $[26,49]$. The mixing exergy is relevant when two or more different streams are mixed causing a spontaneous loss in exergy.

The physical exergy forms that are frequently involved in food processing are the thermal, the pressure and the electrical exergies. However, the chemical exergies are typically much larger than the physical exergies. While most of the chemical exergy is usually preserved during food processing, any unused material side stream represents a significant loss on the total amount of exergy, which is generally larger than most losses due to inefficient use of physical exergy. Recently, Jankowiak et al. [50] compared the extraction of isoflavones from okara (soymilk by-product) by water and by ethanol and showed that, even though water leads to a lower yield of these bioactive components, it is exergetically more efficient than ethanol due to the loss of the latter (chemical exergy loss) during the distillation process and with the spent okara. Evidently, the full use of the raw materials and all material streams involved in a system is more important than the efficient use of physical exergy (e.g., in heating, cooling, and phase changes).

Having all relevant stream exergies calculated, one can construct a Grassmann diagram. This diagram shows schematically the types of exergy flows considered in a process or a system. When the chemical exergy flows are excluded from the Grassmann diagram, the physical exergy streams can be shown better, which reveal those parts in the chain where most non-material losses occur, making the diagram an effective way of communicating the exergy analysis results. 
Table 1. Indicative list of forms of exergy and formulas used for their calculation.

\begin{tabular}{lc}
\hline Form of exergy & Formulas \\
\hline Total exergy of a stream & $B_{i}=B_{i, \text { physical }}+B_{i, \text { chemical }}+B_{\text {mix }}$ \\
Physical exergy of a stream & $B_{i, \text { physical }}=B_{i, t h}+B_{i, p r}+\cdots+B_{i, e}$ \\
Thermal exergy of a stream & $B_{i, t h}=\int_{T_{1}}^{T_{2}}\left(1-\frac{T_{o}}{T}\right) d Q_{i}$ \\
Pressure exergy of an incompressible liquid stream & $B_{i, p r}=\int_{P_{1}}^{P_{2}} P d V$ \\
Pressure exergy of an ideal, gaseous stream & $B_{i, p r}=R T_{o} \ln \left(\frac{P}{P_{o}}\right)$ \\
Chemical exergy of a stream & $B_{i, \text { chemical }}=m_{i} \sum\left(b_{o, j} x_{j}\right)$ \\
Mixing exergy & $B_{\text {mix }}=N_{i} R T_{o} \sum\left(x_{j} \ln \left(a_{j}\right)\right)$ \\
\hline
\end{tabular}

\section{The use of exergetic indicators}

Exergetic indicators, which address different aspects of thermodynamic performance, are useful to obtain a better understanding of the irreversibilities and exergy losses in a food chain. A single exergetic indicator might not be sufficient to describe completely the thermodynamic performance of an industrial food chain. Various exergetic indicators have been used for the exergetic assessment of food processes and food chains as shown in Figure 5, and a summarized (but not exhaustive) list with their definitions and applications is shown on Table 2.

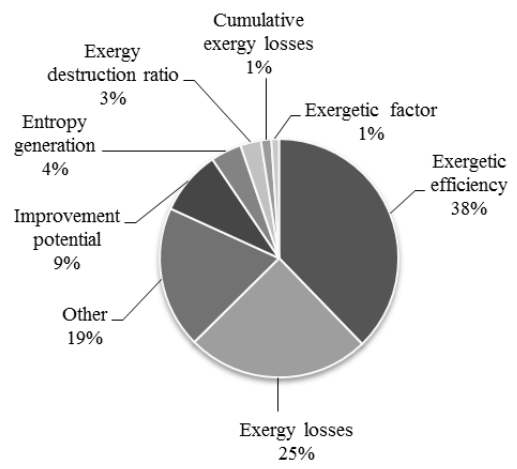

Figure 5. Main exergetic indicators used in industrial food processes and food chains. The results are obtained after the comparison of 134 publications to the best of the authors knowledge. 
- The exergetic efficiency is one of the most frequently used indicators for the sustainability assessment of food processes. It shows how well the exergetic inputs are utilized within the process or chain. It is always lower than the energetic efficiency because it represents the deviation of the current food chain from ideality. It is thus equal to the total amount of useful exergy that emerges from the system $\left(\sum B_{\text {out }}\right.$ useful $)$, divided by the total amount of exergy absorbed by the system $\left(\sum B_{i n}\right)$ :

$$
\eta_{\text {exergy }}=\frac{\sum B_{\text {out }, \text { useful }}}{\sum B_{\text {in }}}
$$

In other words, it shows the loss relative to the maximum theoretical work that could be achieved by the use of processing technologies in the food chain. As a consequence, its maximum achievable value is fixed based on the exergetic efficiencies of the constituent steps in the chain. Therefore, the total food chain exergy efficiency could never reach $100 \%$ even if much more efficient technologies would be used.

The exergetic efficiency can be defined in various ways and the exact definition depends on what the analyst considers as an appropriate description [21, 51]. The simultaneous use of three different exergetic efficiencies has been demonstrated in an evaporating cooling process [52] and in an orange juice concentration process [53]. According to Valero (1998) [54], the way the exergetic efficiency is calculated depends on the way the thermodynamic costs (exergetic contents) of the inputs and the products are allocated. The exergetic content should be allocated proportionally to their quantities when different products of the same quality are produced. In this case, the exergetic efficiency should be expressed according to the exergy of the output products over the total exergetic inputs [54]. If the exergy inputs are not fully exploited and part of them leaves the system (i.e., are discarded as waste and returned to become 
part of the environment), the exergetic efficiency should be expressed according to the exergy of the output product over the part of the input exergy that was utilized [54].

In general, the calculation of the efficiency should meet a set of conditions: it should be based on relevant and influential data, it should be easy to calculate, it should have a practical application, and it should be sensitive to changes, thus enabling a range between zero and one [51]. However, the efficiency is a ratio, and, therefore, a relative number that does not necessarily describe its thermodynamic performance completely. For example, Figure 6 shows that the exergetic efficiency of two different food processes is the same, however, in food process A, a considerably larger amount of exergy is lost. Therefore, the exergetic efficiency should always be explicitly defined and considered along with other thermodynamic indicators.

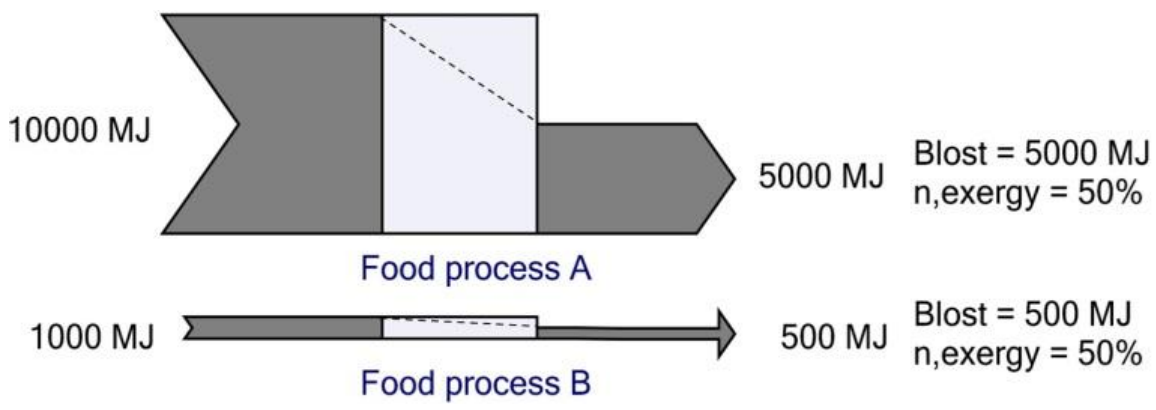

Figure 6. Grassmann diagrams of two different food processes that have the same exergetic efficiency. 
- The second most-used indicator in the publications is the absolute exergy loss. Certain exergy losses are associated with the transformation of raw materials into final products within the food chain. Those losses relate to different mechanisms such as heat transfer in thermal processing, induction of phase changes, concentration and mixing. They can be expressed directly by thermodynamic indicators (e.g. cumulative exergy losses and exergetic efficiency), and visualised by Grassmann diagrams as the decrease in the size of the arrows going in and out of the system. According to Sciubba [30], exergy loss is a "proper indicator of the global conversion performance of an energy-conversion chain, including complex structures". Exergy loss refers to both to the exergy destroyed irreversibly within a process (internal losses), and also to any other exergy that gets wasted to the environment due to other inefficiencies, e.g. from waste streams or by lack of proper insulation (external losses) [54, 55].

Further insights on thermodynamic process performance can be obtained by the Advanced Exergy Analysis [56]. According to this methodology the exergy destruction of a process is split into endogenous losses (due to the operation of a component of the process in real conditions when the rest of its components run in ideal conditions) and exogenous losses (calculated by subtracting the endogenous losses from the overall exergy destruction), as well as in unavoidable losses (that cannot be improved by any technological or economic improvement) and avoidable losses (calculated by subtracting the unavoidable losses from the overall exergy destruction). Szargut [57] proposes a dependency of exergy losses within the different parts of a multistage process, meaning that a modification in one part of a chain might reduce the local losses but could influence the total losses considerably. The importance of considering the total chain of processes instead of focusing on a single unit operation has been demonstrated experimentally in a milk processing system [58]. 
- $\quad$ The third most commonly used indicator is the improvement potential (IP). Van Gool [59] argues that the IP should be used for comparing different processes of different scales and even of different sectors, even though the obvious maximum improvement for a given process is its total exergy loss.

- The fourth most commonly used indicator is entropy generation, which is related to exergy destruction through the Gouy-Stodola relation [60-63]. Exergy destruction and entropy generation should be considered as parallel (and not opposite) concepts because the former gives information about the work that was irreversibly lost during a process in relation to a reference environment, while the latter marks the uncertainty (or disorder) in the quality of energy that is created during the utilization (degradation) of this useful work, and both are expressions of the second law of the thermodynamics [64].

- The fifth indicator is the exergy destruction ratio, which is also known as the depletion number, and it was originally defined by Connelly and Koshland [65] as the exergy destroyed in a process over the total exergetic input. The exergy destruction ratio indicates a better efficiency with a lower value, contrary to most other indicators. The exergy destruction ratio is the reciprocal of the sustainability index SI as proposed by Rosen et al. [24], which shows how a change in the exergetic efficiency impacts the sustainability of a process.

- The cumulative exergy loss is the sixth most-used indicator and it is defined as the summation of the losses that occur during the production of a certain or multiple products [66]. The cumulative exergy losses can be calculated by subtracting the total useful exergy delivered at the last step of the chain (or throughout the chain) from the cumulative exergy consumption [67]. 
Many other indicators have been developed in different scientific fields and have found application in the food industry also but not to a large extent. The use of renewable and non-renewable energy sources can be of relevance in a thermodynamic analysis because both of those energy sources might have the same exergy content but different overall thermodynamic impact, as suggested by Stougie and Van der Kooi [68]. Recently, Maes and Van Passel [19] introduced the renewability fraction that is useful in identifying the actual exergetic value of renewable sources, which considers the sunlight required to produce the renewable resource, the forest abatement costs for carbon dioxide sequestration and oxygen production, and the actual sunlight captured by the process studied. A similar indicator has been used in assessing the performance of strawberry cultivation in greenhouses by different heating methods [69]. Dewulf et al. [70] introduced the exergetic renewability defined as the renewable exergy fraction used over the total exergy input, and the environmental compatibility defined as the total exergy input over the total exergy input plus the exergy required to abate emissions and wastes. Another promising indicator is eco-exergy, a concept developed by Jørgensen and his co-workers [71] in which the embodied information in living organisms in the form of DNA is assigned as potential energy work. Other less used indicators are the specific exergy destruction [72] [73, 74], the exergy loss rate [75], the exergy-toenergy ratio [76], the exergy heating effectiveness [77], the weighted mean overall exergetic efficiency (used in a country scale system) [78, 79], the exergetic factor, productivity lack, relative irreversibility [80], and peak exergy (used in solar drying analysis) [81, 82]. 
Table 2. Indicative but not exhaustive list with various exergetic indicators found in literature after the comparison of 134 publications to the best of the authors knowledge.

\begin{tabular}{|c|c|c|}
\hline Indicator & Formula & References \\
\hline Exergetic efficiency & $\begin{array}{c}\frac{\sum B_{\text {out }}}{\sum B_{\text {in }}} \text { or } \\
\frac{\left(\frac{\sum B_{\text {product }}}{\sum B_{\text {in }}}\right)^{1} \text { or }}{\frac{\sum B_{\text {required }}}{\sum B_{\text {in }}} \text { or }} \\
\frac{\sum B_{\text {required }}}{\sum B_{\text {provided }}}\end{array}$ & $\begin{array}{l}\text { Evaporation of tomato paste [85], milk and bread processing [86], fish } \\
\text { drying [87], extrusion of fish feed [88], drying of rice [89], carrot } \\
\text { cubes [90], cereal grains [91], red pepper [92], mulberry [93], coroba } \\
\text { slices [94, 95], corn [96-98], wheat [99-102], carrot [103], pistachio } \\
{[104] \text {, coffee [105, 106], chili [107], olive leaves [108-110], beef }} \\
\text { [111], mint leaves [112-114], parsley leaves [115], jackfruit leather } \\
\text { [116], multilayer porous media [117], solar greenhouse drying [118], } \\
\text { solar air drying [119], steam production [120], co-generation in sugar } \\
\text { production [121], ethanol production [122], milling of cereals [123], } \\
\text { pasta [124-126], cheese powder [127], ethanol production from banana } \\
\text { and its residues [128]. }\end{array}$ \\
\hline Exergy losses & $\sum B_{\text {lost }}=\sum B_{\text {in }}-\sum B_{\text {out }}=\sum$ & $\begin{array}{l}\text { Drying of potato }[129,130] \text {, pumpkin }[131] \text {, apple [132], apricot } \\
{[133] \text {, strawberry }[134] \text {, pomegranate }[135] \text {, wheat }[136] \text {, multilayer }} \\
\text { porous media [137], non-hygroscopic porous media [138], eggplant } \\
{[139] \text {, plants [140]. }}\end{array}$ \\
\hline Improvement potential & $I P=\left(1-n_{\text {exergy }}\right) \sum B_{\text {lost }}$ & $\begin{array}{l}\text { Drying of broccoli }[141,142] \text {, pasta }[124-126,143] \text {, cheese powder } \\
{[127,144] \text {, plums }[145,146] \text {, green olives }[147] \text {, fruits and vegetables }} \\
{[148,149] \text {, laurel leaves }[150] \text {, tinning of fish }[151] \text {. }}\end{array}$ \\
\hline Entropy generation & $\sum B_{\text {destroyed }}=T_{o}\left(S_{\text {final state }}^{\text {system }}-S_{\text {initial state }}^{\text {system }}+S_{\text {generated }}^{\text {env }}\right)$ & $\begin{array}{l}\text { Pasteurization and concentration of orange juice }[53,152] \text {, spray } \\
\text { drying of milk powder }[153] \text {, spray drying microencapsulation of fish } \\
\text { oil [154-157], waste heat utilization for frying potato [158], solar } \\
\text { drying of fruits and vegetables [159] }]^{2} \text {. }\end{array}$ \\
\hline
\end{tabular}

${ }^{1}$ Also known as cumulative degree of perfection and its use is demonstrated in the production of yoghurt [83], and vegetable oil [84].

${ }^{2}$ Use of the entropy generation number $N_{s}$ which is calculated based on the ratio of the thermal energy of the product over the solar energy absorbed, and it indicates the entropy produced during the conversion of solar to thermal energy. 


\begin{tabular}{|c|c|c|}
\hline Exergy destruction ratio & $D_{p}=\frac{\sum B_{\text {destroyed }}}{\sum B_{\text {in }}}=1-n_{\text {exergy }}$ & $\begin{array}{l}\text { Drying of soybeans [160], plums [161], olive leaves [162], cheese } \\
\text { powder spray drying [163], sugar production [164]. }\end{array}$ \\
\hline Sustainability index & $S I=\frac{1}{D_{p}}$ & $\begin{array}{l}\text { Fruits and vegetables cultivation [69], drying of laurel [165], cheese } \\
\text { powder spray drying [166]. }\end{array}$ \\
\hline $\begin{array}{l}\text { Cumulative exergy } \\
\text { consumption }\end{array}$ & $C E C=\sum B_{\text {input }}$ & $\begin{array}{l}\text { Sugar production }[167,168] \text {, fish feed formulation [169], recycling of } \\
\text { used cooking oil }[170,171] \text {, general agricultural production [172, } \\
173] \text {, vegetable oil production [84]. }\end{array}$ \\
\hline Cumulative exergy losses & $C E L=C E C-\sum B_{\text {useful }}$ & $\begin{array}{l}\text { Sugar production }[168] \text {, societal chains that include the agricultural } \\
\text { sector }[173,174] \text {. }\end{array}$ \\
\hline Exergetic factor & $f=\frac{B_{\text {fuel consumed at process } i}}{\sum B_{\text {fuel input }}}$ & $\begin{array}{l}\text { Drying of plums [145], olive leaves [162], laurel [165], cheese powder } \\
\text { spray drying [166]. }\end{array}$ \\
\hline $\begin{array}{l}\text { Specific exergy } \\
\text { destruction }\end{array}$ & $S E D=\frac{\sum B_{\text {destroyed }}}{m_{\text {produced }}}$ & General chilling process $[72]$. \\
\hline Relative irreversibility & $R I=\frac{B_{\text {destroyed }}^{i}}{\sum B_{\text {destroyed }}}$ & $\begin{array}{l}\text { Drying of olive leaves [162], of laurel [165], cheese powder spray } \\
\text { drying [166]. }\end{array}$ \\
\hline Productivity lack & $\xi_{i}=\frac{B_{\text {destroyed }}^{i}}{\sum B_{\text {product }}}$ & Cheese powder spray drying [166]. \\
\hline Exergetic renewability & $\alpha=\frac{B_{\text {renewable }}}{\sum B_{\text {in }}}$ & Sugar production $[164]^{3}[167]^{4}$, fruits and vegetables cultivation [69]. \\
\hline $\begin{array}{l}\text { Renewability performance } \\
\text { indicator }\end{array}$ & $\lambda=\frac{\sum B_{\text {product }}}{\sum B_{\text {fossil }}+\sum B_{\text {destroved }}+\sum B_{\text {deactivation }}+\sum B_{\text {emissions }}}$ & $\begin{array}{l}\text { Ethanol production from banana and its residues [128], production of } \\
\text { sugar and ethanol [175]. }\end{array}$ \\
\hline Eco-exergy & $B_{\text {eco }}=\sum_{i=0}\left(B_{\text {chemical }} \beta_{i}\right)$ & Fish feed formulation [169]. \\
\hline
\end{tabular}

${ }^{3}$ Defined as exergy renewability ratio: $E R R=\frac{\sum B_{\text {evaporation }}+\sum B_{\text {product }}}{\sum B_{\text {in }}}$

${ }^{4}$ The non-renewable fraction can also be calculated as: $\alpha=\frac{B_{\text {non-renewable }}}{\sum E_{\text {in }}}$ 


\section{Communicating the results of an exergy analysis}

Conveying the main outcomes of an ExA to non-expert stakeholders can be as important as the analysis itself. Grip et al. [176] stated that the lack of a strategy in working with ExA, the lack of information on the opportunities that it offers, the lack of competence within the organization, the lack of time, and different prioritization strategies, hindered the implementation of ExA in Swedish companies. Additionally, companies perceived $E x A$ as a method that was not required or was not applicable, or it was difficult to use and to communicate within their hierarchy levels due to the asymmetric knowledge on the topic. It is clear that the communication aspect of an ExA should be considered during industrial sustainability assessments seriously.

\section{Thermodynamic sustainability}

A process can be considered sustainable in thermodynamic terms when the amount of exergy lost is small during its operation, which results in most of the selected thermodynamic indicators attaining their optimal values. For example, the cumulative exergy losses and the specific exergy losses should be as low as possible, while the total exergetic efficiency should be the highest possible. In other words, the total thermodynamic price to run the process and to produce one unit of product should be minimal, while the total exergy throughput should be as efficient as possible without degrading its quality.

However, some of the indicators may show conflicting results in practice. For example, Aneke et al. [158] compared two industrial food chillers that make use of waste heat: the first one being an organic Rankine cycle powered vapour compression refrigeration process and the second one an ammonia-water absorption refrigeration system. They found that for pressure ratios higher than or equal to the breakeven point (where the coefficient of performance is identical for both processes) the first process was more efficient. However, for lower pressure ratios the second process was more efficient even though it produced higher irreversibility. They assigned this paradox to the fact that the absorption refrigeration process included more heat exchangers that are also entropy generators. Such conflicting 
results require a more in-depth observation of all the obtained values of the indicators and the most relevant one for the studied system should be selected to assess its thermodynamic performance.

Leites et al. [177] pointed out general rules for the design of thermodynamically efficient chemical processes, which could also be applied within the food industry. An important rule is that the use of high quality energy should be avoided in processes that demand low quality energy [178]. An industrial system could improve its exergetic sustainability by avoiding the generation of waste material or heat streams, by re-using those streams, and by making use of renewable energy sources. For example, a feasibility study showed that it is both sustainable and profitable to recover cryo-thermal exergy from a liquefied natural gas regasification process, for deep freezing of agro-food products in the surrounding industries, and for space conditioning in residential and commercial areas nearby [179].

Many recent publications focus on the exergetic assessment of drying processes that use solar energy or heat pumps. The advantages of using solar, wind and geothermal power were discussed by Koroneos et al. [180] who showed that in some cases they can be more efficient than non-renewable energy sources. For example, Le Pierres et al. [181] demonstrated that deep freezing of foods is possible by utilizing solar, lowgrade energy. Hermann [182] quantified the global exergy resources and stressed that it is be possible to meet the global demands in the reduction of energy consumption by best utilizing all known exergetic reservoirs and flows available in our biosphere.

From the information above, it can be inferred that food chains in the future should be designed in such a way that:

1. waste generation is avoided, minimized or re-used, and that the complete raw materials are converted into valuable and useful products,

2. exergy destruction during processing is minimized and,

3. renewable energy sources are used instead of fossil sources. 


\section{Current challenges and future trends in designing sustainable}

\section{food chains}

Several important issues have to be considered when using exergy analysis for more efficient and sustainable food production. First and foremost, the quality and safety of the final product(s) should be guaranteed in any change in a supply chain or processing step. This should be seen as a constraint on any modification that can be proposed. Second, exergy analysis has been developed in the energy conversion and chemical processing industry primarily, and thus will need further development and should gain acceptance in the food industry. We will now shortly discuss these aspects.

- Dealing with product safety, product-process interactions, and nutritional aspects in ExA. Process optimization within the food industry is not straightforward. Even if more sustainable processing technologies can be identified by using ExA, those should comply with safety, legislation, and consumer quality criteria. Additionally, the structure of foods, both at macro- and micro-scale, is of great importance to the bioavailability of nutrients and sensorial quality of the product. For example, the digestibility and metabolism of dietary fatty acids is affected both by their structure and their state [183]. ExA does not reflect the physico-chemical transformations of different food ingredients that occur during processing (e.g. gelatinization of starch), and, therefore, it says nothing about their nutritive value [27].

The application of the concept of exergy on human metabolism and food consumption has been mentioned by Szargut [25]. The conversion of food in the human body releases heat equal to its lower heating value, however, only a part of this initial chemical energy content is used to run all the complex biochemical processes and most of the heat produced is lost to environment [178]. By using calorimetric data, it was shown that ATP hydrolysis is the limiting factor for obtaining the maximum available 
nutritive exergy, and approximately $60 \%$ of this exergy is chemically bound within the human body in the form of ATP [184]. Mady [185] analysed the energy conversion processes within the human body with exergy to develop health performance indicators, while a general procedure for calculating the value of human exergy consumption was given by Shukuya [186]. The above studies show that nutrition is an important factor to consider when designing a food product. They signify the need for extending ExA to include the impact of physico-chemical transformations of food components on their exergetic nutritive quality along the total food chain.

- Dealing with industrial emissions and waste streams. The exergy value for useful streams is by definition always positive even if their main physical variable, e.g. temperature, is lower than the environment of reference [178]. However, the assignment of exergetic values to waste streams is a matter of debate currently. This issue deserves attention since ExA often deals with lost work from waste streams and often suggests their avoidance or their reuse even when that is not possible. All streams that are brought at equilibrium with the environment of reference have zero exergy. This means that the useful work potential of a process stream that is dispersed into the environment will become part of this environment and thus by definition have no exergy anymore. Streams that can cause harm to the environment (e.g. emissions or waste streams), have an exergetic content (e.g. thermal and/or chemical exergy), but cannot or should not be released in the environment as such. They should first be brought into a state that allows them to become at equilibrium with the environment without doing harm. This generally requires additional processing (e.g., waste water treatment, chemical degradation, or even incineration) and therefore requires exergy to be spent. Therefore, harmful emissions bear an exergetic penalty as large as the exergetic investment needed to render them harmless to the environment. 
However, there is, still, no clear agreement on how to treat the exergetic content of such waste streams. Maes and Van Passel [19] argue that ExA cannot capture the immaterial aspects of emissions and waste streams (e.g. land degradation and biodiversity loss), which should be considered by additional metrics in a sustainability assessment.

Gaudreau et al. [187] criticized exergy analysis, posing that ExA is not objective due to the vagueness of the methodology in addressing the impact of waste streams on an infinite reference environment that should actually remain unaltered. Other authors proposed that waste streams should be considered either as constrained or unconstrained, where the former are streams of value (dictated often by economic factors), and the latter are free to impact the environment but have the potential of becoming constrained (valuable) [24, 188]. Zhu and Feng [189] studied the allocation of the cumulative exergy among the separation of multiple products from a stream by introducing a new parameter based on their minimum separation work. A similar approach could be useful for allocating the negative impact of waste streams based on their minimum abatement cost. Nevertheless, whether the exergy content of a toxic or contaminated stream that is released to the environment should be zero, or it should be allocated based on a minimum abatement cost, or even attain a negative value, is a topic that still requires attention.

- Need for a systematic framework and communication standards. The importance of the integration of exergy analysis in industrial practice, policy making, taxation, and education has been stressed by many authors [17, 27, 59, 190]. Companies and governmental organizations are more familiar with the use of footprints. The exergy footprint was proposed by Caudill et al. [191], which could assist in decision making. However, these types of concepts are still not standardized and integrated to reflect the environmental, economic and social aspects of sustainability [192]. 
Hernando and Hector [193] demonstrated the use of a framework that combines ExA with a quality control model based on HACCP (Hazard Analysis of Critical Control Points) guidelines, on the Andean blackberry cold chain. Such a systematic framework could enhance the implementation of ExA by non-expert stakeholders in the future food industries, as part of exergy preservation programs that could be used as mandatory and legislative requirements of governmental sustainability projects.

- Dealing with variability in data. Oftentimes, systems with immense system boundaries are assessed by ExA, and, therefore, the analysis has to rely on data that are not readily available and can be found only in literature or by using expert knowledge. This implies that the analysis can convey some degree of uncertainty due to variability in literature data. Besides, the analysis outcome is strongly dependent on the model assumptions. Therefore, a consensus amongst the scientific community has to be reached for defining an appropriate methodology for reliable model validation, sensitivity and uncertainty analysis.

- Method extension. ExA is continuously extended to include economic and environmental aspects. Maes and Van Passel [19] give an overview of such methodologies like the Cumulative Exergy Content developed by Szargut et al. [55], the Extended Exergy Accounting developed by Sciubba [194], the Ecological Cumulative Exergy Consumption developed by Hau and Bakshi [195], and the Cumulative Exergy Extraction from the Natural Environment developed by Dewulf et al. [196]. Tsatsaronis and Morosuk [45] discuss other exergy-based methods like Exergoeconomics, Exergoenvironmental Analysis, and the Advanced Exergy Analysis. The latter methodology has been applied on the drying of herbs and spices by a gas engine heat pump successfully [197]. The combination of the objective power of ExA with methods stemming from other fields like operations research, can lead to 
the development of useful decision making tools for cases where conflicting objectives (e.g. profit and sustainability) occur. This combination has been demonstrated in the design of a falling film evaporator [198], and of a novel protein food chain [199]. Later on, a new graphical method, which identifies the optimum operating parameters of a distillation column and visualizes exergy losses in 3D, has been introduced by Khoa et al. [200]. Further, Vintila [201] developed an inverse analysis method that accurately measures mass, heat, and exergy transfer coefficients which are essential for describing transfer phenomena in transient multiphase systems.

Artificial neural networks have also been used for predicting the exergetic performance of fish oil microencapsulation by spray drying [156]. Their optimal topology for predicting the energy and exergy in a fluidized bed dryer was determined by using response surface methodology integrated with a genetic algorithm [202] in both a static and a recurrent mode [203]. Response surface methodology was used in combination with exergy analysis for determining the optimal process conditions for the drying of olive leaves [204], of herbal leaves [205], and for identifying the main factors that affect the performance of thin layer drying of pomegranate arils [206]. A more detailed method that extends ExA by considering the coupling of driving forces to minimize entropy production (i.e. exergy destruction) through the use of non-equilibrium thermodynamics was proposed by Kjelstrup et al. [207]. A related field is that of finite time thermodynamics which aims at elucidating the optimal thermodynamic path or mode of operation of processes that produce the minimum amount of entropy (or destroy a minimum amount of exergy) [208]. The potential of those methodologies seems very exciting but their application within the food industry is yet to be explored. 


\section{Conclusions}

ExA is a methodology to assess the sustainability of food chains, based on objective thermodynamic laws. The results of ExA do not provide a direct solution, but they lead to a better understanding of the reasons for the occurrence of losses. Although $E x A$ in the food industry is still in its infancy, it shows a growing trend with most of the applications targeting on drying processes due to the high energy requirements involved in those processes. Exergetic indicators can be used to provide insight for potential improvements along the complete food chain. The most commonly used ones in the food industry are the exergetic efficiency, the absolute exergy loss, the improvement potential, the entropy generation, the exergy destruction ratio, the exergetic factor, and the cumulative exergy losses. A food chain is thermodynamically sustainable when the selected exergetic indicators attain their optimal values. Each process along the food chain should be designed to utilize all the available quality of its input(s), and to degrade it in the best possible manner, i.e. destroying the least amount of exergy while generating the minimum amount of entropy, by avoiding the production of waste streams, or reusing them in case where avoidance is not possible. However, when waste streams are to be reused, the proper allocation of their exergetic content should be considered carefully as this is still a matter of debate amongst the scientific community. Moreover, care should be taken when defining system boundaries because these can affect the outcome of the analysis considerably. Replacing fossil fuel energy sources with renewable energy sources will also contribute in improving the exergetic sustainability of a food chain.

This review identifies several points of attention for ExA to gain acceptance in the food industry. Firstly, it is clear that any modification in the design of a food chain should comply with quality and safety standards, and any impact of physicochemical transformations occurring during processing of food components on their nutritive quality should be quantifiable. Secondly, there is a need for the scientific community to reach a consensus for the appropriate use of model validation, sensitivity, and uncertainty analysis techniques whenever dealing with variability in literature data or experimental uncertainty in $E x A$, and, therefore, enhancing the 
robustness of the assessment. Thirdly, the communication of the results of an ExA to non-expert stakeholders can be difficult and it can be as important as the analysis itself. Considering the above points, it is clear that the acceptance of ExA by the industrial food sector as a credible sustainability assessment method will be enhanced through developing a unified framework that provides guidelines for the design of food products of maximum nutritive value by using processes that destroy a minimum amount of exergy along the complete food chain.

\section{Acknowledgements}

The authors are grateful to the Dutch Food Retail Organization (CBL) and the Federation of the Dutch Food and Grocery Industry (FNLI) for funding this research under the project "Valorization of raw materials and process efficiency" which is under TI Food and Nutrition, a public-private partnership on precompetitive research in food and nutrition. The public partners are responsible for the study design, data collection and analysis, decision to publish, and preparation of the manuscript. The private partners have contributed to the project through regular discussion. 


\section{Nomenclature}

a

$B$

$b_{o}$

$D_{p}$

$f$

$m$

$N$

$N_{S}$

$P$

$Q$

$R$

$S$

$T$

V

$x$

$I P$

$R I$

SI

CEC

$C E L$

$S E D$

Greek letters

\section{$\alpha$}

$\beta$

$\lambda$

$\eta$

$\xi$

\section{Subscripts}

$o$
$i$
$j$
$t h$
$p r$
$e$
eco

Water activity

Exergy

Specific chemical exergy

Exergy destruction ration

Exergetic factor

Mass

Number of moles

Entropy generation number

Pressure

Thermal energy

Universal gas constant

Entropy

Temperature

Volume

Mole fraction

Improvement potential

Relative irreversibility

Sustainability index

Cumulative exergy consumption

Cumulative exergy losses

Specific exergy destruction

Exergetic renewability

Beta value (used in eco-exergy analysis)

Renewability performance indicator

Efficiency

Productivity lack

Environment of reference

Stream

Component

Thermal

Pressure

Electrical

Eco-exergy 


\section{References}

[1] United Nations. World population prospects: the 2012 revision. Press Release. 13 June 2013 ed: Department of Economic and Social Affairs; 2013.

[2] Gerbens-Leenes PW, Nonhebel S, Krol MS. Food consumption patterns and economic growth. Increasing affluence and the use of natural resources. Appetite. 2010;55(3):597-608.

[3] Koning NBJ, Van Ittersum MK, Becx GA, Van Boekel MAJS, Brandenburg WA, Van Den Broek JA, et al. Long-term global availability of food: continued abundance or new scarcity? NJAS - Wageningen Journal of Life Sciences. 2008;55(3):229-92.

[4] Ohlsson T. Chapter 43 - Sustainability and Food Production. In: Motarjemi Y, Lelieveld H, editors. Food Safety Management. San Diego: Academic Press; 2014. p. 1085-97.

[5] Ramirez CA. Monitoring energy efficiency in the food industry: University of Utrecht, 2005.

[6] Gustavsson J., Cederberg C, Sonesson U, Otterdijk Rv, Meybeck A. Global food losses and food waste. Extent, causes and prevention. Rome, Italy: FAO; 2011.

[7] Lee W, Okos MR. Sustainable food processing systems - Path to a zero discharge: reduction of water, waste and energy. Procedia Food Science. 2011;1(0):1768-77.

[8] Alamilla-Beltrán L, Welti-Chanes J, Chanona-Pérez JJ, Perea-flores MdJ, Gutierrez-López GF. Emerging Technologies for Food Processing. Food Processing Handbook: Wiley-VCH Verlag GmbH \& Co. KGaA; 2011. p. 205-24.

[9] Klemeš J, Perry S. Methods to minimise energy use in food processing. In: Klemeš JS, R. Kim, J. K., editor. Handbook of water and energy management in 
food processing: Woodhead Publishing Series in Food Science, Technology and Nutrition; 2008 p. 136-99.

[10] Kytzia S, Faist M, Baccini P. Economically extended-MFA: a material flow approach for a better understanding of food production chain. Journal of Cleaner Production. 2004;12(8-10):877-89.

[11] Giampietro M, Bukkens SGF, Pimentel D. Models of energy analysis to assess the performance of food systems. Agricultural Systems. 1994;45(1):19-41.

[12] Braungart M, McDonough W, Bollinger A. Cradle-to-cradle design: creating healthy emissions - a strategy for eco-effective product and system design. Journal of Cleaner Production. 2007;15(13-14):1337-48.

[13] Roy P, Nei D, Orikasa T, Xu Q, Okadome H, Nakamura N, et al. A review of life cycle assessment (LCA) on some food products. Journal of Food Engineering. 2009;90(1):1-10.

[14] Damour C, Hamdi M, Josset C, Auvity B, Boillereaux L. Energy analysis and optimization of a food defrosting system. Energy. 2012;37(1):562-70.

[15] Herrero M, Laca A, Díaz M. Chapter 15 - Life Cycle Assessment Focusing on Food Industry Wastes. In: Maria K, Colin W, editors. Food Industry Wastes. San Diego: Academic Press; 2013. p. 265-80.

[16] Dalsgard H, Munkoe L. Process integration in the Danish food industry - A case study. International Journal of Applied Thermodynamics. 2000;3(4):163-70.

[17] Gong M, Wall G. On exergy and sustainable development-Part 2: Indicators and methods. Exergy, An International Journal. 2001;1(4):217-33.

[18] Wall G. Exergy flows in industrial processes. Energy. 1988;13(2):197-208. 
[19] Maes D, Van Passel S. Advantages and limitations of exergy indicators to assess sustainability of bioenergy and biobased materials. Environmental Impact Assessment Review. 2014;45(0):19-29.

[20] Van Gool W. Thermodynamic aspects of energy conservation. Energy. 1980;5(8-9):783-92.

[21] Cornelissen RL. Thermodynamics and sustainable development: The use of exergy analysis and the reduction of irreversibility. Enschede, The Netherlands: University of Twente, 1997.

[22] Fritzsche AF, Hahnemann HW, Rant Z. Rundschau. Forsch Ing-Wes. 1956;22(1):33-7.

[23] Berg CA. Process integration and the second law of thermodynamics: Future possibilities. Energy. 1980;5(8-9):733-42.

[24] Rosen MA, Dincer I, Kanoglu M. Role of exergy in increasing efficiency and sustainability and reducing environmental impact. Energy Policy. 2008;36(1):12837.

[25] Szargut J. Exergy analysis. Academia2005. p. 31-3.

[26] Wall G. Exergetics. 2009.

[27] Dincer I. The role of exergy in energy policy making. Energy Policy. 2002;30(2):137-49.

[28] Dincer I, Rosen MA. Chapter 2 - Exergy and Energy Analyses. Exergy (Second Edition): Elsevier; 2013. p. 21-30.

[29] Hevert HW, Hevert SC. Second law analysis: An alternative indicator of system efficiency. Energy. 1980;5(8-9):865-73.

[30] Sciubba E. Exergy-based ecological indicators - A necessary tool for resource use assessment studies. Termotehnica. 2009;1:11-25. 
[31] Zvolinschi A, Kjelstrup S, Bolland O, van der Kooi HJ. Exergy Sustainability Indicators as a Tool in Industrial Ecology. Journal of Industrial Ecology. 2007;11(4):85-98.

[32] Dincer I, Rosen MA. Chapter 5 - Applications of exergy in industry. In: Ibrahim D, Marc AR, editors. Exergy (Second Edition): Elsevier; 2013. p. 75-82.

[33] Dincer I, Cengel Y. Energy, Entropy and Exergy Concepts and Their Roles in Thermal Engineering. Entropy. 2001;3(3):116-49.

[34] BoroumandJazi G, Rismanchi B, Saidur R. A review on exergy analysis of industrial sector. Renewable and Sustainable Energy Reviews. 2013;27(0):198-203.

[35] Luis P. Exergy as a tool for measuring process intensification in chemical engineering. Journal of Chemical Technology and Biotechnology. 2013;88(11):1951-8.

[36] Apaiah RK, Linnemann AR, Van Der Kooi HJ. Exergy analysis: A tool to study the sustainability of food supply chains. Food Research International. 2006;39(1):1-11.

[37] Panwar NL, Kaushik SC, Kothari S. A review on energy and exergy analysis of solar drying systems. Renewable and Sustainable Energy Reviews. 2012 16:2812-9.

[38] Bennamoun L. An overview on application of exergy and energy for determination of solar drying efficiency. International Journal of Energy Engineering. 2012 2(5):184-94.

[39] El-Sebaii AA, Shalaby SM. Solar drying of agricultural products: A review. Renewable and Sustainable Energy Reviews. 2012;16(1):37-43.

[40] Colak N, Hepbasli A. A review of heat pump drying: Part 1 - Systems, models and studies. Energy Conversion and Management. 2009;50(9):2180-6. 
[41] Bruttini R, Crosser OK, Liapis AI. Exergy analysis for the freezing stage of the freeze drying process Dry Technol. 2001;19(9):2303-13.

[42] Dincer I, Sahin AZ. A new model for thermodynamic analysis of a drying process. International Journal of Heat and Mass Transfer. 2004;47(4):645-52.

[43] Dincer I. Exergy as a potential tool for sustainable drying systems. Sustainable Cities and Society. 2011;1(2):91-6.

[44] Aghbashlo M, Mobli H, Rafiee S, Madadlou A. A review on exergy analysis of drying processes and systems. Renewable and Sustainable Energy Reviews. 2013;22(0):1-22.

[45] Tsatsaronis G, Morosuk T. Understanding and improving energy conversion systems with the aid of exergy-based methods. Int J Exergy. 2012;11(4):518-42.

[46] Seckin C, Sciubba E, Bayulken AR. Extended exergy analysis of Turkish transportation sector. Journal of Cleaner Production. 2013;47(0):422-36.

[47] Stanek W, Gazda W. Exergo-ecological evaluation of adsorption chiller system. Energy. 2014 1(7).

[48] Dincer I, Rosen MA. Chapter 3 - Chemical Exergy. In: Ibrahim D, Marc AR, editors. Exergy (Second Edition): Elsevier; 2013. p. 31-49.

[49] Szargut J. Chemical exergies of the elements. Applied Energy. 1989;32(4):26986.

[50] Jankowiak L, Jonkman J, Rossier-Miranda FJ, van der Goot AJ, Boom RM. Exergy driven process synthesis for isoflavone recovery from okara. Energy. 2014;74(0):471-83.

[51] Stougie L, Bart GCJ, Boelman EC, Asada H, Infante Ferreira CA, van Der Kooi HJ, et al. Energy efficiency and the quality of energy in the food processing industry: Delft University of Technology, 2002. 
[52] Dincer I, Rosen MA. Chapter 6 - Exergy analysis of psychrometric processes. In: Ibrahim D, Marc AR, editors. Exergy (Second Edition): Elsevier; 2013. p. 83100.

[53] Balkan F, Colak N, Hepbasli A. Performance evaluation of a triple-effect evaporator with forward feed using exergy analysis. International Journal of Energy Research. 2005;29(5):455-70.

[54] Valero A. Thermoeconomics as a conceptual basis for energy-ecological analysis. In: Ulgiati S, editor. Advances in Energy Studies - Energy Flows in Ecology and Economy1998. p. 415-44.

[55] Szargut J, Morris DR, Steward FR. Exergy analysis of thermal, chemical, and metallurgical processes. New York: Hemisphere, 1988.

[56] Morosuk T, Tsatsaronis G, Schult M. Conventional and Advanced Exergetic Analyses: Theory and Application. Arabian Journal for Science and Engineering. 2013;38(2):395-404.

[57] Szargut J. International progress in second law analysis. Energy. 1980;5(89):709-18.

[58] Fang Z, Larson DL, Fleischmen G. Exergy analysis of a milk processing system. Trans ASAE. 1995;38(6):1825-32.

[59] Van Gool W. Energy Policy: Fairy Tales and Factualities. In: Soares OD, Cruz AM, Pereira GC, Soares IRT, Reis APS, editors. Innovation and Technology Strategies and Policies: Springer Netherlands; 1997. p. 93-105.

[60] Gouy G. Sur les transformation et l'equilibre en Thermodynamique. Comptes Rendus de l'Academie des Sciences Paris. 1889;108(10):507-9.

[61] Gouy G. Sur l' energie utilisable. Journal de Physique. 1889;8:501-18. 
[62] Duhem P. Sur les transformations et l' equilibre en Thermodynamique - Note de M.P. Duhem. Comptes Rendus de l'Academie des Sciences Paris. 1889;108(13):666-7.

[63] Gouy G. Sur l' energie utilisable et le potentiel thermodynamique - Note de M. Gouy. Comptes Rendus de l'Academie des Sciences Paris. 1889;108(10):794.

[64] Kay JJ. Musings on the second law and life. In: Minkel RJ, editor. http://www.jameskay.ca/musings/thermomusings.pdf. 2002

[65] Connelly L, Koshland CP. Two aspects of consumption: using an exergy-based measure of degradation to advance the theory and implementation of industrial ecology. Resources, Conservation and Recycling. 1997;19(3):199-217.

[66] Szargut J. Analysis of cumulative exergy consumption. International Journal of Energy Research. 1987;11(4):541-7.

[67] Szargut J. Exergy losses in the chains of technological processes. Bulletin of the Polish Academy of Sciences Technical Sciences. 1988;36(7-9):513-21.

[68] Stougie L, Van Der Kooi HJ. The relation between exergy and sustainability according to literature. 2nd International Exergy, Life Cycle Assessment and Sustainability Workshop \& Symposium (ELCAS2). Nisyros, Greece2011.

[69] Hepbasli A. A comparative investigation of various greenhouse heating options using exergy analysis method. Applied Energy. 2011;88(12):4411-23.

[70] Dewulf J, Van Langenhove H, Mulder J, van den Berg MMD, van der Kooi HJ, de Swaan Arons J. Illustrations towards quantifying the sustainability of technology. Green Chemistry. 2000;2(3):108-14.

[71] Jørgensen SE. Evolution and exergy. Ecological Modelling. 2007;203(34):490-4. 
[72] Ducoulombier M, Sorin M, Teyssedou A. Thermodynamic bounds for food deep chilling tray tunnel operation. International Journal of Thermal Sciences. 2007;46(2):172-9.

[73] Catton W, Carrington G, Sun Z. Exergy analysis of an isothermal heat pump dryer. Energy. 2011;36(8):4616-24.

[74] Tambunan AH, Manalu LP, Abdullah K. Exergy Analysis on Simultaneous Charging and Discharging of Solar Thermal Storage for Drying Application. Dry Technol. 2010;28(9):1107-12.

[75] Pandey SD, Nema VK. An experimental investigation of exergy loss reduction in corrugated plate heat exchanger. Energy. 2011;36(5):2997-3001.

[76] Quijera JA, Labidi J. Pinch and exergy based thermosolar integration in a dairy process. Applied Thermal Engineering. 2013;50(1):464-74.

[77] Akpinar EK. Exergy analysis associated with heat transfer during heating of slab products. Int J Exergy. 2010;7(1):66-75.

[78] Ahamed JU, Saidur R, Masjuki HH, Mekhilef S, Ali MB, Furqon MH. An application of energy and exergy analysis in agricultural sector of Malaysia. Energy Policy. 2011;39(12):7922-9.

[79] Xydis G, Koroneos C, Nanaki E. Exergy-based comparison of two Greek industries. Int J Exergy. 2011;8(4):460-76.

[80] Xiang JY, Calì M, Santarelli M. Calculation for physical and chemical exergy of flows in systems elaborating mixed-phase flows and a case study in an IRSOFC plant. International Journal of Energy Research. 2004;28(2):101-15.

[81] Kumar N, Vishwanath G, Gupta A. An exergy based unified test protocol for solar cookers of different geometries. Renewable Energy. 2012;44(0):457-62. 
[82] Cuce E, Cuce PM. Energetic and exergetic performance assessment of solar cookers with different geometrical designs. International Journal of Ambient Energy. 2013:1-8.

[83] Sorgüven E, Özilgen M. Energy utilization, carbon dioxide emission, and exergy loss in flavored yogurt production process. Energy. 2012;40(1):214-25.

[84] Özilgen M, Sorgüven E. Energy and exergy utilization, and carbon dioxide emission in vegetable oil production. Energy. 2011;36(10):5954-67.

[85] Sogut Z, Ilten N, Oktay Z. Energetic and exergetic performance evaluation of the quadruple-effect evaporator unit in tomato paste production. Energy. 2010;35(9):3821-6.

[86] Ho JC, Wijeysundera NE, Chou SK. Energy analysis applied to food processing. Energy. 1986;11(9):887-92.

[87] Tiwari GN, Das T, Chen CR, Barnwal P. Energy and exergy analyses of greenhouse fish drying. Int J Exergy. 2009;6(5):620-36.

[88] Boyar S, Akdeniz RC, Hepbasli A. Performance evaluation of an extruder system in a mixed feed factory. J Food Agric Environ. 2012;10(3-4):524-7.

[89] Pandey AK, Tyagi VV, Park SR, Tyagi SK. Comparative experimental study of solar cookers using exergy analysis. 2012;109(1):425-31.

[90] Nazghelichi T, Kianmehr MH, Aghbashlo M. Thermodynamic analysis of fluidized bed drying of carrot cubes. Energy. 2010;35(12):4679-84.

[91] Amantéa RP, Fortes M, Martins JH, Ferreira WR. Numerical Simulation Techniques for Optimizing Thermodynamic Efficiencies of Cereal Grain Dryers. Dry Technol. 2013;31(6):672-83. 
[92] Akpinar EK. Energy and exergy analyses of drying of red pepper slices in a convective type dryer. International Communications in Heat and Mass Transfer. 2004;31(8):1165-76.

[93] Akbulut A, Durmuş A. Energy and exergy analyses of thin layer drying of mulberry in a forced solar dryer. Energy. 2010;35(4):1754-63.

[94] Corzo O, Bracho N, Vásquez A, Pereira A. Energy and exergy analyses of thin layer drying of coroba slices. Journal of Food Engineering. 2008;86(2):151-61.

[95] Corzo O, Bracho N, Vásquez A, Pereira A. Optimization of a thin layer drying process for coroba slices. Journal of Food Engineering. 2008;85(3):372-80.

[96] Syahrul S, Dincer I, Hamdullahpur F. Thermodynamic modeling of fluidized bed drying of moist particles. International Journal of Thermal Sciences. 2003;42(7):691-701.

[97] Fortes M, Martins JH, Amantéa RP, Ferreira WR. Transient and spatial energy and exergy analysis of deep-bed corn drying. Conference Transient and spatial energy and exergy analysis of deep-bed corn drying, vol. 1. p. 226-33.

[98] Bolaji BO. Exergetic analysis of solar energy drying systems. Natural Resources. 2011;2:92-7.

[99] Fortes M. Second-law modeling of deep bed drying processes with a simulation study of wheat air-recirculated fluidized-bed drying. Conference Second-law modeling of deep bed drying processes with a simulation study of wheat airrecirculated fluidized-bed drying, Sao Paulo, Brazil vol. A. p. 18-32.

[100] Fortes M, Ferreira WR. Second law analysis of drying - Modeling and simulation of fluidized bed grain drying. Conference Second law analysis of drying Modeling and simulation of fluidized bed grain drying, Sao Paulo, Brazil vol. A. p. $301-8$. 
[101] Inaba H. Heat and mass transfer analysis of fluidized bed grain drying. Memoirs of the Faculty of Engineering: Okayama University; 2007. p. 52-62.

[102] Assari MR, Basirat Tabrizi H, Najafpour E. Energy and exergy analysis of fluidized bed dryer based on two-fluid modeling. International Journal of Thermal Sciences. 2013;64(0):213-9.

[103] Aghbashlo M, Kianmehr MH, Arabhosseini A. Performance analysis of drying of carrot slices in a semi-industrial continuous band dryer. Journal of Food Engineering. 2009;91(1):99-108.

[104] Midilli A, Kucuk H. Energy and exergy analyses of solar drying process of pistachio. Energy. 2003;28(6):539-56.

[105] Hernández-Díaz WN, Hernandez-Campos FJ, Vargas-Galarza Z, RodríguezJimenes GC, García-Alvarado MA. Coffee grain rotary drying optimization optimizacion del secado de granos de cafe en un secador rotatorio. Revista Mexicana de Ingeniera Qumica. 2013;12(2):315-25.

[106] Fissore D, Pisano R, Barresi AA. Applying quality-by-design to develop a coffee freeze-drying process. Journal of Food Engineering. 2014;123(0):179-87.

[107] Sami S, Etesami N, Rahimi A. Energy and exergy analysis of an indirect solar cabinet dryer based on mathematical modeling results. Energy. 2011;36(5):2847-55.

[108] Erbay Z, Icier F. Optimization of drying of olive leaves in a pilot-scale heat pump dryer. Dry Technol. 2009;27(3):416-27.

[109] Erbay Z, Icier F. Energy and exergy analyses on drying of olive leaves in tray drier J Food Process Eng. 2011;34(6):2105-23.

[110] Celma AR, Cuadros F. Energy and exergy analyses of OMW solar drying process. Renewable Energy. 2009;34(3):660-6. 
[111] Liu Y, Zhao Y, Feng X. Exergy analysis for a freeze-drying process. Applied Thermal Engineering. 2008;28(7):675-90.

[112] Colak N, Kuzgunkaya E, Hepbasli A. Exergetic assessment of drying of mint leaves in a heat pump dryer. J Food Process Eng. 2008;31(3):281-98.

[113] Akpinar EK. Drying of mint leaves in a solar dryer and under open sun: Modelling, performance analyses. Energy Conversion and Management. 2010;51(12):2407-18.

[114] Boulemtafes-Boukadoum A, Benzaoui A. Energy and exergy analysis of solar drying process of mint. Conference Energy and exergy analysis of solar drying process of mint, vol. 6. p. 583-91.

[115] Akpinar EK. Drying of parsley leaves in a solar dryer and under open sun: Modelling, energy and exergy aspects. J Food Process Eng. 2011;34(1):27-48.

[116] Chowdhury MMI, Bala BK, Haque MA. Energy and exergy analysis of the solar drying of jackfruit leather. Biosystems Engineering. 2011;110(2):222-9.

[117] Prommas R, Keangin P, Rattanadecho P. Energy and exergy analyses in convective drying process of multi-layered porous packed bed. International Communications in Heat and Mass Transfer. 2010;37(8):1106-14.

[118] Ozgener L, Ozgener O. Exergy Analysis of Drying Process: An Experimental Study in Solar Greenhouse. Dry Technol. 2009;27(4):580-6.

[119] Tyagi SK, Tyagi VV, Anand S, Chandra V, Diwedi RC. First and second law analyses of a typical solar air dryer system: a case study. International Journal of Sustainable Energy. 2009;29(1):8-18.

[120] Saidur R, Ahamed JU, Masjuki HH. Energy, exergy and economic analysis of industrial boilers. Energy Policy. 2010;38(5):2188-97. 
[121] Kamate SC, Gangavati PB. Exergy analysis of cogeneration power plants in sugar industries. Applied Thermal Engineering. 2009;29(5-6):1187-94.

[122] Palacios-Bereche R, Mosqueira-Salazar KJ, Modesto M, Ensinas AV, Nebra SA, Serra LM, et al. Exergetic analysis of the integrated first- and second-generation ethanol production from sugarcane. Energy. 2013;62(0):46-61.

[123] Akinoso R, Lawal IA, Aremu AK. Energy requirements of size reduction of some selected cereals using attrition mill. International Food Research Journal. 2013;20(3):1205-9.

[124] Ozgener L. Exergoeconomic analysis of small industrial pasta drying systems. Proceedings of the Institution of Mechanical Engineers, Part A: Journal of Power and Energy. 2007;221(7):889-906.

[125] Ozgener L, Ozgener O. Exergy analysis of industrial pasta drying process. International Journal of Energy Research. 2006;30(15):1323-35.

[126] Ozgener L, Ozgener O. Parametric study of the effect of reference state on energy and exergy efficiencies of a small industrial pasta drying process. Int $\mathrm{J}$ Exergy. 2009;6(4):477-90.

[127] Erbay Z, Koca N, Kaymak-Ertekin F, Ucuncu M. Optimization of spray drying process in cheese powder production. Food and Bioproducts Processing. 2014(0).

[128] Velásquez-Arredondo HI, Ruiz-Colorado AA, De Oliveira junior S. Ethanol production process from banana fruit and its lignocellulosic residues: Energy analysis. Energy. 2010;35(7):3081-7.

[129] Akpinar EK, Midilli A, Bicer Y. Energy and exergy of potato drying process via cyclone type dryer. Energy Conversion and Management. 2005;46(15-16):253052. 
[130] Aghbashlo M, Kianmehr MH, Arabhosseini A. Energy and Exergy Analyses of Thin-Layer Drying of Potato Slices in a Semi-Industrial Continuous Band Dryer. Dry Technol. 2008;26(12):1501-8.

[131] Akpinar EK, Midilli A, Bicer Y. The first and second law analyses of thermodynamic of pumpkin drying process. Journal of Food Engineering. 2006;72(4):320-31.

[132] Akpinar EK. Thermodynamic analysis of the apple drying process. Proceedings of the Institution of Mechanical Engineers, Part A: Journal of Power and Energy. 2005;219:1-14.

[133] Akpinar EK, Sarsilmaz C. Energy and exergy analyses of drying of apricots in a rotary solar dryer. Int J Exergy. 2004;1(4):457-74.

[134] Akpinar EK. Thermodynamic analysis of strawberry drying process in a cyclone type dryer. Journal of Scientific \& Industrial Research. 2007;66:152-61.

[135] Motevali A, Minaei S. Effects of microwave pretreatment on the energy and exergy utilization in thin-layer drying of sour pomegranate arils. Chemical Industry \& Chemical Engineering Quarterly. 2012;18(1).

[136] Syahrul S, Hamdullahpur F, Dincer I. Exergy analysis of fluidized bed drying of moist particles. Exergy, An International Journal. 2002;2(2):87-98.

[137] Prommas R, Rattanadecho P, Cholaseuk D. Energy and exergy analyses in drying process of porous media using hot air. International Communications in Heat and Mass Transfer. 2010;37(4):372-8.

[138] Prommas R, Rattanadecho P, Jindarat W. Energy and exergy analyses in drying process of non-hygroscopic porous packed bed using a combined multi-feed microwave-convective air and continuous belt system (CMCB). International Communications in Heat and Mass Transfer. 2012;39(2):242-50. 
[139] Akpinar EK. Energy and exergy analyses of drying of eggplant slices in a cyclone type dryer. Journal of Mechanical Science and Technology. 2005;19(2):692-703.

[140] Gungor A, Erbay Z, Hepbasli A. Exergoeconomic (Thermoeconomic) Analysis and Performance Assessment of a Gas Engine-Driven Heat Pump Drying System Based on Experimental Data. Dry Technol. 2011;30(1):52-62.

[141] Icier F, Colak N, Erbay Z, Kuzgunkaya EH, Hepbasli A. A Comparative Study on Exergetic Performance Assessment for Drying of Broccoli Florets in Three Different Drying Systems. Dry Technol. 2010;28(2):193-204.

[142] Colak N, Balta MT, Icier F, Kuzgunkaya E, Hepbasli A, Erbay Z. Exergy analysis of food drying processes. In: Dincer I, Hepbasli A, Midilli A, Hikmet Karakoc T, editors. Global Warming - Engineering Solutions2010

[143] Colak N, Erbay Z, Hepbasli A. Performance assessment and optimization of industrial pasta drying. International Journal of Energy Research. 2013;37(8):91322.

[144] Erbay Z, Koca N. Energetic, Exergetic, and Exergoeconomic Analyses of Spray-Drying Process during White Cheese Powder Production. Dry Technol. 2012;30(4):435-44.

[145] Hepbasli A, Erbay Z, Colak N, Hancioglu E, Icier F. An exergetic performance assessment of three different food driers. Proceedings of the Institution of Mechanical Engineers, Part A: Journal of Power and Energy. 2010;224(1):1-12.

[146] Hepbasli A, Colak N, Hancioglu E, Icier F, Erbay Z. Exergoeconomic analysis of plum drying in a heat pump conveyor dryer. Dry Technol. 2010;28(12):1385-95.

[147] Colak N, Hepbasli A. Performance analysis of drying of green olive in a tray dryer. Journal of Food Engineering. 2007;80(4):1188-93. 
[148] Gungor A, Erbay Z, Hepbasli A. Exergoeconomic analyses of a gas engine driven heat pump drier and food drying process. Applied Energy. 2011;88(8):267784.

[149] Gungor A, Erbay Z, Hepbasli A. Exergetic analysis and evaluation of a new application of gas engine heat pumps (GEHPs) for food drying processes. Applied Energy. 2011;88(3):882-91.

[150] Kuzgunkaya EH, Hepbasli A. Exergetic evaluation of drying of laurel leaves in a vertical ground-source heat pump drying cabinet. International Journal of Energy Research. 2007;31(3):245-58.

[151] Quijera JA, García A, Alriols MG, Labidi J. Heat integration options based on pinch and exergy analyses of a thermosolar and heat pump in a fish tinning industrial process. Energy. 2013(0).

[152] Waheed MA, Jekayinfa SO, Ojediran JO, Imeokparia OE. Energetic analysis of fruit juice processing operations in Nigeria. Energy. 2008;33(1):35-45.

[153] Jin Y, Chen XD. Entropy production during the drying process of milk droplets in an industrial spray dryer. International Journal of Thermal Sciences. 2011;50(4):615-25.

[154] Aghbashlo M, Mobli H, Rafiee S, Madadlou A. Energy and exergy analyses of the spray drying process of fish oil microencapsulation. Biosystems Engineering. 2012;111(2):229-41.

[155] Aghbashlo M, Mobli H, Rafiee S, Madadlou A. Optimization of emulsification procedure for mutual maximizing the encapsulation and exergy efficiencies of fish oil microencapsulation. Powder Technology. 2012;225(0):10717. 
[156] Aghbashlo M, Mobli H, Rafiee S, Madadlou A. The use of artificial neural network to predict exergetic performance of spray drying process: A preliminary study. Computers and Electronics in Agriculture. 2012;88(0):32-43.

[157] Aghbashlo M, Mobli H, Madadlou A, Rafiee S. Influence of spray dryer parameters on exergetic performance of microencapsulation processes. Int $\mathrm{J}$ Exergy. 2012;10(3):267-89.

[158] Aneke M, Agnew B, Underwood C, Menkiti M. Thermodynamic analysis of alternative refrigeration cycles driven from waste heat in a food processing application. International Journal of Refrigeration. 2012;35(5):1349-58.

[159] Lamnatou C, Papanicolaou E, Belessiotis V, Kyriakis N. Experimental investigation and thermodynamic performance analysis of a solar dryer using an evacuated-tube air collector. Applied Energy. 2012;94(0):232-43.

[160] Ranjbaran M, Zare D. Simulation of energetic- and exergetic performance of microwave-assisted fluidized bed drying of soybeans. Energy. 2013;59(0):484-93.

[161] Erbay Z, Hepbasli A. Advanced Exergy Analysis of a Heat Pump Drying System Used in Food Drying. Dry Technol. 2013;31(7):802-10.

[162] Erbay Z, Icier F, Hepbasli A. Exergetic performance assessment of a pilotscale heat pump belt conveyor dryer. International Journal of Energy Research. 2010;34(3):249-64.

[163] Erbay Z, Koca N. Investigating the effects of operating conditions on the exergetic performance of a pilot-scale spray-drying system. Int $J$ Exergy. 2012;11(3):302-21.

[164] Bapat SM, Majali VS, Ravindranath G. Exergetic evaluation and comparison of quintuple effect evaporation units in Indian sugar industries. International Journal of Energy Research. 2013;37(12):1415-27. 
[165] Erbay Z, Hepbasli A. Application of conventional and advanced exergy analyses to evaluate the performance of a ground-source heat pump (GSHP) dryer used in food drying. Energy Conversion and Management. 2014;78(0):499-507.

[166] Erbay Z, Koca N. Investigating the effects of operating conditions on the exergetic performance of a pilot-scale spray drying system. Int $\mathbf{J}$ Exergy. 2012;11(3):302-21.

[167] Moya C, Domínguez R, Van Langenhove H, Herrero S, Gil P, Ledón C, et al. Exergetic analysis in cane sugar production in combination with Life Cycle Assessment. Journal of Cleaner Production. 2013;59(0):43-50.

[168] Raghu Ram J, Banerjee R. Energy and cogeneration targeting for a sugar factory. Applied Thermal Engineering. 2003;23(12):1567-75.

[169] Draganovic V, Jørgensen SE, Boom R, Jonkers J, Riesen G, van der Goot AJ. Sustainability assessment of salmonid feed using energy, classical exergy and ecoexergy analysis. Ecological Indicators. 2013;34(0):277-89.

[170] Talens Peiró LT, Méndez GV, Durany XGI. Exergy analysis of integrated waste management in the recovery and recycling of used cooking oils. Environmental Science and Technology. 2008;42(13):4977-81.

[171] Talens Peiró L, Lombardi L, Villalba Méndez G, Gabarrell i Durany X. Life cycle assessment (LCA) and exergetic life cycle assessment (ELCA) of the production of biodiesel from used cooking oil (UCO). Energy. 2010;35(2):889-93.

[172] Hoang V-N, Rao DSP. Measuring and decomposing sustainable efficiency in agricultural production: A cumulative exergy balance approach. Ecological Economics. 2010;69(9):1765-76.

[173] Wall G. Exergy conversion in the Japanese society. Energy. 1990;15(5):43544. 
[174] Gong M, Wall G. Exergy use in the Swedish society 1994. TAIES '97. Beijing, China1997. p. 453-60.

[175] Pellegrini LF, de Oliveira Junior S. Combined production of sugar, ethanol and electricity: Thermoeconomic and environmental analysis and optimization. Energy. 2011;36(6):3704-15.

[176] Grip CE, Elfgren E, Soderstrom M, Thollander P, Berntsson T, Asblad A, et al. Possibilities and problems in using exergy expressions in process integration. World Renewable Energy Congress Linkoping, Sweden2011.

[177] Leites IL, Sama DA, Lior N. The theory and practice of energy saving in the chemical industry: some methods for reducing thermodynamic irreversibility in chemical technology processes. Energy. 2003;28(1):55-97.

[178] Shukuya M. Renewing Our View with the Concept of Exergy. Exergy: Springer London; 2013. p. 1-15.

[179] La Rocca V. Cold recovery during regasification of LNG part two: Applications in an Agro Food Industry and a Hypermarket. Energy. 2011;36(8):4897-908.

[180] Koroneos C, Spachos T, Moussiopoulos N. Exergy analysis of renewable energy sources. Renewable Energy. 2003;28(2):295-310.

[181] Le Pierrès N, Stitou D, Mazet N. New deep-freezing process using renewable low-grade heat: From the conceptual design to experimental results. Energy. 2007;32(4):600-8.

[182] Hermann WA. Quantifying global exergy resources. Energy. 2006;31(12):1685-702.

[183] Michalski MC, Genot C, Gayet C, Lopez C, Fine F, Joffre F, et al. Multiscale structures of lipids in foods as parameters affecting fatty acid bioavailability and lipid metabolism. Progress in Lipid Research. 2013;52(4):354-73. 
[184] Mady CEK. Human body exergy metabolism. International Journal of Thermodynamics. 2013;16(2).

[185] Mady CEK, Silva Ferreira M, Itizo Yanagihara J, Hilário Nascimento Saldiva P, de Oliveira Junior S. Modeling the exergy behavior of human body. Energy. 2012;45(1):546-53.

[186] Shukuya M. Theory for Open Systems. Exergy: Springer London; 2013. p. 231-364.

[187] Gaudreau K, Roydon AF, Murphy S. The tenuous use of exergy as a measure of resource value or waste impact. Sustainability. 2009;1:1444-63.

[188] Dincer I. On energetic, exergetic and environmental aspects of drying systems. International Journal of Energy Research. 2002;26(8):717-27.

[189] Zhu P, Feng X. Allocation of cumulative exergy in multiple product separation processes. Energy. 2007;32(2):137-42.

[190] Tsatsaronis G, Cziezla F. Strengths and limitations of exergy analysis. Encyclopedia of Life Support Systems: Technical University of Berlin; 1999.

[191] Caudill RJ, Olapiriyakul S, Seale B. An exergy footprint metric normalized to US exergy consumption per capita. Conference An exergy footprint metric normalized to US exergy consumption per capita. p. 1-6.

[192] Čuček L, Klemeš JJ, Kravanja Z. A Review of Footprint analysis tools for monitoring impacts on sustainability. Journal of Cleaner Production. 2012;34(0):920.

[193] Hernando FMD, Hector CA. An exergetic cold chain methodological analysis on horticultural productive chains to evaluate productivity and competitiveness Study case Andean blackberry. International Journal of Agriculture and Forestry. 2013;3(1):16-28. 
[194] Sciubba E. Beyond thermoeconomics? The concept of Extended Exergy Accounting and its application to the analysis and design of thermal systems. Exergy, An International Journal. 2001;1(2):68-84.

[195] Hau JL, Bakshi BR. Expanding Exergy Analysis to Account for Ecosystem Products and Services. Environmental Science \& Technology. 2004;38(13):3768-77.

[196] Dewulf J, Bösch ME, Meester BD, Vorst GVd, Langenhove HV, Hellweg S, et al. Cumulative Exergy Extraction from the Natural Environment (CEENE): a comprehensive Life Cycle Impact Assessment method for resource accounting. Environmental Science \& Technology. 2007;41(24):8477-83.

[197] Gungor A, Erbay Z, Hepbasli A, Gunerhan H. Splitting the exergy destruction into avoidable and unavoidable parts of a gas engine heat pump (GEHP) for food drying processes based on experimental values. Energy Conversion and Management. 2013;73(0):309-16.

[198] Nishitani H, Kunugita E. Multiobjective Analysis for Energy and Resource Conservation in an Evaporation System. Efficiency and Costing: AMERICAN CHEMICAL SOCIETY; 1983. p. 333-47.

[199] Apaiah R. K. LAR, van der Kooi H.J. Desigining food supply chains - A structured methodology: A case on Novel Protein Foods: Wageningen University, 2006.

[200] Khoa TD, Shuhaimi M, Hashim H, Panjeshahi MH. Optimal design of distillation column using three dimensional exergy analysis curves. Energy. 2010;35(12):5309-19.

[201] Vintila I. Mass and heat transfer coefficients assessment, optimisation and validation for multiphase food systems under transient stages. Trends in Food Science \& Technology. 2012;26(2):114-9. 
[202] Nazghelichi T, Aghbashlo M, Kianmehr MH. Optimization of an artificial neural network topology using coupled response surface methodology and genetic algorithm for fluidized bed drying. Computers and Electronics in Agriculture. 2011;75(1):84-91.

[203] Nazghelichi T, Aghbashlo M, Kianmehr MH, Omid M. Prediction of Energy and Exergy of Carrot Cubes in a Fluidized Bed Dryer by Artificial Neural Networks. Dry Technol. 2011;29(3):295-307.

[204] Erbay Z, Icier F. Optimization of hot air drying of olive leaves using response surface methodology. Journal of Food Engineering. 2009;91(4):533-41.

[205] Karimi F, Rafiee S, Taheri-Garavand A, Karimi M. Optimization of an air drying process for Artemisia absinthium leaves using response surface and artificial neural network models. Journal of the Taiwan Institute of Chemical Engineers. 2012;43(1):29-39.

[206] Nikbakht AM, Motevali A, Minaei S. Energy and exergy investigation of microwave assisted thin-layer drying of pomegranate arils using artificial neural networks and response surface methodology. Journal of the Saudi Society of Agricultural Sciences. 2013(0).

[207] Kjelstrup S, Rosjorde A, Johannessen E. Non-equilibrium thermodynamics in industry. In: Letcher TM, editor. Chemical thermodynamics for industry: RSC Publishin; 2004.

[208] Andresen B. Current trends in finite-time thermodynamics. Angewandte Chemie - International Edition. 2011;50(12):2690-704. 


\section{Chapter 3}

\section{Exergetic comparison of food waste valorization in industrial bread production}

Published as:

Zisopoulos F.K., Moejes S.N., Rossier-Miranda F.J., van der Goot A.J., Boom R.M. (2015). Exergetic comparison of food waste valorization in industrial bread production. Energy. 82(0): 640-649. 


\begin{abstract}
This study compares the thermodynamic performance of three industrial bread production chains: one that generates food waste, one that avoids food waste generation, and one that reworks food waste to produce new bread. The chemical exergy flows were found to be much larger than the physical exergy consumed in all the industrial bread chains studied. The par-baked brown bun production chain had the best thermodynamic performance because of the highest rational exergetic efficiency (71.2\%), the lowest specific exergy losses (5.4 MJ/kg brown bun), and the almost lowest cumulative exergy losses (4768 MJ/1000 kg of dough processed). However, recycling of bread waste is also exergetically efficient when the total fermented surplus is utilizable. Clearly, preventing material losses (i.e. utilizing raw materials maximally) improves the exergetic efficiency of industrial bread chains. In addition, most of the physical (non-material related) exergy losses occurred at the baking, cooling and freezing steps. Consequently, any additional improvement in industrial bread production should focus on the design of thermodynamically efficient baking and cooling processes, and on the use of technologies throughout the chain that consume the lowest possible physical exergy.
\end{abstract}

Keywords: Sustainability; Food industry; Bread production; Food waste; Recycling; Exergy; 


\section{Introduction}

The food industry is challenged with increasing pressure to render their processes more efficient, implying minimizing energy use and waste production [1, 2]. Exergy analysis is an objective sustainability assessment method that has been developed and has been applied successfully in different fields, from the energy and chemical sectors to environmental engineering and the construction industries in the past decades [3-11], and more recently in the feed and food industry [12, 13]. According to Szargut [14], exergy can be defined as "the amount of work obtainable when some matter is brought to a state of thermodynamic equilibrium with the common components of its surrounding nature by means of reversible processes, involving interaction only with the above mentioned components of nature". The main advantages of exergy analysis is that it identifies thermodynamically inefficient processes in a system, and it leads to a better understanding of the physical and chemical reasons for those inefficiencies [15, 16]. The analysis itself does not identify solutions but it can be used to compare the exergetic sustainability of alternative scenarios. Exergy analysis allows the expression of chemical exergy (i.e. exergy stored in materials) and physical exergy in one single unit.

Generally, the chemical exergy of material streams can be much larger than the physical exergy, a remark that was also made by Bösch et al.. [17] who studied the exergetic comparison of ethanol and biogas poly-generation processes. Consequently, it is expected that losing parts of material streams (e.g. raw material inputs and food products) as waste will severely affect the exergetic sustainability of a food chain. More recently, Vandermeersch et al. [18] compared different bread waste valorization options and proposed that animal feed technology is a better option than anaerobic digestion in terms of exergetic performance, but only for food waste with more than $60 \%$ dry matter because it reduces the raw material requirements of the traditional production of animal feed, which includes drying. They also concurred with the waste hierarchy framework that food waste should always be avoided. 
In this article, we compare the thermodynamic performance of a process system that generates food waste with a technology that avoids food waste generation and a technology that reworks food waste to produce new food products. The hypothesis is that avoiding food waste is in principle better than recycling food waste, also from a thermodynamic perspective. Industrial bread production in the Netherlands has been chosen as a case study for two reasons. First, because bread is produced in large quantities in the Netherlands with an average annual per capita consumption of about $60 \mathrm{~kg}$ [19], and second, because bread losses occur at different parts of the chain and account for $30 \%$ of total bread production [20]. Two different bread types were considered to capture variations in recipes, types and quantities of raw materials, as well as the operation conditions used in processing.

The thermodynamic performances of all six industrial bread chains are assessed using exergetic indicators found in the literature such as the cumulative exergy losses (CEL), the specific exergy losses (SEL), and the rational exergetic efficiency (n) $[21],[22]$

\section{Materials and methods}

\section{General description of the industrial bread production chains}

Three different technologies were defined for the assessment (Figure 1). The conventional method of fresh white tin bread production with losses at certain parts of the chain was compared with a chain that was assumed to be free of losses due to its technology (par-baked bread), and a chain in which wasted bread was reworked to produce a product of similar quality (fermented breadcrumb bread). Such recycling could be technologically feasible on a large scale by fermenting wasted bread with a particular type of starter, to deliver a product with better quality than normal white bread in terms of softness and taste [23].

The two different bread recipes (white tin bread and brown buns), and the chemical composition of the raw materials are given in Table A.1 and Table A.2 in the Appendix. These recipes were selected to cover the variations in processing 
technology in industrial bread production. The calculations were based on processing $1000 \mathrm{~kg}$ of dough for all six bread chains. The white breads and brown buns produced were assumed to have a mass of $0.8 \mathrm{~kg}$ and $0.06 \mathrm{~kg}$, respectively. In order to make a fair exergetic comparison between the industrial chains, the moisture content for all white breads and brown buns was assumed to be $37.6 \%$ and $34.6 \%$, respectively, for all three technologies (Table A.3 in the Appendix). For the calculation of the moisture content of the final products, the fresh bread production chain was used as a base case where it was assumed that $10 \%$ of the initial water added during dough production evaporates during baking. All breads were assumed to have the same specific density of $0.005 \mathrm{~m}^{3} / \mathrm{kg}$. The main process simulation parameters are shown in Table A.4 in the Appendix.

Energy use at the industrial bakery oven for all three technologies was assumed to be provided by natural gas and it was calculated based on the energy required to evaporate water and to produce the steam used for crust formation. The total energy consumption in the industrial bakery was assumed to be twice the energy required for baking (personal communication). The other 50\% of the energy used was assumed to be electricity, which was distributed according to the requirements calculated for each process (personal communication). The energy use for the conveyor was assumed to be the same for the fresh and the par-baked bread bakeries, whereas it was a bit higher for the fermented breadcrumb bakery due to the extra processing steps involved in the chain.

The distance to transport the raw materials to the bakery $(100 \mathrm{~km})$ and transport the product to the retailer $(80 \mathrm{~km})$ were assumed to be identical for all three technologies. Additional assumptions related to transportation are shown in Table A.5 in the Appendix. 


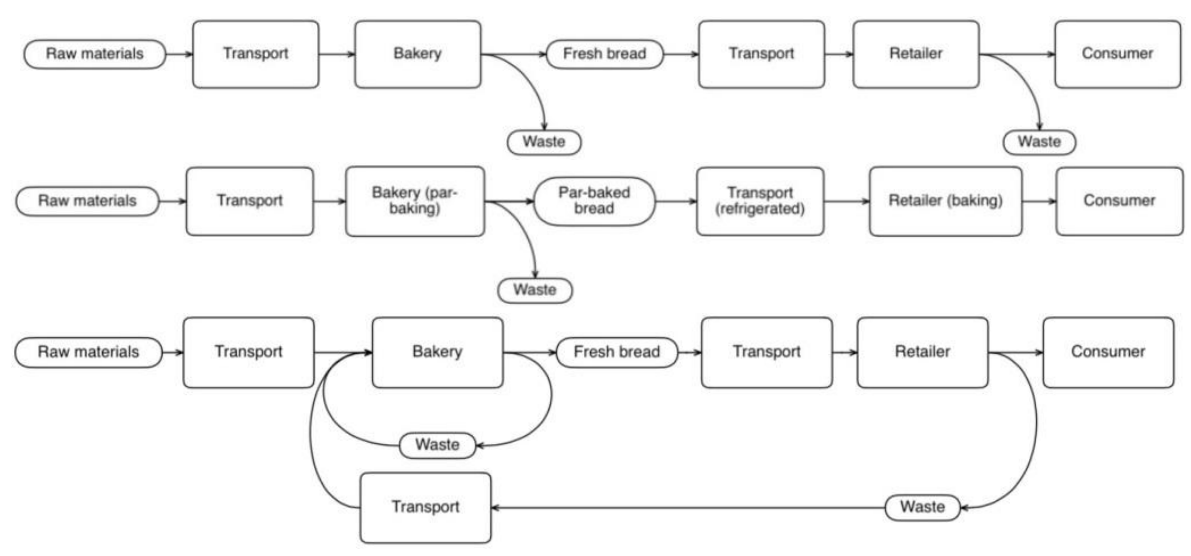

Figure 1. Flowchart for the production of fresh bread (top), par-baked bread (middle) and fermented breadcrumb bread (bottom).

\section{Dough processing}

The first processing steps of mixing, fermenting, dividing and proving are common to all six industrial chains. First, the raw materials are mixed either by normal mixing for $15 \mathrm{~min}$ (15 kJ/kg dough) or by the Chorleywood Bread Process which involves intense mixing for $3 \mathrm{~min}$ (40 kJ/kg dough) [24]. All raw materials are at ambient temperature except the water; the temperature of the water is

$$
T_{\text {water }}=2\left(T_{\text {dough }}-\Delta T_{\text {mix }}\right)-T_{\text {flour }}
$$

where $\Delta T_{\text {mix }}=8(\mathrm{~K})$ is the increase in dough temperature per mixing period and $T_{\text {dough }}(\mathrm{K})$ is the final dough temperature [25]. The dough is fermented for $1 \mathrm{~h}$ at 28 ${ }^{\circ} \mathrm{C}$ in fermentors with a capacity of 200 breads and each of which consumes $6.2 \mathrm{~kW}$ [26]. During fermentation, $2 \%$ of the simple sugars are converted into ethanol and carbon dioxide. The electricity consumption for cutting the dough into individual units is $0.6 \mathrm{~kW}$ per 1000 units (one unit is $0.8 \mathrm{~kg}$ and $0.06 \mathrm{~kg}$ for white bread and for brown buns, respectively) [27]. Subsequently, the fermentation continues under the same conditions for one more hour and additional electricity is consumed. 


\section{Base case: fresh bread production}

The baking is done in a continuous oven at $235{ }^{\circ} \mathrm{C}$ for $35 \mathrm{~min}$. It is assumed that all carbon dioxide and ethanol resulting from yeast activity are removed from the bread during baking. The energy to bake the product is the energy required to evaporate $10 \%$ of the water. It is assumed that $10 \%$ of the dough becomes crust and the crumb and crust temperatures reach a maximum of $100{ }^{\circ} \mathrm{C}$ (evaporative cooling) and $180{ }^{\circ} \mathrm{C}$, respectively. The energy distribution in the oven is as follows: $25 \%$ of the energy is used to bake the product, $15 \%$ of the energy is due to steam usage for crust formation and $60 \%$ is heat loss [28]. The oven is heated by natural gas with a lower heating value of $54 \mathrm{MJ} / \mathrm{kg}$ natural gas. Steam at $123.3{ }^{\circ} \mathrm{C}$ and $220 \mathrm{kPa}$ is produced in a natural gas-fired boiler with $70 \%$ energy efficiency [29]. Subsequently, the baked breads are cooled for $30 \mathrm{~min}$ and the electricity consumed is calculated by estimating the amount of heat that has to be removed for the bread to reach $20{ }^{\circ} \mathrm{C}$. Cooling is done using three fans (400 W each) per $40 \mathrm{~kg}$ of bread to be cooled [28]. During cooling, $0.028 \mathrm{~kg}$ of water per $\mathrm{kg}$ of bread is removed [30]. The cooled breads are packed in polyethylene bags. It is assumed that the capacity for packaging white bread is 30 units/min (single unit packaging), whereas it is 180 units/min for brown buns ( 6 buns per package) by a machine with electricity consumption of 2.8 $\mathrm{kW}$ [31]. Finally, the breads are transported to the retailer in returnable polyethylene crates (Broban crates) each $0.07 \mathrm{~m}^{3}$ and with a capacity of 8 white breads per crate or 107 brown buns per crate. Finally, they are sold to the customer and $11.2 \%$ of the bread is assumed to be wasted [20].

\section{Par-baked bread production}

The baking is done at $160{ }^{\circ} \mathrm{C}$ for $30 \mathrm{~min}$ in a continuous oven fired by natural gas. It is assumed that all $\mathrm{CO}_{2}$ and ethanol are removed during this baking step. The energy to bake the product is the energy required to evaporate $8 \%$ of the water for the white breads and $5.5 \%$ for the brown buns. It is assumed that $5 \%$ of the dough becomes crust and that the crumb and crust temperatures reach a maximum of $100{ }^{\circ} \mathrm{C}$ (evaporating cooling) and $120^{\circ} \mathrm{C}$, respectively. The conditions for heat distribution, 
energy supply and steam production are assumed to be the same as for fresh bread production. Subsequently, the par-baked breads are frozen at $-40{ }^{\circ} \mathrm{C}$ for $2 \mathrm{~h}$. The energy required is calculated in a similar manner as for cooling, assuming that the bread mass reaches $-15{ }^{\circ} \mathrm{C}$ where $70 \%$ of the water freezes and $3 \%$ of the water is removed [32]. The frozen breads are then put into returnable polyethylene crates (CBL crates), each $0.06 \mathrm{~m}^{3}$ with a capacity of 8 breads per crate for transportation. The energy consumption for this process is assumed to be $1.5 \mathrm{~kW}$ with a capacity of 15 crates $/$ min [33], which translates into $0.9 \mathrm{~kJ} / \mathrm{kg}$ bread. The transportation of the frozen product is done in trucks with a refrigeration unit requiring an additional $3 \mathrm{~L}$ of diesel per hour.

Finally, the breads are transported and baked at the retailers at $220{ }^{\circ} \mathrm{C}$ for $10 \mathrm{~min}$, where $2 \%$ of water is removed and no additional steam is added. The breads are packed in polyethylene bags when sold to the consumer. With this technology, it is assumed that the retailer bakes on demand, therefore no bread is wasted.

\section{Fermented breadcrumb bread production}

The production of fermented breadcrumb comprises three steps: mixing, fermenting, and chilling [23]. In the mixing step, $100 \%$ old bread (a mixture of retailer waste and industrial waste) is mixed for $3 \mathrm{~min}$ with $110 \%$ water and $3.8 \%$ starter, assuming identical conditions as in normal dough processing (for both the conventional and the Chorleywood Bread Process mixing). The fermentation of the sugars is assumed to be proportional to the holding time $\left(12 \mathrm{~h}\right.$ at $\left.30{ }^{\circ} \mathrm{C}\right)$. Electricity use during fermentation is assumed to be identical to conventional fermentation and proportional to the holding time. The fermented dough is cooled down to $4{ }^{\circ} \mathrm{C}$ for another $12 \mathrm{~h}$ and the electricity use is calculated in the same manner as for normal cooling. Only up to $11 \%$ of the fermented breadcrumb produced can be introduced into the dough in the fresh bread production chain due to recipe constraints. The fermented breadcrumb surplus is assumed to be discarded. In addition, the new dough recipe is corrected for water addition due to the high moisture content of the fermented breadcrumb (about 70\%). However, the water content in the new dough is 
still high, and to achieve products with the same moisture content as the fresh and the par-baked breads, longer baking is required. Thus, the moisture removed during baking of white and brown bun fermented breadcrumb breads is $12.9 \%$ and $13.7 \%$, respectively. Packaging and transportation are assumed to be done in the same manner as for fresh bread production. An extra transportation step is included to transport the waste produced at the retailer back to the bakery.

\section{Process modelling}

The input and output streams for each process are shown in Table A.6 in the Appendix. The mass, energy and exergy content were calculated for each stream. These data were then used to construct Sankey (mass and energy) diagrams and Grassmann (exergy) diagrams with E!Sankey 3.0 software. The mass balance reads

$$
\begin{gathered}
\sum m_{i, \mathrm{in}}-\sum m_{i, \mathrm{out}}=0 \\
m_{i j}=m_{i} x_{j}
\end{gathered}
$$

where $m_{i}$ is the total mass flow of stream $i(\mathrm{~kg})$ and $x_{j}$ and $m_{j j}$ are the mass fraction and the total mass content of component $j$ in stream $i$, respectively. It was assumed for the energy balance that the only relevant forms of energy are the thermal and electrical energy flows.

$$
\begin{gathered}
\sum Q_{i, \mathrm{in}}+\sum E_{i}=\sum Q_{i, \mathrm{out}}+Q_{\mathrm{losses}} \\
Q_{i}=m_{i} c_{\mathrm{p}, i}\left(T_{i}-T_{\mathrm{o}}\right) \\
c_{\mathrm{p}, i}=\sum\left(c_{\mathrm{p}, j} x_{j}\right)
\end{gathered}
$$

where $Q_{i}, T_{i}$ and $c_{\mathrm{p}, i}$ are the thermal energy of stream $i$ in relation to the environmental temperature $T_{\mathrm{o}}(\mathrm{J})$, the temperature $(\mathrm{K})$, and the heat capacity $(\mathrm{MJ} / \mathrm{kg} / \mathrm{K})$ (assumed to be temperature independent) of stream $i, c_{\mathrm{p}, j}(\mathrm{MJ} / \mathrm{kg} / \mathrm{K})$ is the 
heat capacity of component $j$ in stream $i, E_{i}$ is the electrical content of stream $i(\mathrm{MJ})$, and $Q_{\text {losses }}(\mathrm{MJ})$ are the thermal losses to the environment. The heat of evaporation of water was considered in processes where there was a phase change. The heat capacities of the components studied are given in Table A.7 in the Appendix. The environment of reference was set at $T_{\mathrm{o}}=293 \mathrm{~K}$, pressure $P_{\mathrm{o}}=101 \mathrm{kPa}$ and moisture content of $w_{\mathrm{o}}=0.008 \mathrm{~kg}$ water per $\mathrm{kg}$ air, which corresponds to a relative humidity of $56 \%$. The most relevant forms of exergy that are usually considered in exergy analyses of food processes and chains are the thermal and/or pressure exergies of streams, while other physical forms of exergy, such as gravitational or momentum exergies are often neglected [34-37]. In this article we also stress the need for considering the chemical exergy, which is directly related to material streams and it can be considerably larger than the physical exergy, and the mixing exergy which is relevant whenever two or more material streams are mixed together. Therefore, the exergetic content $B_{i}$ of a stream $i$ was calculated as follows:

$$
B_{i}=B_{i, \text { physical }}+B_{i, \text { chemical }}+B_{i, \text { mix }}
$$

The physical exergy forms considered for this study were the thermal ( $\left.B_{i, \text { thermal }}\right)$, the electrical $\left(B_{i, \text { electrical }}\right)$, the pressure $\left(B_{i, \text { pressure }}\right)$, the chemical $\left(B_{i, \text { chemical }}\right)$, and the mixing $\left(B_{i, \mathrm{mix}}\right)$ exergy $(\mathrm{MJ})$.

$$
\begin{gathered}
B_{i, \text { physical }}=B_{i, \text { thermal }}+B_{i, \text { pressure }}+B_{i, \text { electrical }} \\
B_{i, \text { thermal }}=\int_{T_{i}}^{T_{\mathrm{o}}} \frac{T_{i}-T_{o}}{T_{i}} d Q_{i}=m_{i} c_{\mathrm{p}, i}\left[\left(T_{i}-T_{\mathrm{o}}\right)-T_{\mathrm{o}} \ln \left(\frac{T_{i}}{T_{\mathrm{o}}}\right)\right] \\
B_{i, \text { pressure }}=m_{i} \frac{R \cdot T_{\mathrm{o}}}{0.018} \ln \left(\frac{P_{i}}{P_{\mathrm{o}}}\right)
\end{gathered}
$$


where $R$ is the universal gas constant $(\mathrm{MJ} / \mathrm{mol} / \mathrm{K}), P_{i}$ is the pressure of the gaseous stream $i(\mathrm{kPa})$, and $P_{\mathrm{o}}$ is the environmental pressure $(\mathrm{kPa})$. The heat capacities $c_{p, i}$ were assumed to be independent of the temperature.

$$
B_{i, \text { chemical }}=m_{i} \sum\left(b_{\mathrm{o}, j} x_{j}\right)
$$

where $b_{\mathrm{o}, j}$ is the specific chemical exergy $(\mathrm{MJ} / \mathrm{kg})$ for component $j$ in stream $i$, which is defined as the minimum amount of exergy required to create this component from the particular environment of reference. The specific exergies of the components studied are given in Table A.3 in the Appendix. The electrical exergy input is equal to the electrical energy input. When two or more streams are mixed together, exergy is lost spontaneously:

$$
B_{\text {mix }}=N_{i} R T_{\mathrm{o}} \sum\left(x_{j} \ln \left(a_{j}\right)\right)
$$

where $N_{i}$ is the total number of moles of stream $i$ calculated from average values of the molecular weight of the components found in the literature (Table A.7 in the Appendix), and $a_{j}$ is the activity of component $j$, which is proportional to the mole fraction of this component in the total mixture (the activity coefficient is assumed to be 1). The exergy destruction of a process $B_{\text {destroyed }}(\mathrm{MJ})$ is the exergy that is irreversibly lost during the process and it is calculated as follows:

$$
B_{\text {destroyed }}=\sum B_{i, \text { in }}-\sum B_{i, \text { out }}-\sum B_{i, \text { wasted }}
$$

where $\sum B_{i, \text { in }}, \sum B_{i, \text { out }}$, and $\sum B_{i, \text { wasted }}(\mathrm{MJ})$ are the total useful exergetic content of all input streams, the total useful exergy content of all output streams, and the total exergetic content of all streams that are wasted to the environment and that could theoretically be re-used, respectively. The exergetic indicators considered in this study were the cumulative exergy losses (CEL) (MJ/1000 kg of dough processed), which are the sum of the total exergy wasted and the irreversibilities 
produced along the total food chain for processing a certain amount of raw materials, the specific exergy losses (SEL) (MJ/kg), which indicate the exergy lost to produce $1 \mathrm{~kg}$ of final product reaching the consumer, and the overall rational exergetic efficiency $(n)(\%)$, which shows how well the total exergy flows are preserved along the complete food chain.

$$
\begin{gathered}
\mathrm{CEL}=\sum B_{\text {destroyed }}+\sum B_{i, \text { wasted }} \\
\mathrm{SEL}=\frac{\mathrm{CEL}}{m_{\text {bread sold }}} \\
n=\frac{\sum B_{i, \text { out }}}{\sum B_{i, \text { in }}} \times 100
\end{gathered}
$$

\section{Results and discussion}

The results of the exergy analysis are shown in Figure 2 and the Grassmann diagrams that visualize the physical and chemical exergy flows are shown in Figures 3-6. It is clear that the chemical exergy of the material streams greatly surpasses any physical (electricity) input. The plastic crates (Broban and CBL) used to transport the breads to the retailer have a considerable amount of chemical exergy, but this exergy is not considered in the calculations because the crates are completely reusable, and therefore do not affect the thermodynamic performance of any bread chain as such. When the chemical exergy is removed from the Grassmann diagrams, the locations where physical exergy is destroyed can be identified; they are mainly in the baking, cooling and freezing processes.

The inputs with the highest chemical exergy content for processing $1000 \mathrm{~kg}$ of dough for all six cases are wheat flour (ranging from $3991 \mathrm{MJ}$ to $9745 \mathrm{MJ}$ ) and whole meal (ranging from $4022 \mathrm{MJ}$ to $4376 \mathrm{MJ}$ ), followed by natural gas (ranging from $1881 \mathrm{MJ}$ to $2462 \mathrm{MJ}$ ), and diesel (ranging from $553 \mathrm{MJ}$ to $562 \mathrm{MJ}$ ). 
The chemical exergy of all end products varies depending on the recipe and technology used, which in turn determines the material yield obtained. The specific chemical exergy for all breads produced is shown in Table 1. The brown buns have higher specific chemical exergy (12.7 MJ/kg bread) than the white breads $(11.5$ $\mathrm{MJ} / \mathrm{kg}$ bread) for all three technologies due to their higher dry matter content and due to the higher protein content, which has a relatively high specific chemical exergy (22.61 MJ/kg protein).

The industrial bread chain with the highest chemical exergy output is the par-baking technology for brown buns (11778 MJ) because it has the highest material yield $(884 \mathrm{~kg})$, and a high specific chemical exergy $(12.7 \mathrm{MJ} / \mathrm{kg}$ bread). The material yield is the highest for this industrial chain as a result of the assumption that no bread losses occur (baking on demand), and because the initial water content of the brown bun recipe is lower than for the white bread. The lowest yield is obtained by the fermented breadcrumb bread technology for brown buns because more water is introduced in the industrial production to rework the wasted bread. Therefore, the water content in the main fermented breadcrumb bread production chain increases, meaning that more water has to be evaporated to reach the desired water content of $34.6 \%$ in the brown buns. It is clear that developing this technology further towards fermentation at higher solids content will mitigate this. The industrial chain with the lowest exergy output, however, is the fermented breadcrumb bread technology for white bread, rather than brown buns, because of the lower amount of packaging chemical exergy delivered to the consumer. The chemical exergy of packaging in this case is low because a smaller number of $800 \mathrm{~g}$ white bread units is produced (1041), which requires a smaller amount of packaging material compared with the higher number of 60 -g brown bun units $(13,760)$.

The exergetic indicators calculated are shown in Table 2. The highest CEL occurs in the fresh brown bun production chain (5287 MJ/1000 kg dough processed), mainly due to the wastage of bread (chemical exergy), followed by the fermented breadcrumb brown bun production chain (5275 MJ/1000 kg dough processed) where some additional processing is required and where the fermented breadcrumb surplus 
is considered as waste. The CEL for the par-baked white bread production chain (4860 MJ/1000 kg dough processed) is almost as high as for the fresh white bread production chain (4917 MJ/1000 kg dough processed) because additional processes are required (freezing, refrigerated transport, baking at the retailer). This means that the chemical exergy of the wasted bread that was saved by the par-baking process chain requires a technology that consumes an amount of physical exergy similar to the saving in chemical exergy. However, the par-baking technology shows the lowest SEL for both types of bread produced $(5.6 \mathrm{MJ} / \mathrm{kg}$ white bread and $5.4 \mathrm{MJ} / \mathrm{kg}$ brown bun) because the amount of bread delivered to the consumer is much higher compared with the other technologies. The SEL for the fermented breadcrumb technology (6.3 MJ/kg white bread and 7.2 MJ/kg brown bun) is almost as high as the SEL for the fresh bread technology $(6.5 \mathrm{MJ} / \mathrm{kg}$ white bread and $6.9 \mathrm{MJ} / \mathrm{kg}$ brown bun) because their CEL values are similar, and because the amount of bread delivered to the consumer is also quite low.

The industrial bread chain with the highest exergetic efficiency is the par-baked brown bun production chain $(71.2 \%)$ because it has the highest exergetic output compared with the total exergy input utilized. The fresh white bread production chain has the lowest rational exergetic efficiency $(64.5 \%)$ due to the wasted bread (chemical exergy). The exergetic efficiencies of the other industrial bread chains were around the same low level due to material losses (e.g. wasted fermented breadcrumb surplus). However, when the surplus of the fermented breadcrumb process is considered as a useful product (additional $682 \mathrm{MJ}$ and $718 \mathrm{MJ}$ of chemical exergy in the total exergy output for the fermented breadcrumb chains for white and the brown bun, respectively) then the figures for all three indicators will improve. For the industrial production of white fermented breadcrumb bread the CEL, SEL and exergetic efficiency become $3998 \mathrm{MJ} / 1000 \mathrm{~kg}$ dough processed, 5.4 $\mathrm{MJ} / \mathrm{kg}$ bread, and $70.0 \%$, respectively. For the industrial production of brown bun fermented breadcrumb bread the CEL, SEL and exergetic efficiency become 4557 MJ/1000 kg dough processed, 6.2 MJ/kg bread, and 69.7\%. Therefore, the full use of all fermented breadcrumb in products that have high value would in fact lead to a 
supply chain as efficient as the par-baked chain. Similar conclusions where obtained also by Berghout et al. [38] who compared the exergetic performance of the conventional aqueous fractionation of oilseeds with dry fractionation, and they found that the use of all material side streams improved the exergetic efficiency of all fractionation methods. The importance of preserving the chemical exergy of all material streams within the production chain has also been addressed by Jankowiak et al. [39]. In their study they compared exergetically the extraction of isoflavones from okara by using ethanol or water, and they proposed that the loss of solvents with high specific chemical exergy should be avoided. These results clearly show that the first priority in designing a sustainable industrial food chain should always be to prevent the loss of any part of the raw material or food as a low-value waste stream [40]. It makes sense to optimize the use of physical exergy only after the waste production has been minimized. However, savings in physical exergy are still interesting because they can be considerable. 

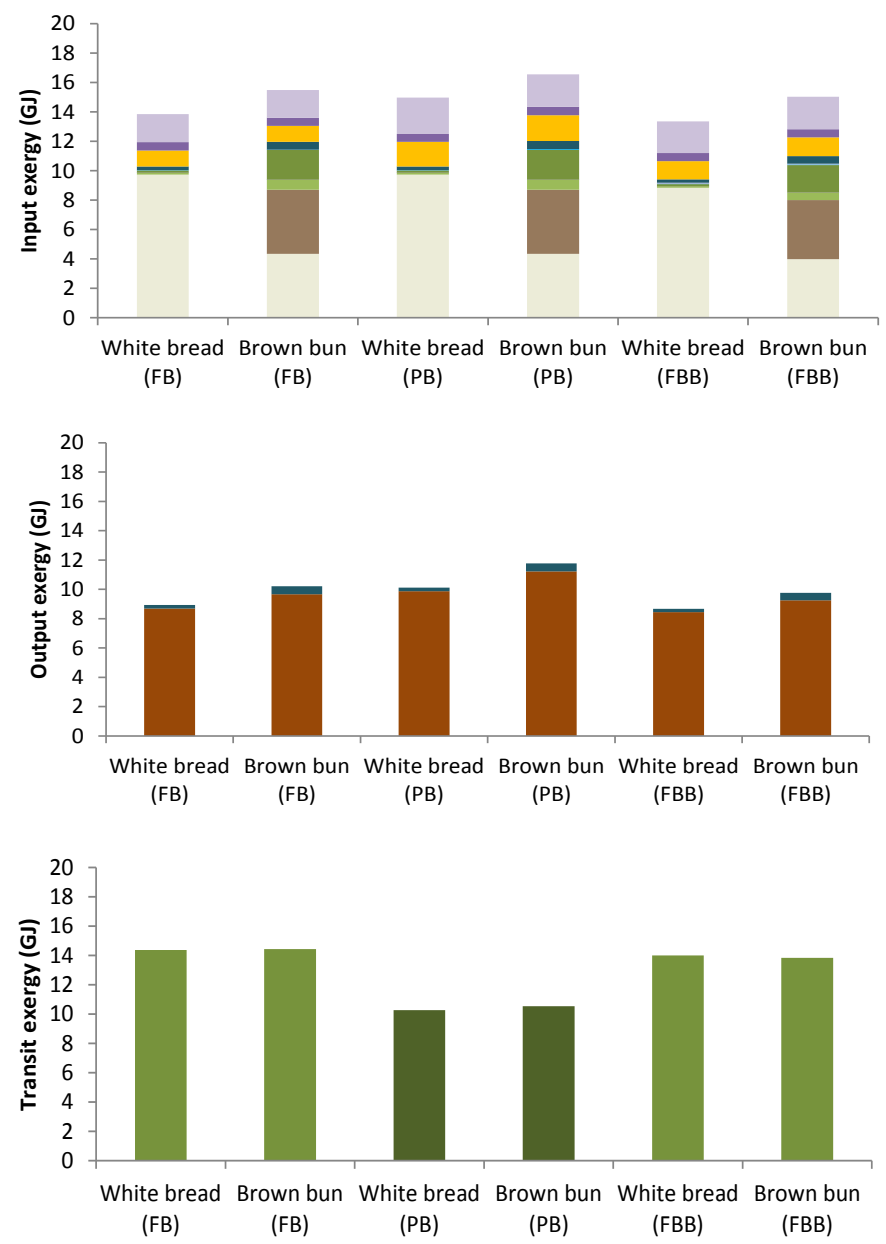

Figure 2. Exergy analysis results: (top) input physical and chemical exergy of raw materials, (middle), output chemical exergy of products, (bottom) transiting exergy. FB: Fresh bread chain, PB: Par-baked bread chain; FBB: Fermented breadcrumb bread chain. The water used in the recipe, in the boiler for steam production, and the water used in the fermented breadcrumb when applicable are considered. All electricity consumed in the industrial bakery, including the conveyors, is considered. Transportation of raw materials to the bakery and transportation of final product to the retailer are considered. The use of natural gas for baking and steam production is considered. 
Table 1. Yield and specific chemical exergy (MJ/kg bread) of the different types of breads produced.

\begin{tabular}{lcccccc}
\hline & \multicolumn{2}{c}{$\begin{array}{l}\text { Fresh bread } \\
\text { production }\end{array}$} & $\begin{array}{c}\text { Par-baked bread } \\
\text { production }\end{array}$ & $\begin{array}{c}\text { Fermented } \\
\text { breadcrumb bread } \\
\text { production }\end{array}$ \\
& $\begin{array}{l}\text { White } \\
\text { bread }\end{array}$ & $\begin{array}{c}\text { Brown } \\
\text { bun }\end{array}$ & $\begin{array}{c}\text { White } \\
\text { bread }\end{array}$ & $\begin{array}{c}\text { Brown } \\
\text { bun }\end{array}$ & $\begin{array}{c}\text { White } \\
\text { bread }\end{array}$ & $\begin{array}{c}\text { Brown } \\
\text { bun }\end{array}$ \\
& 760 & 763 & 861 & 884 & 740 & 731 \\
Yield (kg) & 1069 & 14317 & 1098 & 15037 & 1041 & 13720 \\
Number of units produced & 11.5 & 12.7 & 11.5 & 12.7 & 11.5 & 12.7 \\
$\begin{array}{l}\text { Specific chemical exergy } \\
\text { (MJ/kg bread) }\end{array}$ & & & & & &
\end{tabular}

Table 2. Exergetic indicators calculated for all three technologies and both types of breads with conventional mixing (the results for the Chorleywood Bread Process method are similar).

\begin{tabular}{lcccccc}
\hline & \multicolumn{2}{c}{$\begin{array}{l}\text { Fresh bread } \\
\text { production }\end{array}$} & $\begin{array}{c}\text { Par-baked bread } \\
\text { production }\end{array}$ & $\begin{array}{c}\text { Fermented } \\
\text { breadcrumb bread } \\
\text { production }\end{array}$ \\
& $\begin{array}{l}\text { White } \\
\text { bread }\end{array}$ & $\begin{array}{c}\text { Brown } \\
\text { bun }\end{array}$ & $\begin{array}{c}\text { White } \\
\text { bread }\end{array}$ & $\begin{array}{c}\text { Brown } \\
\text { bun }\end{array}$ & $\begin{array}{c}\text { White } \\
\text { bread }\end{array}$ & $\begin{array}{c}\text { Brown } \\
\text { bun }\end{array}$ \\
\hline CEL (MJ) & 4917 & 5287 & 4860 & 4768 & 4680 & 5275 \\
SEL (MJ/kg bread sold) & 6.5 & 6.9 & 5.6 & 5.4 & 6.3 & 7.2 \\
$n(\%)$ & 64.5 & 65.9 & 67.5 & 71.2 & 65.0 & 64.9 \\
\hline
\end{tabular}



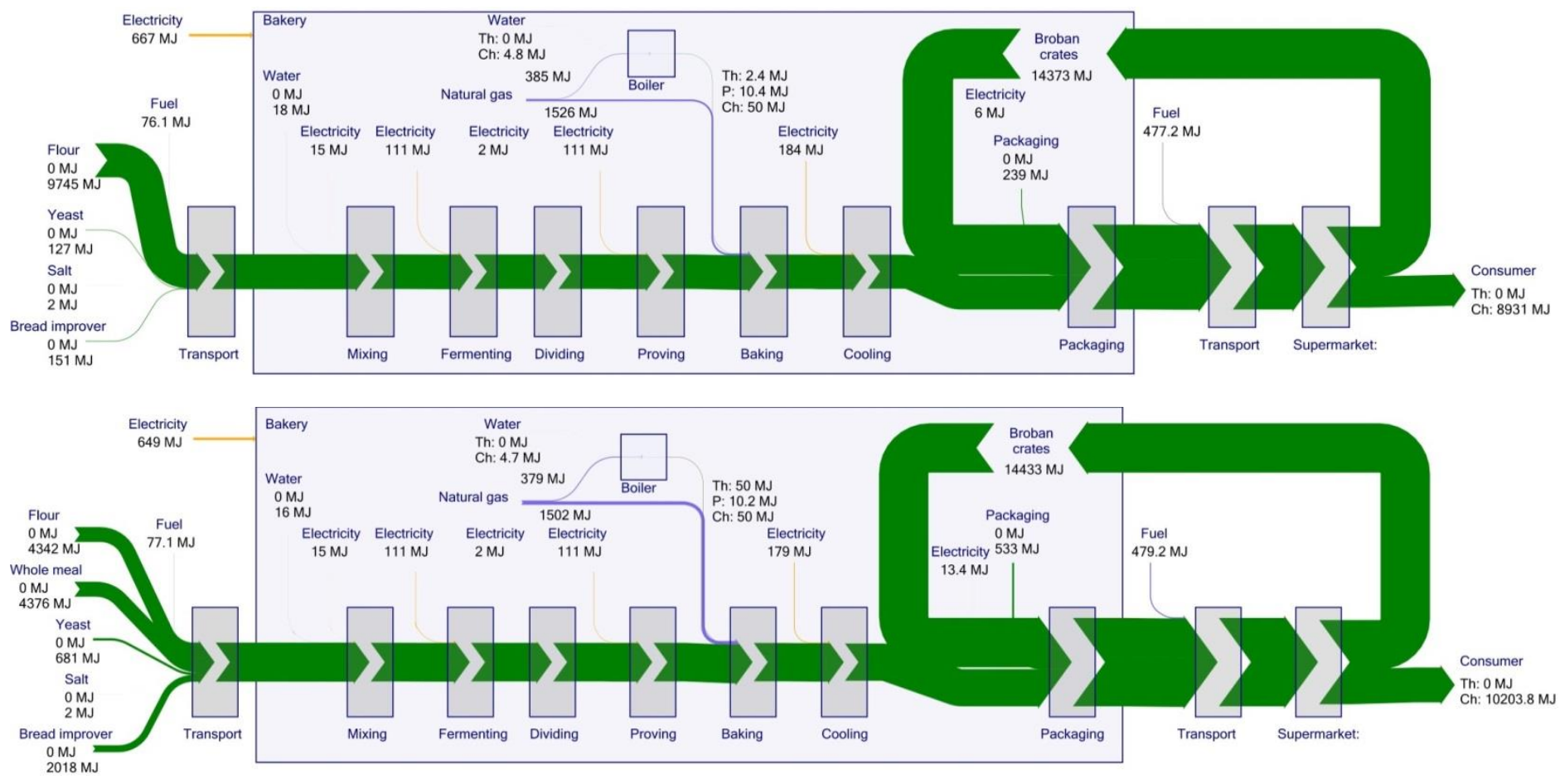

Figure 3. Grassmann diagrams: (top) fresh white bread production, (bottom) fresh brown bun production. The green colour indicates material (chemical) exergy flows, the purple colour indicates fuel (chemical) exergy flows, and the orange colour indicates electrical (physical) exergy flows, where Th indicates the thermal exergy content, $\mathrm{P}$ indicates pressure exergy content, E indicates electrical exergy content, and $\mathrm{Ch}$ indicates chemical exergy content. 


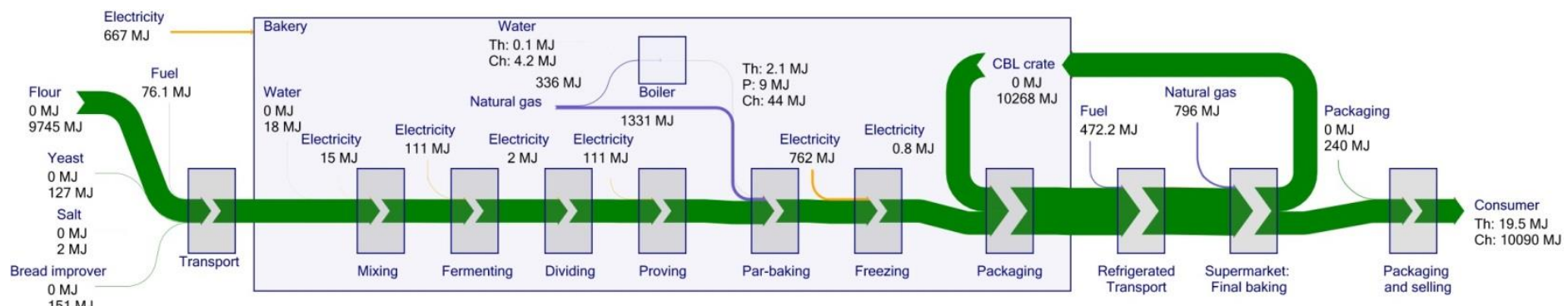

$0 \mathrm{MJ}$
$151 \mathrm{MJ}$

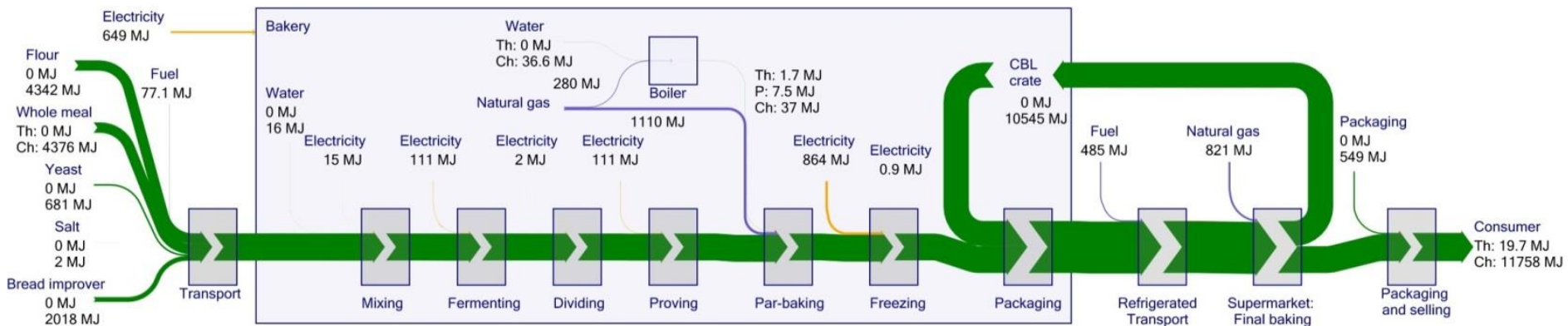

Figure 4. Grassmann diagrams: (top) par-baked white bread production, (bottom) par-baked brown bun production. The green colour indicates material (chemical) exergy flows, the purple colour indicates fuel (chemical) exergy flows, and the orange colour indicates electrical (physical) exergy flows, where Th indicates thermal exergy content, $\mathrm{P}$ indicates pressure exergy content, E indicates electrical exergy content, and Ch indicates chemical exergy content. 


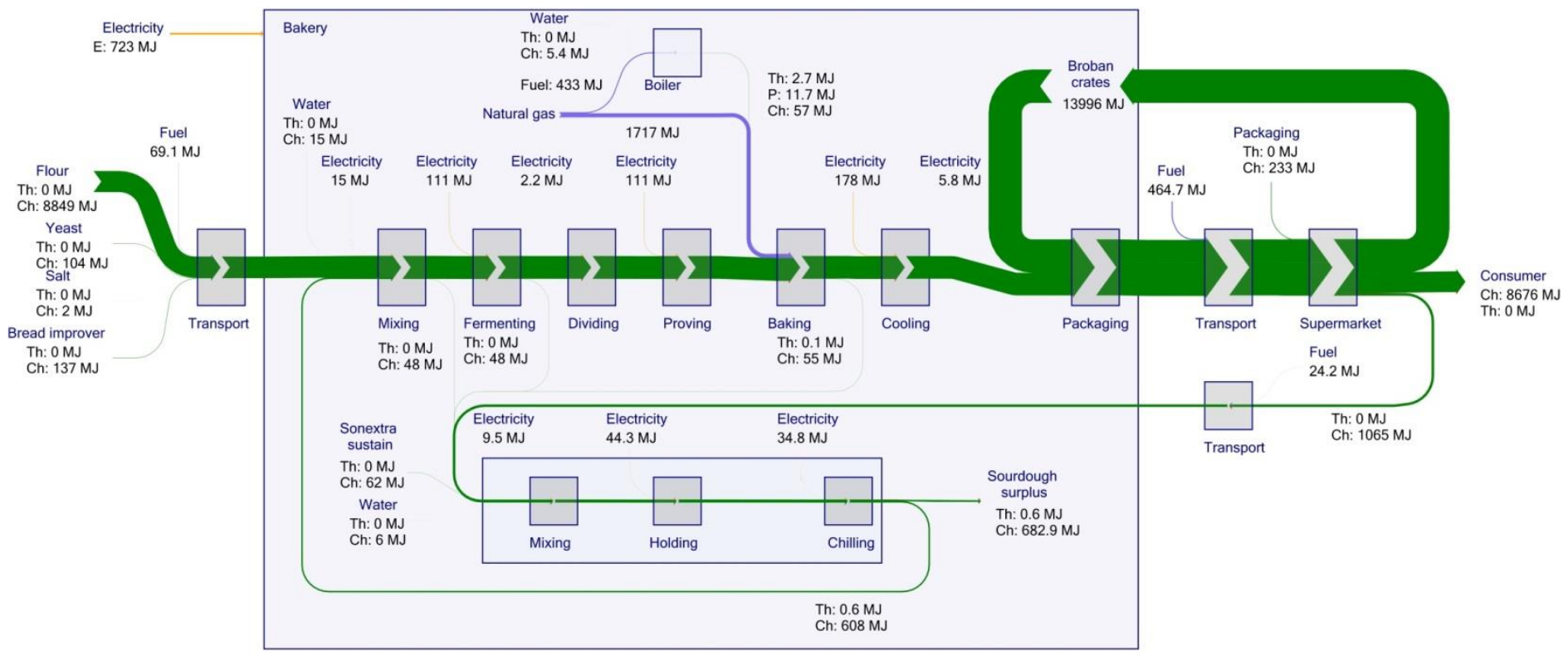

Figure 5. Grassmann diagram of white fermented breadcrumb bread production. The green colour indicates material (chemical) exergy flows, the purple colour indicates fuel (chemical) exergy flows, and the orange colour indicates electrical (physical) exergy flows, where Th indicates thermal exergy content, P indicates pressure exergy content, E indicates electrical exergy content, and Ch indicates chemical exergy content. 


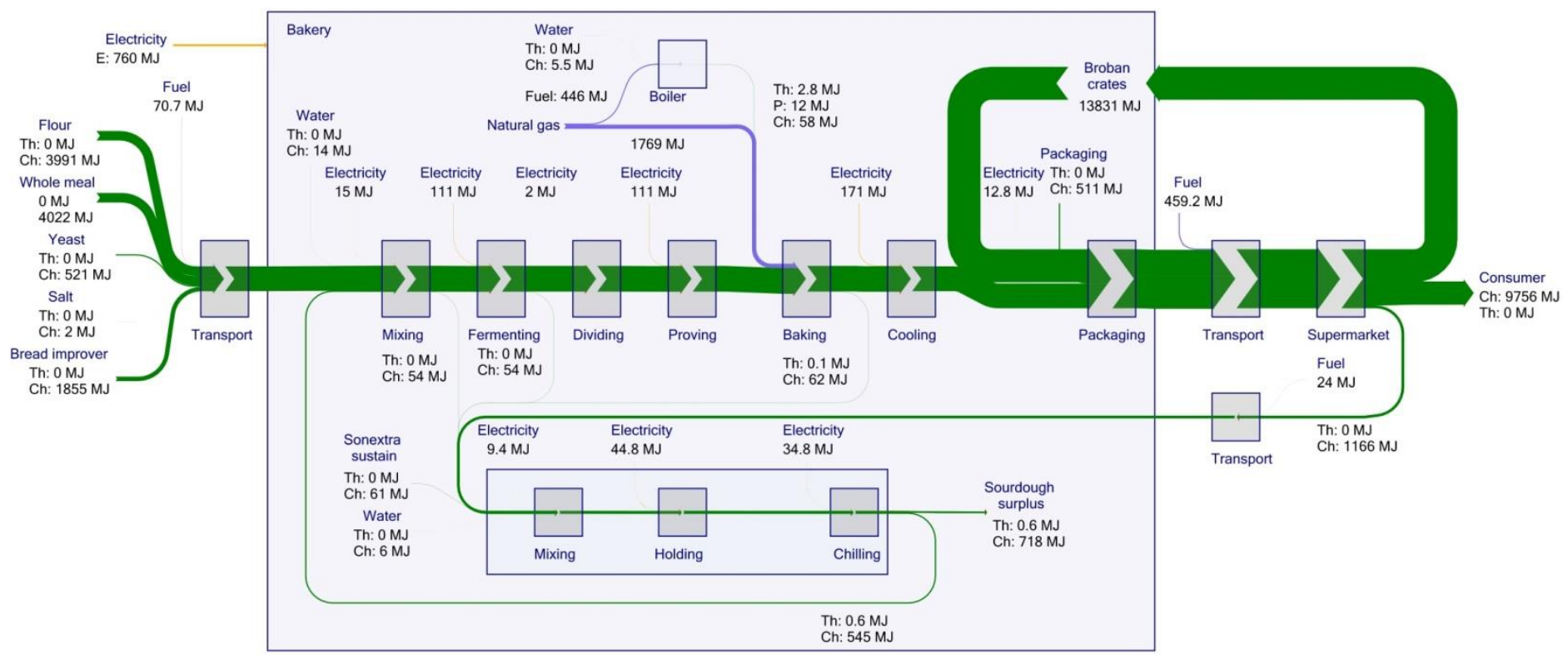

Figure 6. Grassmann diagram of brown bun fermented breadcrumb bread production. The green colour indicates material (chemical) exergy flows, the purple colour indicates fuel (chemical) exergy flows, and the orange colour indicates electrical (physical) exergy flows, where Th indicates thermal exergy content, P indicates pressure exergy content, E indicates electrical exergy content, and Ch indicates chemical exergy content. 


\section{Conclusion}

The exergetic performances of different bread waste valorization options were compared using three exergetic indicators: the cumulative exergy losses (CEL), the specific exergy loss (SEL), and the rational exergetic efficiency $(n)$.

The analysis indicated the importance of using all of the materials for high-quality products as a requirement in obtaining high exergetic efficiencies, which can be explained by the fact that chemical exergies are much larger than physical exergies. The industrial bread chain with the best thermodynamic performance was the parbaked brown bun production chain because it had the most optimal values for most of the exergetic indicators: i.e. the highest $n(71.2 \%)$, the lowest SEL (5.4 MJ/ kg brown bun), and a very low CEL (4768 MJ).

Recycling of wasted bread through a fermented breadcrumb technology, in which part of the wasted bread can be re-used in the dough, did not result in a better overall exergetic efficiency, due to the partial utilization of the upgraded waste by recipe constraints. Further studies are proposed to adjust the process and recipe such that the surplus produced can be completely used as a valuable raw material, and to predict the production of bread waste, such that only just the exact amount required is produced. In that case, recycling of bread waste would become a highly efficient option for improving the exergetic sustainability of industrial bread production.

For all six industrial chains most of the physical (non-material related) exergy losses occur at the baking, cooling and freezing steps. Consequently, improvements in the bread chain should also focus on two aspects: the design of thermodynamically efficient baking and cooling processes. These are challenging tasks because bread production has been optimized continuously over time and, therefore, the outcome of this study signals the need for conceptually new and thermodynamically more efficient process designs. 


\section{Acknowledgements}

The authors are grateful to the Dutch Food Retail Organization (CBL) and the Federation of the Dutch Food and Grocery Industry (FNLI) for funding this research under the project "Valorization of raw materials and process efficiency" which is under TI Food and Nutrition, a public-private partnership on precompetitive research in food and nutrition. The public partners are responsible for the study design, data collection and analysis, decision to publish, and preparation of the manuscript. The private partners have contributed to the project through regular discussion. The authors would also like to thank Peter Weegels (European Bakery Innovation Centre, Papendrecht, The Netherlands), Marcel Peeters (Turnstone, Etten Leur, The Netherlands), Jan Broeze (Food \& Biobased Research, Wageningen, The Netherlands) and Friso van Assema (NIZO Food Research, Ede, The Netherlands) for their valuable comments.

\section{Nomenclature}

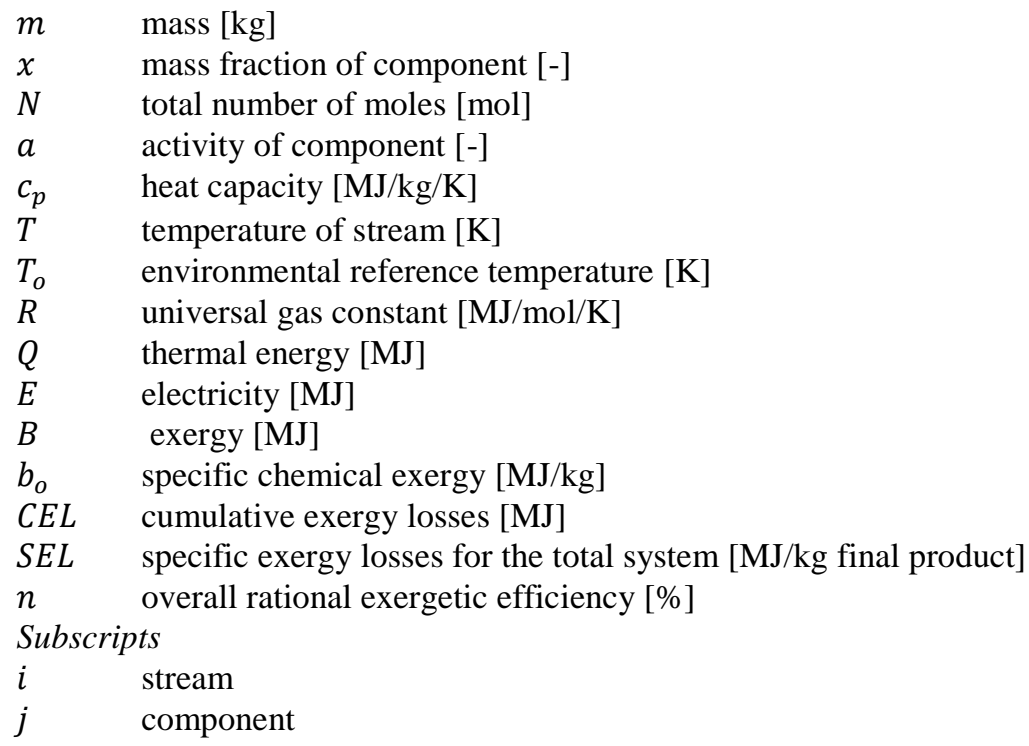




\section{Appendix}

Table A.1. Dough recipes and composition.

\begin{tabular}{|c|c|c|c|c|c|c|}
\hline \multirow[t]{2}{*}{ Raw material } & \multicolumn{2}{|c|}{$\begin{array}{c}\text { Fresh and par-baked bread } \\
\text { dough }(\%)^{\mathrm{a}}\end{array}$} & \multicolumn{2}{|c|}{ Fermented breadcrumb $(\%)^{\mathrm{a}}$} & \multicolumn{2}{|c|}{$\begin{array}{l}\text { Dough from fermented } \\
\text { breadcrumb }(\%)^{\mathrm{b}}\end{array}$} \\
\hline & White bread & Brown bun & White bread & Brown bun & White bread & Brown bun \\
\hline \multicolumn{7}{|l|}{ Recipe } \\
\hline Wheat flour & 61.7 & 27.5 & - & & 56.1 & 25.3 \\
\hline Whole meal & - & 27.5 & - & & - & 25.3 \\
\hline Yeast & 0.6 & 3.3 & - & & 0.5 & 2.5 \\
\hline Salt & 0.9 & 1.0 & - & & 0.8 & 0.9 \\
\hline Bread improver & 0.6 & 8.3 & - & & 0.6 & 7.6 \\
\hline Water & 36.1 & 32.5 & 52.6 & & 30.8 & 28.3 \\
\hline $\begin{array}{l}\text { Fermented } \\
\text { breadcrumb }\end{array}$ & - & - & - & & 11.2 & 10.1 \\
\hline Starter & - & - & 1.7 & & - & - \\
\hline Wasted bread & - & - & 45.7 & & - & - \\
\hline \multicolumn{7}{|l|}{ Composition } \\
\hline Dry matter & 54.6 & 58.7 & 29.7 & 27.9 & 52.8 & 56.3 \\
\hline Protein & 8.3 & 14.4 & 4.5 & 6.6 & 8.0 & 13.6 \\
\hline Carbohydrates & 44.3 & 40.9 & 24.1 & 19.7 & 42.9 & 39.4 \\
\hline Simple & 1.1 & 1.0 & 0.6 & 0.4 & 1.1 & 0.9 \\
\hline Complex & 43.0 & 39.7 & 23.2 & 19.0 & 41.6 & 38.2 \\
\hline Fibres & 0.3 & 0.2 & 0.3 & 0.3 & 0.3 & 0.2 \\
\hline Fat & 0.8 & 2.2 & 0.4 & 1.0 & 0.8 & 2.2 \\
\hline Salt & 0.9 & 1.0 & 0.5 & 0.5 & 0.9 & 0.9 \\
\hline Ash & 0.3 & 0.2 & 0.1 & 0.1 & 0.2 & 0.2 \\
\hline Carbon dioxide & - & - & - & - & 0.01 & 0.01 \\
\hline Ethanol & - & - & - & - & 0.01 & 0.01 \\
\hline
\end{tabular}

${ }^{\mathrm{a}}$ Recipe for white bread adapted from Weegels [23] and from Sonneveld [41].

${ }^{\mathrm{b}}$ Recipe adapted from personal communication with the industry (EBIC, Papendrecht, The Netherlands). 
Table A.2. Chemical composition of the raw materials.

\begin{tabular}{|c|c|c|c|c|c|c|c|c|}
\hline \multirow{3}{*}{ Ingredient } & \multirow{3}{*}{ Dry matter } & \multirow{3}{*}{ Protein } & \multicolumn{3}{|c|}{ Carbohydrates } & \multirow{3}{*}{ Fat } & \multirow{3}{*}{ Salt } & \multirow{3}{*}{ Ash } \\
\hline & & & & & & & & \\
\hline & & & Simple & Complex & Fibres & & & \\
\hline Wheat flour ${ }^{\mathrm{a}}$ & 85.0 & 12.1 & 1.8 & 69.2 & 0.4 & 1.1 & - & 0.4 \\
\hline Whole meal $^{\mathrm{a}}$ & 85.0 & 10.0 & 1.8 & 70.4 & 0.4 & 2.0 & - & 0.4 \\
\hline Yeast $^{b}$ & - & 60.0 & - & 40.0 & - & - & - & - \\
\hline Bread improver $^{\mathrm{c}}$ & 93.0 & 60.4 & 8.4 & 8.4 & 0.9 & 0.9 & - & - \\
\hline Starter $^{\mathrm{d}}$ & 91.0 & 13.0 & 0.0 & 63.0 & 12.0 & 2.0 & 1.0 & - \\
\hline
\end{tabular}

${ }^{\mathrm{a} C}$ Composition adapted from Pyler [42] assuming that most of the carbohydrates are starch (complex carbohydrates).

${ }^{\mathrm{b}}$ Composition adapted from Reed and Nagodawithana [43].

${ }^{c}$ Composition adapted from Sonneveld [44] assuming that the flour improver is 50\% protein and 50\% complex carbohydrates, the enzymes are all protein, the emulsifiers are all fat and the malted barley flour has the same composition as wheat flour.

${ }^{\mathrm{d}}$ Composition adapted from Sonneveld [45].

Table A.3. Final bread composition (\%) for all three technologies.

\begin{tabular}{lcc}
\hline Composition & White bread & Brown bun \\
\hline Dry matter & 62.4 & 65.4 \\
Protein & 9.5 & 16.0 \\
Carbohydrates & 50.7 & 45.5 \\
Simple & 1.3 & 1.1 \\
Complex & 49.1 & 44.2 \\
Fibres & 0.3 & 0.2 \\
Fat & 0.9 & 2.5 \\
Salt & 1.1 & 1.1 \\
Ash & 0.3 & 0.2 \\
\hline
\end{tabular}


Table A.4. Simulation parameters.

\begin{tabular}{|c|c|c|c|c|}
\hline Unit operation & Time (min) & $T\left({ }^{\circ} \mathrm{C}\right)$ & $\begin{array}{l}\text { Electricity } \\
(\mathrm{MJ} / \mathrm{kg})\end{array}$ & $\begin{array}{c}\text { Material losses } \\
(\%)\end{array}$ \\
\hline \multicolumn{5}{|l|}{ Dough processing } \\
\hline Mixing & & & & \\
\hline Conventional & 10 & 20 & $0.015^{\mathrm{a}}$ & \\
\hline Chorleywood Bread Process & 3 & & $0.040^{\mathrm{a}}$ & 0.5 \\
\hline Fermenting & 60 & 28 & $0.111^{\mathrm{a}}$ & 0.5 \\
\hline Dividing & - & - & $0.002^{\mathrm{a}}$ & - \\
\hline Proving & 60 & 28 & $0.111^{\mathrm{a}}$ & - \\
\hline
\end{tabular}

Fresh bread production

Baking

White bread

Brown bun

Cooling

White bread

Brown bun

Packaging

White bread

Brown bun

Retailer

Par-baked bread production

Par-baking

White bread

Brown bun

Freezing

White bread

Brown bun
30

35

30

80

160

$1.486^{\mathrm{b}}$

$1.207^{\mathrm{b}}$

$0.885^{\mathrm{b}}$

120

$-40$

$1.893^{\mathrm{b}}$

$0.243^{\mathrm{b}}$

$0.234^{\mathrm{b}}$

$0.008^{\mathrm{b}}$

$0.018^{\mathrm{b}}$

$-$

$1.931^{\mathrm{b}}$

11.2

0.5 
Packaging

White bread

$0.001^{\mathrm{b}}$

Brown bun

$0.001^{\mathrm{b}}$

Baking at the retailer

White bread

Brown bun

Retailer

Fermented breadcrumb production

Mixing of breadcrumb

White bread

Brown bun

Fermenting of breadcrumb

White bread

Brown bun

Chilling of breadcrumb

White bread

Brown bun

Baking

White bread

Brown bun

Cooling

White bread

Brown bun

Packaging

White bread

Brown bun

Retailer
10

$0.889^{\mathrm{b}}$

$0.892^{\mathrm{b}}$
25

$0.013^{b}$

$0.013^{\mathrm{b}}$

$0.060^{\mathrm{b}}$

$0.062^{\mathrm{b}}$

$0.047^{\mathrm{b}}$

4

$0.049^{\mathrm{b}}$

$2.231^{\mathrm{b}}$

235

$2.327^{\mathrm{b}}$

$0.241^{\mathrm{b}}$

20

$0.234^{\mathrm{b}}$

$0.008^{\mathrm{b}}$

$0.018^{\mathrm{b}}$

${ }^{a}$ Electricity consumed in MJ per kg of dough processed.

${ }^{\mathrm{b}}$ Electricity consumed in MJ per kg of bread type sold to the consumer.

${ }^{\mathrm{c}}$ These bread losses are transported back to the industrial bakery to be reworked into fermented breadcrumb. 
Table A.5. Assumptions related to transportation.

\begin{tabular}{lc}
\hline Capacity (tons) & 4 \\
Volume $\left(\mathrm{m}^{3}\right)$ & 18 \\
Fuel type & Diesel \\
Lower heating value ${ }^{\mathrm{a}}(\mathrm{MJ} / \mathrm{kg})$ & 42.6 \\
Exergy quality factor ${ }^{\mathrm{a}}(-)$ & 1.07 \\
Fuel efficiency $^{\mathrm{b}}(\mathrm{L} / \mathrm{km})$ & 0.33 \\
Fuel use by refrigeration unit & \\
Average constant speed $(\mathrm{km} / \mathrm{h})$ & 3 \\
\hline
\end{tabular}

${ }^{a}$ Value obtained from Koroneos and Nanaki [46].

${ }^{\mathrm{b}}$ Average value obtained from McKinnon [47].

${ }^{\mathrm{c}}$ Value obtained from Tassou et al. [48]. 
Table A.6. Stream description for the mass flow analysis.

\begin{tabular}{|c|c|c|}
\hline Process & Stream in & Stream out \\
\hline \multirow[t]{7}{*}{ Mixing } & Wheat flour & \\
\hline & Whole meal & \\
\hline & Water & \\
\hline & & Dough \\
\hline & Yeast & \\
\hline & Bread improver & \\
\hline & Salt & \\
\hline Fermenting & Dough & Fermented dough \\
\hline Dividing & Fermented dough & Fermented dough \\
\hline Proving & Fermented dough & Fermented dough \\
\hline Baking & Fermented dough & Baked bread \\
\hline Par-baking & Fermented dough & Par-baked bread \\
\hline Cooling & Baked bread & Cooled bread \\
\hline Freezing & Par-baked bread & Frozen bread \\
\hline \multirow[t]{3}{*}{ Packaging (single) } & Cooled bread & \\
\hline & & Packaged bread \\
\hline & Packaging (LDPE) & \\
\hline \multirow[t]{3}{*}{ Packaging (multi) } & Frozen bread & \\
\hline & & Packaged bread \\
\hline & Packaging (cardboard) & \\
\hline Baking at the retailer & Packaged bread & Fully baked bread \\
\hline \multirow[t]{3}{*}{ Mixing (fermented breadcrumb) } & Water & \\
\hline & Starter & Breadcrumb \\
\hline & Wasted bread & \\
\hline Fermenting (fermented breadcrumb) & Dough & Fermented breadcrumb \\
\hline Chilling (fermented breadcrumb) & Fermented breadcrumb & Chilled fermented breadcrumb \\
\hline
\end{tabular}


Table A.7. Heat capacity $\left(c_{\mathrm{p}}\right)$, specific chemical exergy $\left(b_{0}\right)$ and molecular weight (MW) of the components used for the calculations.

\begin{tabular}{|c|c|c|c|}
\hline Component & $c_{\mathrm{p}}(\mathrm{kJ} / \mathrm{kg} / \mathrm{K})$ & $b_{0}(\mathrm{MJ} / \mathrm{kg})$ & MW $(\mathrm{kg} / \mathrm{mol})$ \\
\hline Water (l) & 4.18 & $0.05^{\mathrm{a}}$ & \\
\hline & & & 0.018 \\
\hline Water $(\mathrm{g})$ & 1.84 & $0.53^{\mathrm{a}}$ & \\
\hline Protein & 1.71 & $22.61^{\mathrm{a}}$ & $80,000^{\mathrm{f}}$ \\
\hline Simple carbohydrates & 1.55 & $16.70^{\mathrm{a}}$ & 0.180 \\
\hline Complex carbohydrates & 1.55 & $17.64^{\mathrm{a}}$ & $48,600^{g}$ \\
\hline Fibres & 1.55 & $13.80^{\mathrm{b}}$ & $22,000^{\mathrm{b}}$ \\
\hline Fat & 1.93 & $43.09^{c}$ & $0.280^{\mathrm{c}}$ \\
\hline Salt & 0.88 & $0.24^{\mathrm{a}}$ & 0.058 \\
\hline Ash & 0.84 & $0.02^{\mathrm{a}}$ & $0.035^{\mathrm{h}}$ \\
\hline Carbon dioxide & 0.92 & $0.24^{\mathrm{a}}$ & 0.044 \\
\hline Ethanol (g) & 2.44 & $30.14^{\mathrm{a}}$ & 0.046 \\
\hline $\begin{array}{l}\text { Low density polyethylene } \\
\text { (LDPE) }\end{array}$ & 2.10 & $48.48^{\mathrm{d}}$ & - \\
\hline Cardboard & 1.34 & $16.83^{\mathrm{e}}$ & - \\
\hline
\end{tabular}

\footnotetext{
${ }^{\mathrm{a}}$ Value adapted from Szargut [49].

${ }^{b}$ Value calculated assuming that all fibres are arabinoxylans composed of a linear chain of D-xylopyranose with attached branches of $\alpha$-L-arabinofuranose. Both have the same structural groups and therefore assumed to have the same specific chemical exergy, which is calculated based on the chemical structure data of Szargut [49]. Assuming a molecular weight of wheat arabinoxylan of $220,000 \mathrm{~g} / \mathrm{mol}$ found by Le Gall et al. . [50] and a molecular weight of xylose of $150 \mathrm{~g} / \mathrm{mol}$, there are 1465 units of xylopyranose and thus the specific exergy of the fibres can be calculated.
}

${ }^{\mathrm{c}}$ Assuming it is linoleic acid.

${ }^{\mathrm{d}}$ Value calculated by assuming that it is composed of 10,000 ethylene units $(0.028 \mathrm{~kg} / \mathrm{mol})$ [51]

${ }^{\mathrm{e}}$ Assuming that the cardboard is composed of cellulose and has the same thermal properties as paper.

${ }^{\mathrm{f}}$ Value adapted from Goesaert et al.. [52] as an average value for gluten.

${ }^{g}$ Assuming a degree of polymerization of glucose units of 300 .

${ }^{\mathrm{h}}$ Assuming it is composed $50 \%$ from phosphorus and $50 \%$ potassium. 


\section{References}

[1] Wognum PM, Bremmers H, Trienekens JH, van der Vorst JGAJ, Bloemhof JM. Systems for sustainability and transparency of food supply chains - Current status and challenges. Advanced Engineering Informatics. 2011;25(1):65-76.

[2] Saguy IS, Singh RP, Johnson T, Fryer PJ, Sastry SK. Challenges facing food engineering. Journal of Food Engineering. 2013;119(2):332-42.

[3] Bellu A. Energy storage systems - an approach involving the concept of exergy. KTH and Universita Degli Studi di Padova, 2009.

[4] Cornelissen RL. Thermodynamics and sustainable development: the use of exergy analysis and the reduction of irreversibility. Enschede, The Netherlands: University of Twente, 1997.

[5] Wall G, Gong M. On exergy and sustainable development-Part 1: Conditions and concepts. Exergy. 2001;1(3):128-45.

[6] Szargut J. Exergy analysis. Academia2005. p. 31-3.

[7] Koroneos C, Spachos T, Moussiopoulos N. Exergy analysis of renewable energy sources. Renewable Energy. 2003;28(2):295-310.

[8] Sreejith CC, Muraleedharan C, Arun P. Energy and exergy analysis of steam gasification of biomass materials: a comparative study. International Journal of Ambient Energy. 2012;34(1):35-52.

[9] Caliskan H, Dincer I, Hepbasli A. Energy, exergy and sustainability analyses of hybrid renewable energy based hydrogen and electricity production and storage systems: modeling and case study. Applied Thermal Engineering. 2013:61(2):784789.

[10] Ashrafizadeh SA, Amidpour M, Abolmashadi M. Exergy analysis of distillation column using concept of driving forces. Journal of Chemical Engineering of Japan. 2013;46(7):434-43. 
[11] Moran MJ, Sciubba E. Exergy Analysis: Principles and practice. Journal of Engineering for Gas Turbines and Power. 1994;116(2):285-90.

[12] Apaiah RK, Linnemann AR, Van Der Kooi HJ. Exergy analysis: a tool to study the sustainability of food supply chains. Food Research International. 2006;39(1):111.

[13] Draganovic V, Jørgensen SE, Boom R, Jonkers J, Riesen G, van der Goot AJ. Sustainability assessment of salmonid feed using energy, classical exergy and ecoexergy analysis. Ecological Indicators. 2013;34:277-89.

[14] Szargut J. International progress in second law analysis. Energy. 1980;5(89):709-18.

[15] Wall G., editor. Exergetics. Colombia. Bucaramanga; 2009.

[16] Dincer I, Rosen MA. Exergy and energy analyses. In: Ibrahim D, Marc AR, editors. Exergy (2nd edition). Elsevier; 2013. p. 21-30.

[17] Bösch P, Modarresi A, Friedl A. Comparison of combined ethanol and biogas polygeneration facilities using exergy analysis. Applied Thermal Engineering. 2012;37:19-29.

[18] Vandermeersch T, Alvarenga RAF, Ragaert P, Dewulf J. Environmental sustainability assessment of food waste valorization options. Resources, Conservation and Recycling. 2014;87:57-64.

[19] HBD. Figures for bread and pastry businesses. 2006. Central industry retail. http://www.hbd.nl

[20] Blonk H. Sustainable bread production: phase analysis work document from Bakker Wiltink Bakery Gouda, The Netherlands: Blonk Milieu Advies, 2006.

[21] Szargut J. Analysis of cumulative exergy consumption. International Journal of Energy Research. 1987;11(4):541-7. 
[22] Kotas TJ. Exergy criteria of performance for thermal plant: second of two papers on exergy techniques in thermal plant analysis. International Journal of Heat and Fluid Flow. 1980;2(4):147-63.

[23] Weegels P. Fast return: Reusing one-day-old bread by fermentation. European Bakery Innovation Centre; 2010.

[24] Brennan JG. Food processing handbook. Weinheim, Germany: Willey-VCH; 2006.

[25] Cauvain S. Breadmaking processes. Technology of breadmaking: New York: Springer; 2007. p. 21-49.

[26] Bakery proofer B-1800. C.S.Aerotherm; 2013.

[27] Divider and rounder. Fortuna-Derby-RS; 2013.

[28] EU-Freshbake Project. Do you like fresh bread? Brussels; 2010.

[29] Therkelsen P, Masanet E, Worrell E. Energy efficiency opportunities in the U.S. commercial baking industry. Journal of Food Engineering. 2014;130:14-22.

[30] Wiggins C, Cauvain S. Proving, baking and cooling. Technology of Breadmaking: Springer US; 2007. p. 141-73.

[31] DXDZ-350 Horizontal flow packing machine. Guangzhou-Dade. Packing Machinery Co., Ltd.; 2013.

[32] Hamdami N, Pham QT, Le-Bail A, Monteau JY. Two-stage freezing of part baked breads - application and optimization. Journal of Food Engineering. 2007;82(4):418-26.

[33] Rentian W. Automatic 20-30 cases Carton box Erector. Packaging Technology Co., Ltd.; 2013. 
[34] Colak N, Kuzgunkaya E, Hepbasli A. Exergetic assessment of drying of mint leaves in a heat pump dryer. J Food Process Eng. 2008;31(3):281-98.

[35] Balkan F, Colak N, Hepbasli A. Performance evaluation of a triple-effect evaporator with forward feed using exergy analysis. International Journal of Energy Research. 2005;29(5):455-70.

[36] Ducoulombier M, Sorin M, Teyssedou A. Thermodynamic bounds for food deep chilling tray tunnel operation. International Journal of Thermal Sciences. 2007;46(2):172-9.

[37] Akpinar EK, Midilli A, Bicer Y. Energy and exergy of potato drying process via cyclone type dryer. Energy Conversion and Management. 2005;46(15-16):253052.

[38] Berghout JAM, Pelgrom PJM, Schutyser MAI, Boom RM, van der Goot AJ. Sustainability assessment of oilseed fractionation processes: A case study on lupin seeds. Journal of Food Engineering. 2015;150:117-24.

[39] Jankowiak L, Jonkman J, Rossier-Miranda FJ, van der Goot AJ, Boom RM. Exergy driven process synthesis for isoflavone recovery from okara. Energy. 2014;74:471-83.

[40] Papargyropoulou E, Lozano R, K. Steinberger J, Wright N, Ujang Zb. The food waste hierarchy as a framework for the management of food surplus and food waste. Journal of Cleaner Production. 2014;76:106-15.

[41] Sonneveld. Brown bun recipe. 2014. http://www.sonneveld.com/nl/recepten

[42] Pyler EJ. Baking science \& technology. 3rd edition. Kansas City: Sosland Publishing; 1988.

[43] Reed G, Nagodawithana TW. Yeast technology. 2nd edition. Van Nostrand Reinhold, 1991. 
[44] Sonneveld. Bread improver: Sonplus bruin. 2013. http://www.sonneveld.com

[45] Sonneveld. Sonextra sustain. 2013. http://www.sonneveld.com

[46] Koroneos CJ, Nanaki EA. Energy and exergy utilization assessment of the Greek transport sector. Resources, Conservation and Recycling. 2008;52:700-6.

[47] McKinnon A. The role of road transport in a green transport system. Conference on the role of road transport in a green transport system. Brussels. 2012.

[48] Tassou SA, De-Lille G, Ge YT. Food transport refrigeration - approaches to reduce energy consumption and environmental impacts of road transport. Applied Thermal Engineering. 2009;29(8-9):1467-77.

[49] Szargut J. Chemical exergies of the elements. Applied Energy. 1989;32:169285.

[50] Le Gall M, Eybye KL, Bach Knudsen KE. Molecular weight changes of arabinoxylans of wheat and rye incurred by the digestion processes in the upper gastrointestinal tract of pigs. Livestock Science. 2010;134(1-3):72-5.

[51] NZIC. The manufacture of polyethylene. 2013. http://www.nzic.org.nz

[52] Goesaert H, Brijs K, Veraverbeke WS, Courtin CM, Gebruers K, Delcour JA. Wheat flour constituents: how they impact bread quality, and how to impact their functionality. Trends in Food Science \& Technology. 2005;16(1-3):12-30. 


\section{Chapter 4}

\section{A resource efficiency assessment of the industrial mushroom production chain: The influence of data variability}

Published as:

Zisopoulos F.K., Becerra Ramírez H.A., van der Goot A.J, Boom R.M. (2016). A resource efficiency assessment of the industrial mushroom production chain: the influence of data variability. Journal of Cleaner Production. 126: 394-408. 


\begin{abstract}
We compare the exergetic performance of a conventional industrial mushroom production chain with a mushroom production chain where part of the compost waste is recycled and reused as raw material. The critical exergy loss points (CEPs) identified are the cooking-out process of the spent mushroom substrate, and the phase I composting process which are related to chemical and physical exergy losses, respectively. The total exergy input requirements for the conventional chain are higher (24 GJ per three flushes of mushrooms) than for the alternative chain (17 GJ per three flushes of mushrooms) since more raw materials are required. The largest exergy losses are due to unclosed material balances, i.e. chemical exergy losses, which represent $69 \%$ of the total exergy losses for the conventional chain, and $56 \%$ for the alternative production chain. Therefore, it only makes sense to reduce any avoidable physical exergy losses after utilizing all mass streams maximally that translate into chemical exergy flows. Further comparison of exergetic indicators (e.g. specific exergy losses, and exergetic cost) shows that recycling material streams would improve the resource efficiency of the industrial mushroom production chain considerably. The variations in the assumed electricity consumption values for the ventilation in phase I composting and for the ammonia scrubbing process affect greatly the exergetic indicators and the number of critical exergy loss points indicating that any further improvement on the exergetic performance of the mushroom production chain should focus on these two process variables. This study shows that variability in data can influence both quantitatively and qualitatively the outcome of exergetic analyses of food production chains since it can lead to the calculation of different values for the selected indicators as well as to the identification of completely different critical exergy loss points.
\end{abstract}

Keywords: Sustainability; Exergy analysis; Food industry; Recycling; 


\section{Introduction}

A proper investigation of the resource flows, particularly in the food manufacturing and processing sectors is crucial for achieving a better sustainable food supply system [1]. The feasibility of reducing resource consumption and waste in three different food production chains was shown by Lee and Okos [2] while the potential for designing novel side-stream valorisation strategies into added value products has been discussed by Fava et al. [3]. Several indicators have been developed for assessing the sustainability of food production chains which include economic, social, and environmental aspects [4]. However, there seems to be no agreement in the scientific community on a standardization procedure for the use of all the available sustainability metrics and footprints [5].

The fundamental laws of thermodynamics for assessing the sustainability of food production are objective beyond dispute, they can be used to identify the causes of inefficiencies in the use of material and energy, and they can help in designing food production chains in a more sustainable manner. An objective tool for assessing the sustainability of food production chains that is based on the second law of thermodynamics is exergy analysis [6-12] where all input resources (e.g. raw materials, energy) are considered in terms of useful work (exergy). The main steps for exergetically analysing a food production chain have been summarized in literature [13]. Exergy analysis is useful in identifying Critical Exergy loss Points (CEPs) that are defined as locations in the food production chain where most of the input exergy is lost (destroyed and/or wasted). The number of CEPs might vary for different food production chains depending on the number of processing steps that are either exergy intensive by nature (e.g. phase change processes like drying) or exergetically wasteful (e.g. processes where a lot of material, i.e. chemical exergy, is wasted). Therefore, the types of exergy loss (chemical or physical) can influence the decision on selecting an alternative process or chain modification to be assessed.

The determination of a processing step along the chain as a CEP or not can be influenced greatly by the variability of data used during the assessment, and it can affect the final decision for any potential improvement on the food production chain. 
Therefore, screening for influential variables in the model can be very useful for providing more information on the comparison of the exergetic performance of industrial food production chains, and it should be an integral part of any exergy analysis.

This paper compares the exergetic performance of two industrial mushroom production chains (A. bisporus) by taking into consideration the influence of data variability on the identification of CEPs. The conventional mushroom production chain is compared with a production chain design where part of its compost waste is recycled and reused as a raw material. First, both mushroom production chains are analysed by material, energy, and exergy balances. Secondly, the chains are compared based on the cumulative exergy losses, specific exergy losses, exergetic efficiency, and critical exergy points.

Finally, a sensitivity analysis is used to screen for the most influencing variables of the model on the identification of CEPs. This study demonstrates that assumptions can have a considerable influence on the identification of CEPs, and, consequently, on the outcome of the assessment.

\section{Methods}

\section{General description of the industrial mushroom production chain}

The industrial production of fresh white button mushrooms (A. bisporus) is studied. The system boundaries and the most relevant input material and energy streams in the industrial production of fresh mushrooms are shown in Figure 1. In summary, the main parts of the industrial mushroom production chain include: the composting process (mixing, phases I, II and III, and ammonia scrubbing), the casing soil production, and the growing and harvesting of mushrooms [14].

The mushrooms are grown on composted organic waste (amongst others horse manure), which is covered by a layer of peaty material, called casing soil. Therefore, both the productions of the compost as well as of the casing soil are considered as integral parts of the industrial mushroom production chain. Compost provides the 
main nutrients (i.e. carbon and nitrogen) for the fungus while the casing soil has a supportive function and acts as a fast water absorber and slow water releaser for the mycelia to start pinning $[15,16]$. The final compost is transported to growers where mushrooms (the final product) are harvested to up to three consecutive flushes (batches), each one with a lower yield due to potential infections. Growers in reality chose their own production plans, however, here it is assumed that all three flushes are produced from a certain amount of compost. The remaining spent mushroom substrate and casing soil, after the harvesting of mushrooms, is called spent mushroom substrate (also known as "champost"), and usually is steamed ("cookedout") to become pathogen-free before it is discarded as landfill. In this analysis this side-stream is considered as a waste stream, and its impact on the sustainability of the total chain by potential recycling as a useful raw material is studied.

Clearly, the complexity of the industrial mushroom production chain lies on the multiple sources of data used for the analysis, which come both from literature as well as from personal communication with experts in the field. Therefore, the majority of data used in the analysis are represented in the form of tables. The most relevant considerations shown in Table 1 are briefly discussed:

A fixed amount of 3.5 tonnes of initial raw material mix is assumed to be processed leading to the production of three flushes of fresh mushroom $(365 \mathrm{~kg}, 231 \mathrm{~kg}$, and $91 \mathrm{~kg}$, respectively) for both production chains to set a benchmark for a fair comparison.

Additional quality aspects (e.g. initial moisture content of the raw materials mix, the carbon to nitrogen ratio, the composition of the final product, etc.) are assumed to be the same in the two industrial mushroom production chains in order to deem their comparison fair.

Other important assumptions, being the recipe for the initial compost mix, the composition of the raw materials and final products, and the assumptions related to the exergy analysis can be found in Tables A.1, A.2, A.3, and A.4 of the Appendix, respectively. 


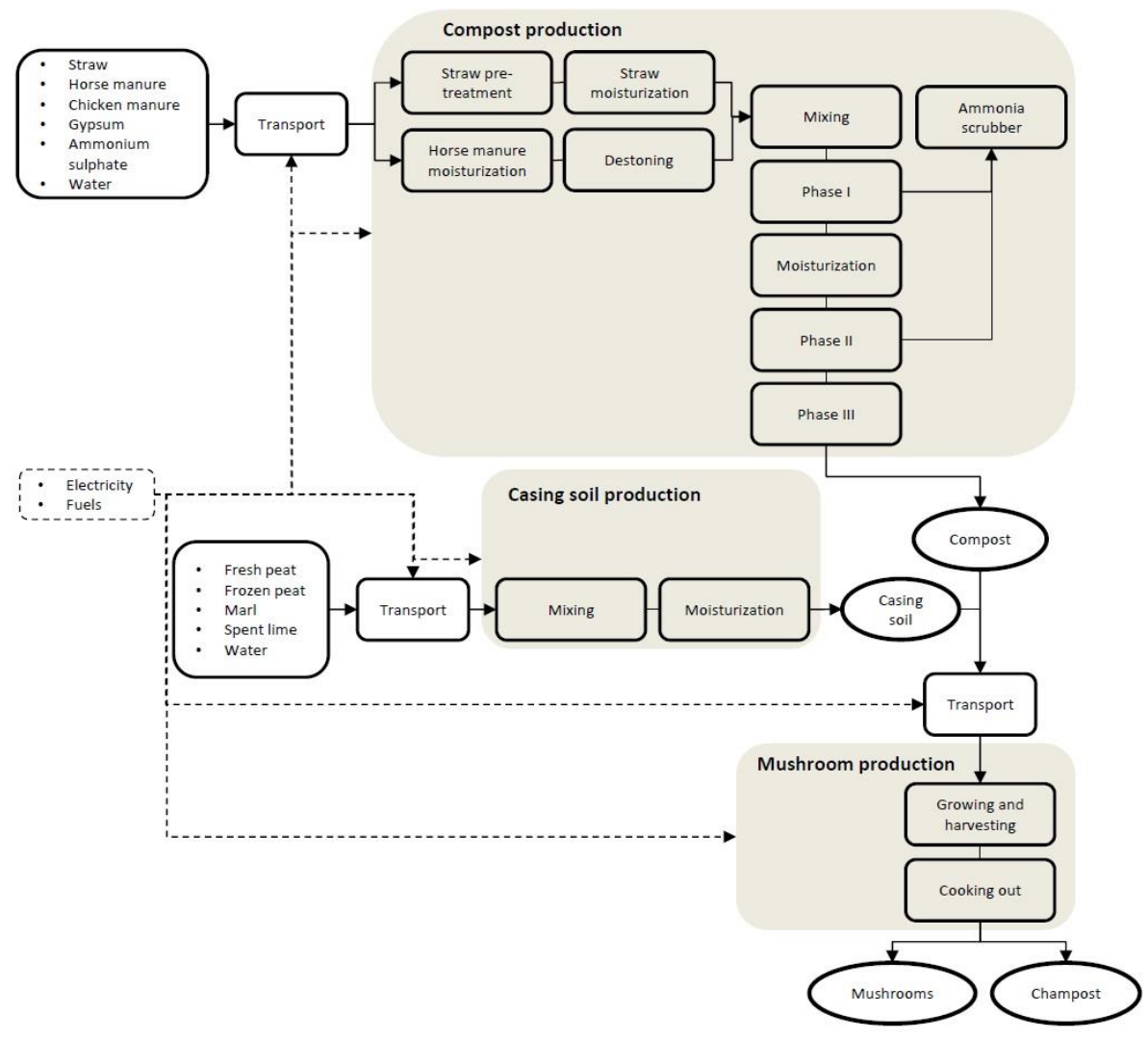

Figure 1. Flowchart of the conventional mushroom production chain, split into three sub-chains highlighted in grey colour: the production of compost, the production of casing soil, and the growing of mushrooms.

Table 1. Industrial mushroom production chain description.

\footnotetext{
Comment

The total mushroom yield is fixed (Table A.1.)

The total initial amount of raw material mixture is fixed (Table A.1)

The carbon to nitrogen ratio in the initial raw material mix should be the same (Table A.1.)

The moisture content in the initial raw material mix should be the same (Table A.3.)

The composition of mushrooms should be the same (Table A.3.)

The compost: casing soil ratio reaching the growers should be the same (Table A.1.)
} 


\section{Detailed description of the industrial mushroom production chain}

The selected process variables used in this study (Table 2) are discussed. The main raw materials used in the compost recipe are straw and horse manure (carbon sources), chicken manure and ammonium sulphate (nitrogen sources), gypsum (physical conditioner that reduces the greasiness of the compost [17]), and water. These materials are mixed together to a certain carbon to nitrogen ratio of 10.2 , reaching an initial nitrogen content of $21 \mathrm{~kg}$ per tonne of straw used [18]. The electricity used for mixing is assumed to range between 64 and $75 \mathrm{~W} / \mathrm{kg} \operatorname{mix}$ [19], while the fuel used for mobilizing mixing trucks is assumed to range between 0.015 and $0.054 \mathrm{~m}^{3} / \mathrm{h}$ [20]. The electricity use for conveyor belts is assumed to range between 0.007 and $0.035 \mathrm{~W} / \mathrm{kg}$ mix [21]. Further processing conditions are required to make the compost a selective substrate for A. bisporus. Composting is a process where a plethora of biochemical reactions occur, heating up the substrate, producing ammonia [22], and evaporating considerable amounts of water [17, 18]. Therefore, proper aeration of the substrate by ventilation is necessary for preventing anaerobic conditions that can lead to infections. Aeration is run at specified time intervals by regulating both oxygen, and temperature levels inside the tunnels. The electricity use depends heavily on the ventilation program where accurate information is not readily available in literature. By considering certain duration and vent operation schedule for each phase, its estimated value ranges between $0.0001 \mathrm{kWh} / \mathrm{m}^{3}$ (www.fancom.com, 2015) and $0.0025 \mathrm{kWh} / \mathrm{m}^{3}$ of air ventilated. The maximum value was calculated by considering an electricity use of $34.4 \mathrm{kWh} / \mathrm{ton}$ of compost ventilated $[23,24]$. Legislation prevents the release of the ammonia produced to the environment, and therefore, the airstream leaving the tunnels is scrubbed in spray towers by concentrated sulphuric acid producing ammonium sulphate [25].

The electricity use for this process is also not readily available. Its minimum value has been found to be around $0.00006 \mathrm{kWh} / \mathrm{m}^{3}$ [26] while its maximum value was calculated to be $0.00534 \mathrm{kWh} / \mathrm{m}^{3}$ of air processed (Appendix B). Casing soil is produced using peat due to its high air to water ratio, and its high water holding capacity. The natural acidity of the peat is counteracted by using spent lime and marl 
[17]. The transportation energy use was represented by an average distance between certain locations of our industrial partner in the Netherlands, and by assuming that diesel trucks of a pre-specified capacity, and fuel efficiency are used, as further specified in the appendix (Table A.1). All values discussed, even though seemingly small, apply for processing vast amounts of air, and, therefore, are relevant for the analysis. Table shows the minimum and maximum values for each process variable considered in the analysis. The illustrative figures with the material and exergy flows that are discussed in this paper, correspond to the base case scenario which is considered as the average value between the minimum and maximum values of the selected process parameters.

Table 2. Selected process variables.

\begin{tabular}{|c|c|c|c|c|}
\hline & $\min$ & Base case & $\max$ & Reference \\
\hline \multicolumn{5}{|l|}{ Mixing process } \\
\hline electricity use (W/kg mix) & 64 & 69 & 75 & [19] \\
\hline fuel use $\left(\mathrm{m}^{3} / \mathrm{h}\right)$ & 0.015 & 0.034 & 0.054 & {$[20]$} \\
\hline Conveyor & & & & \\
\hline electricity use (W/kg mix) & 0.007 & 0.021 & 0.035 & [21] \\
\hline \multicolumn{5}{|l|}{ Composting process } \\
\hline ventilation electricity use $\left(\mathrm{kWh} / \mathrm{m}^{3}\right.$ air $)$ & 0.0001 & 0.0013 & 0.0025 & {$[23,24]$} \\
\hline \multicolumn{5}{|l|}{ Scrubbing process } \\
\hline electricity use $\left(\mathrm{kWh} / \mathrm{m}^{3}\right.$ air $)$ & 0.0001 & 0.0027 & 0.0053 & {$[26,27]$} \\
\hline ammonia removal efficiency (\%) & 70 & 80 & 90 & {$[26,28]$} \\
\hline use of excess sulphuric acid (\%) & 0 & 10 & 20 & Assumed \\
\hline \multicolumn{5}{|l|}{ Growing process } \\
\hline electricity use $\left(\mathrm{W} / \mathrm{m}^{3}\right)$ & 15 & 17 & 19 & {$[29]$} \\
\hline wall overall heat transfer coefficient $\left(\mathrm{W} / \mathrm{m}^{2} \mathrm{~K}\right)$ & 9 & 10 & 10 & {$[30]$} \\
\hline safety factor (-) & 1.1 & 1.23 & 1.35 & {$[31]$} \\
\hline heater efficiency (\%) & 75 & 85 & 95 & [32] \\
\hline cooking-out temperature $(K)$ & 343 & 418 & 493 & {$[33,34]$} \\
\hline
\end{tabular}




\section{Thermodynamic assessment}

The mass, energy, and exergy balances of the industrial mushroom production chains are used to construct Sankey and Grassmann diagrams using the software E!Sankey Pro. The conservation of mass and energy has been applied throughout the chain. More specific calculations regarding particular processing steps such as for the energy use at the scrubber and for the cooking out process are shown in Appendix B. Table 3 shows all relevant calculations considered in the analysis. The yield, the water footprint (WF), and the specific energy consumption (SEC) are calculated to be juxtaposed with the exergetic indicators to demonstrate the usefulness of the latter for capturing the impact of chain modifications on the outcome of the sustainability assessment.

The concept of exergy is valid in relation to a particular environment of reference only. In this study, the environment of reference is set at 1 atmosphere, at $298 \mathrm{~K}$, and at $8 \mathrm{~g}$ water per $\mathrm{kg}$ dry air (41\% relative humidity). The relevant forms of exergy considered for this industrial food production chain are the thermal exergy, the chemical exergy, and the mixing exergy of streams. By setting up the exergy balance it is possible to calculate several exergetic indicators. The cumulative exergy losses (CEL) are useful for estimating the total exergy wasted and destroyed for processing a certain amount of raw materials. A lower CEL-value implies a less exergy intensive food production chain. The specific exergy losses (SEL) show the total exergy lost to produce one $\mathrm{kg}$ of final product. The lower the SEL the less resistance there is to produce this particular food product. The rational exergetic efficiency shows how well the exergy is passing through the whole industrial food production chain. A higher exergetic efficiency reflects a more sustainable industrial food production chain. The exergetic cost (EC) shows the ratio of the total exergy investment over the total product exergy. The lower the EC the less exergy demanding is the food production chain. To identify a CEP, a threshold criterion has to be set. Here, a CEP is considered as any location in the mushroom production chain where more than $10 \%$ of the total exergy losses occur. 
Table 3. Relevant equations used in the assessment.

\begin{tabular}{|c|c|}
\hline Material balance & $\sum m_{i, \text { in }}-\sum m_{i, o u t}=0$ \\
\hline Mass efficiency & $n_{m}=\frac{m_{\text {product }}}{m_{\text {raw material input }}}$ \\
\hline Water footprint & $W F=\frac{m_{\text {water }}}{m_{\text {product }}}$ \\
\hline Energy balance & $E_{i}+\sum F_{i}=\sum Q_{i, \text { losses }}$ \\
\hline Thermal energy of stream i & $Q_{i}=m_{i} c_{p, i}\left(T_{i}-T_{o}\right)$ \\
\hline Heat capacity of stream i & $c_{p, i}=\sum\left(c_{p, j} x_{j}\right)$ \\
\hline Specific energy consumption & $S E C=\frac{\text { total input energy used }}{m_{\text {product }}}$ \\
\hline Exergy of stream i & $B_{i}=B_{i, p h y s i c a l}+B_{i, \text { chemical }}+B_{i, \text { mix }}$ \\
\hline Physical exergy of stream i & $B_{i, \text { physical }}=B_{i, \text { thermal }}+B_{i, \text { pressure }}+B_{i, \text { electrical }}$ \\
\hline Thermal exergy of stream i & $B_{i, \text { thermal }}=m_{i} c_{p, i}\left[\left(T_{i}-T_{o}\right)-T_{o} \ln \left(\frac{T_{i}}{T_{o}}\right)\right]$ \\
\hline Pressure exergy of stream i & $B_{i, \text { pressure }}=N_{i} R T_{o} \ln \left(\frac{P_{i}}{P_{o}}\right)$ \\
\hline Chemical exergy of stream i & $B_{i, \text { chemical }}=m_{i} \sum\left(b_{o, j} x_{j}\right)$ \\
\hline Specific mixing exergy of air i & $b_{i, \text { mix }}=R T_{o}\left[\frac{w}{M W_{w}} \ln \left(\frac{w \cdot M W_{a}}{w \cdot M W_{a}+M W_{w}}\right)+\frac{1}{M W_{a}} \ln \left(\frac{M W_{w}}{w \cdot M W_{a}+M W_{w}}\right)\right]$ \\
\hline Specific chemical exergy of air $\mathrm{i}$ & $b_{i, \text { chemical }}=\left|b_{\text {mix }}(w)-b_{\text {mix }}\left(w_{o}\right)\right|+\left|w-w_{o}\right| b_{o, s t}$ \\
\hline Mixing exergy of stream i & $B_{\text {mix }}=N_{i} R T_{o} \sum\left(x_{j} \ln \left(a_{j}\right)\right)$ \\
\hline Fuel chemical exergy & $B_{f}=f_{l} \cdot$ calorific value \\
\hline Cumulative exergy losses ${ }^{1}$ & $C E L=\sum B_{i, \text { in }}-\sum B_{i, \text { out }}=\sum B_{i, \text { destroyed }}+\sum B_{i, \text { wasted }}$ \\
\hline Specific exergy losses ${ }^{1}$ & $S E L=\frac{C E L}{m_{\text {product }}}$ \\
\hline Rational exergetic efficiency ${ }^{1,2}$ & $\eta=\frac{\sum B_{\text {product }}}{\sum B_{i, \text { in }}}$ \\
\hline Exergetic $\cos \mathrm{t}^{3}$ & $E C=\frac{\sum B_{i, i n}}{B_{\text {product }}}$ \\
\hline
\end{tabular}

${ }^{1}$ As described by Szargut [35].

${ }^{2}$ As described by Szargut [35] and Kotas [36].

${ }^{3}$ As described by Sciubba [37]. 


\section{Sensitivity analysis}

A sensitivity index (SI) is calculated to assess the influence of the variability of data on the outcome of the analysis in a relatively fast manner. The use of the SI has been demonstrated in energy conservation studies in the field of civil engineering [38]. In this paper, the SI is used to screen for the most influential variables on the indicators studied, and their impact on CEP identification. SI is defined as:

$$
S I_{i}^{j}=\left|\frac{I_{i}^{\text {max }}-I_{i}^{\text {min }}}{I_{i}^{\text {base case }}}\right|
$$

where $I_{i}^{\max }, I_{i}^{\min }$, and $I_{i}^{\text {base case }}$ are the calculated values for the indicator $j$ at the maximum, the minimum, and the base case value of the selected process variable $i$, while all other process variables remain constant at their base case values. The higher the sensitivity index for a selected variable, the more influential that variable is on the calculated indicators.

\section{Results and discussion}

The results of the overall sustainability assessment are shown in Table 4.

\section{Assessment of the conventional mushroom production chain}

The Sankey mass flow diagram for the base case mushroom production chain can be seen in Figure 2. The total yield of mushrooms (of three flushes) is $687 \mathrm{~kg}$ after processing $3500 \mathrm{~kg}$ of initial raw material mix and about $600 \mathrm{~kg}$ of casing soil with a mass efficiency of $15 \%$. This low mass efficiency is due to the wastage of spent mushroom substrate. Typically, the spent mushroom substrate is steamed (cookedout) for reasons of microbiological safety, and then it is transported and applied on fields. The water footprint (WF) is $3.4 \mathrm{~kg}$ of water per $\mathrm{kg}$ of mushrooms produced. The specific energy consumption (SEC) is $14.1 \mathrm{MJ} / \mathrm{kg}$ mushrooms. The cumulative exergy loss (CEL) is 24.9 GJ per three flushes of mushrooms. The thermodynamic price to produce one $\mathrm{kg}$ of mushrooms (SEL) is $36.3 \mathrm{MJ}$. The overall exergetic 
efficiency (n) is $4.8 \%$, or in other words, the exergetic cost (EC) to run the industrial mushroom production chain is 20.9 times the product exergy.

The exergy losses in the conventional chain (expressed as percentages of the total exergy loss) are shown in Figure 3. Most of the chemical exergy losses, which are also the main type of exergy losses, occur after the cooking-out process where the spent mushroom substrate is wasted, while most of the physical exergy losses occur at the phase I of the composting process. These findings are visualized in the Grassmann diagram (Figure 4). The spent mushroom substrate is discarded to the environment, which means that it attains zero exergy by definition as soon as it becomes part of the environment, provided it does not lead to pollution effects. Consequently, phase I composting and the cooking-out process can be considered as CEPs for the conventional mushroom production chain with the base case values for the process variables.

\section{Assessment of the recycling mushroom production chain}

The case where the spent mushroom substrate is seen as a useful input raw material is also assessed, because the chemical exergy losses at the cooking our process are the main causes of inefficiencies. The Sankey and Grassmann diagrams of the recycling mushroom production chain are shown in 5 and 6 , respectively. Approximately $45 \%$ of the total spent mushroom substrate being wasted in the conventional chain can be recycled theoretically when considering the carbon-tonitrogen ratio and the moisture content, and further assuming that the total amount to be composted has to remain the same as in the conventional chain. Moreover, it is assumed that the complete replacement of wheat straw, horse manure, and ammonium sulphate by recycling spent mushroom substrate is possible and yields a similar amount and quality of mushrooms, required for a fair exergetic comparison.

In the recycling case, the ammonium sulphate becomes a valuable product. About $0.06 \mathrm{~kg}$ ammonium sulphate per $\mathrm{kg}$ mushrooms is produced in the ammonia scrubbing process while the produced amount is insufficient to fulfil the compost recipe requirements in the conventional mushroom production chain. The mass 
efficiency is increased up to $20 \%$ since less spent mushroom substrate is wasted. The WF and SEC are slightly reduced by $5 \%$ and $4 \%$, respectively, since no wheat straw and horse manure are added anymore, and because less spent mushroom substrate is wasted and transported for disposal. The CEL, SEL, n, and EC now are 17.3 GJ per three flushes, $25.2 \mathrm{MJ} / \mathrm{kg}$ mushrooms, $8.0 \%$, and 12.5 , respectively. Also in this case, phase I composting and the cooking-out process remain the CEPs when using the base case values for the process variables.

\section{Comparison of the two food production chains at their base case}

\section{values}

Clearly, there is a considerable improvement in all indicators studied when part of the spent mushroom substrate is recycled. More specifically, the SEC, CEL, SEL, n, and EC for the base case values of the process variables, are improved by $4 \%, 30 \%$, $30 \%, 3.3 \%$, and $41 \%$, respectively.

Figure 7 shows that the total exergy input requirements for the recycling chain are lower (17 GJ per three flushes of mushrooms) than for the conventional chain (24 GJ per three flushes of mushrooms) since less raw material is required. It is worth noting that the chemical exergies related to raw materials have the greater share of the total exergy input in both chains.

Figure 8 shows the evolution of the specific chemical exergy of raw materials, intermediate products, and final products in both chains. As the compost mix becomes more concentrated during composting due to the moisture evaporation, its specific chemical exergy increases. The specific exergy values shown for the recycling chain are lower than the conventional chain due to the different elemental composition of the compost raw material mix. Based on the above, it makes sense to utilize the complete amount of produced spent mushroom substrate e.g. for energy recovery [39] or as a fertilizer [40]. Therefore, when the total amount of spent mushroom substrate is seen as a useful product in the recycling chain then the exergetic indicators CEL, SEL, n, and EC become 10.6 GJ per three flushes, 15.5 
$\mathrm{MJ} / \mathrm{kg}$ mushrooms, 36.8\% (including the additional spent mushroom substrate exergy), and 2.7 (including the additional spent mushroom substrate exergy), respectively.

\section{Variability and its impact on the final assessment}

Table 4 shows that the value of a given process variable can greatly affect the outcome of the analysis. The CEP for both mushroom production chains is the cooking-out process when all the process variables attain their minimum values. However, the maximum values for all variables results in phase I composting as additional CEP for both the base case. Moreover, the SI index calculated for the improvement of all the indicators shows that mainly the SEL and $n$ are strongly affected by the value of the process variables. In contrast, the mass efficiency and the water footprint are not influenced at all. The reason for this is that mass-related assumptions and estimations have less variability since they are strongly coupled and/or depend on the compositions and flows that are usually known or can be measured in industrial practices.

Figure 9 shows that the electricity used for ventilation during the composting process and the electricity use during ammonia scrubbing are the dominant process variables that affect the SEC, CEL, SEL, n, and EC in both the conventional and the recycling mushroom production chain when all other variables are held constant at their base case values. The exergy losses at phase I are too small to consider this process step to be a CEP in case the electricity use for ventilation during the composting process is at its minimum value. However, when it attains its maximum value, the physical exergy losses become quite large. A similar effect can be observed for the electricity use during the scrubbing of the ammonia, however, its magnitude is smaller. 


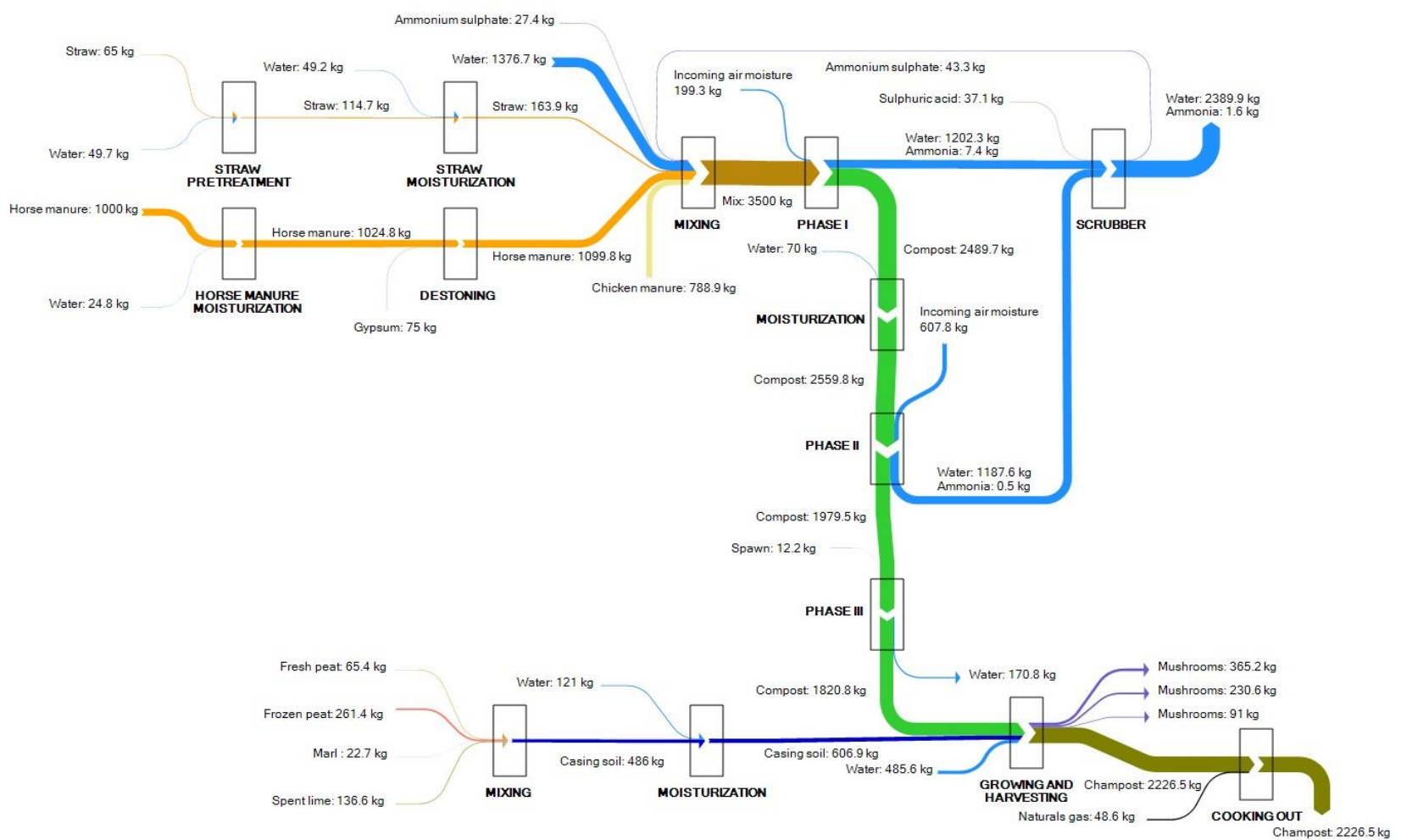

Figure 2. Sankey mass flow diagram of the conventional mushroom production chain for the base case scenario. The dry air flows during the composting phases are excluded for visualization purposes. 

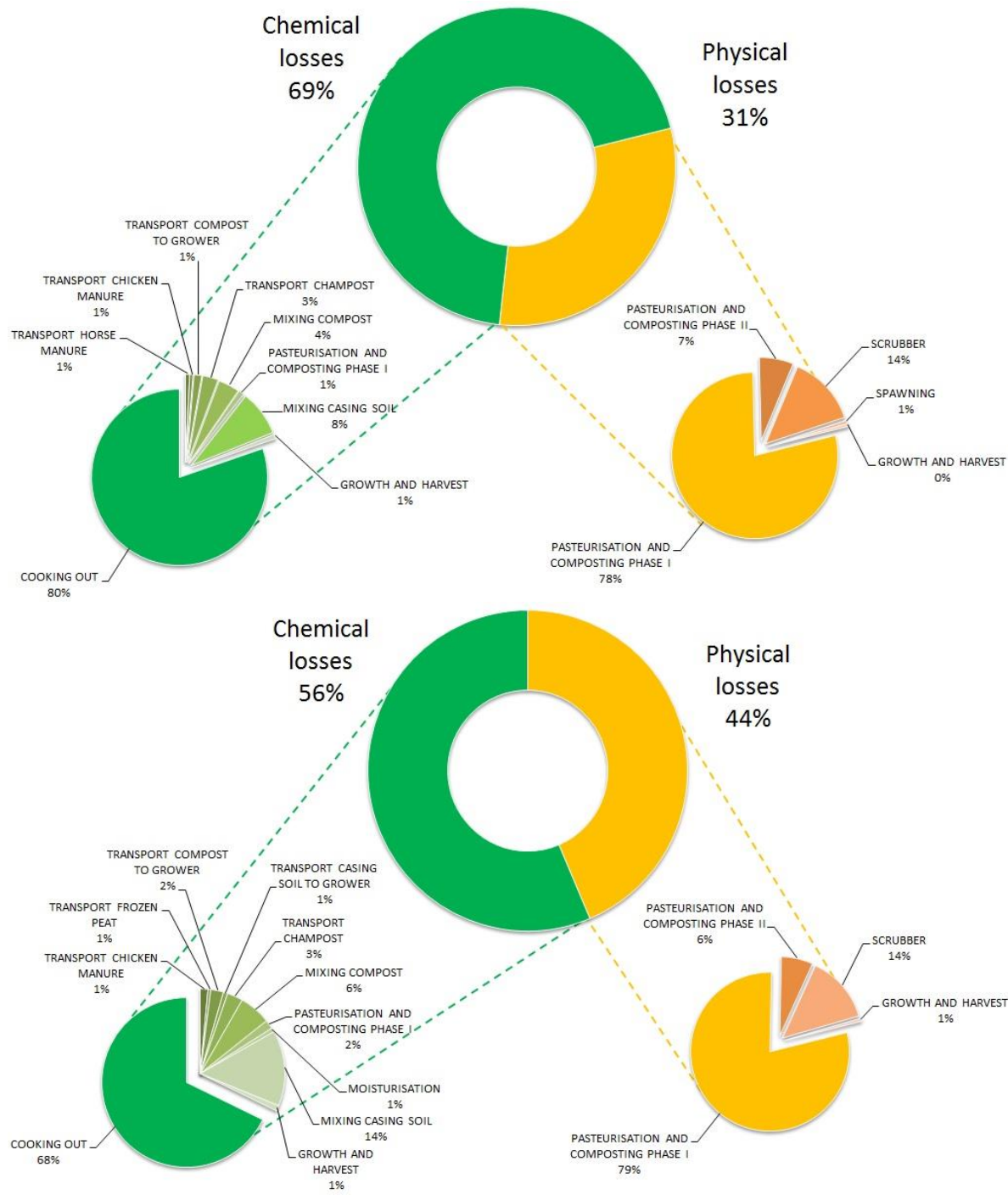

Figure 3. Distribution of exergy losses for the base case scenario occurring in locations in top: the conventional and bottom: the alternative (recycling) mushroom production chain. 


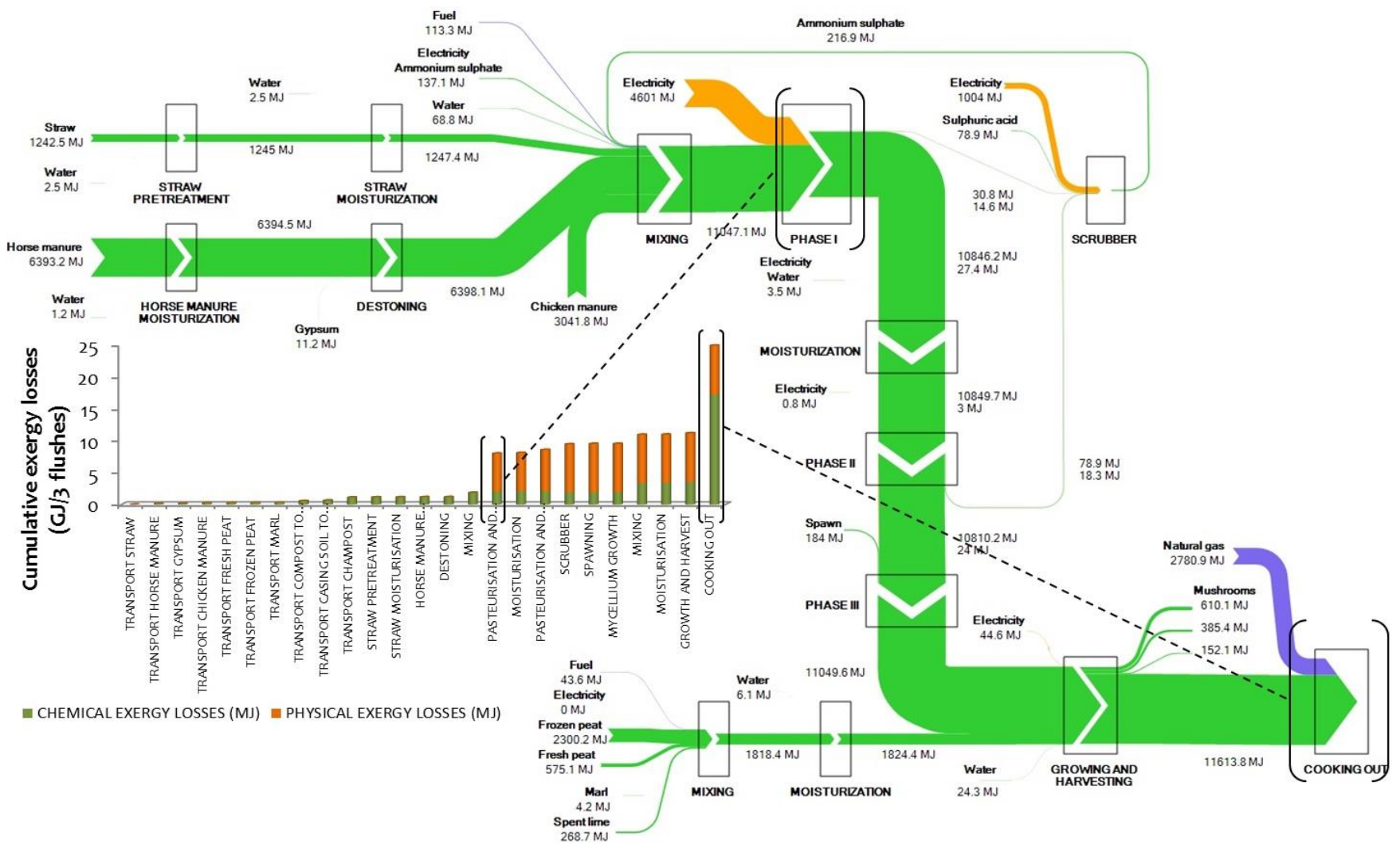

Figure 4. Grassmann diagram of the conventional mushroom production chain for the base case scenario, depicting the cumulative exergy losses (GJ/three flushes of mushrooms) and the critical exergy loss points (CEPs). 


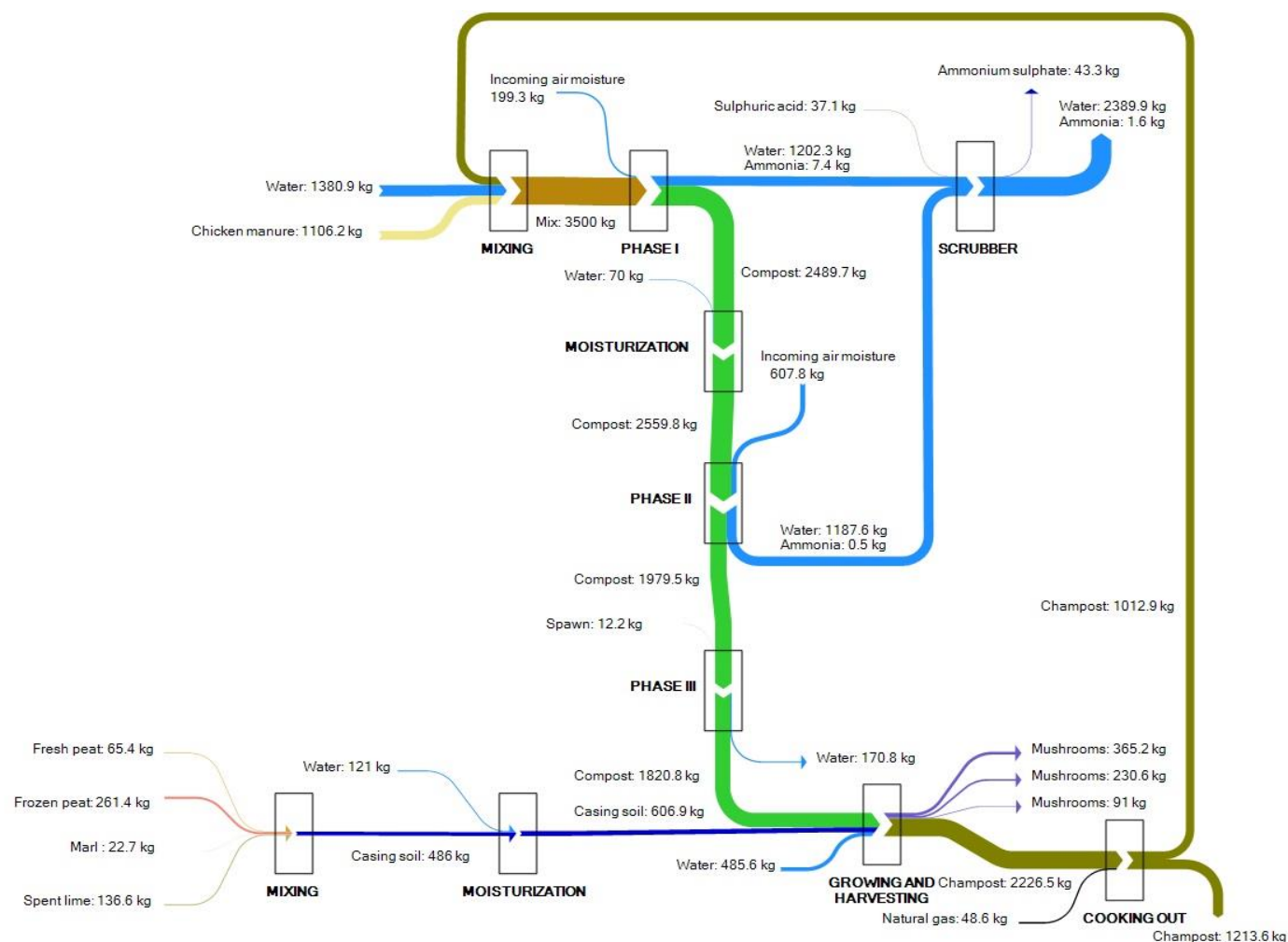

Figure 5. Sankey mass flow diagram of the recycling mushroom production chain for the base case scenario. The dry air flows during the composting phases are excluded for visualization purposes. 


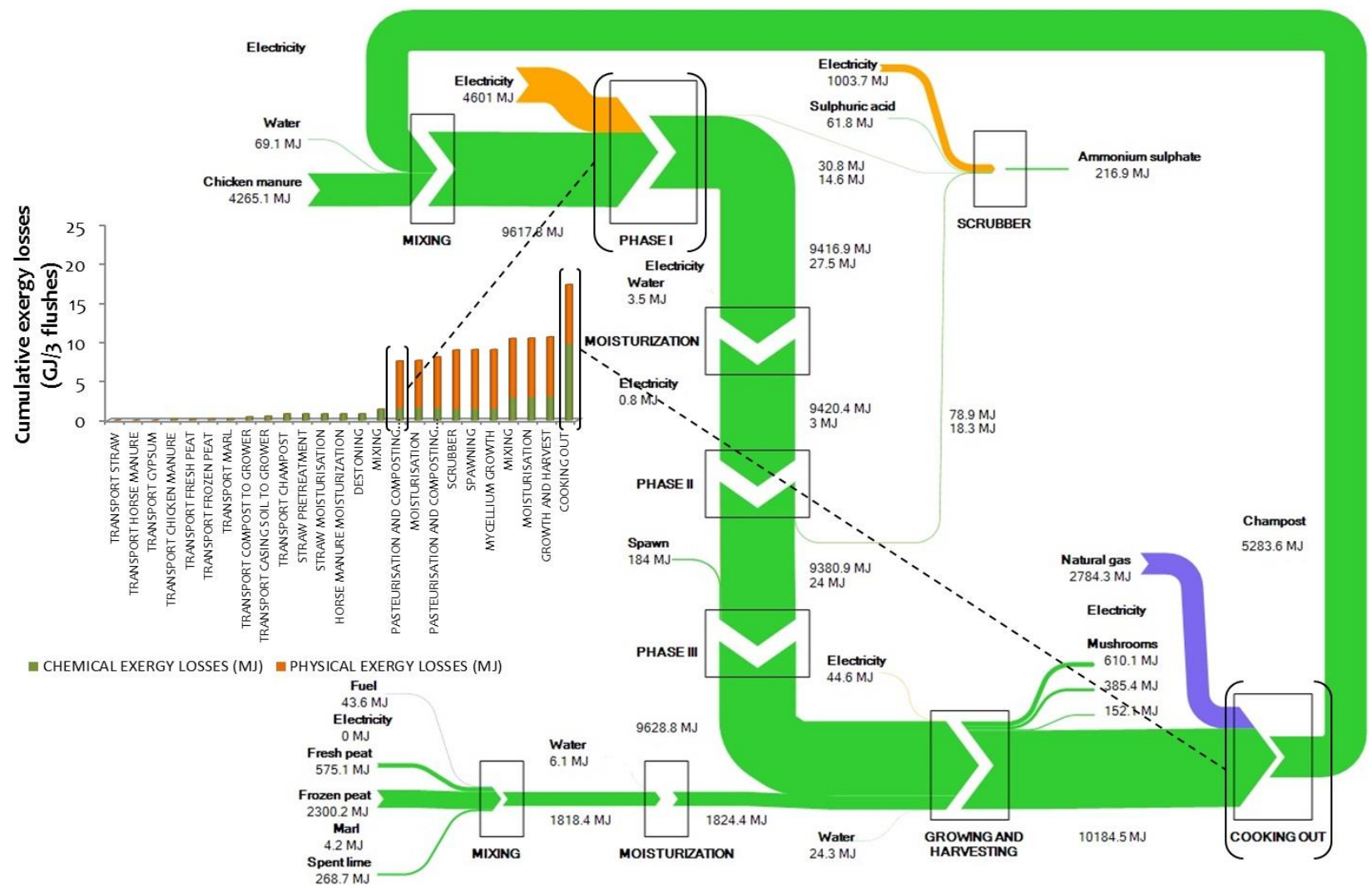

Figure 6. Grassmann diagram of the recycling mushroom production chain for the base case scenario, depicting the cumulative exergy losses (GJ/three flushes of mushrooms) and the critical exergy loss points (CEPs). 


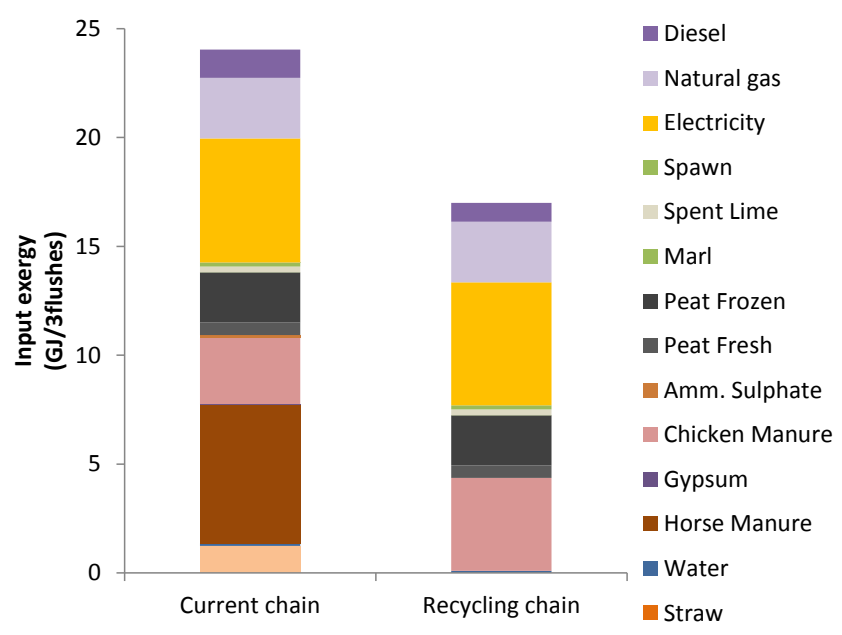

Figure 7. Exergy inputs used to drive both the conventional and the recycling mushroom production chain for the base case scenario.

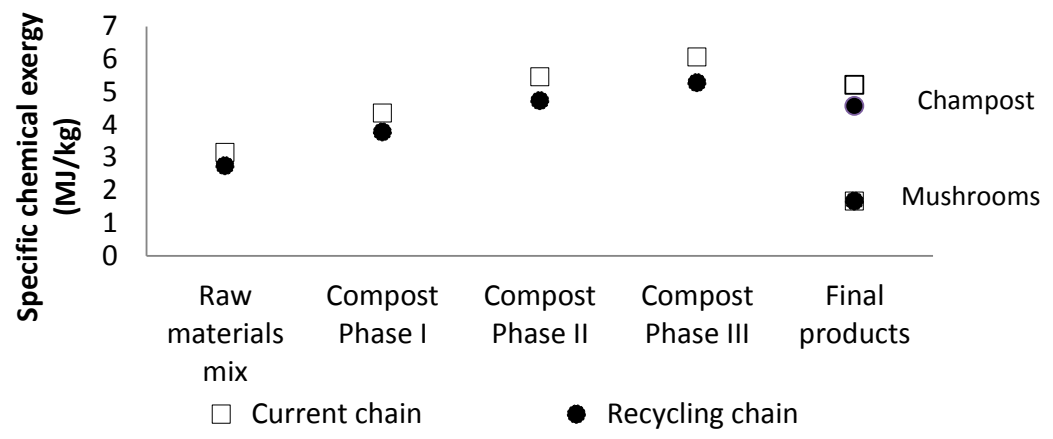

Figure 8. Evolution of specific chemical exergy $(\mathrm{MJ} / \mathrm{kg})$ in both the conventional and the recycling mushroom production chains for the base case scenario. 


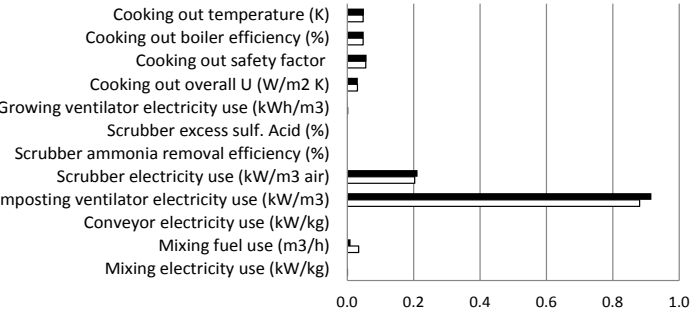

- Recycling chain

$\square$ Current chain

b)

Cooking out temperature $(\mathrm{K})$ Cooking out boiler efficiency (\%)

Cooking out safety factor

Cooking out overall $\mathrm{U}(\mathrm{W} / \mathrm{m} 2 \mathrm{~K})$

Growing ventilator electricity use $(\mathrm{kWh} / \mathrm{m} 3)$

Scrubber excess sulf. Acid (\%)

Scrubber ammonia removal efficiency (\%)

Scrubber electricity use $(\mathrm{kW} / \mathrm{m} 3 \mathrm{air})$

Composting ventilator electricity use $(\mathrm{kW} / \mathrm{m} 3)$

Conveyor electricity use $(\mathrm{kW} / \mathrm{kg})$ Mixing fuel use $(\mathrm{m} 3 / \mathrm{h})$

Mixing electricity use $(\mathrm{kW} / \mathrm{kg})$

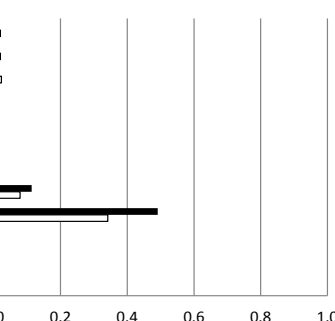

- Recycling chain

$\square$ Current chain

c)

Cooking out temperature (K) Cooking out boiler efficiency (\%) Cooking out safety factor Cooking out overall $\mathrm{U}(\mathrm{W} / \mathrm{m} 2 \mathrm{~K})$ Growing ventilator electricity use $(\mathrm{kWh} / \mathrm{m} 3)$ Scrubber excess sulf. Acid (\%) Scrubber ammonia removal efficiency (\%) Scrubber electricity use $(\mathrm{kW} / \mathrm{m} 3 \mathrm{air}$ Composting ventilator electricity use $(\mathrm{kW} / \mathrm{m} 3)$ Conveyor electricity use $(\mathrm{kW} / \mathrm{kg})$ Mixing fuel use $(\mathrm{m} 3 / \mathrm{h})$ Mixing electricity use $(\mathrm{kW} / \mathrm{kg})$

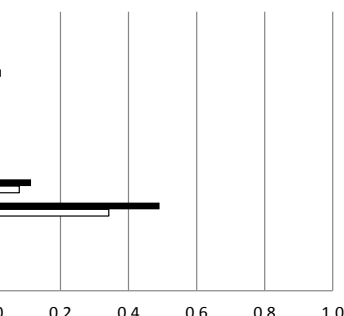

- Recycling chain $\square$ Current chain

- Recycling chain

$\square$ Current chain Scrubber excess sulf. Acid (\%) Scrubber ammonia removal efficiency $(\%)$ Scrubber electricity use $(\mathrm{kW} / \mathrm{m} 3$ air Composting ventilator electricity use $(\mathrm{kW} / \mathrm{m} 3)$ Conveyor electricity use $(\mathrm{kW} / \mathrm{kg})$ Mixing fuel use $(\mathrm{m} 3 / \mathrm{h})$ Mixing electricity use $(\mathrm{kW} / \mathrm{kg}$

Cooking out temperature $(\mathrm{K})$ Cooking out boiler efficiency (\%) Cooking out safety factor

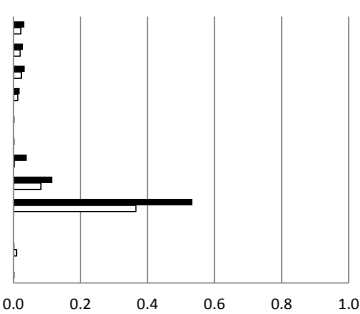

e)

Cooking out temperature (K) Cooking out boiler efficiency (\%) Cooking out safety factor Cooking out overall $\mathrm{U}(\mathrm{W} / \mathrm{m} 2 \mathrm{~K})$ Growing ventilator electricity use $(\mathrm{kWh} / \mathrm{m} 3)$ Scrubber excess sulf. Acid (\%) Scrubber ammonia removal efficiency (\%) Scrubber electricity use $(\mathrm{kW} / \mathrm{m} 3$ air Composting ventilator electricity use $(\mathrm{kW} / \mathrm{m} 3)$ Conveyor electricity use $(\mathrm{kW} / \mathrm{kg}$ Mixing fuel use $(\mathrm{m} 3 / \mathrm{h})$ Mixing electricity use $(\mathrm{kW} / \mathrm{kg})$

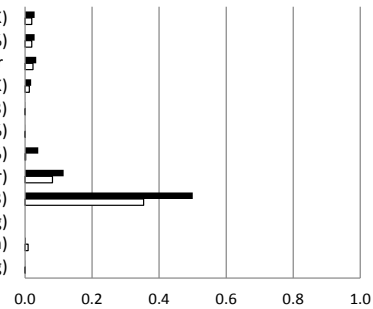

- Recycling chain $\square$ Current chain

Figure 9. Sensitivity indexes for: a) the specific energy consumption (MJ/kg mushrooms), b) the cumulative exergy losses (GJ/three flushes of mushrooms), c): the specific exergy losses (MJ/kg mushrooms), d): the rational exergetic efficiency $(\%)$, and e) the exergetic cost (-). 
Table 4. Indicators calculated for both mushroom production chains for the minimum and maximum values of the most influencing variable (electricity use of the ventilation of Phase I composting).

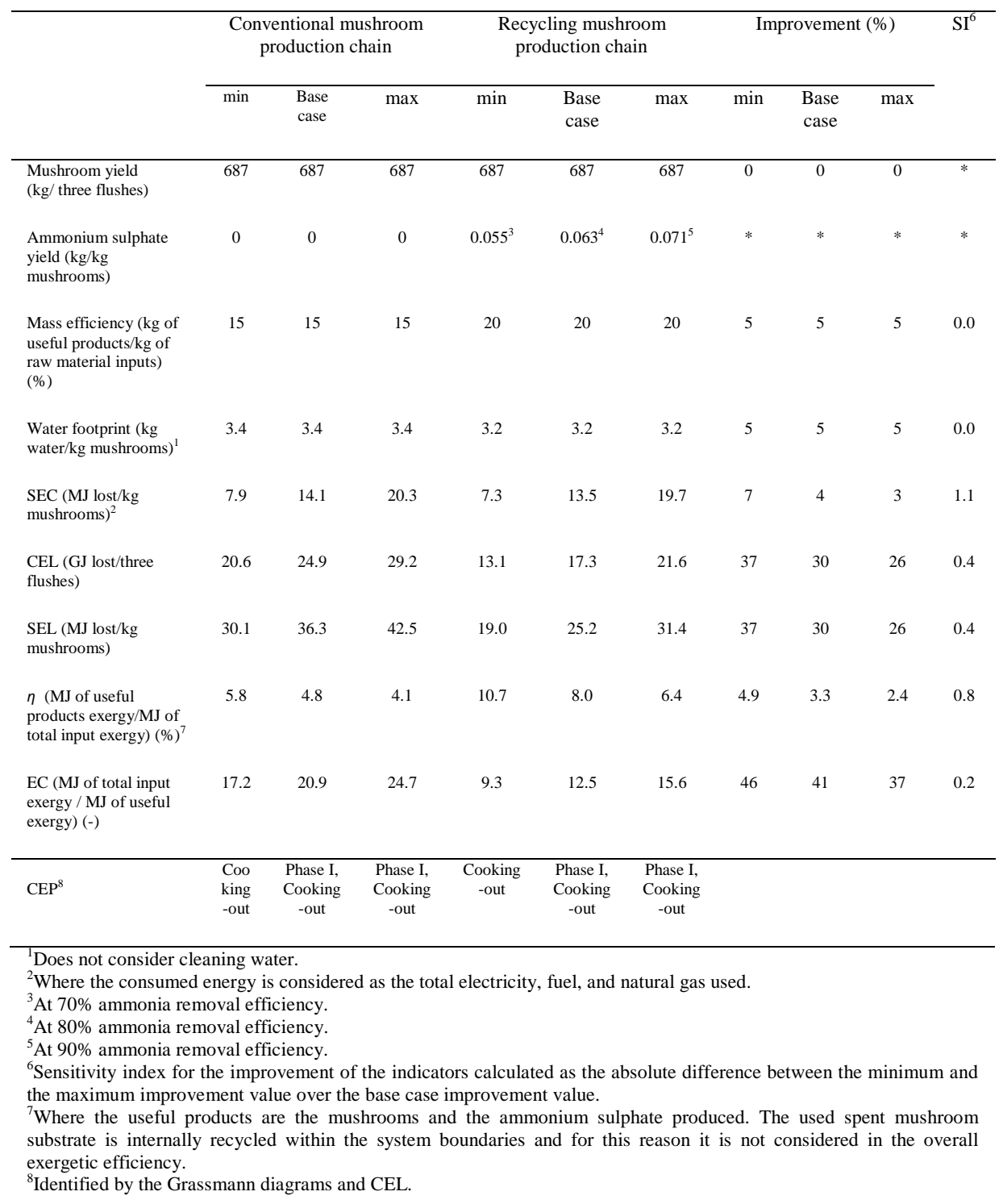




\section{Conclusion}

The paper analysed the mushroom production chain using exergy analysis. The main outcomes of the analysis are:

- The Critical Exergy loss Points (CEPs) identified for both the conventional and the recycling mushroom production chain, in all cases studied (minimum, maximum, and base case values of the process variables), are the cooking-out process of the spent mushroom substrate (chemical exergy losses), and the phase I composting process (physical exergy losses).

- Partial recycling of the spent mushroom substrate improves all indicators. The chemical exergy losses are much larger than physical exergy losses and, therefore, it makes sense to improve the mushroom production chain first by closing any material loops and only then improving the chain in terms of physical exergy. Utilizing the complete amount of spent mushroom substrate would theoretically improve the overall thermodynamic performance of the mushroom production chain considerably. However, the complete recycling of the spent mushroom substrate could not sustain the same composition in the substrate (e.g. nitrogen to carbon ratio, moisture content, etc.) that is required for the proper growth of A. bisporus. Perhaps other potential uses of the wasted spent mushroom substrate as is could be considered for an exergetic assessment e.g. for energy recovery or as a fertilizer. In those cases, the system boundaries should be extended in order to consider any additional processes and streams required.

This paper further demonstrates the effect of the variability in data on the identification of CEPs in the industrial production of compost for mushroom growing, giving the following additional conclusions:

- The variability of the values of the process variables influences the overall assessment greatly. The process variables that influence the most the 
outcome of the assessment are the electricity consumption values used at the ventilation of Phase I composting and at the ammonia scrubbing process. Those variables affect mainly the SEC, n, CEL, and SEL indicators which in turn determine the number of CEPs. When the electricity consumption for ventilation in Phase I composting attains its minimum value then the only CEP is the cooking-out process. However, when it attains its base case, or maximum value then the Phase I composting process also becomes a CEP. The value assumed for the electricity use during scrubbing also influences the indicators but to a much lesser extent. Therefore, any further improvement of the exergetic performance of the mushroom production chain should focus on the electricity consumed for ventilation in the Phase I composting process.

- The results of this case study are of broader relevance for the exergetic assessment of industrial food production chains since they show that the sensitivity to variation in process (model) parameters is essential in determining the final outcome of the analysis. Variability in data can lead to both quantitative and qualitative different outcomes i.e. obtaining different values for the selected indicators but also identifying completely different CEPs.

\section{Acknowledgements}

The authors are grateful to the Dutch Food Retail Organization (CBL) and the Federation of the Dutch Food and Grocery Industry (FNLI) for funding this research under the project "Valorization of raw materials and process efficiency" which is under TI Food and Nutrition, a public-private partnership on precompetitive research in food and nutrition. The public partners are responsible for the study design, data collection and analysis, decision to publish, and preparation of the manuscript. The private partners have contributed to the project through regular discussion. The authors would also like to thank Caroline van der Horst (C4C Holding B.V., Moerdijk, The Netherlands), Aleksander Banasik, Argyris 
Kanellopoulos, Frits G.D.H. Claassen, Jacqueline Bloemhof and Jack van der Vorst (all from Operations Research \& Logistics, Wageningen University, Wageningen, The Netherlands), Jan Broeze and Friso van Assema (both from Food \& Biobased Research, Wageningen, The Netherlands), Nicolas Hardt and Marta Rodriguez-Illera (both from Food Process Engineering, Wageningen University, Wageningen, The Netherlands) for their valuable comments.

\section{Nomenclature}

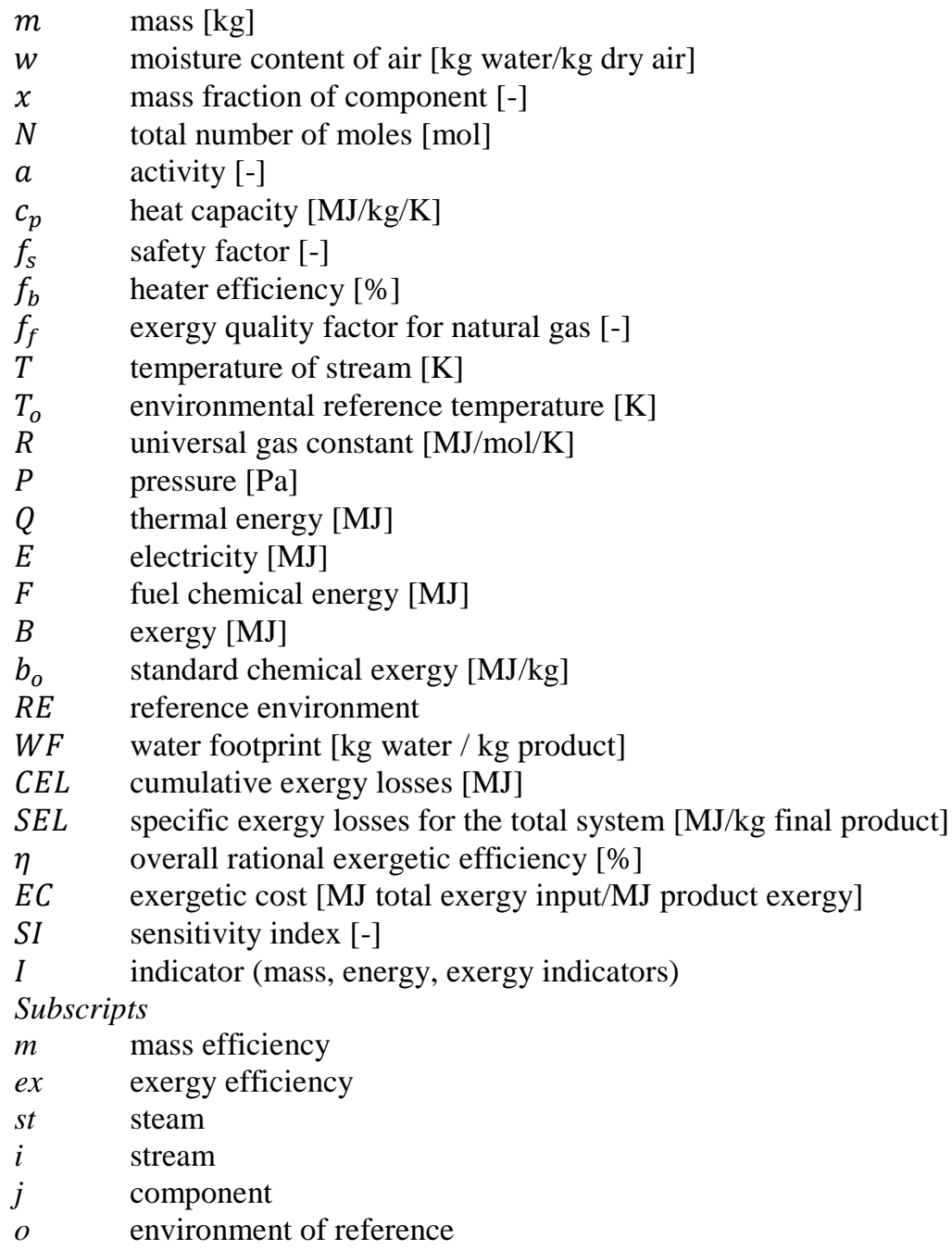




\section{Appendix A}

Table A.1. Main assumptions considered for the industrial mushroom production chain.

Value

Composting production

Initial amount of raw materials mix (tonnes)

Carbon to nitrogen ratio in the initial raw material mix

Total nitrogen in the initial raw material mix ( $\mathrm{kg} /$ tonne of straw in mix)

Density of raw materials mix $\left(\mathrm{kg} / \mathrm{m}^{3}\right)$

Water losses by evaporation in phase I (\%)

Water losses by evaporation in phase II (\%)

Ammonia produced in phase I ( $\mathrm{kg} /$ tonne of compost)

Ammonia produced in phase II ( $\mathrm{kg} /$ tonne of compost

Air ventilated in phase I $\left(\mathrm{m}^{3} / \mathrm{h}\right.$ per tonne compost)

Air ventilated in phase II $\left(\mathrm{m}^{3} / \mathrm{h}\right.$ per tonne compost

Duration of phase I $(h)$

Duration of phase II $(h)$

Vent operational time of phase $I(h)$

Vent operational time of phase II $(h)$

Latent heat of vaporization $(M J / \mathrm{kg}$ water

Latent heat of metabolic reaction (MJ/kg compost dry matter)

Spawn density (l/tonne of compost phase I)

Sulphuric acid concentration $(\% \mathrm{w} / \mathrm{v})$

Scrubber operation time $(h)$

Scrubber capacity (l of sulphuric acid solution/h)

Sulphuric acid solution to air ratio (l of sulphuric acid solution $/ \mathrm{m}^{3}$ air)

Scrubber pressure drop $(k P a)$
3.5

10.2 Estimated on the basis of the total amount of nitrogen

21

485

35

30

2.1

0.2

15

200

120

96

40

12

2.44

17.6

7

96

52

0.77

0.2

4.4

[18]

Assuming that it is operating for the required ventilation time

Assuming a proportional value to Zhao et al. [28]

[41]

$[42,43]$ 
Casing soil production

$\begin{array}{rcc}\text { Casing soil density }\left(\mathrm{kg} / \mathrm{m}^{3}\right) & 900 & \text { [17] } \\ \text { Peat density }\left(\mathrm{kg} / \mathrm{m}^{3}\right) & 570 & \text { [17] } \\ \text { Spent lime density }\left(\mathrm{kg} / \mathrm{m}^{3}\right) & 1500 & \text { [44] }\end{array}$

Mushroom production

\begin{tabular}{|c|c|c|}
\hline Natural gas calorific value $(\mathrm{MJ} / \mathrm{kg})$ & 54.5 & Assumed \\
\hline Compost : casing soil ratio & 3 & \\
\hline Approximate harvesting area $\left(\mathrm{m}^{2}\right)$ & 20 & Estimated \\
\hline Water added ( $\mathrm{kg}$ water $/ \mathrm{m}^{2}$ compost) & 24 & [18] \\
\hline Compost use ( $\mathrm{kg}$ compost $\left./ \mathrm{m}^{2}\right)$ & 90 & [18] \\
\hline Flushes (batches) produced & 3 & Assumed \\
\hline Average yield for all three flushes ( $\mathrm{kg}$ mushrooms $/ \mathrm{m}^{2}$ ) & 12 & [18] \\
\hline Average yield losses (\%) & 7 & Personal communication \\
\hline Average distance $(\mathrm{km})$ & 246 & Estimated for the Netherlands \\
\hline Average fuel consumption in trucks $\left(\mathrm{m}^{3} / \mathrm{km}\right)$ & 0.0005 & Assumed \\
\hline Average truck capacity (tonnes) & 30 & Assumed \\
\hline Diesel density $\left(\mathrm{kg} / \mathrm{m}^{3}\right)$ & 830 & {$[45]$} \\
\hline Diesel calorific value $(\mathrm{MJ} / \mathrm{kg})$ & 42.6 & [46] \\
\hline
\end{tabular}


Table A.2. Initial raw materials (compost) mix recipes for the conventional and for the recycling mushroom production chain.

\begin{tabular}{|c|c|c|}
\hline & $\begin{array}{c}\text { Conventional } \\
\text { production chain }(\%)\end{array}$ & $\begin{array}{l}\text { Recycling production } \\
\text { chain }(\%)\end{array}$ \\
\hline \multicolumn{3}{|l|}{ Initial raw materials (compost) mix } \\
\hline Wheat straw & 1.857 & 0.0 \\
\hline Horse manure & 28.571 & 0.0 \\
\hline Gypsum & 2.143 & 0.0 \\
\hline Chicken manure & 22.54 & 31.604 \\
\hline Ammonium sulphate & 2.021 & 0.0 \\
\hline Water & 42.868 & 39.455 \\
\hline Spent mushroom substrate ("champost") & $*$ & 28.941 \\
\hline \multicolumn{3}{|l|}{ Casing soil mix } \\
\hline Water & \multicolumn{2}{|c|}{19.928} \\
\hline Spent mushroom substrate ("champost") & \multicolumn{2}{|c|}{ * } \\
\hline Peat (fresh) & \multicolumn{2}{|c|}{10.767} \\
\hline Peat (frozen) & \multicolumn{2}{|c|}{43.067} \\
\hline Marl & \multicolumn{2}{|c|}{22.5} \\
\hline Lime & \multicolumn{2}{|c|}{3.738} \\
\hline
\end{tabular}


Table A.3. Composition of raw materials, intermediate streams, and final products $(\%)$.

\begin{tabular}{|c|c|c|c|c|c|c|c|c|c|c|}
\hline Ingredient & $\begin{array}{l}\text { Wheat } \\
\text { straw }\end{array}$ & $\begin{array}{l}\text { Horse } \\
\text { manure }\end{array}$ & $\begin{array}{c}\text { Chicken } \\
\text { manure }\end{array}$ & $\begin{array}{c}\text { Initial } \\
\text { raw } \\
\text { material } \\
\text { mix }^{12}\end{array}$ & $\begin{array}{l}\text { Comp. } \\
\text { phase I }^{12}\end{array}$ & $\begin{array}{c}\text { Comp. } \\
\text { phase II }\end{array}$ & $\begin{array}{l}\text { Comp. } \\
\text { phase III }\end{array}$ & Peat & Mushrooms & $\begin{array}{c}\text { Spent } \\
\text { mushroom } \\
\text { substrate }\end{array}$ \\
\hline Dry Matter & $88.250^{I}$ & $27.670^{2}$ & $25.470^{6}$ & 18.128 & 24.500 & 31.657 & 35.000 & $28.000^{7}$ & $9.300^{10}$ & $34.825^{11}$ \\
\hline Carbon & $40.206^{1}$ & $17.19^{3}$ & $9.220^{6}$ & 7.736 & 10.578 & 13.679 & 15.269 & $13.342^{9}$ & * & 12.800 \\
\hline Nitrogen & $0.636^{1}$ & $0.573^{4}$ & 1.503 & 0.758 & 0.800 & 1.014 & 1.178 & $0.616^{9}$ & * & 0.600 \\
\hline Phosphorus & 0.120 & 0.210 & 0.165 & 0.099 & 0.136 & 0.176 & 0.191 & $*$ & * & 0.156 \\
\hline Oxygen & $39.092^{1}$ & $3.480^{5}$ & $4.822^{5}$ & 3.365 & 4.601 & 5.949 & 6.568 & 13.048 & * & 7.286 \\
\hline Hydrogen & $4.620^{1}$ & $0.411^{5}$ & $0.570^{5}$ & 0.401 & 0.498 & 0.640 & 0.695 & 0.812 & * & 0.688 \\
\hline Sulphur & 0.112 & $0.010^{5}$ & $0.014^{5}$ & 0.288 & 0.392 & 0.507 & 0.551 & 0.182 & * & 0.478 \\
\hline Protein & $*$ & $*$ & $*$ & $*$ & $*$ & * & * & $*$ & $3.069^{10}$ & $*$ \\
\hline Fat & $*$ & $*$ & $*$ & * & * & * & * & * & $0.186^{10}$ & * \\
\hline Carbohydrates & * & $*$ & $*$ & * & * & * & * & * & $1.86^{10}$ & * \\
\hline
\end{tabular}

${ }^{1}$ Based on the average value of four wheat straws found in Zhang et al. [47].

${ }^{2}$ Based on Aikman [48].

${ }^{3}$ Assuming that it is 30 times the nitrogen content [49].

${ }^{4}$ Based on Moreno-Caselles et al. [50].

${ }^{5}$ Assuming that is is proportional to the composition of wheat straw.

${ }^{6} \mathrm{Based}$ on Quiroga et al. [51] where the composition was converted in total weight percentage.

${ }^{7}$ Based on Fereira Batista [17].

${ }^{8}$ Almost negligible amount when converted in total weight percentage [52].

${ }^{9}$ Based on Kulikova and Kuular [53].

${ }^{10}$ Based on Nasiri et al. [54].

${ }^{11}$ Based on Gerrits [55].

${ }^{12}$ Based on its elemental composition. 
Table A.4. Assumptions used for the calculation of chemical exergies.

\begin{tabular}{|c|c|c|}
\hline & $\begin{array}{c}\text { Specific chemical exergy } \\
(\mathrm{MJ} / \mathrm{kg})\end{array}$ & Reference \\
\hline Straw & 19.1 & Estimated $^{1}$ \\
\hline Gypsum & 0.14 & [56] \\
\hline Ammonium sulphate & 5 & [57] \\
\hline Ammonia & 19.87 & [57] \\
\hline Sulphuric acid & 1.66 & [57] \\
\hline Lime & 1.96 & [57] \\
\hline Marl & 0.18 & [56] \\
\hline Water (liquid) & 0.05 & [58] \\
\hline Water (gas) & 0.53 & [58] \\
\hline Ash & 0.048 & [59] \\
\hline Carbon & 34.18 & [60] \\
\hline Nitrogen & 0.047 & [60] \\
\hline Phosphorus & 0.028 & [58] \\
\hline Potassium & 0.009 & [61] \\
\hline Hydrogen & 116 & [60] \\
\hline Oxygen & 0.003 & [58] \\
\hline Sulphur & 0.609 & [61] \\
\hline Peat & 8.8 & [62] \\
\hline Proteins & 22 & {$[10]$} \\
\hline Fats & 43 & [10] \\
\hline Simple carbohydrates & 16 & [10] \\
\hline Fibres & 17 & {$[10]$} \\
\hline Exergy factor for diesel & 1.07 & [46] \\
\hline Exergy factor natural gas & 1.05 & [63] \\
\hline
\end{tabular}




\section{Appendix B}

Scrubber energy use

The maximum value of electricity use at the scrubbing process is calculated by considering both the electricity used for pumping the scrubbing liquid, and the electricity used for ventilation using the formulae given by Joseph et al. [27]. The pumping electricity use $\left(\mathrm{kWh} / \mathrm{m}^{3}\right)$ was calculated by assuming an inlet pressure of $101 \mathrm{kPa}$, and a liquid to air ratio of $0.2 \mathrm{~L} / \mathrm{m}^{3}$ air [41]:

$$
E_{\text {liquid }}=0.28 \cdot P_{\text {in }} \cdot \text { ratio }
$$

The electricity used for ventilation $\left(\mathrm{kWh} / \mathrm{m}^{3}\right)$ was calculated by assuming a pressure drop of $4.4 \mathrm{kPa}[42,43]$ :

$$
E_{\text {air }}=2.724 \cdot 10^{-4} \cdot \Delta P
$$

\section{Cooking out energy use}

The calculation for the natural gas used in the cooking out process is described below. The calculation considers the amount of heat required by the champost and the heat losses through the walls where a safety factor, and a certain heating efficiency are assumed. Depending on the application the safety factor can range between $10 \%$ and $35 \%$ [31]. In the base case scenario the safety factor is chosen as the average between the minimum and the maximum value while a heating efficiency of $85 \%$ is assumed. The minimum temperature for the cooking out process is set at $70{ }^{\circ} \mathrm{C}$ for $8 \mathrm{~h} \mathrm{[33],} \mathrm{while} \mathrm{the} \mathrm{maximum} \mathrm{temperature/time}$ combination has been set at $220{ }^{\circ} \mathrm{C}$ for $0.2 \mathrm{~h}$. This temperature/time combination has been used in a study where different heat treatments were evaluated to determine the total inactivation of wood decaying fungi that belong to the family of basidiomycetes, the same as A. bisporus [34].

$$
Q_{\text {natural gas }}=\left(Q_{\text {champost }}+Q_{\text {losses }}\right) f_{s}+\frac{\left(100-f_{b}\right)}{100}\left(Q_{\text {champost }}+Q_{\text {losses }}\right)
$$




$$
\begin{gathered}
Q_{\text {champost }}=m_{\text {champost }} c_{p, \text { champost }}\left(T_{\text {cookout }}-T_{\text {champost }}\right) \\
Q_{\text {losses }}=h A\left(T_{\text {cookout }}-T_{o}\right) t_{\text {cookout }}\left(m_{\text {compost }}+m_{\text {casing soil }}\right) \\
B_{\text {natural gas }}=Q_{\text {natural gas }} f_{f} \\
m_{\text {natural gas }}=\frac{B_{\text {natural gas }}}{b_{\text {o,natural gas }}}
\end{gathered}
$$

\section{References}

[1] Martindale W, Finnigan T, Needham L. Current Concepts and Applied Research in Sustainable Food Processing. Sustainable Food Processing: John Wiley \& Sons, Ltd; 2013. p. 9-38.

[2] Lee W, Okos MR. Sustainable food processing systems - Path to a zero discharge: reduction of water, waste and energy. Procedia Food Science. 2011;1(0):1768-77.

[3] Fava F, Zanaroli G, Vannini L, Guerzoni E, Bordoni A, Viaggi D, et al. New advances in the integrated management of food processing by-products in Europe: sustainable exploitation of fruit and cereal processing by-products with the production of new food products (NAMASTE EU). New Biotechnology. 2013;30(6):647-55.

[4] Turi A, Goncalves G, Mocan M. Challenges and Competitiveness Indicators for the Sustainable Development of the Supply Chain in Food Industry. Procedia Social and Behavioral Sciences. 2014;124(0):133-41.

[5] Čuček L, Klemeš JJ, Kravanja Z. A Review of Footprint analysis tools for monitoring impacts on sustainability. Journal of Cleaner Production. 2012;34(0):920. 
[6] Apaiah RK, Linnemann AR, Van Der Kooi HJ. Exergy analysis: A tool to study the sustainability of food supply chains. Food Research International. 2006;39(1):111.

[7] Colak N, Balta MT, Icier F, Kuzgunkaya E, Hepbasli A, Erbay Z. Exergy analysis of food drying processes. In: Dincer I, Hepbasli A, Midilli A, Hikmet Karakoc T, editors. Global Warming - Engineering Solutions2010

[8] Dincer I. Exergy as a potential tool for sustainable drying systems. Sustainable Cities and Society. 2011;1(2):91-6.

[9] Jankowiak L, Jonkman J, Rossier-Miranda FJ, van der Goot AJ, Boom RM. Exergy driven process synthesis for isoflavone recovery from okara. Energy. 2014;74(0):471-83.

[10] Berghout JAM, Pelgrom PJM, Schutyser MAI, Boom RM, van der Goot AJ. Sustainability assessment of oilseed fractionation processes: A case study on lupin seeds. Journal of Food Engineering. 2015;150(0):117-24.

[11] Draganovic V, Jørgensen SE, Boom R, Jonkers J, Riesen G, van der Goot AJ. Sustainability assessment of salmonid feed using energy, classical exergy and ecoexergy analysis. Ecological Indicators. 2013;34(0):277-89.

[12] Zisopoulos FK, Moejes SN, Rossier-Miranda FJ, van der Goot AJ, Boom RM. Exergetic comparison of food waste valorization in industrial bread production. Energy. 2015;82(0):640-9.

[13] Zisopoulos FK, Rossier-Miranda FJ, Van der Goot AJ, Boom RM. The use of exergetic indicators in the food industry - A review. Critical Reviews in Food Science and Nutrition. 2015.

[14] Chen Y, Chefetz B, Rosario R, van Heemst JDH, Romaine CP, Hatcher PG. Chemical Nature and Composition of Compost During Mushroom Growth. Compost Science \& Utilization. 2000;8(4):347-59. 
[15] Jarial RS, Shandilya TR, Jarial K. Casing in mushroom beds - A review. Agricultural Reviews. 2005;26(4):261-71.

[16] Nair MC, Gokulpalan C, Lalu D. Advances in mushroom biotechnology. Jodhpur, Rajastan, India: Scientific Publishers, 1994.

[17] Fereira Batista JG. Water in compost for mushroom production. Terra Cha: Universidade dos Acores, 1991.

[18] Den Ouden M. Reader Mushroom Cultivation. 's Hertogenbosch PO box 2035, 5202 CA: Mushroom Office; 2012.

[19] www.vermeer.com. Compost turner line. http://www2vermeercom/vermeer/NA/en/N/equipment/compost_turners/ct820;jsessi onid=50796D6BF1BC7EA92A43179510D42BEB2015.

[20] Assakkaf I. Equipment cost. ENCE 420 - Construction planning, equipment, and methods: Department of Civil and Environmental Engineering, University of Maryland; 2003.

[21] www.patzcorp.com. Conveyor specifications. http://patzcorpcom/wpcontent/uploads/2014/01/Patz_8912-8916-1608_Conveyor_Specspdf2015.

[22] Van Lier JJC, Van Ginkel JT, Straatsma G, Gerrits JPG, Van Griensven LJLD. Composting of mushroom substrate in a fermentation tunnel: compost parameters and a mathematical model. Wageningen Journal of Life Sciences. 1994;42(4).

[23] www.epem.gr. Tunnel composting. In: EPEM S.A. EPaM, editor. http://wwwepemgr/waste-c-control/database/html/Composting-03htm2015.

[24] www.fancom.com. Agricultural fans. http://wwwfancomcom/uk/fans/2015.

[25] www.cnc.nl. CNC Grondstoffen B.V. 2015. 
[26] Melse RW, Ogink NWM. Air scrubbing techniques for ammonia and odor reduction at livestock operations: Review of on-farm research in the Netherlands. American Society of Agricultural Engineers. 2005;48(6):2303-13.

[27] Joseph GTB, D.S. Scrubber systems operation review. APTI Course SI:412C: North Carolina State University; 1998.

[28] Zhao L, Hadlocon LJS, Manuzon R. Wet scrubbers for recovering ammonia emissions from poultry facilities for nitrogen fertilizer. Department of Food, Agricultural and Biological Engineering, Ohio State University; 2012

[29] www.brodhan.com. Hot air devices for agriculture and horticulture. http://wwwbrodhancom/Portals/1/Brochures/Brodhan\%20Heaters\%20\%20Brochure pdf: Brodhan Agriequipment; 2015.

[30] Nakayama A, Nakasaki K, Kuwahara F, Sano Y. A Lumped Parameter Heat Transfer Analysis for Composting Processes With Aeration. Journal of Heat Transfer. 2007;129(7):902-6.

[31] www.watlow.com. Application guide - Electric heaters In: Watlow, editor. https://wwwwatlowcom/reference/files/powercalculationspdf2015.

[32] Therkelsen P, Masanet E, Worrell E. Energy efficiency opportunities in the U.S. commercial baking industry. Journal of Food Engineering. 2014;130(0):14-22.

[33] Caslin B, Cirillo M, Finnan J, Forristal D, Gaffney M, McCutcheon G, et al. Energy use in agriculture. In: Authority T-AaFD, editor. Sustainable Energy Authority of Ireland2011.

[34] Carlsson F, Edman M, Holm S, Eriksson A-M, Jonsson BG. Increased heat resistance in mycelia from wood fungi prevalent in forests characterized by fire: a possible adaptation to forest fire. Fungal Biology. 2012;116(10):1025-31.

[35] Szargut J. Analysis of cumulative exergy consumption. International Journal of Energy Research. 1987;11(4):541-7. 
[36] Kotas TJ. Exergy criteria of performance for thermal plant: Second of two papers on exergy techniques in thermal plant analysis. International Journal of Heat and Fluid Flow. 1980;2(4):147-63.

[37] Sciubba E. Can an Environmental Indicator valid both at the local and global scales be derived on a thermodynamic basis? Ecological Indicators. 2013;29(0):12537.

[38] Molinari M. Exergy and parametric analysis - Methods and concepts for a sustainable built environment. Stockholm, Sweden: Kungliga Tekniska Högskolan, 2012.

[39] Finney KN, Ryu C, Sharifi VN, Swithenbank J. The reuse of spent mushroom compost and coal tailings for energy recovery: Comparison of thermal treatment technologies. Bioresource Technology. 2009;100(1):310-5.

[40] Oei PT. The alternative uses of spent mushroom compost. In: Oei P, editor. Productschap Tuinbouw. Tiel, The Netherlands 2007.

[41] www.mu-company.com. High-performance wet type exhaust gas treatment $\begin{array}{llll}\text { equipment mixing scrubber http://wwwmu- } & \text { system. }\end{array}$ companycom/ourproduct/en_brochure_mu_scrubber.pdf 2010.

[42] Straatsma G, Gerrits JPG, Thissen JTNM, Amsing JGM, Loeffen H, Van Griensven LJLD. Adjustment of the composting process for mushroom cultivation based on initial substrate composition. Bioresource Technology. 2000;72(1):67-74.

[43] Harper E, Miller F, Macauley B. Physical management and interpretation of an environmentally controlled composting ecosystem. Australian Journal of Experimental Agriculture. 1992;32(5):657-67.

[44] www.aqua-calc.com. Density calculator. 2015.

[45] Martinez I. Fuel properties. 2015. 
[46] Koroneos CJ, Nanaki EA. Energy and exergy utilization assessment of the Greek transport sector. Resources, Conservation and Recycling. 2008;52:700-6.

[47] Zhang Y, Ghaly AE, Li B. Determination of the exergy of four wheat straws. American Journal of Biochemistry and Biotechnology. 2013;9(3):338-47.

[48] Aikman CM. Manures and the principles of manuring. In: Giacomelli S, Kosker B, editors.: Cornell University; 2008.

[49] OSU. Review C:N ratios of mixes. In: Oregon State University, editor. http://extensionoregonstateedu/lincoln/sites/default/files/documents/microorgansims _involved_in_composting_0.pdf 2013

[50] Moreno-Caselles J, Moral R, Perez-Murcia M, Perez-Espinosa A, Rufete B. Nutrient value of animal manures in front of environmental hazards. Communications in Soil Science and Plant Analysis. 2002;33(15-18):3023-32.

[51] Quiroga G, Castrillón L, Fernández-Nava Y, Marañón E. Physico-chemical analysis and calorific values of poultry manure. Waste Management. 2010;30(5):880-4.

[52] Ihnat M, Fernandes L. Trace elemental characterization of composted poultry manure. Bioresource Technology. 1996;57(2):143-56.

[53] Kulikova MP, Kuular LL. Study of the chemical composition of peat. Fundamental research. 2013;4.

[54] Nasiri F, Ghiassi Tarzi B, Bassiri AR, Hoseini SE, Aminafshar M. Comparative study on the main chemical composition of button mushrooms (Agaricus bisporus) cap and stripe. Journal of food biosciences and technology. 2013;3(3):41-8.

[55] Gerrits JPG. Preparation of compost for the production of mushrooms in the Netherlands. Acta Hort (ISHS). 1985;172:252-4. 
[56] De Meester B, Dewulf J, Janssens A, Van Langenhove H. An Improved Calculation of the Exergy of Natural Resources for Exergetic Life Cycle Assessment (ELCA). Environmental Science \& Technology. 2006;40(21):6844-51.

[57] Ayres RU, Ayres LW, Martinás K. Eco-thermodynamics: exergy and life cycle analysis. In: Centre for the Management fo Environmental Resources I, editor. Fontainebleau, France1996.

[58] Szargut J, Morris DR, Steward FR. Exergy analysis of thermal, chemical, and metallurgical processes. New York: Hemisphere, 1988.

[59] Song G, Shen L, Xiao J, Chen L. Estimation of Specific Enthalpy and Exergy of Biomass and Coal Ash. Energy Sources, Part A: Recovery, Utilization, and Environmental Effects. 2013;35(9):809-16.

[60] Rivero R, Garfias M. Standard chemical exergy of elements updated. Energy. 2006;31(15):3310-26.

[61] Wall G. Exergetics. 2009.

[62] Dewulf J, Bösch ME, Meester BD, Vorst GVd, Langenhove HV, Hellweg S, et al. Cumulative Exergy Extraction from the Natural Environment (CEENE): a comprehensive Life Cycle Impact Assessment method for resource accounting. Environmental Science \& Technology. 2007;41(24):8477-83.

[63] Jørgensen SE, Nielsen SN. Sustainable energy landscapes, designing, planning, and development: CRC Press, 2013.

[64] Song G, Shen L, Xiao J. Estimating specific chemical exergy of biomass from basic analysis data. Industrial \& Engineering Chemistry Research. 2011;50:9758-66. 


\section{Chapter 5}

Thermodynamic efficiency analysis of a conceptual drying process: Towards resource use efficiency in the food industry 


\begin{abstract}
We assess the resource use efficiency of a conceptual drying process of a sprayed lactose solution by natural convection described by a conventional mass and heat transfer model. The efficiency is described in terms of environmental performance that is considered as the irreversible consumption of natural resources using the concept of exergy (available work). The results show that the more the quality of the air (i.e. dry bulb temperature and moisture content) used for drying deviates from the environment of reference, the higher its value is in terms of exergy. The use of high driving forces (i.e. air of high dry bulb temperature and low relative humidity) leads to drying processes with high exergetic efficiencies. However, the drying rate matters on the overall process performance, i.e. fast drying has a higher exergy destruction rate and lower exergy efficiencies than slow drying. If possible, outlet air of high quality should be cascaded to other processes to improve dryer resource efficiency. The most relevant exergy forms to consider in a natural convective drying process are the thermal, pressure, and chemical exergy of the air and the food product, while the effect of the kinetic, potential, and surface tension exergy is negligible. Finally, it was shown that the exergy destruction is independent of the selection of the environment of reference. The outcome of this analysis shows the usefulness of the exergy concept for assessing the real efficiency of resource use in food processes.
\end{abstract}

Keywords: Sustainability; Food industry; Exergy analysis; Irreversibility; 


\section{Introduction}

Drying is one of the most common technologies used in the food industry for extending the shelf life of food products and reducing transportation and storage expenses. It is an energy intensive process because it requires at least as much energy as the latent heat of vaporization of water. In practice, however, even more energy has to be supplied to generate the driving force for fast drying, to fuel the process due to heat losses from e.g. the exhaust airstream, the walls of the dryer, the steam generation system, and any additional equipment such as pumps and fans etc. [1].

There are different ways of drying foods such as drum drying, spray drying, microwave-assisted drying, freeze drying and solar drying. In convective drying the process is driven by thermal and chemical potential gradients between the product and the air, leading to simultaneous heat and mass transfer, which influence a number of factors such as the quality of the final product, the duration, and the total energy requirements. Air quality, i.e. the capacity of the air to generate the potential gradients, can be expressed in terms of its dry bulb temperature and its moisture content. These two parameters affect the relative humidity of the air, and therefore, its capacity to remove water. For example, air of high quality has a high dry bulb temperature and a low relative humidity, while air of low quality has a low dry bulb temperature and a high relative humidity. Fast drying, required because of the limited residence time of a food product in a dryer, needs large driving forces and thus the use of high quality air indicating the consumption of considerable amounts of resources for upgrading its quality from its ambient state.

The provision of the necessary conditions for inducing the phase change of water is costly and, needs further research in the sustainable design of drying processes [2] In this paper, sustainability is considered in terms of efficiency in the use of resources. An objective method for assessing the resource use of any process is exergy analysis because it is based on the first and second law of thermodynamics which quantifies the irreversible consumption of the natural resources. The use of exergy analysis in assessing drying systems has been reviewed [3], and it has 
already been demonstrated that the exergy efficiency of drying processes in general is lower than their energy efficiency due to the irreversibility produced, and, therefore, it provides more relevant information for their sustainable design [4-6]. Besides, food drying process and drying related technologies are amongst the most important and most frequently assessed processes in the food industry [7].

Exergy is defined as the maximum useful work that can be extracted from a system when it reaches equilibrium with a particular environment of reference [8]. For a process to run, a certain amount of exergy input has to be invested part of which has to be destroyed. Exergy is wasted with the side-streams released to the environment, and together with the exergy destruction they constitute the total exergy losses.

Within this context, a process can be considered sustainable when it does not require a lot of exergy input, and when it does not lose vast amounts of exergy. Exergy analysis therefore, helps in quantifying these losses, and in designing more sustainable drying processes.

Exergy losses in dryers occur for a number of reasons, e.g. by the destruction of high quality chemical exergy (e.g. natural gas) at the air pre-treatment process (i.e. the burner), by the destruction of electrical (pure) exergy for the operation of the fans, due to inappropriate insulation leading to thermal exergy wasted to the environment, due to the atomization process in nozzles (e.g. in spray drying), and due to uncascaded residual air quality wasted in the environment. These losses are related to technical aspects of the dryer (e.g. type of insulation material, type of fan, type of burner and fuel etc.). The necessary amount of exergy invested and destroyed for the evaporation of water from the product to the drying medium can be estimated by analysing the exergy requirements of an adiabatic process (i.e. where all exergy is utilized in the process and there are no additional heat losses to the environment). It is expected that a fast drying process which requires large driving forces (e.g. warm and dry air) is more exergy-intensive than a slow process. 
General rules for exergy-efficient process design have been proposed already in the 50s by Denbigh: "all heat transfers should take place at the least possible temperature difference" [9], while more recently Leites et al. proposed twelve "commandments" [10] amongst which are the following:

- “...the increase in the process rate often leads to an increase in energy resource consumption."

- $\quad$ "The best process is one in which energy and species enter and leave along the full length of the apparatus."

- "Select the lowest temperature heat sources."

- "The driving force of a process must approach zero at all points in a reactor, at all times."

These commandments aimed at energy saving practices in chemical processes, however, they seem to be of broader validity, and they seem to hold also for drying processes.

A key aspect in exergy analysis is the choice of the environment of reference because it is used to calculate the exergy content of streams with given properties and composition. This implies that the choice of reference environment alters the results of the analysis. This issue renders exergy a pseudo-property [11]. The aim of this paper is therefore to illustrate the impact of both the drying rate as well as the selection of the environment of reference on the thermodynamic performance of a simplified conceptual drying process of a spray-dried lactose solution. 


\section{General description of the system}

We consider a conceptual drying process of a sprayed lactose solution by natural convection. A schematic representation of the system is shown in Figure 1. The model considers only the constant drying rate period, where the heat flux is equal to the mass flux. This constant drying rate period represents the largest part of the drying taking place in a spray dryer. The main assumptions made are listed below.

- The exergy content of the inlet drying air describes the minimum amount of work spent to induce its quality.

- The pressure drop of air in the filter, the heater, the spray dryer, and the cyclones can be around $0.3,1.0,1.2$, and $0.6 \mathrm{kPa}$, respectively, while the static pressure gained by a blower can be around $3.4 \mathrm{kPa}$ [12]. Therefore, a total pressure drop of about $3 \mathrm{kPa}$ was assumed.

- The lactose solution droplets are perfect spheres of uniform size.

- Any additional exergy expenditure for droplet formation (e.g. pressurizing through the nozzles) is assumed to not be affected by the airflow provided and, therefore, it is not considered in this study.

- The wet bulb temperature of the air is described as a function of the dry bulb temperature and the relative humidity with an approximation developed by Stull [13]:

$$
\begin{gathered}
T_{\text {wet }}=T_{d r y} \cdot \operatorname{atan}\left[0.151977 \cdot(R H \%+8.313659)^{\frac{1}{2}}\right]+\operatorname{atan}\left(T_{d r y}+R H \%\right) \\
-\operatorname{atan}(R H \%-1.676331)+0.00391838(R H \%)^{\frac{3}{2}} \operatorname{atan}(0.023101 \cdot R H \%) \\
-4.686035
\end{gathered}
$$

where $T_{d r y}(\mathrm{~K})$ is the dry bulb temperature of the air. This model is constrained to a dry bulb temperature range between $-20{ }^{\circ} \mathrm{C}$ and $50{ }^{\circ} \mathrm{C}$, and 
within a relative humidity range between $5 \%$ and $99 \%$, and excluding the cases of combined low temperatures and low relative humidity.

- The temperature at the surface and in the interior of the droplets increases from a fixed initial temperature of $298 \mathrm{~K}$ to the wet bulb temperature at which it remains constant during the constant drying rate period.

- The inlet air used for drying has a fixed inlet moisture content of $8 \mathrm{~g}$ water per kg dry air in all environments of reference studied.

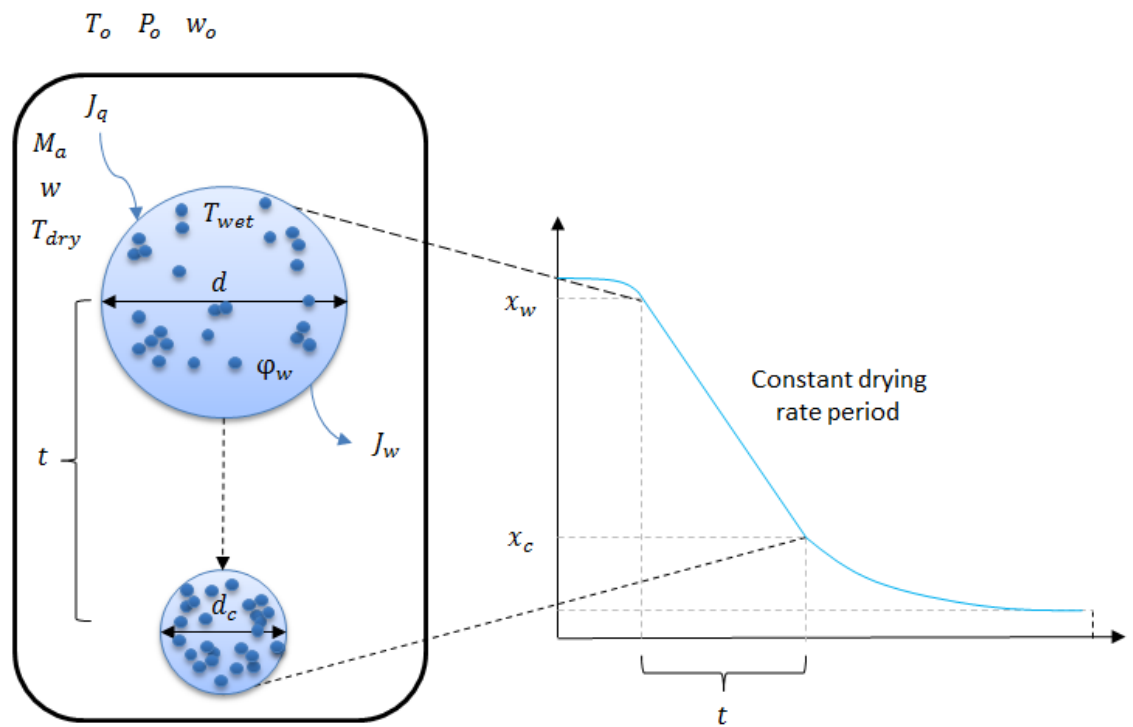

Figure 1. Conceptual drying process of a sprayed lactose solution by natural convection during the constant drying rate period. 


\section{Modelling}

The mass, energy and exergy balances are required to calculate the exergetic indicators. The dry bulb temperature of the inlet air and its moisture content determine its exergy content, i.e. its quality as a natural resource. The drying time for the constant drying rate period is considered as a constraint; all other parameters are kept constant or they are calculated as polynomial (fitted) functions of the dry or wet bulb temperature of the air (Tables A.1 and A.2 in Appendix). The total amount of water evaporated and the average evaporation rate are calculated from the mass balance. The water evaporation flux $J_{w}\left(\mathrm{~kg} / \mathrm{m}^{2} \mathrm{~s}\right)$ for a specific drying time is estimated by considering the decrease of droplet radius and integrating for the constant drying rate period. During the constant drying rate period the heat flux $J_{q}$ $\left(\mathrm{kJ} / \mathrm{m}^{2} \mathrm{~s}\right)$ equals the water evaporation flux, where the Lewis number $(L e)$ is close to unity:

$$
\begin{gathered}
J_{q}=J_{w} \\
J_{w}=k \rho_{a}\left(w_{s}-w\right) \\
J_{q}=\frac{h}{\Delta H_{e v}}\left(T-T_{w e t}\right) \\
L e=\frac{h}{k \rho_{a} c_{p a}}
\end{gathered}
$$

where $k(\mathrm{~m} / \mathrm{s})$ is the mass transfer coefficient, $\rho_{a}\left(\mathrm{~kg} / \mathrm{m}^{3}\right)$ is the density of air evaluated at the dry bulb temperature, $w$ ( $\mathrm{kg}$ water $/ \mathrm{kg}$ dry air) is the moisture content at the bulk of the air, $h\left(\mathrm{~kJ} / \mathrm{m}^{2} \mathrm{sK}\right)$ is the heat transfer coefficient, $\Delta H_{e v}$ $(\mathrm{kJ} / \mathrm{kg}$ water) is the latent heat of evaporation of water evaluated at the wet bulb temperature, $T(\mathrm{~K})$ is the dry bulb temperature at the bulk of the air, $T_{\text {wet }}(\mathrm{K})$ is the wet bulb temperature, and $c_{p a}(\mathrm{~kJ} / \mathrm{kgK})$ is the heat capacity of air evaluated at the dry bulb temperature. 
The mass and heat transfer coefficients are calculated by using the diameter of the droplets as the characteristic length:

$$
k=\frac{D_{w a} S h}{d} \quad h=\frac{\lambda_{a} N u}{d}
$$

where the thermal conductivity of air $\lambda_{a}(\mathrm{~kJ} / \mathrm{msK})$ and the diffusion coefficient of vapour in air $D_{w a}\left(\mathrm{~m}^{2} / \mathrm{s}\right)$ are expressed as functions of the dry bulb temperature [14]:

$$
D_{w a}=0.220 \cdot 10^{-4}\left(\frac{T_{d r y}}{273.15}\right)^{1.75}
$$

The following empirical and generic formulas of Reynolds $(R e)$, Prandlt $(P r)$, Schmidt $(S c)$, Nusselt $(N u)$, and Sherwood $(S h)$ dimensionless numbers are considered:

$$
\begin{gathered}
N u=2+0.644 \operatorname{Re}^{1 / 2} \operatorname{Pr}^{1 / 3} \\
S h=2+0.644 R e^{1 / 2} S c^{1 / 3} \\
\operatorname{Re}=\frac{\rho_{a} v d}{\mu_{a}} \quad \operatorname{Pr}=\frac{c_{p a} \mu_{a}}{\lambda_{a}} \quad S c=\frac{\mu_{a}}{\rho_{a} D_{w a}}
\end{gathered}
$$

The velocity of the lactose solution droplets $v(\mathrm{~m} / \mathrm{s})$ is calculated using Stokes' law:

$$
v=\frac{2 r^{2}\left[\rho_{d}-\rho_{a}\right] g}{9 \mu_{a}}
$$

where the viscosity of the air $\mu_{a}(\mathrm{~Pa} \cdot \mathrm{s})$ is evaluated at the dry bulb temperature, and $\rho_{d}\left(\mathrm{~kg} / \mathrm{m}^{3}\right)$ is the density of the lactose solution, estimated by:

$$
\varrho_{d}=\frac{\varrho_{w} \varrho_{s}}{\varrho_{w} x_{s}+\varrho_{s} x_{w}}
$$


The density of water $\varrho_{w}\left(\mathrm{~kg} / \mathrm{m}^{3}\right)$ is expressed as a function of the wet bulb temperature, and the density of the lactose solution $\varrho_{s}\left(\mathrm{~kg} / \mathrm{m}^{3}\right)$ expressed as a function of the lactose content [15]:

$$
\rho_{s}=\left(0.00001263\left(100-\varphi_{w}\right)^{2}+0.003717\left(100-\varphi_{w}\right)+0.99707\right) \cdot 10^{3}
$$

Consequently, the moisture content and the dry bulb temperature at the bulk of the air (outlet) are calculated by using the heat and mass flux equations. Additional equations used in the mass balance are shown on Table 1 . The required airflow rate is calculated from the energy balance. Additional equations used in the energy balance are shown on Table 2 .

Table 1. Equations used in the drying model.

\begin{tabular}{|c|c|c|}
\hline & Formula & Units \\
\hline Initial water content & $M_{w d}=N_{d} \frac{\varphi_{w}}{100} \rho_{w} V_{d}$ & {$[\mathrm{~kg}]$} \\
\hline Initial amount of lactose & $M_{s d}=N_{d}\left(1-\frac{\varphi_{w}}{100}\right) \rho_{s} V_{d}$ & {$[\mathrm{~kg}]$} \\
\hline Total mass of solution & $M_{d}=M_{s d}+M_{w d}$ & {$[\mathrm{~kg}]$} \\
\hline Critical water content & $M_{w d}^{c r i t}=\frac{\varphi_{c}}{100} M_{w d}$ & {$[\mathrm{~kg}]$} \\
\hline Water evaporated & $M_{e v}=M_{w d}-M_{w d}^{c r i t}$ & {$[\mathrm{~kg}]$} \\
\hline Critical droplet diameter & $d_{\text {crit }}=2\left(\frac{3}{4} \frac{V_{d}^{\text {crit }}}{\pi}\right)^{1 / 3}$ & {$[\mathrm{~m}]$} \\
\hline $\begin{array}{l}\text { Average water evaporation } \\
\text { rate }\end{array}$ & $\overline{M_{e v}}=\frac{M_{e v}}{\frac{t_{t o t a l}}{M_{e v} \Delta H_{e v}}}$ & {$\left[\mathrm{~kg} \mathrm{~s}^{-1}\right]$} \\
\hline Dry air flowrate & $M_{a}=\overline{\left[c_{p s}+w_{i n} c_{p w}\right]\left(T_{d r y}^{i n}-T_{o}\right)-\left[c_{p s}+w c_{p w}\right]\left(T_{d r y}^{o u t}-T_{o}\right)}$ & {$\left[\mathrm{kg} \mathrm{s}^{-1}\right]$} \\
\hline
\end{tabular}

Table 2. Equations used in energy analysis.

\begin{tabular}{lcc}
\hline & Formula & Units \\
\hline Specific thermal energy of air & $q_{a}=\left[c_{p s}+w c_{p w}\right]\left(T_{d r y}-T_{o}\right)$ & {$\left[\mathrm{kJ} \mathrm{kg}^{-1}\right]$} \\
Thermal energy rate or air & $Q_{a}=M_{a} q_{a}$ & {$\left[\mathrm{~kJ} \mathrm{~s}^{-1}\right]$} \\
Heat for water evaporation & $Q_{e v}=\overline{M_{e v}} \Delta H_{e v}$ & {$\left[\mathrm{~kJ} \mathrm{~s}^{-1}\right]$} \\
Specific thermal energy of lactose solution & $q_{d}=\left[x_{s} c_{p s}+x_{w} c_{p w}\right]\left(T_{w e t}-T_{o}\right)$ & {$\left[\mathrm{kJ} \mathrm{kg}^{-1}\right]$} \\
Thermal energy of lactose solution & $Q_{d}=M_{d} q_{d}$ & {$[\mathrm{~kJ}]$} \\
\hline
\end{tabular}


The forms of exergy considered relevant in this study are shown in Table 3 and are calculated for the air and the lactose solution before and after the drying process. The thermal exergy of the air is evaluated at its dry bulb temperature, while the thermal exergy of the lactose solution is evaluated at the wet bulb temperature. The exergy transfer rate required to induce the phase change of water is considered as the product of the average evaporation rate with the latent heat of evaporation of water. Sometimes, this product is also multiplied with the Carnot efficiency to attribute a thermal quality aspect for phase change. In this way, however, the calculated work required is much less than what is necessary to evaporate the water, and therefore, the Carnot factor is not considered in this term. The pressure exergy of air is calculated by multiplying the volumetric airflow rate with its pressure difference with the environment of reference. The chemical exergy of the air is calculated by subtracting the exergy of mixing of the drying air from the exergy of mixing of the air at the conditions (i.e. moisture content) of the environment of reference.

The exergy of mixing of the air accounts for the degree of mixing of its moisture with the dry air. The chemical exergy of the lactose solution is calculated based on the molar fractions of water and lactose present before and after drying, on their respective standard chemical exergies, and on the mixing exergy of lactose with water. The standard chemical exergy values of liquid water, of water vapour, and of lactose are shown in Table A.1. The kinetic, potential and surface tension forms of exergy are calculated by considering that their energy is fully convertible into work.

Apart from the exergy input rate $(\mathrm{kJ} / \mathrm{s})$, and the exergy destruction rate $(\mathrm{kJ} / \mathrm{s})$, the exergetic indicators considered in this study are the specific exergy input use (kJ exergy of inlet air per $\mathrm{kg}$ vapour), the specific exergy destruction (kJ exergy destroyed per kg vapour), and the exergetic efficiency expressed in two ways (Table 4). The first efficiency (universal) considers only the exergy destruction, i.e. the total output of the process is useful (i.e. both the air, and the concentrated lactose solution) and therefore, this efficiency indicates the maximum relative gain in exergy (in different environments of reference) when all output streams are cascaded. The second exergy efficiency accounts both for the exergy destruction as 
well as for the wastage of the process (i.e. total exergy loss). The physical meaning of the other exergetic indicators has been described in literature [7]. An illustrative example of exergy flows entering and leaving a process is shown in Figure 2.

The impact of the environment of reference on the thermodynamic analysis is assessed by selecting different intensive properties (i.e. ambient temperature, and moisture content) that describe it (Figure 3).

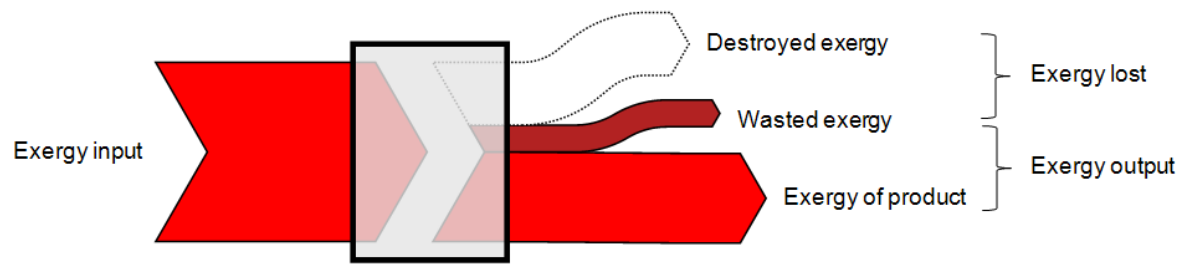

Figure 2. Grassmann diagram of exergy flows over a conceptual process.

\begin{tabular}{|c|c|c|c|}
\hline $\begin{array}{l}\text { Warm } \\
308 \mathrm{~K}\end{array}$ & $1.75 \mathrm{~g} \mathrm{w} / \mathrm{kg} \mathrm{da}$ & $14.4 \mathrm{~g} \mathrm{w} / \mathrm{kg} \mathrm{da}$ & $32.3 \mathrm{~g} \mathrm{w} / \mathrm{kg} \mathrm{da}$ \\
\hline $298 \mathrm{~K}$ & $1 \mathrm{~g} \mathrm{w} / \mathrm{kg} \mathrm{da}$ & $8 \mathrm{~g} \mathrm{w} / \mathrm{kg} \mathrm{da}$ & $17.8 \mathrm{~g} \mathrm{w} / \mathrm{kg} \mathrm{da}$ \\
\hline $\begin{array}{l}\text { Cold } \\
280 \mathrm{~K}\end{array}$ & $0.31 \mathrm{~g} \mathrm{w} / \mathrm{kg} \mathrm{da}$ & $2.5 \mathrm{~g} \mathrm{w} / \mathrm{kg} \mathrm{da}$ & $5.48 \mathrm{~g} \mathrm{w} / \mathrm{kg} \mathrm{da}$ \\
\hline & $\begin{array}{l}5 \% \\
\text { Dry }\end{array}$ & $41 \%$ & $\begin{array}{l}90 \% \\
\text { Moist }\end{array}$ \\
\hline
\end{tabular}

Figure 3. Intensive properties of the environment of reference (absolute moisture content in $g$ water per kg dry air, dry bulb temperature, and relative humidity) that are used to describe climates ranging from dry to moist and from cold to warm. 
Table 3. Equations used in calculating the exergy of air and lactose solution streams.

\begin{tabular}{|c|c|c|}
\hline & Formula & Units \\
\hline Specific thermal exergy of air & $b_{t h, a}=\left[c_{p a}+w c_{p v}\right]\left[T_{d r y}-T_{o}-T_{o} \ln \left(\frac{T_{d r y}}{T_{o}}\right)\right]$ & {$\left[\mathrm{kJ} \mathrm{kg}^{-1}\right]$} \\
\hline Thermal exergy rate of air & $B_{t h, a}=M_{a} b_{t h, a}$ & {$\left[\mathrm{~kJ} \mathrm{~s}^{-1}\right]$} \\
\hline Exergy for phase change & $B_{e v}=\overline{M_{e v}} \Delta H_{e v}$ & {$\left[\mathrm{~kJ} \mathrm{~s}^{-1}\right]$} \\
\hline Pressure exergy rate of air & $B_{p r, a}=\frac{\frac{M_{a}}{\varrho_{a}}\left|P-P_{o}\right|}{1000}$ & {$\left[\mathrm{~kJ} \mathrm{~s}^{-1}\right]$} \\
\hline Specific mixing exergy of air & $\begin{aligned} b_{m i x, w}=T_{o} R\left[\frac{w}{M W_{w}} \ln (\right. & \left.\frac{w M W_{a}}{w M W_{a}+M W_{w}}\right) \\
& \left.+\frac{1}{M W_{a}} \ln \left(\frac{M W_{w}}{w M W_{a}+M W_{w}}\right)\right]\end{aligned}$ & {$[\mathrm{kJ} \mathrm{kg} \mathrm{dry} \mathrm{air}$} \\
\hline Specific chemical exergy of air & $b_{c h, a}=\left|b_{\text {mix }}\left(w_{a}\right)-b_{\text {mix }}\left(w_{o}\right)\right|+\left|w_{a}-w_{o}\right| b_{o, s t}$ & {$[\mathrm{~kJ} \mathrm{~kg}$ dry air } \\
\hline Chemical exergy rate of air & $B_{c h, a}=M_{a} b_{c h, a}$ & {$\left[\mathrm{~kJ} \mathrm{~s}^{-1}\right]$} \\
\hline $\begin{array}{r}\text { Specific thermal exergy of lactose } \\
\text { solution }\end{array}$ & $b_{t h, d}=\left[x_{s} c_{p s}+x_{w} c_{p w}\right]\left[T_{w e t}-T_{o}-T_{o} \ln \left(\frac{T_{w e t}}{T_{o}}\right)\right]$ & {$\left[\mathrm{kJ} \mathrm{kg}^{-1}\right]$} \\
\hline Thermal exergy of lactose solution & $B_{t h, d}=\frac{M_{d} b_{t h, d}}{t}$ & {$\left[\mathrm{~kJ} \mathrm{~s}^{-1}\right]$} \\
\hline $\begin{array}{r}\text { Specific chemical exergy of lactose } \\
\text { solution }\end{array}$ & $b_{c h, d}=\chi_{w} \frac{b_{o, w}}{M W_{w}}+\chi_{s} \frac{b_{o, s}}{M W_{s}}$ & {$\left[\mathrm{~kJ} \mathrm{~mol}{ }^{-1}\right]$} \\
\hline Mixing exergy of lactose solution & $B_{m i x, d}=n_{\text {total }} R T_{o} \sum \chi_{i} \ln \left(\chi_{i}\right)$ & {$[\mathrm{kJ}]$} \\
\hline Chemical exergy of lactose solution & $B_{c h, d}=\frac{M_{d} b_{c h, d}+B_{m i x, d}}{t}$ & {$\left[\mathrm{~kJ} \mathrm{~s}^{-1}\right]$} \\
\hline $\begin{array}{r}\text { Surface tension exergy of lactose } \\
\text { solution }\end{array}$ & $B_{\gamma}=\frac{V_{d} N_{d} \Delta P_{d}}{1000 t}$ & {$\left[\mathrm{~kJ} \mathrm{~s}^{-1}\right]$} \\
\hline Potential exergy rate ${ }^{a}$ & $B_{p}=\frac{M g L_{\text {dryer }}}{1000 t}$ & {$\left[\mathrm{~kJ} \mathrm{~s}^{-1}\right]$} \\
\hline Kinetic exergy rate & $B_{k}=\frac{\frac{1}{2} M v^{2}}{1000 t}$ & {$\left[\mathrm{~kJ} \mathrm{~s}^{-1}\right]$} \\
\hline \multicolumn{3}{|l|}{ Exergy balance equations } \\
\hline Exergy input rate of lactose solution & $\sum B_{d}^{i n}=B_{c h, d}^{i n}+B_{t h, d}^{i n}+B_{\gamma, d}^{i n}+B_{k, d}^{i n}+B_{p, d}^{i n}$ & {$\left[\mathrm{~kJ} \mathrm{~s}^{-1}\right]$} \\
\hline Exergy input rate of air & $\sum \overline{B_{a}^{i n}}=B_{c h, a}^{i n}+B_{t h, a}^{i n}+B_{e v}+B_{p r, a}^{i n}+B_{k, a}^{i n}+B_{p, a}^{i n}$ & {$\left[\mathrm{~kJ} \mathrm{~s}^{-1}\right]$} \\
\hline Total exergy input rate & $\sum B_{\text {total }}^{i n}=\sum B_{d}^{i n}+\sum B_{a}^{i n}$ & {$\left[\mathrm{~kJ} \mathrm{~s}^{-1}\right]$} \\
\hline Exergy output rate of lactose solution & $\sum_{d}^{\text {out }}=B_{c h, d}^{\text {out }}+B_{t h, d}^{\text {out }}+B_{\gamma, d}^{\text {out }}+B_{k, d}^{\text {out }}+B_{p, d}^{\text {out }}$ & {$\left[\mathrm{kJ} \mathrm{s}^{-1}\right]$} \\
\hline Exergy output rate of air & $\begin{aligned} \sum B_{a}^{\text {out }}=B_{c h, a}^{\text {out }}+B_{\text {th,a }}^{\text {out }} & +B_{p r, a}^{\text {out }}+B_{k, a}^{\text {out }}+B_{p, a}^{\text {out }} \\
& =\left(B_{\text {wasted }}\right)\end{aligned}$ & {$\left[\mathrm{kJ} \mathrm{s}^{-1}\right]$} \\
\hline Total exergy output rate & $\sum B_{\text {total }}^{\text {out }}=\sum B_{d}^{\text {out }}+\sum_{D} B_{a}^{\text {out }}$ & {$\left[\mathrm{kJ} \mathrm{s}^{-1}\right]$} \\
\hline Exergy destruction rate & $B_{\text {destroyed }}=\sum B_{\text {total }}^{\text {in }}-\sum B_{\text {total }}^{\text {out }}$ & {$\left[\mathrm{kJ} \mathrm{s}^{-1}\right]$} \\
\hline Exergy loss rate & $B_{\text {lost }}=B_{\text {destroyed }}+B_{\text {wasted }}$ & {$\left[\mathrm{kJ} \mathrm{s}^{-1}\right]$} \\
\hline
\end{tabular}

${ }^{a}$ The length of the dryer is calculated by the product of droplet velocity with the fixed drying time. 
Table 4. Exergetic indicators.

\begin{tabular}{|c|c|c|c|}
\hline & Formula & Units & Comment \\
\hline Specific exergy input & $S E I_{v}=\frac{B_{a}^{i n}}{\overline{M_{e v}}}$ & {$\left[\mathrm{~kJ} \mathrm{~kg}^{-1}\right.$ vapour $]$} & $\begin{array}{l}\text { Resource quality required } \\
\text { per kg water removed }\end{array}$ \\
\hline $\begin{array}{l}\text { Specific exergy } \\
\text { destroyed }\end{array}$ & $S E D_{v}=\frac{B_{\text {destroyed }}}{\overline{M_{e v}}}$ & [kJ kg ${ }^{-1}$ vapour $]$ & $\begin{array}{l}\text { Irreversibly lost work } \\
\text { per kg water removed }\end{array}$ \\
\hline $\begin{array}{l}\text { Exergy efficiency } \\
\text { (universal) }\end{array}$ & $\eta_{I I, 1}=1-\frac{B_{\text {destroyed }}}{\sum B_{\text {in }}}=\frac{\sum B_{\text {total }}^{\text {out }}}{\sum B_{\text {in }}}$ & {$[\%]$} & $\begin{array}{l}\text { Considering only the exergy } \\
\text { destruction }\end{array}$ \\
\hline Exergy efficiency & $\eta_{I I, 2}=1-\frac{B_{\text {lost }}}{\sum B_{\text {in }}}=\frac{\sum B_{d}^{\text {out }}}{\sum B_{\text {in }}}$ & [\%] & $\begin{array}{l}\text { Considering both exergy } \\
\text { destruction and exergy } \\
\text { wastage }\end{array}$ \\
\hline
\end{tabular}




\section{Results and discussion}

\section{Results}

Short drying times require high evaporation rates which, as expected, lead to high dry air flow requirements (Figure 4). Given that the inlet air has a fixed moisture content at $8 \mathrm{~g}$ water per kg dry air, a high inlet air dry bulb temperature increases its capacity to remove water (i.e. low relative humidity) explaining, therefore, a faster drying process. It has to be noted that the drying model is restricted by the model of Stull [13] for calculating the relative humidity and wet bulb temperature, and which can be considered valid within the dry bulb temperature range tested in this study (Appendix B).

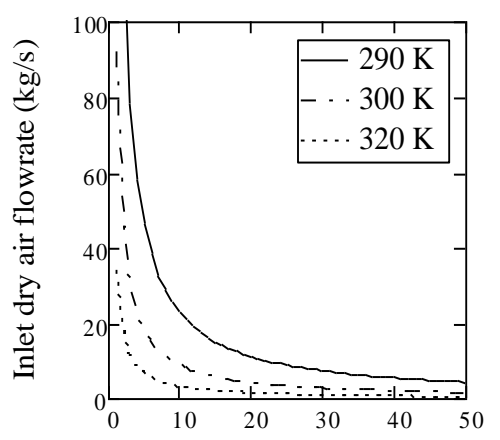

Dry ing time (s)

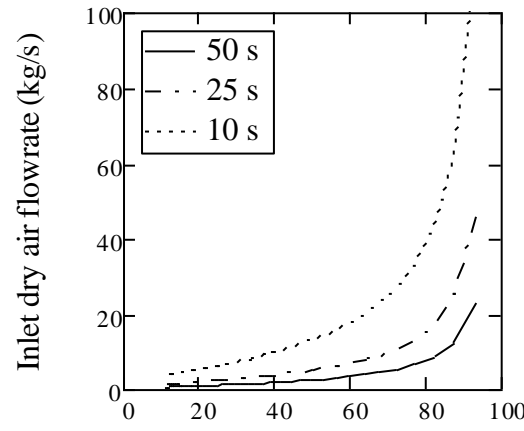

Relative humidity (\%)

Figure 4. Left: Dry air flowrate as a function of drying time and dry bulb temperature, and right: relative humidity.

Figure 5 shows that a higher the dry bulb temperature lowers the input air exergy rate (i.e. thermal, chemical, pressure, kinetic, and potential exergy) due to the lower amount of airflow required. The kinetic, potential, and surface tension forms of exergy are small and can therefore be neglected in the analysis. In general, fast drying requires a higher exergy input rate than slow drying. It is noted that the inlet air exergy is only a very small fraction (ranging from $0.1 \%$ to $5 \%$ depending on the dry bulb temperature, the drying time, and the environment of reference) of the total 
inlet exergy because it is dwarfed by the large amount of chemical exergy of the lactose solution (not shown).

The exergy content of inlet air is affected by the selection of the environment of reference to a small degree. The lowest exergy investment required is calculated for a temperate environment of reference (i.e. $298 \mathrm{~K}$ and $41 \%$ relative humidity) when compared to the exergy inputs required in colder, warmer, dryer or moister environments of reference. This is because at this environment of reference the inlet air used for drying has the same moisture content ( $8 \mathrm{~g}$ water/kg dry air) as the air of the environment of reference, and therefore, which means that its exergy is mainly determined by the latent heat of evaporation (its chemical exergy is zero). 

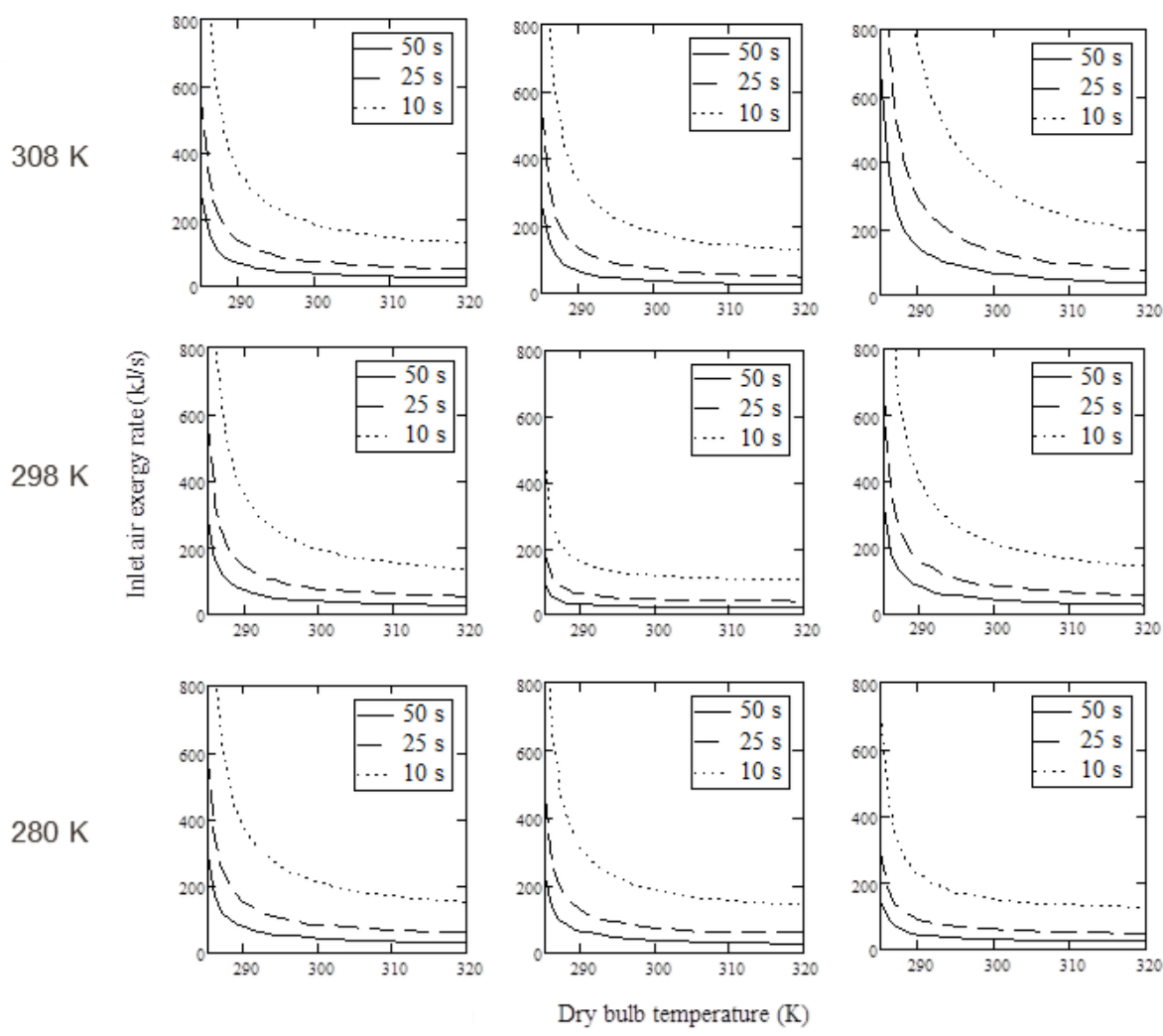

$5 \%$

$41 \%$

$90 \%$

Figure 5. Inlet air exergy rate (chemical, thermal, pressure, kinetic, and potential exergy) as a function of its dry bulb temperature, assessed at different drying times, and at nine different environments of reference ranging from cold $(280 \mathrm{~K})$ to warm (308 K) and dry (5\% relative humidity) to very moist (90\% relative humidity). Details for the environment of reference intensive properties are shown in Figure 3. 
Figure 6 shows that faster drying leads to a higher exergy destruction rate compared to slow drying. At first sight, the exergy destruction rate seems much higher than the exergy input rate. This is misleading, because the exergy destruction rate accounts also for the chemical exergy change of the lactose solution. As the lactose solution gets concentrated, its standard chemical exergy increases. However, the mass of the total lactose solution at the critical moisture content is less than before drying, leading to a considerable reduction in output chemical exergy, which effect is reflected in the exergy destruction rate. The exergy destruction rate for a fast drying process shows a mild decreasing profile as the dry bulb temperature increases, due to the more efficient use of the available work at high temperatures (related to the Carnot efficiency). Slower drying shows an almost constant exergy destruction rate.

One should bear in mind that our analysis only includes the constant rate period, and therefore it is still possible to dry with air of $298 \mathrm{~K}$ and $90 \%$ relative humidity, albeit using prodigious amounts of air; evident in the large numbers for the exergy destruction. Of course, for the falling rate period, this air would not be suitable anymore. In addition, the velocity difference between droplet and air was freely adapted to find the required mass and heat transfer for a specific drying time. In reality, this velocity is much more limited and may even be dictated by the free falling velocity of a small droplet. In that case, air with low temperature and higher relative humidity cannot be used to dry in a given, short time.

The selection of the environment of reference does not affect the profile of exergy destruction rate. When the share of exergy destruction by changes in chemical exergy is excluded, then thermal effects dominate ( $90 \%)$ on exergy destruction over pressure effects for high dry bulb temperatures (low relative humidity), while they are much smaller ( $20 \%)$ at low dry bulb temperatures (high relative humidity) due to the larger amounts of air pushed through the dryer (Appendix C). 
$308 \mathrm{~K}$
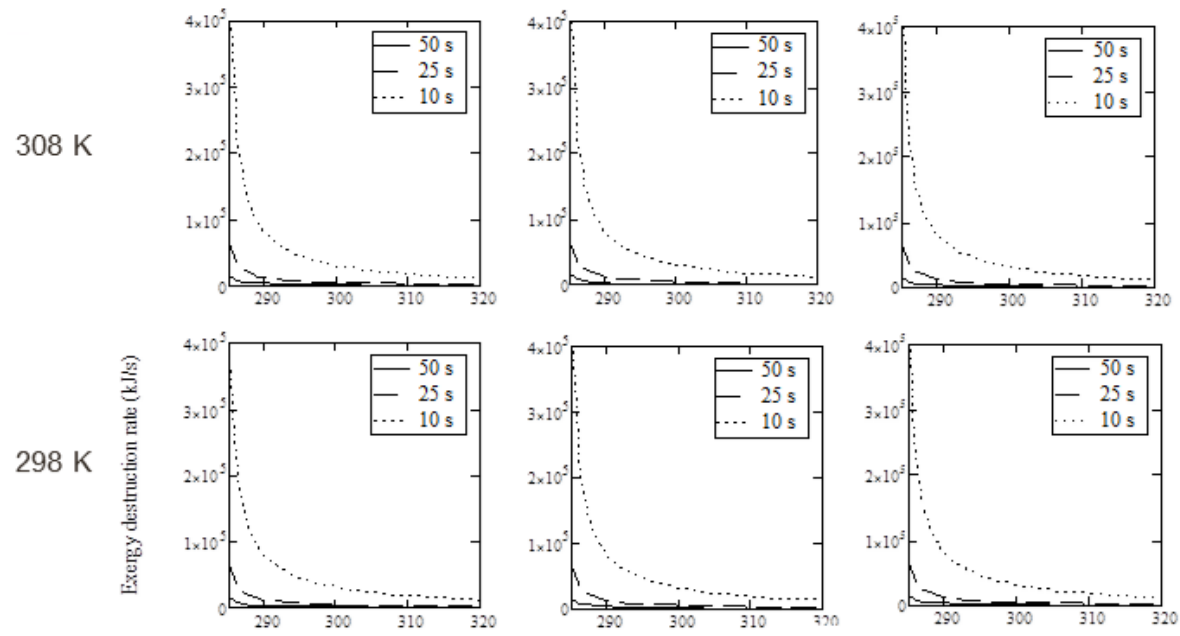

$280 \mathrm{~K}$
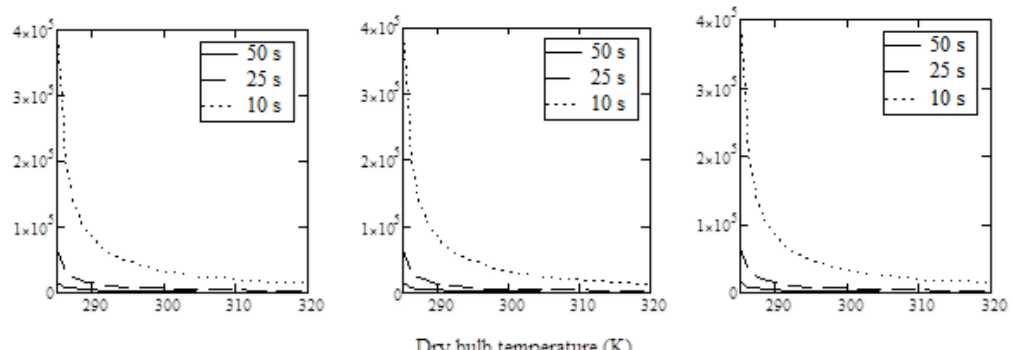

$5 \%$

$41 \%$

$90 \%$

Figure 6. Exergy destruction rate as a function of the dry bulb temperature, assessed at different drying times, and at nine different environments of reference ranging from cold $(280 \mathrm{~K})$ to warm $(308 \mathrm{~K})$ and dry (5\% relative humidity) to very moist (90\% relative humidity). Details for the environment of reference intensive properties are shown in Figure 3. 
The exergy invested per unit mass of water evaporated $\left(S E I_{v}\right)$ shown in Figure 7 is independent of the drying time. Please note that in these figures, the independent parameter is the relative humidity of the drying air: a low relative humidity refers to a high air dry bulb temperature, and a high relative humidity to a low temperature. Thus, the dry bulb temperature decreases from left to right. It can be seen that the use of high dry bulb temperatures (i.e. low relative humidity) lead to a lower exergy requirement per $\mathrm{kg}$ of water evaporated than the use of low dry bulb temperatures (i.e. high relative humidity) because less air is required to complete the drying process.

The profile with the lowest specific exergy investment required per unit mass of resource used is at a temperate environment of reference (i.e. $298 \mathrm{~K}$ and $41 \%$ relative humidity), while a steeper profile with higher values is obtained at a warm and moist environment of reference. The reason for these higher values at the warm and moist environment of reference is due to the difference of the absolute moisture content of the inlet air ( $8 \mathrm{~g}$ of water / $\mathrm{kg}$ dry air) with the moisture content of that particular environment of reference $(32.3 \mathrm{~g}$ of water / $\mathrm{kg}$ dry air). In that environment of reference the inlet air is considered as dry, and therefore, has a high exergy value independently of its temperature. 

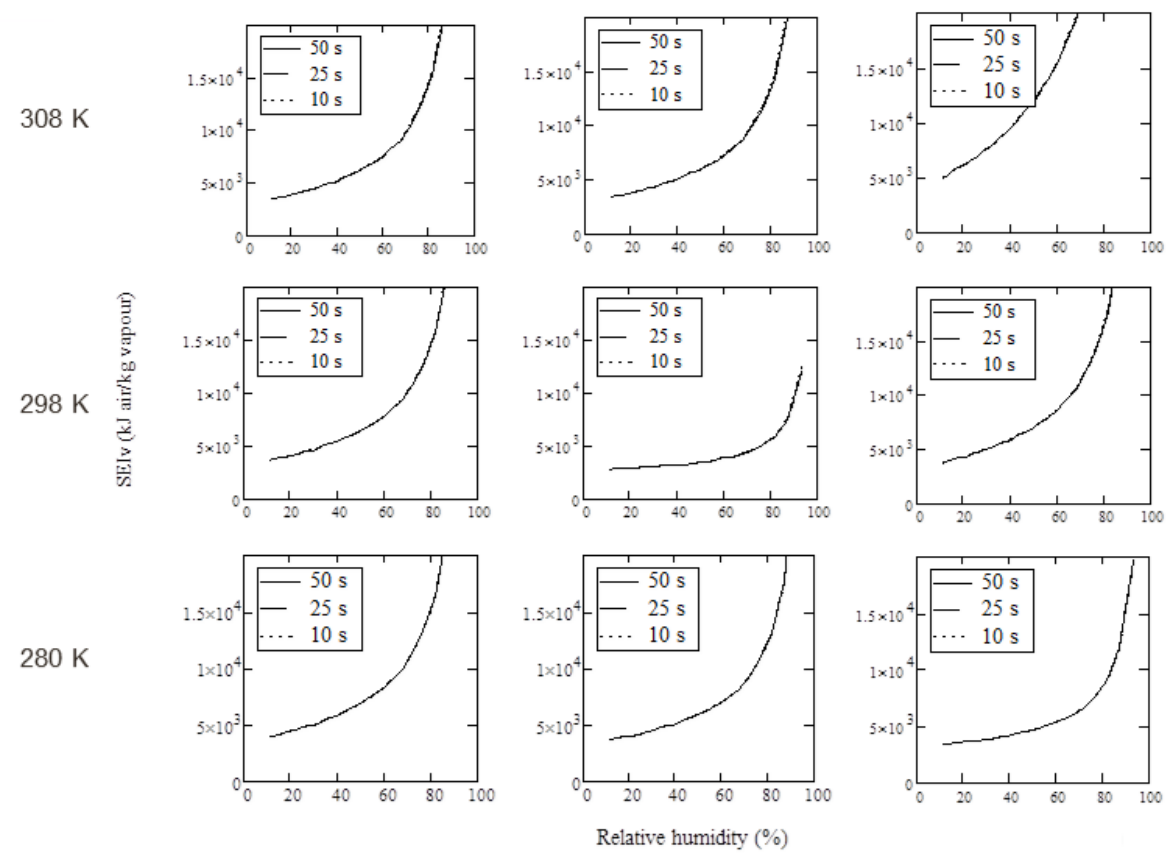

$5 \%$

$41 \%$

$90 \%$

Figure 7. Specific exergy of inlet air invested per $\mathrm{kg}$ of water evaporated as a function of its dry bulb temperature, assessed at different drying times, and at nine different environments of reference ranging from cold $(280 \mathrm{~K})$ to warm $(308 \mathrm{~K})$ and dry (5\% relative humidity) to very moist ( $90 \%$ relative humidity). Details for the environment of reference intensive properties are shown in Figure 3. 
The exergy destroyed per unit mass of water evaporated $\left(S E D_{v}\right)$ is shown in Figure 8. The specific exergy destruction for fast drying is higher compared to slow drying, and its profile shows a decreasing trend as the relative humidity decreases (i.e. the dry bulb temperature increases) due to the more efficient use of available work at high temperatures (related to the Carnot efficiency). Moreover, the selection of the environment of reference does not affect the profile of specific exergy destruction.

$308 \mathrm{~K}$
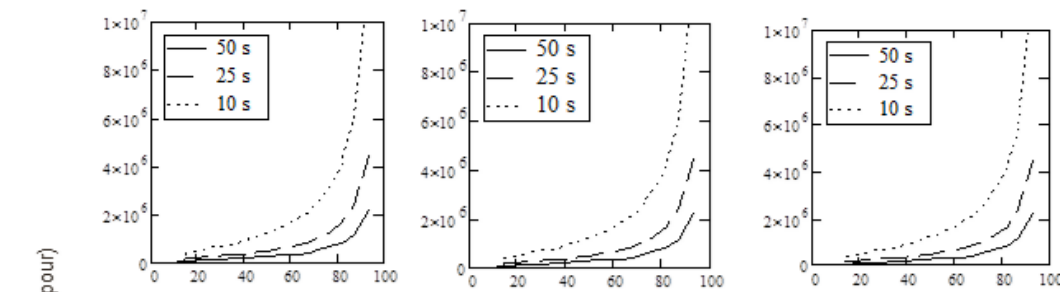

$298 \mathrm{~K}$
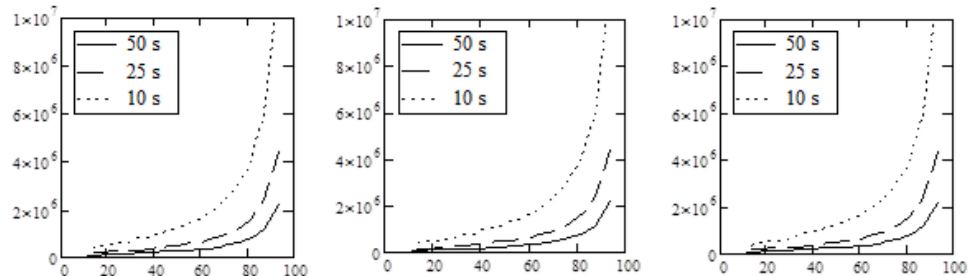

$280 \mathrm{~K}$
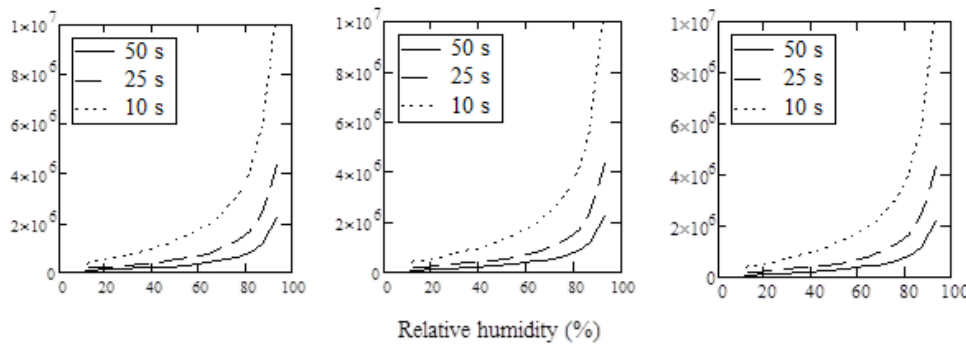

$5 \%$

$41 \%$

$90 \%$

Figure 8. Specific exergy destroyed per $\mathrm{kg}$ of water evaporated as a function of the dry bulb temperature of inlet air, assessed at different drying times, and at nine different environments of reference ranging from cold $(280 \mathrm{~K})$ to warm $(308 \mathrm{~K})$ and dry (5\% relative humidity) to very moist ( $90 \%$ relative humidity). Details for the environment of reference intensive properties are shown in Figure 3. 
The exergy efficiencies $n_{I I, I}$ (universal) and $n_{I I, 2}$ of the drying process are shown in Figure 9. The universal exergy efficiency profile is affected by the inlet air dry bulb temperature, the drying time, and the selection of the environment of reference. This efficiency is higher than the $n_{I I, 2}$ efficiency with all environments of reference studied. The reason is that it accounts also for the exergy content of the air leaving the process, therefore, showing the potential gain in resource efficiency if this air would be considered as useful. The maximum $n_{I I, 1}$ efficiency is around $10 \%$ and is obtained when air of low relative humidity (i.e. high dry bulb temperature) is used for drying, while the lowest efficiency can be as low as almost $1 \%$ when very moist air is used for drying due to psychrometric reasons that affect its capacity to absorb water. At an environment of reference that is warm $(308 \mathrm{~K})$ and moist $(90 \%$ relative humidity), the outlet air leaving the process still has much lower moisture content than the environment of reference and therefore has high exergy content, which makes it valuable for cascading it to another process. It is also interesting to note that, in general, slow drying is much more efficient exergy-wise than fast drying in all of the nine environments of reference. In most of the environments of reference, the $n_{I I, I}$ efficiency follows a similar profile. A minimum of $n_{I I, I}$ is observed when the process is assessed at environments of reference that are warm $(308 \mathrm{~K})$ and with moderate $(41 \%)$ and high $(90 \%)$ relative humidity. The minimum occurs at a relative humidity of inlet air which corresponds to a dry bulb temperature that equals the temperature of the environment of reference (i.e. the thermal exergy content is zero).

The highest value of the exergy efficiency $n_{I I, 2}$ is around $3.5 \%$ which is obtained when air of low relative humidity (i.e. high dry bulb temperature) is used, and, in general, it is higher for slow drying rates than for fast drying rates. The use of very moist air leads to a very low $n_{I I, 2}$ exergy efficiency which is explained by its lack of capacity to provide useful work for drying. The profile for this efficiency seems to be almost identical for all nine environments of reference. 
$308 \mathrm{~K}$
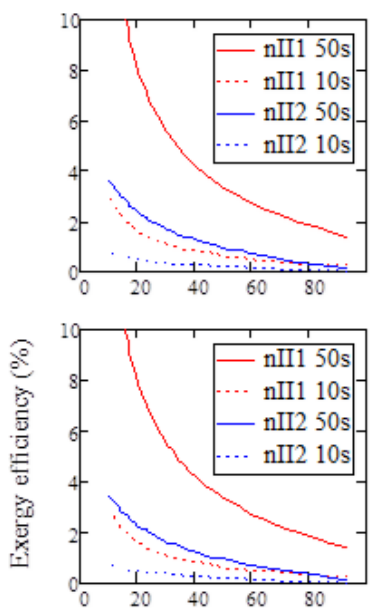

$280 \mathrm{~K}$

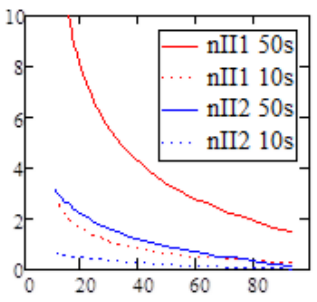

$5 \%$
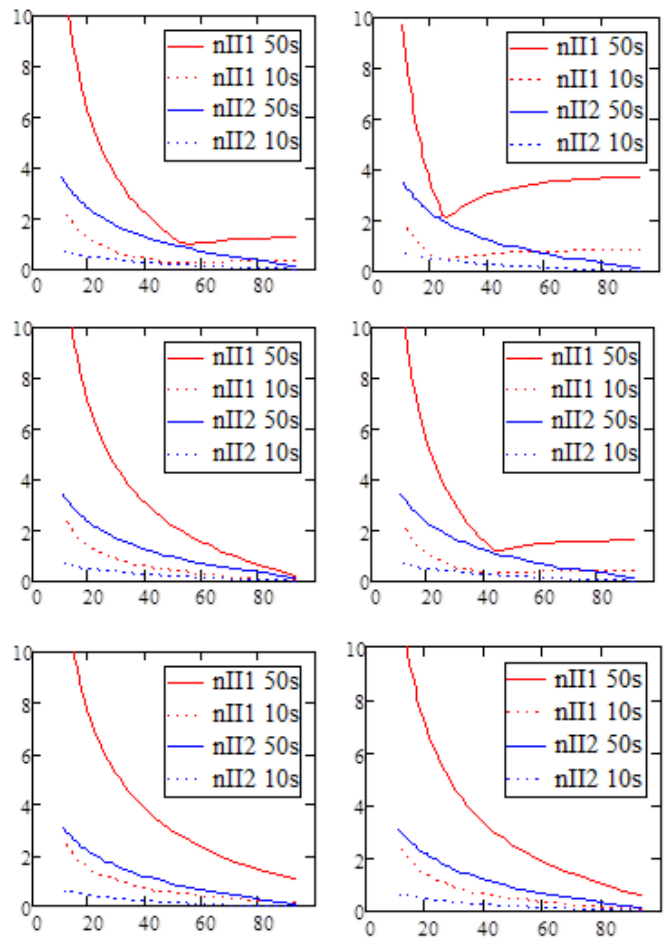

Relative humidity (\%)

$41 \%$

$90 \%$

Figure 9. Universal exergy efficiency $\left(n_{I I, 1}\right)$ and exergy efficiency $\left(n_{I I, 2}\right)$ as functions of the dry bulb temperature of inlet air, assessed for ten and fifty seconds of drying time, and at nine different environments of reference ranging from cold $(280 \mathrm{~K})$ to warm $(308 \mathrm{~K})$ and dry (5\% relative humidity) to very moist (90\% relative humidity). Details for the environment of reference intensive properties are shown in Figure 3. 


\section{Discussion}

The results of this case study are in line with some of the commandments proposed by Leites et al. [10]. For example, it was shown that an increased drying rate led to an increase in the specific exergy input requirement and exergy destruction per unit mass water removed. Additionally, the most exergy-efficient drying process was the one in which exergy entered and exited "along the full length" of the dryer (i.e. was utilized, and further cascaded). However, it was also shown that the heat transfer that took place at the highest (and not lowest) temperature difference (i.e. non-zero driving force) between the air and the lactose solution led to the most exergyefficient drying process. Perhaps the reason could be attributed to the coupling effect between heat and mass transfer affecting the capacity of air to remove water: a small change in one driving force can have a large impact on the effect of other driving forces, therefore affecting the overall exergy-efficiency of a process.

The main findings of this analysis are summarized in the following points in the form of general rules that can be used as guidelines for designing efficient drying processes from an exergy point of view:

- A slow process reduces the dissipation of resource quality. The reason is that fast drying destroys more exergy than slow drying, i.e. it is less exergyefficient. Obviously, practical limitations hinder the application of this rule in existing dryer designs, indicating that future research should focus on dryer designs that would allow for the longest possible drying times.

- When fast drying is unavoidable, one should use a limited amount of hot air that provides a large driving force which is used almost completely.

- Since a high driving force is used for only a very small part of the drying process, if possible, one should cascade any remaining driving force (potential gradients) in the air elsewhere. In this way the overall exergy losses can be minimised, and resource efficiency can be improved. 
The exergy losses would be much higher if, for example, the additional expenditure for preheating the air in a burner would be considered in the assessment. However, this would not change the conclusions, as this expenditure is proportional to the thermal exergy of the inlet air. Therefore, this part of the analysis was intentionally left out in order to focus completely on the exergy destruction of the drying process and on the potential improvement by reusing the outlet air.

A few more methodological aspects where shown with this study:

- The kinetic, potential, and surface tension forms of exergy were much lower than $0.1 \%$ of the total exergy input for all cases studied, which renders their contribution negligible.

- This study indicates that, even though exergy is considered as a pseudoproperty, the degree of quality dissipation per unit mass water evaporated, and the exergetic efficiency stay almost unaffected by the selection of the intensive properties of the environment of reference. Similar outcomes have been obtained by other authors who studied aircraft technology. Etele et al. [16] analysed the exergetic performance of an aerospace engine in two different environments of reference (i.e. at sea level and at $15000 \mathrm{~m}$ ). They showed that the selection of a constant reference environment that is independent of the actual operating conditions of the system, is enough to accurately describe its exergetic efficiency [16]. The environment of reference affects the distribution of exergy destroyed and exergy wasted, however, the overall relation between exergy destruction and exergy input to the system is independent of its selection [17]. Therefore, the study presented in this paper shows that exergy analysis can be considered as an objective tool for assessing the resource efficiency of industrial food processes. 


\section{Conclusions}

The exergy concept was demonstrated to be useful in assessing the real efficiency of the use of resources in a conceptual drying process. The thermodynamic performance of the drying process of a lactose solution is strongly affected by the quality of air used, which is described by its dry bulb temperature (affecting its thermal exergy) and its absolute moisture content (affecting its chemical exergy). The contribution of surface tension, kinetic and potential exergy is negligible and can be neglected.

The case study presented here demonstrates that the more the quality of air used deviates from the environment of reference the higher its value. The results show that the use of high driving forces (i.e. air of high dry bulb temperature and low relative humidity) lead to drying processes with high exergetic efficiencies. However, faster drying rates lead to higher exergy destruction and lower exergy efficiency than slow drying rates. This indicates that cascading high quality outputs to other processes and processing slower can theoretically improve the resource efficiency of drying processes.

Additionally, it was shown that the exergy destruction is independent of the selection of the environment of reference. This analysis contributes in identifying general guidelines for the effective (production of high-quality foods), and efficient (use of the least possible quantity of natural resources) design of industrial food production processes. 


\section{Acknowledgements}

The authors are grateful to the Dutch Food Retail Organization (CBL) and the Federation of the Dutch Food and Grocery Industry (FNLI) for funding this research under the project "Valorization of raw materials and process efficiency" which is under TI Food and Nutrition, a public-private partnership on precompetitive research in food and nutrition. The public partners are responsible for the study design, data collection and analysis, decision to publish, and preparation of the manuscript. The private partners have contributed to the project through regular discussion. The authors would like to thank Jan Broeze (Food \& Biobased Research, Wageningen, The Netherlands), and Nicolas Hardt (Food Process Engineering, Wageningen, The Netherlands) for the constructive discussions.

\section{Nomenclature}

$A_{d} \quad$ surface area of droplet $\left[\mathrm{m}^{2}\right]$

$B_{t h, a} \quad$ thermal exergy rate of air $\left[\mathrm{kJ} \mathrm{s}^{-1}\right]$

$B_{e v} \quad$ exergy rate required for the phase change of water $\left[\mathrm{kJ} \mathrm{s}^{-1}\right]$

$B_{c h, a} \quad$ chemical exergy rate of air $\left[\mathrm{kJ} \mathrm{s}^{-1}\right]$

$B_{p r, a} \quad$ pressure exergy rate of air $\left[\mathrm{kJ} \mathrm{s}^{-1}\right]$

$B_{k, a} \quad$ kinetic exergy rate of air $\left[\mathrm{kJ} \mathrm{s}^{-1}\right]$

$B_{p, a} \quad$ potential exergy rate of air $\left[\mathrm{kJ} \mathrm{s}^{-1}\right]$

$B_{m i x, d} \quad$ mixing exergy of lactose and water [kJ]

$B_{t h, d} \quad$ thermal exergy of lactose solution [kJ]

$B_{c h, d} \quad$ chemical exergy rate of lactose solution $[\mathrm{kJ}]$

$B_{p r, d} \quad$ pressure exergy rate of lactose solution $\left[\mathrm{kJ} \mathrm{s}^{-1}\right.$ ]

$B_{k, d} \quad$ kinetic exergy rate of lactose solution [ $\mathrm{kJ} \mathrm{s}^{-1}$ ]

$D_{w a}$ diffusion coefficient of water vapour in air $\left[\mathrm{m}^{2} \mathrm{~s}^{-1}\right]$

$J_{w} \quad$ water evaporation flux $\left[\mathrm{kg}\left(\mathrm{m}^{2}\right)^{-1} \mathrm{~s}^{-1}\right]$

$J_{q} \quad$ heat flux $\left[\mathrm{kJ}\left(\mathrm{m}^{2}\right)^{-1} \mathrm{~s}^{-1}\right]$

$L_{\text {dryer }}$ height of dryer [m]

$M$ mass $[\mathrm{kg}]$

$M_{a} \quad$ air flow rate $\left[\mathrm{kg} \mathrm{s}^{-1}\right]$

$M_{e v} \quad$ total amount of water evaporated [kg]

$\overline{M_{e v}} \quad$ average evaporation rate $\left[\mathrm{kg} \mathrm{s}^{-1}\right]$

$M_{d} \quad$ total mass of the droplet [kg]

$M_{w d} \quad$ water mass in the droplet [kg]

$M_{s d} \quad$ lactose mass in the droplet [kg]

$M_{d}^{c r i t} \quad$ critical mass of the droplet [kg]

$M_{w d}^{c r i t}$ critical water mass in the droplet [kg]

$M_{d}^{\text {final }}$ final mass of the droplet $[\mathrm{kg}]$ 


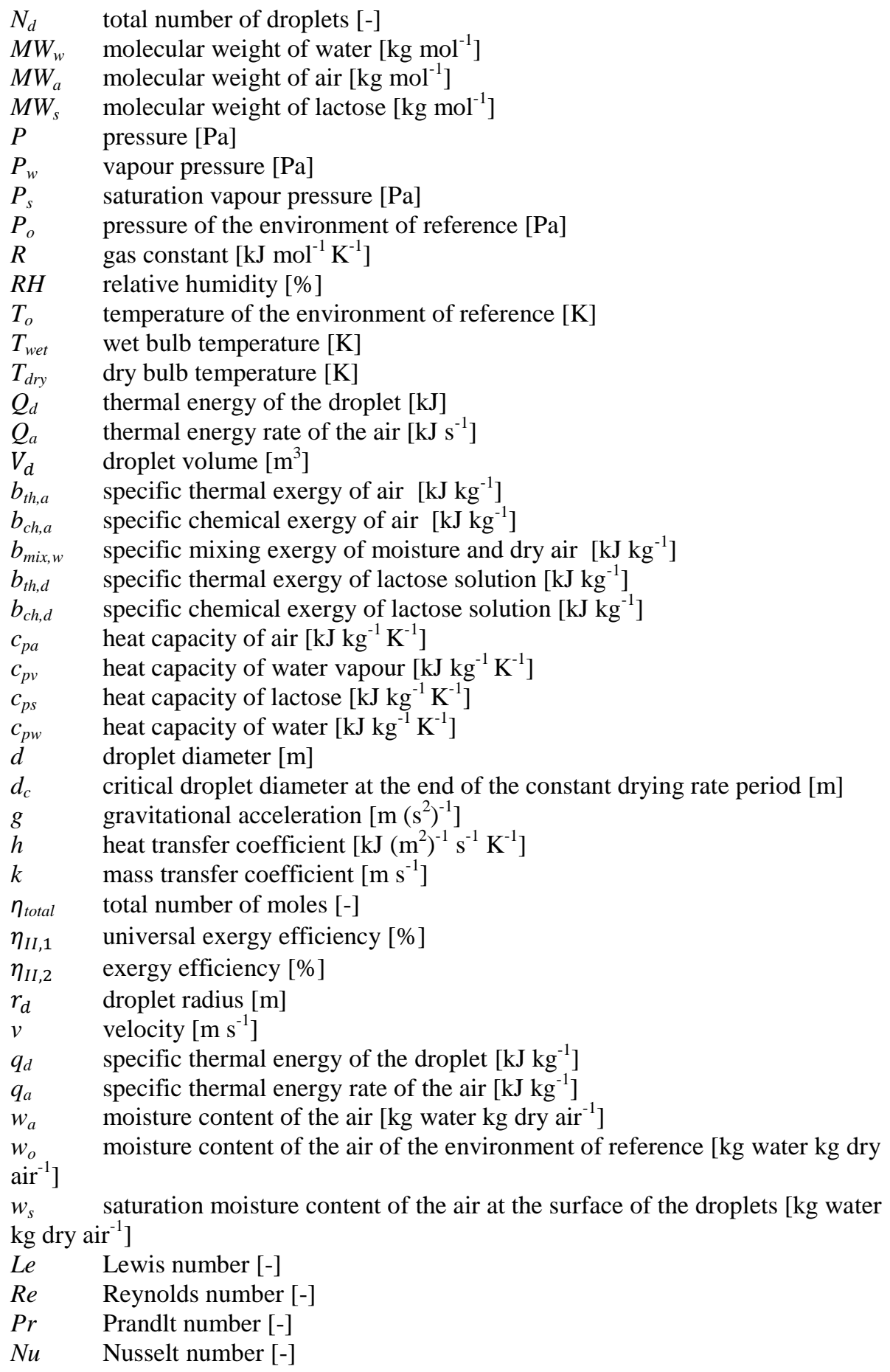




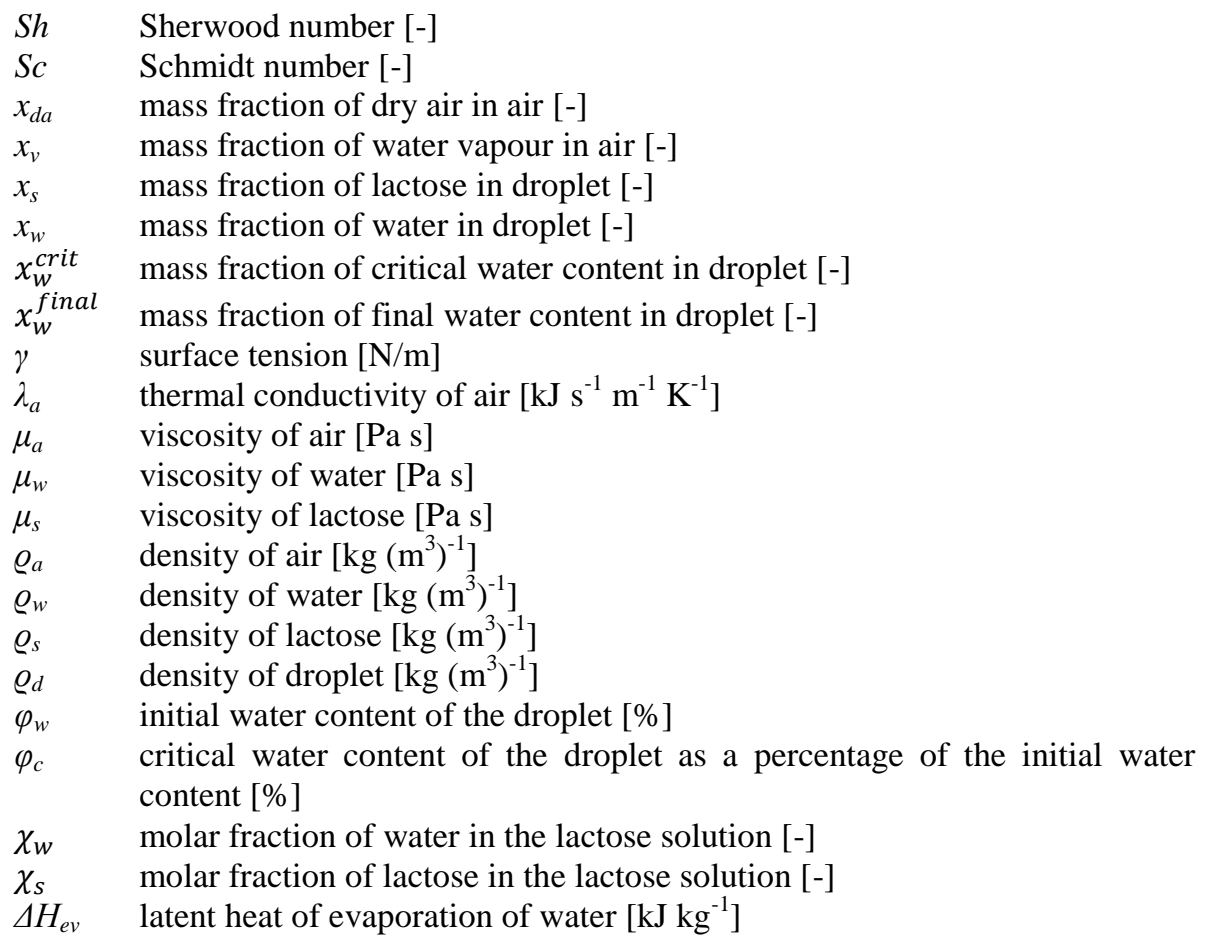




\section{Appendix A}

Table A.1. Additional parameters and assumptions used in the analysis.

\begin{tabular}{|c|c|c|}
\hline Parameter & Value & Units \\
\hline Universal gas constant & 8.314 & {$\left[\mathrm{~J} \mathrm{~mol}^{-1} \mathrm{~K}^{-1}\right]$} \\
\hline Ambient temperature & 298 & {$[\mathrm{~K}]$} \\
\hline Ambient pressure & 101325 & {$[\mathrm{~Pa}]$} \\
\hline Ambient moisture content & 8 & [g water kg ${ }^{-1}$ dry air] \\
\hline Outlet air moisture content & 9 & [g water kg ${ }^{-1}$ dry air] \\
\hline Inlet lactose solution temperature & 298 & {$[\mathrm{~K}]$} \\
\hline Droplet diameter & $100 \cdot 10^{-6}$ & {$[\mathrm{~m}]$} \\
\hline Number of droplets & $10^{9}$ & - \\
\hline Water fraction in the droplet & 90 & $\%$ \\
\hline Critical water content & 20 & $\%$ of initial water content \\
\hline Heat capacity of lactose & $1.2^{\mathrm{a}}$ & {$\left[\mathrm{kJ} \mathrm{kg}^{-1} \mathrm{~K}^{-1}\right]$} \\
\hline Pressure drop & $\Delta P_{d}=\frac{2 \gamma}{r_{d}}$ & {$[\mathrm{~Pa}]$} \\
\hline Inner pressure of the droplet & $P_{i}=\Delta P+P_{o}$ & {$[\mathrm{~Pa}]$} \\
\hline Relative humidity & $R H=\frac{P_{w}}{P_{s a t}} 100$ & {$[\%]$} \\
\hline Water vapour pressure & $P_{w}=\frac{P_{o} w_{a}}{\frac{M W_{w}}{M W_{a}}+w_{a}}$ & {$[\mathrm{~Pa}]$} \\
\hline Saturation vapour pressure & $P_{s}=\frac{P_{o}}{760} 10^{8.07131-\frac{1730.63}{233.426+T_{d r y}-273.15}}$ & {$[\mathrm{~Pa}]$} \\
\hline saturation moisture content & $w_{s}=\frac{M W_{w}}{M W_{a}} \frac{P_{s}}{P_{o}-P_{s}}$ & [g water kg ${ }^{-1}$ dry air] \\
\hline Molecular weight of water & 0.018 & {$\left[\mathrm{~kg} \mathrm{~mol}^{-1}\right]$} \\
\hline Molecular weight of air & 0.029 & {$\left[\mathrm{~kg} \mathrm{~mol}^{-1}\right]$} \\
\hline Molecular weight of lactose & 0.342 & {$\left[\mathrm{~kg} \mathrm{~mol}^{-1}\right]$} \\
\hline Standard chemical exergy of water & $50^{\mathrm{b}}$ & {$\left[\mathrm{kJ} \mathrm{kg}^{-1}\right]$} \\
\hline Standard chemical exergy of vapour & $530^{\mathrm{c}}$ & {$\left[\mathrm{kJ} \mathrm{kg}^{-1}\right]$} \\
\hline Standard chemical exergy of lactose & $16000^{d}$ & {$\left[\mathrm{~kJ} \mathrm{~kg}^{-1}\right]$} \\
\hline
\end{tabular}

\footnotetext{
${ }^{\mathrm{a}}$ Assumed to be the same with the heat capacity of crystal sugar [18].

${ }^{b, c, d}$ Values adapted from [19].
} 
Table A.2. Polynomial constants for the calculated properties of the drying air and the lactose solution with data obtained from [20].

\begin{tabular}{|c|c|c|c|c|c|c|c|c|c|c|}
\hline Constants & $\mu_{a}$ & $\varrho_{a}$ & $\varrho_{d a}$ & $c_{p a}$ & $\lambda_{a}$ & $\mu_{w}{ }^{a}$ & $\varrho_{w}$ & $c_{p w}$ & $\Delta \boldsymbol{H}_{e v}$ & $c_{p v}$ \\
\hline Units & {$[\mathrm{Pa} \mathrm{s}]$} & {$\left[\mathrm{Kg}\left(\mathrm{m}^{3}\right)^{-1}\right]$} & {$\left[\mathrm{Kg}\left(\mathrm{m}^{3}\right)^{-1}\right]$} & {$\left[\mathrm{kJ} \mathrm{kg}^{-1} \mathrm{~K}^{-1}\right]$} & {$\left[\mathrm{kJ} \mathrm{s}^{-1} \mathrm{~m}^{-1} \mathrm{~K}^{-1}\right]$} & {$[\mathrm{Pa} \mathrm{s}]$} & {$\left[\mathrm{Kg}\left(\mathrm{m}^{3}\right)^{-1}\right]$} & {$\left[\mathrm{kJ} \mathrm{kg}^{-1} \mathrm{~K}^{-1}\right]$} & {$\left[\mathrm{kJ} \mathrm{kg}^{-1}\right]$} & {$\left[\mathrm{kJ} \mathrm{kg}^{-1} \mathrm{~K}^{-1}\right]$} \\
\hline Function of & $T_{d r y}(\mathrm{~K})$ & $T_{d r y}(\mathrm{~K})$ & $T_{d r y}(\mathrm{~K})$ & $T_{d r y}(\mathrm{~K})$ & $T_{d r y}(\mathrm{~K})$ & $T_{\text {wet }}(\mathrm{K})$ & $T_{\text {wet }}(\mathrm{K})$ & $T_{\text {wet }}(\mathrm{K})$ & $T_{\text {wet }}(\mathrm{K})$ & $T_{d r y}(\mathrm{~K})$ \\
\hline C6 & $2.190 \mathrm{E}-21$ & $4.422 \mathrm{E}-17$ & $2.417 \mathrm{E}-17$ & $9.227 \mathrm{E}-17$ & $-7.286 \mathrm{E}-22$ & $-1.126 \mathrm{E}-09$ & $-4.895 \mathrm{E}-12$ & $2.757 \mathrm{E}-13$ & $-7.695 \mathrm{E}-13$ & $1.244 \mathrm{E}-21$ \\
\hline $\mathrm{C} 5$ & $-7.970 \mathrm{E}-18$ & $-1.798 \mathrm{E}-13$ & $-7.235 \mathrm{E}-14$ & $-7.889 \mathrm{E}-14$ & $2.430 \mathrm{E}-18$ & $1.847 \mathrm{E}-06$ & $1.327 \mathrm{E}-08$ & $-7.019 \mathrm{E}-10$ & $1.691 \mathrm{E}-09$ & $-2.522 \mathrm{E}-17$ \\
\hline $\mathrm{C} 4$ & $1.150 \mathrm{E}-14$ & $2.961 \mathrm{E}-10$ & $9.384 \mathrm{E}-11$ & $1.872 \mathrm{E}-11$ & $-3.025 \mathrm{E}-15$ & $-1.184 \mathrm{E}-03$ & $-1.484 \mathrm{E}-05$ & $7.350 \mathrm{E}-07$ & $-1.545 \mathrm{E}-06$ & $1.980 \mathrm{E}-13$ \\
\hline $\mathrm{C} 3$ & $-8.393 \mathrm{E}-12$ & $-2.573 \mathrm{E}-07$ & $-7.268 \mathrm{E}-08$ & $-5.136 \mathrm{E}-10$ & $1.736 \mathrm{E}-12$ & $3.603 \mathrm{E}-01$ & $8.758 \mathrm{E}-03$ & $-4.050 \mathrm{E}-04$ & $7.358 \mathrm{E}-04$ & $-7.413 \mathrm{E}-10$ \\
\hline $\mathrm{C} 2$ & 3.244E-09 & $1.280 \mathrm{E}-04$ & $3.896 \mathrm{E}-05$ & $2.446 \mathrm{E}-07$ & $-4.550 \mathrm{E}-10$ & $-4.632 \mathrm{E}+01$ & $-2.876 \mathrm{E}+00$ & $1.238 \mathrm{E}-01$ & $-1.913 \mathrm{E}-01$ & $1.235 \mathrm{E}-06$ \\
\hline $\mathrm{C} 1$ & $-5.860 \mathrm{E}-07$ & $-3.656 \mathrm{E}-02$ & $-1.470 \mathrm{E}-02$ & $1.828 \mathrm{E}-05$ & $1.117 \mathrm{E}-07$ & $0.000 \mathrm{E}+00$ & $4.980 \mathrm{E}+02$ & $-1.991 \mathrm{E}+01$ & $2.332 \mathrm{E}+01$ & $-2.262 \mathrm{E}-04$ \\
\hline $\mathrm{b}$ & $5.338 \mathrm{E}-05$ & $5.583 \mathrm{E}+00$ & $3.425 \mathrm{E}+00$ & $1.005 \mathrm{E}+00$ & 5.853E-06 & $3.663 \mathrm{E}+05$ & $-3.446 \mathrm{E}+04$ & $1.320 \mathrm{E}+03$ & $1.757 \mathrm{E}+03$ & $1.844 \mathrm{E}+00$ \\
\hline
\end{tabular}

${ }^{\mathrm{a} C}$ Converted into Pa.s by multiplying with $10^{-6}$. 


\section{Appendix B}

\section{Psychrometric model}

The drying model in this research is limited within the temperature range studied (from $280 \mathrm{~K}$ to $323 \mathrm{~K}$ ). As expected, the relative humidity at fixed moisture content, decreases as the dry bulb temperature increases, and a higher moisture content at a particular dry bulb temperature corresponds to a higher relative humidity.
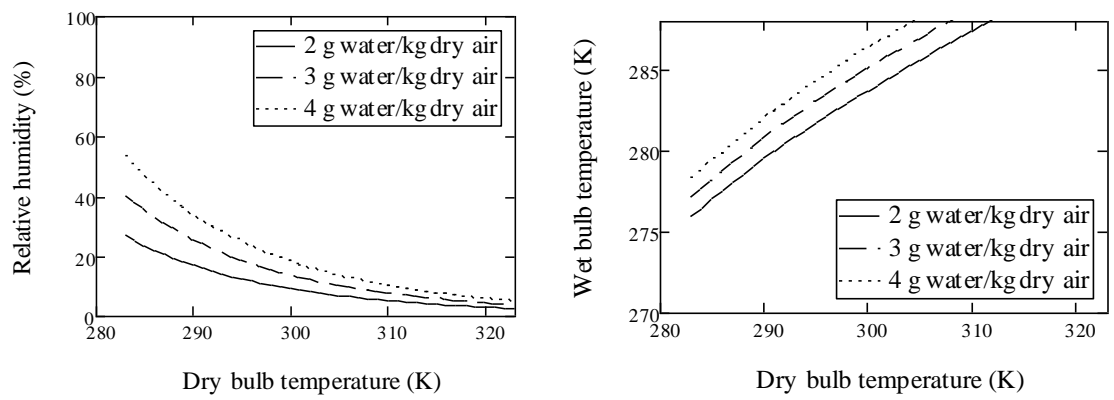

Figure B1. Left: relative humidity as a function of the dry bulb temperature $(\mathrm{K})$ and moisture content (g water/kg dry air), right: wet bulb temperature $(\mathrm{K})$ as a function of the dry bulb temperature $(\mathrm{K})$ and moisture content (g water/kg dry air) following the model of Stull [13]. 


\section{Appendix C}

$308 \mathrm{~K}$
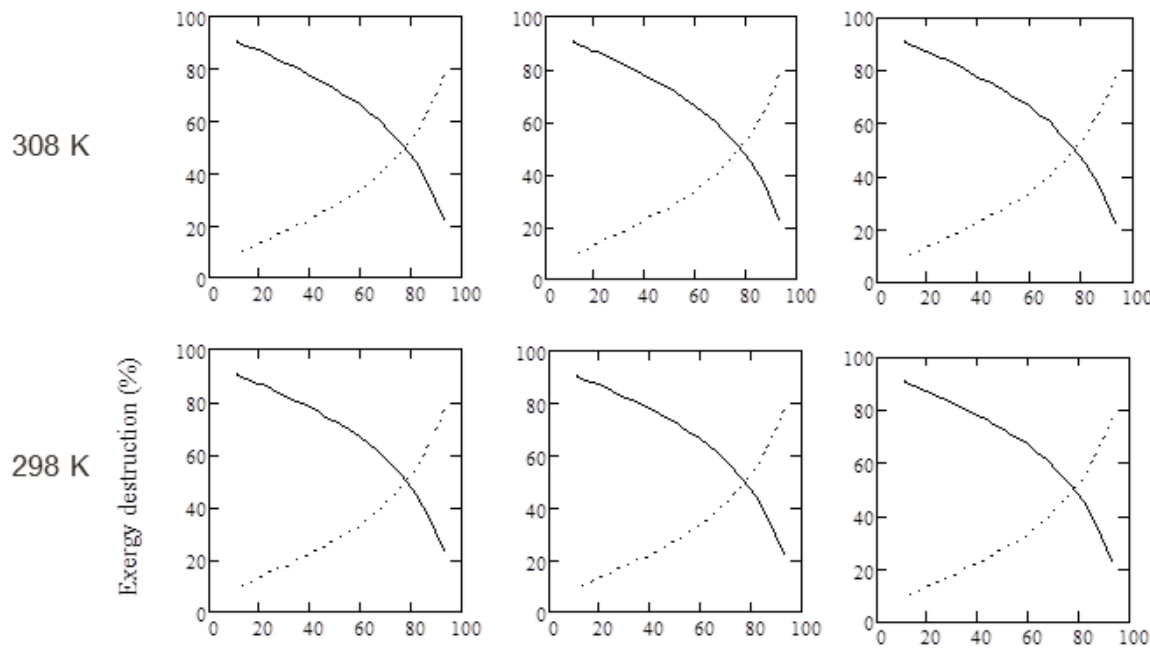

$280 \mathrm{~K}$
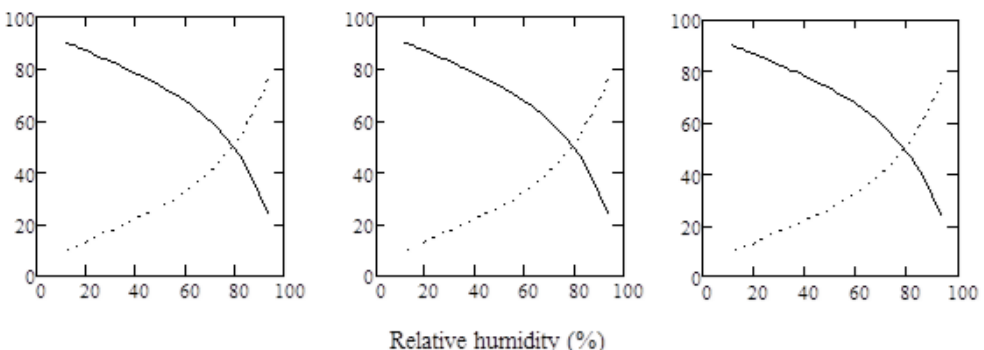

$5 \%$

$41 \%$

$90 \%$

Figure C.1. Exergy destruction share (excluding chemical exergy destruction) between thermal exergy destruction (continuous line) and pressure exergy destruction (dotted line) as a function of the dry bulb temperature, assessed at nine different environments of reference ranging from cold $(280 \mathrm{~K})$ to warm $(308 \mathrm{~K})$ and dry (5\% relative humidity) to very moist (90\% relative humidity). Details for the environment of reference intensive properties are shown in Figure 3. 


\section{References}

[1] Kemp IC. Fundamentals of Energy Analysis of Dryers. Modern Drying Technology: Wiley-VCH Verlag GmbH \& Co. KGaA; 2011. p. 1-45.

[2] Kerr WL, Kutz M. Chapter 12 - Food Drying and Evaporation Processing Operations. Handbook of Farm, Dairy and Food Machinery Engineering (Second Edition). San Diego: Academic Press; 2013. p. 317-54.

[3] Aghbashlo M, Mobli H, Rafiee S, Madadlou A. A review on exergy analysis of drying processes and systems. Renewable and Sustainable Energy Reviews. 2013;22(0):1-22.

[4] Dincer I. Exergy as a potential tool for sustainable drying systems. Sustainable Cities and Society. 2011;1(2):91-6.

[5] Syahrul S, Hamdullahpur F, Dincer I. Exergy analysis of fluidized bed drying of moist particles. Exergy, An International Journal. 2002;2(2):87-98.

[6] Syahrul S, Dincer I, Hamdullahpur F. Thermodynamic modeling of fluidized bed drying of moist particles. International Journal of Thermal Sciences. 2003;42(7):691-701.

[7] Zisopoulos FK, Rossier-Miranda FJ, Van der Goot AJ, Boom RM. The use of exergetic indicators in the food industry - A review. Critical Reviews in Food Science and Nutrition. 2015.

[8] Szargut J. International progress in second law analysis. Energy. 1980;5(89):709-18.

[9] Denbigh KG. The second-law efficiency of chemical processes. Chemical Engineering Science. 1956;6(1):1-9.

[10] Leites IL, Sama DA, Lior N. The theory and practice of energy saving in the chemical industry: some methods for reducing thermodynamic irreversibility in chemical technology processes. Energy. 2003;28(1):55-97. 
[11] Gaudreau K. Sustainability assessment of energy systems. Ontario, Canada: University of Waterloo, 2013.

[12] Zhen-Xiang G, Sachin VJ, Arun SM. Simprosys: Software for Dryer Calculations. Handbook of Industrial Drying, Fourth Edition: CRC Press; 2014. p. 1209-28.

[13] Stull R. Wet-Bulb Temperature from Relative Humidity and Air Temperature. Journal of Applied Meteorology and Climatology. 2011;50(11):2267-9.

[14] Dalmaz N, Ozbelge HO, Eraslan AN, Uludag Y. Heat and Mass Transfer Mechanisms in Drying of a Suspension Droplet: A New Computational Model. Dry Technol. 2007;25(2):391-400.

[15] McDonald EJ, Turcotte AL. Density and refractive indices of lactose solutions. Part of the Journal of Research of the National Bureau Standards. 1948;41.

[16] Etele J, Rosen MA. Sensitivity of exergy efficiencies of aerospace engines to reference environment selection. Exergy, An International Journal. 2001;1(2):91-9.

[17] de Oliveira S. Exergy Method for Conception and Assessment of Aircraft Systems. Exergy: Production, Cost and Renewability. London: Springer London; 2013. p. 237-79.

[18] www.sugartech.com. Heat capacity of sugar. 2016.

[19] Wall G. Exergetics. 2009.

[20] www.engineeringtoolbox.com 


\section{Chapter 6}

General discussion 


\section{Introduction}

This thesis focused on understanding sustainability in the food industry in terms of natural resource use by adopting the concept of exergy. The aim was to bridge the fields of exergy and food engineering and to identify overarching principles that can lead to the formulation of general rules in the form of guidelines for the sustainable design of industrial food production chains. Firstly, different industrial food production chains and processes were assessed to pinpoint exergy-inefficient locations, and secondly, the reasons behind these inefficiencies were studied. The thermodynamic performance of industrial food production chains was assessed both at a chain level (industrial bread and mushroom production), as well as on a process level (spray drying of a lactose solution).

During the research, a number of questions of methodological nature arose from the use of the concept of exergy that are highly relevant both for the assessment as well as for the design of resource-efficient food production chains. The most important questions were: What should be the value of a resource in the exergetic assessment of industrial food production chains? How to deal with the embodied exergy value of the external inputs used (e.g. an enzyme formulation)? How should the different outputs be valued? Should a waste-stream that is released to the environment of reference have a negative exergy content? What is the impact of the system boundaries on the analysis and how should one consider them?

This chapter summarizes the main findings of the cases studied, discusses the questions posed above, describes resource efficiency in the context of exergy, lists general rules for the sustainable design of industrial food production chains, and proposes future directions for the practical implementation of exergy analysis. 


\section{Methodological aspects of exergy analysis}

\section{Exergy analysis as a sustainability assessment tool}

The cases studied demonstrated the usefulness of exergy analysis as a sustainability assessment tool for the food industry, which is briefly recapped in the following points:

- Exergy is an objective concept because it is based on the first and second law of thermodynamics. However, subjective decisions have to be made with regard to the selection of the environment of reference, the system boundaries, the interpretation of the thermodynamic analysis, and the suggestion of potential improvements.

- Exergy is expressed in a single unit (Joule). This enables the comparison of streams of different nature (e.g., energy and mass), but should not be confused with the unit Joule for energy.

- Exergy analysis can be applied for assessing the thermodynamic performance of any system, and therefore, also industrial food production chains. Thermodynamics is a concept that applies to all of nature, and therefore has no limiting area of validity. Exergy analysis thus can be applied on microscale, mesoscale and macroscale.

- Exergy can quantify the resource investment in terms of available work required to drive the production of foods.

- Exergy analysis can quantify the dissipation of the quality of resources, revealing exergy wasteful locations (Critical Exergy loss Points) along a food production chain. Processes are seen as thermodynamic engines the performance of which is assessed by using exergetic indicators (e.g. exergy lost to produce one $\mathrm{kg}$ of product). 
- Exergy analysis is a tool for comparing different systems, or scenarios with each other, and it identifies side-streams (material and immaterial) that can theoretically be reused.

\section{A critical view on the use of exergy for describing the quality of}

\section{resources}

Even though the exergy concept offers a considerable number of benefits compared to, for example, an energy analysis, it should also be critically assessed. A resource within exergy analysis is considered as any stream, material or immaterial, the state of which differs from a predefined environment of reference in terms of e.g. concentration, temperature, pressure, and any other aspect that might be relevant for the assessment, and which is used as an input to a process. Material streams are described by their chemical exergy (e.g. due to concentration gradients and effects of mixing) and physical exergy (e.g. thermal, potential, kinetic, pressure gradients etc.), while immaterial streams are described solely by their physical exergy. However, the exergy of a stream is the amount of work that can be extracted in relation to an environment of reference at ideal condition and infinitely slow exchange rate. As a result, the physical meaning of exergy of a stream has to be considered only in relative terms. Therefore, exergy is a co-property because its value depends on the selection of the environment of reference [1]. Exactly because of this sensitivity on a (subjective) selection of environment of reference, exergy has been characterized as a pseudo-property [2]. Nevertheless, exergy consumption is independent of the selection of the environment of reference and, therefore, it can still be used to compare industrial food production chains and processes in an objective manner (Chapter 5). 


\section{Considering the exergy content of resources and products in}

\section{industrial food production}

The consumption of physical exergy (and more precisely thermal exergy) in industrial processing has been studied extensively, and to the best of the author's knowledge, it is the most commonly used approach to assess the exergetic performance of food processes. However, little attention is given to the chemical exergy of streams. Often this is allowed because those streams are "transiting" only, and therefore constant in the amount and composition. Chemical exergy is generally much larger in magnitude than physical exergy, and it can play an important role in the final result of an exergy analysis, particularly for cases where material losses take place. This is an important lesson from exergy analysis: one should always close the material balances before one optimises the energy balance (physical exergy use). This is in agreement with more qualitatively based philosophies such as the cradle-to-cradle design approach, which also states that all material should be used and recycled, while it does not concern itself with the efficient use of energy.

The currently available databases of chemical exergy values are limited to the standard chemical exergy of elements, and of inorganic and relatively simple organic compounds [3-6]. Dewulf et al. [7] proposed a methodology that connects life cycle assessment databases with exergy analysis, and captures eight different resource categories that represent natural resource consumption into a single cumulative exergy value.

Unfortunately, there are no values tabulated for most of the raw materials, ingredients, and other inputs used in the food industry, and their standard chemical exergy has to be calculated. According to Morris and Szargut [3]: "if an exact calculation of the chemical exergy of a particular element is impossible because of the lack of sufficiently exact thermodynamic data, the calculation should be done as exactly as possible (with currently available data) and the result should be accepted as a conventional standard value of the chemical exergy of the element under consideration". Following this reasoning a "quick reference library" with chemical 
exergy values for raw materials, ingredients, foods, food products, and other inputs would be very valuable for designing, assessing, improving, and monitoring the exergetic performance of the food industry. However, for the creation of an exergybased library a certain distinction has to be made between the standard chemical exergy of material streams, and their additional cumulative exergy consumption (if any). Moreover, the following aspects should be considered:

- When reference substances are not readily available, then the standard chemical exergy of a material has to be calculated based on its composition (by considering ingredients such as protein, starch, fat content etc. or elements such as carbon, hydrogen, oxygen etc.) which can range considerably (e.g. variation in the moisture content of a crop due to seasonal variation).

- A mixing exergy term is added to account for the compositional ingredients that are "brought together from the environment of reference" to form it. However, except for very small molecules, this mixing exergy is usually a very small negative number, and is clearly not enough to account for the formation of materials and products which require additional inputs and particular conditions to grow or to form (e.g. vegetables, milk, meat, bread etc.). Moreover, the value in a food product is often not in its degree of mixing, but in its state of de-mixing, i.e., the microstructure of the components, which by necessity implies a system that is not completely mixed.

- Any additional embodied exergy value listed would depend greatly on the way the material has been either extracted, grown, harvested, transported, or processed. 
Therefore, the calculated chemical exergy of food ingredients, food products, and other raw materials involved in the whole production chain can be considered as the available work that is stored within the chemical bonds of the raw material or food product, and which is useful due to its concentration difference in relation to the environment of reference. The higher the standard chemical exergy of a material the more valuable it is in terms of exergy. As a quantitative example, the specific standard chemical exergy of wheat straw used as a raw material in the industrial mushroom production chain (Chapter 4), was calculated at $19.1 \mathrm{MJ} / \mathrm{kg}$ [8] which is very close to the value of Song et al. [9] (19.3 MJ/kg), and to the values of Zhang et al. [10] (21.1-21.5 MJ/kg). The difference is due to the relative percentage of the ingredients assumed in the straw, particularly the amount of water present. The influence of the moisture content is large because the standard chemical exergy of liquid water $(0.05 \mathrm{MJ} / \mathrm{kg})$ is much smaller than the standard chemical exergy of other food components such as proteins (e.g. $20 \mathrm{MJ} / \mathrm{kg}$ ), carbohydrates (e.g. 16 $\mathrm{MJ} / \mathrm{kg}$ ), and fats (e.g. $22 \mathrm{MJ} / \mathrm{kg}$ ). Thus, the chemical exergy of very moist products is influenced much less by the composition of their dry matter than by their moisture content.

As another example, the specific chemical exergy of four different tomato varieties was calculated based on compositional data by Hernandez et al. [11]. The specific chemical exergy values of the tomato varieties were $0.84 \mathrm{MJ} / \mathrm{kg}$ for Dorothy, at 0.99 $\mathrm{MJ} / \mathrm{kg}$ for Boludo, at $1.00 \mathrm{MJ} / \mathrm{kg}$ for Dominique, and at $1.02 \mathrm{MJ} / \mathrm{kg}$ for Thomas (Figure 1). Even if the composition amongst the tomato varieties differs, the range of the standard chemical exergy value is quite narrow. Moreover, while the contribution of water in weight percentage is dominant, exergy-wise it is only $5 \%$ of the average standard chemical exergy of tomato. Fibres have the highest contribution in the average specific chemical exergy at $36 \%$, followed by fructose at $21 \%$, while glucose and proteins are both at $19 \%$. 
This indicates that a highly concentrated food product is more valuable in terms of exergy per kilo in comparison to a dilute food product. However, this distinction neither accounts for additional resource consumption for its production (embodied exergy) nor for any nutritional value.
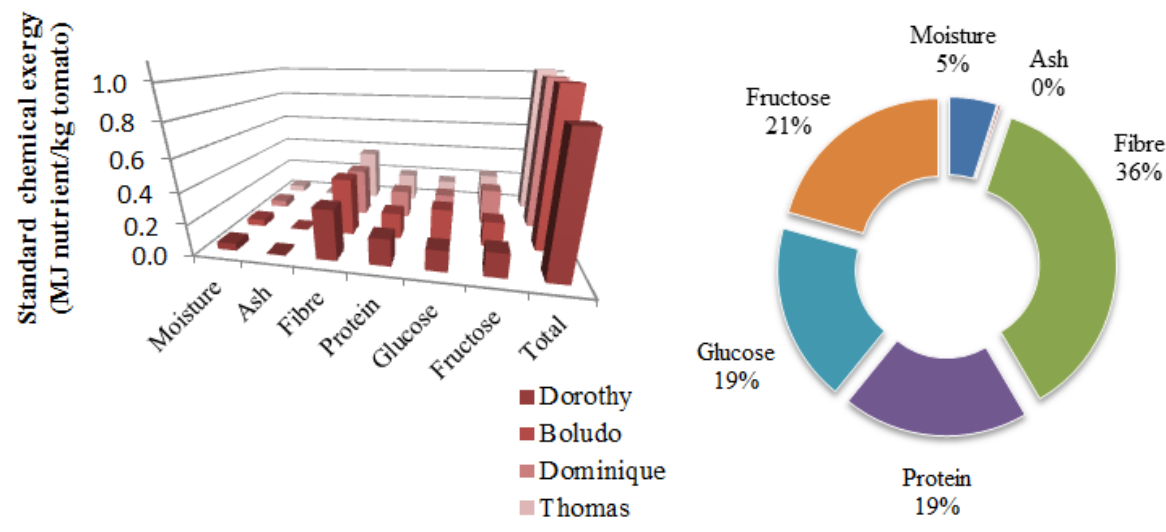

Figure 1. Distribution of the standard chemical exergy values of four tomato varieties (Dorothy, Boludo, Dominique, and Thomas) in left: absolute values for each nutrient and variety, and right: as a relative share of the chemical exergy of nutrients in the average standard chemical exergy (of all four varieties). The compositional data are obtained by Hernandez et al. [11]. The standard chemical exergies of each nutrient assumed were: protein $22 \mathrm{MJ} / \mathrm{kg}$, fibre $17 \mathrm{MJ} / \mathrm{kg}$, glucose and fructose $16 \mathrm{MJ} / \mathrm{kg}$, ash $0.4 \mathrm{MJ} / \mathrm{kg}$, water $0.05 \mathrm{MJ} / \mathrm{kg}$. The mixing exergy has been neglected for simplification.

\section{The importance of the environment of reference}

The intensive variables (e.g. temperature, pressure, and moisture content) as well as the standard chemical exergy values (tabulated in literature) that describe the environment of reference have to be defined for all relevant streams that are assessed. The differences between different environments of reference that are used in exergy analysis have been discussed by Dincer [1]. 
One of the most commonly used environments of reference is the naturalenvironment-subsystem model where the air is assumed to be at atmospheric pressure, at temperate temperatures (e.g. $25{ }^{\circ} \mathrm{C}$ ), and saturated with water [1] However, the selection of the moisture content of the environment of reference should be considered in more depth. In drying processes, the use of psychrometrics is mandatory for capturing the exergetic content of drying air (both chemical and thermal) which depicts the magnitude of the driving forces (e.g. temperature and humidity differences with the product). In an environment of reference where the air is considered saturated, any airflow with a relative humidity lower than $100 \%$ used for drying will have a capacity to remove water from a product, i.e. have the ability to exert work. Obviously, the use of saturated ambient air as a point of reference is not always realistic since it is restricted to describing only moist environments. Additionally, one could argue that in reality the natural environment has global properties with dynamic gradients that can be exploited to produce useful work (e.g. wind power, tidal forces etc.). In exergy analysis the environment of reference is usually chosen as a local, static sink. The main problem of using a global definition of the environment of reference with its standard atmosphere, standard sea and standard bed-rock, is the disequilibrium between all these sub-environments. To mitigate this problem, the use of local and seasonal standards has been proposed instead [1]. It can even be used to indicate most ideal places for specific transformations in food products, and perhaps explain the origin of some traditional products (e.g. sun-dried tomatoes, pickles, cured meat etc).

In cases where chemical exergy is relevant (e.g. changes in material flows, reactions etc.), the standard chemical exergies of the main elements that describe the environment of reference have to be defined. The most commonly used reference substances are the ones proposed by Szargut et al. [12] stating that the main elements that describe it are selected by meeting two criteria: a) the Earth similarity criterion, which states that they should be most abundant on Earth, and b) the stability criterion, which states that they should be in their most stable form. These criteria, and particularly the stability criterion, remove any disequilibrium issues 
between the reference substances. The standard chemical exergy values for a number of elements and molecules have been tabulated and they have been used extensively in literature for the calculation of the chemical exergy values of material streams. However, Szargut's environment of refence has also been criticized with the argument that it is used to define the chemical exergy of the very elements from which it is self-defined [2]. The reconstruction of an environment of reference that is ontologically solid will strengthen the methodological foundations of exergy analysis.

For the food industry, an environment of reference that considers the nutrional aspects of foods should be developed because the purpose of industrial food production chains is to supply food products with chemical exergy that should be of nutritional value to the consumers. Currently, the chemical exergy content does not consider nutritional values: e.g. differentiating between one kilo of bread (around 11-13 MJ) from one kilo of wood (around 11 MJ [13]). The use of additional nutritional quality factors would allow for a distinction amongst e.g. a non-digestible raw material, and a nutritious food product. In the cases studied in this thesis, similar food products (e.g. bread products) were compared with each other where their quality aspects were set as the main constraint for a fair comparison. When completely different food products are to be compared (e.g. the exergetic requirements for the production of a loaf of bread with those of a box of mushrooms) then nutritional aspects should also be considered as system constraints. A nutritional extension of exergy analysis would enhance its power in comparing the "nutritive exergy" of different food products.

\section{The exergy content of waste streams}

In a conventional exergy analysis, any stream dispersed into the environment of reference is assumed to attain complete equilibrium with that environment, and therefore, loses its exergy content. Waste streams in industrial food processes can be either material (e.g. spoilt or unsold food products, leakages, emissions etc.) or immaterial (e.g. waste heat). Considering that material streams can have a much 
higher exergy value than physical streams, their inefficient use has a great impact on the sustainability of the total food production chain (as has been shown in Chapters 3 and 4). One could choose to not represent the exergy content of a waste stream on a Grassmann diagram. However, by illustrating this wasted exergy, one can also communicate in a visual manner the theoretical useful work that could be regained if the side stream was regarded as a useful.

Of course, avoiding, reducing, or reusing material side streams is usually not for free. The upgrade of a waste stream requires additional exergy expenditure by further processing with e.g. additional raw materials (e.g. adding an enzyme formulation to assist the fermentation of recycled bread waste for the production of sourdough) or by providing particular conditions (e.g. mimicking seasonal changes during the industrial composting process of horse and chicken manure which are used as a substrate for mushroom production). Waste streams can occur at any part along the food production chain. It is intuitive that the later the wastage occurs in the chain, the higher is its embodied exergy and its quality/nutritional value (since the chain is designed to generate this quality or nutritional value). Therefore, the later the wastage in the chain, the worse the impact is for the overall sustainability of the chain. There might be additional implications for recycling or reusing food waste streams that are not necessarily of technological nature such as food safety issues, extensive legislative support, considerable financial investment, and efficient and effective communication between all stakeholders involved in the chain [14].

Clearly, the first priority in reducing food wastage should be its prevention, and only whenever that is not possible, other options such as reuse and recycling should be considered [15]. However, recycling might also not be the best option for improving environmental performance. A redesign of the total chain could be more beneficial. For example, a recent study on the recycling of phosphorus demonstrated that it is actually better to redesign agricultural systems to minimize phosphorus loss rather than to use recycling technologies [16]. Other studies that deal with the recovery of functional ingredients from waste streams for both the food and pharma industries, proposed: (1) the use of industrial symbiosis between sectors/stakeholders, (2) the 
classification of waste streams according to their nature and size, and (3), the use of assessment methods that consider the whole system of actors and processes for identifying potential markets for these ingredients [17].

The potential reuse of immaterial waste heat streams can be assessed by considering their thermal exergy. Ideally, high quality heat should be used for processes that require this high quality but high temperature waste heat streams occur only in certain food processes (e.g. spray drying or batch sterilization). By making use of pinch analysis, the most exergy-efficient heat exchange network designs can be found, however, this method is mainly aimed at continuous production processes, and is less developed for batch process systems, which is the nature of many food production processes. In addition, any practical implementation of exergy-efficient heat network is usually feasible only when it is considered in the initial design phases of an industrial food processing plant.

Greenhouse gases (e.g. carbon dioxide) and other types of emissions (e.g. ammonia) can also be included in an exergy analysis. Transportation emissions are waste streams occurring in the logistical network of industrial food production chains. It has been proposed that the chemical exergy of transportation emissions can be used as an environmental impact indicator that shows the degree of disequilibrium with the environment [18]. Another proposition was to consider the exergy content of the emissions and waste streams as constrained and unconstrained, where a constrained exergy stream would be one that does not harm the environment, and an unconstrained one could potentially harm the environment due to its unleashed exergy [19]. However, other authors who criticize exergy have argued that this is contradicting with a reference environment that is in equilibrium and its only function is to act as a sink "soup of chemicals" [20].

For the cases studied in this thesis, transportation exergy losses were considered only in terms of chemical exergy losses, i.e. the amount of fuel chemical exergy consumed for sourcing and delivering a certain amount of raw materials and products. Furthermore, a simplified logistical network was assumed in all cases. It 
was found that the exergy losses due to transportation were quite low compared to other steps in the chain. That could potentially be different for industrial food production chains that extend globally where transportation exergy losses could have a more pronounced effect on the total exergy losses. In the case where harmful emissions are produced during production (e.g. ammonia during composting), environmental policy regulations oblige the industry to abate these emissions (e.g. by scrubbing the air with a highly concentrated sulphuric acid solution), indicating additional exergy expenditure. The exergetic requirements of abatement processes can be considered as the necessary amount of exergy required to bring the emission streams "back to equilibrium" with the reference environment.

\section{The effect of system boundaries on exergy analysis}

The industrial production of food comes at a price that is not solely economic. All food products, and each one of their ingredients and other inputs used for their production, have a certain "embodied" cost of production depending on the way they were collected, harvested or produced. Several indicators have been developed that consider the cumulative consumption of a particular natural resource, or the cumulative impact for producing a food product before it reaches the consumer. A few well known indicators are food miles, carbon footprint, water footprint, and embodied energy content. For example, it has been estimated that to produce one litre of diesel approximately $46 \mathrm{MJ}$ of energy have to be spent ${ }^{1}$, of which $99.8 \%$ is coming from non-renewable resources (Figure 2) [21].

\footnotetext{
${ }^{1}$ According to the Netherlands Enterprise Agency [21]: The Gross Energy Requirement (GER) is a measure of the gross energy content of a substance expressed in primary energy. Primary energy is the energy content of energy in their natural form, before any technical transformation has taken place. The GER value consists of two components: a share of renewable energy and a share of non-renewable energy. Non-renewable energy represents the energy which leads to depletion of resources and thus to an environmental impact. Renewable energy represents either inexhaustible sources which do not lead to pollution effects, or forms of energy that are always present (wind, solar, hydro, geothermal), or the calorific value of a renewable crop.
} 


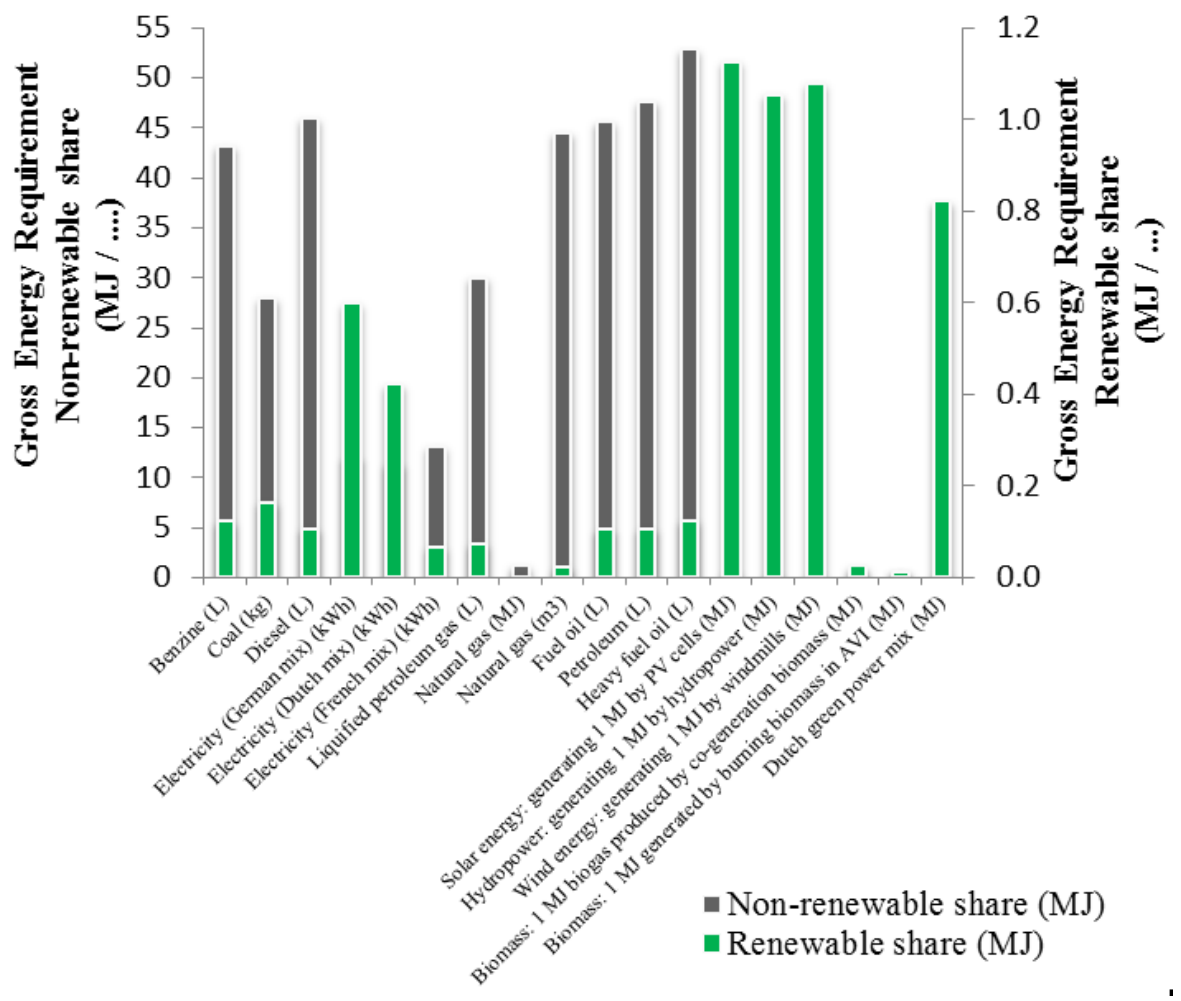

Figure 2. Gross energy requirement (GER) for different types of fuels, and electricity [21].

Burning fuels for producing fuels is irrational in terms of natural resource consumption, especially when there are "greener" options available. The same argument could apply to the current way of industrial food production: burning fuels (that were produced in processes that were heated by burning fuels) for producing food (of which $1 / 3$ is wasted on a global scale [22]) is not sustainable. However, even though the numbers used in these analyses are constructed by following wellestablished methodologies (e.g. life cycle assessment), they should be treated with care, and their contents should only be used as indicative values, because they usually do not consider the "quality of energy" invested, and their derivation might not be always straightforward (e.g. due to the level of complexity of the analysis, the assumptions made etc.). The sole consideration of the compositional chemical 
exergy values of raw materials and other inputs omits their embodied exergy value (and hence neglects the cumulative resource consumption for their production), but it does simplify the analysis to a level that still allows for relevant conclusions to be drawn, also for other actors within the food production network studied.

The values of the chemical exergy calculated in the cases studied in this thesis do not consider any additional exergy expenditure. Composite food products would require an extensive analysis to account for an embodied exergy value for each individual ingredient. For example, the production of wheat flour has additional steps, and even after excluding wheat cultivation the complexity of the analysis is considerable (Figure 3). Mulder et al. [23] already showed that if the system boundaries of an exergy analysis are extended backwards in the chain including the sun as the main source of exergy input, then the inefficient transformation of solar exergy into biomass (e.g. wheat straw) diminishes the effect of any additional exergy inputs (e.g. pesticides, nutrients, gasoline etc.). Solar exergy is abundant and could be considered as a less relevant input in the design of industrial food production chains, especially because it would dwarf the effects of other sources, therefore, not allowing for a comprehensive visualization of other exergy flows. However, solar exergy is a limiting factor for solar capturing technologies and in this particular case it makes sense to include it in the analysis.

By considering the whole production chain the relevance of the analysis for a particular stakeholder of the chain (e.g. a particular food processor) is generally lost within the vast complexity. The consideration of embodied exergy values for each ingredient, even though useful for estimating the cumulative exergy loss, could render the analysis complex, ambiguous, potentially hard to overview due to the width of the system boundaries, and likely relevant only for very specific cases (e.g. for a particular product). The extensive use of details in the assumptions for analysing the exergetic performance of an industrial food production chain, even though useful in capturing production practices, might have limited contribution in the overall assessment. For example, the use of rough estimates on the composition of foods on carbohydrates, proteins, and fats, followed by a simplified assumption 
on their average molecular weights is adequate to describe the chemical exergy of products.

Moreover, using extensive details for describing a unit operation (e.g. detailed operation of a belt conveyor), especially during the preliminary stages of the analysis where a simple overview of the main exergy flows is sufficient, might cost additional effort without providing considerable added value on the outcome of the analysis (e.g. negligible losses). Besides, data might either not be readily available, or might range considerably for a number of process parameters. Therefore, a simplification of the overall food production chain to its most essential parts is sufficient to capture crucial aspects of data variability and process inefficiency, and will facilitate the analysis. 


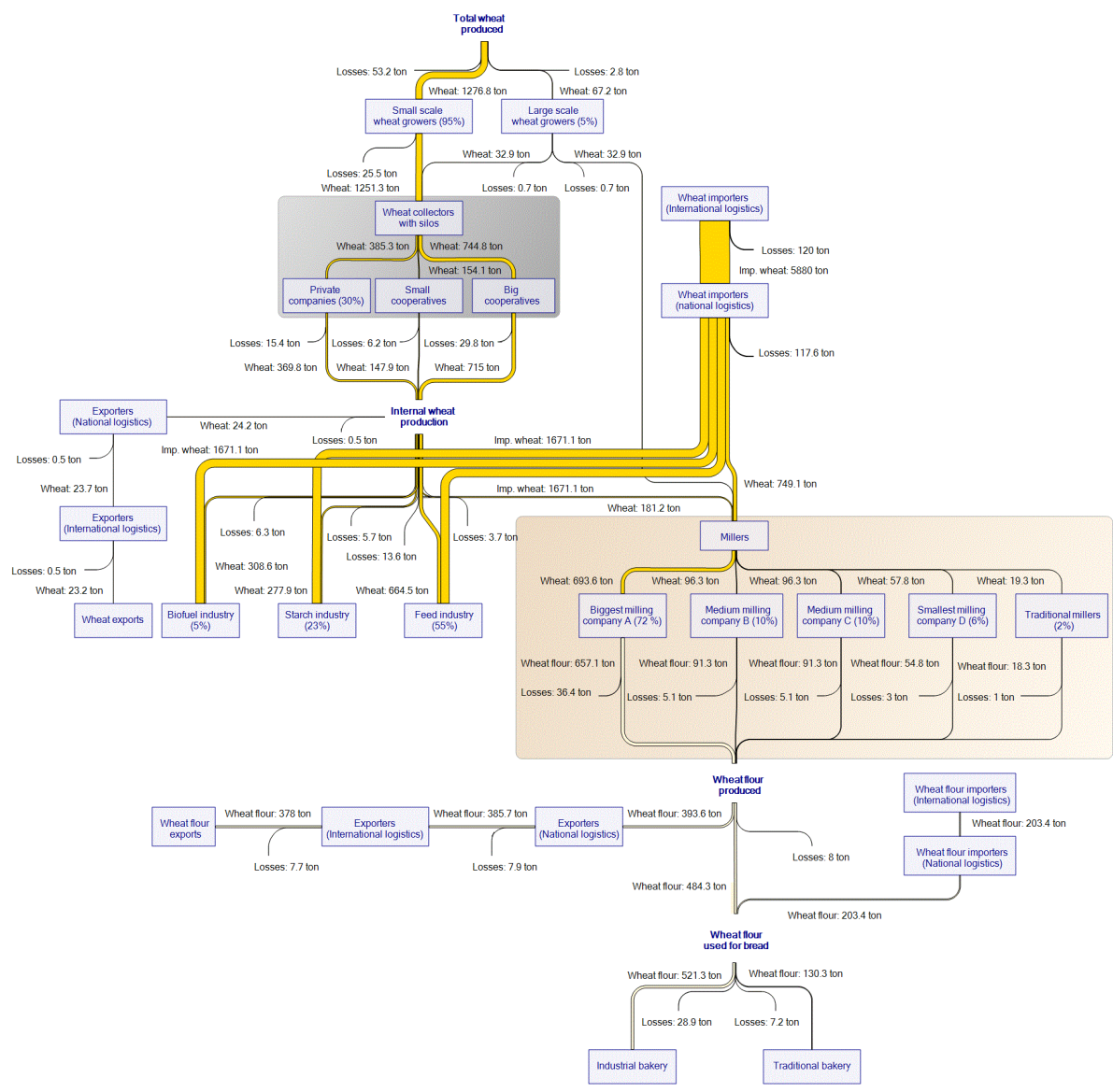

Figure 3. Mass flow analysis of the Dutch wheat flour distribution network. The network was constructed by the author with information from [24]. Data (e.g. imports and exports) were collected by FAOSTAT for 2010 [25] (most of which are likely to be traded, and not processed amounts). The losses coefficients are from FAO [22]. The losses were split into: a) postharvest handling and storage (4\%), transportation $(2 \%)$, processing and packaging $(5.25 \%)$. 


\section{Summarizing}

The main methodological aspects of exergy analysis discussed are summarized:

- Exergy has been characterized as a pseudo-property, however, it can still be considered as an objective concept for the sustainability assessment of industrial food production chains and processes when the results are expressed in an intensive way (e.g. per kg product or resource used) as they are not dependent on the selection of the environment of reference.

- A "quick reference library" listing the chemical exergy, and embodied exergy values of raw materials, ingredients, foods, food products, and other inputs will assist the sustainable design and assessment of industrial food production chains and processes.

- A nutritional extension of exergy analysis would assist the design of sustainable food production chains and facilitate the comparison of different food products.

- The inefficient use of material streams greatly impacts the sustainability of the total food production chain because the chemical exergy content is usually much larger than the physical exergy. Therefore, a thorough mass flow analysis can be as important as an exergy analysis. The theoretical useful work that could be regained from a side-stream should be included in a Grassmann diagram for visualization purposes.

- Harmless side-streams (i.e. non-toxic) that are wasted into the environment have a zero exergy value. Toxicity cannot be accounted for in an exergy analysis yet. Therefore, the exergy content of the side-streams that are harmful and which are wasted into the environment should represent the minimum exergy that has to be spent for their abatement, i.e. in order to 
bring them "back to equilibrium" with the reference environment. It can also be included as a design criterion when developing a new process.

- Simplifying the analysis by considering only the relevant system boundaries facilitates the assessment. Solar exergy can dwarf the effects of other exergy flows on the exergetic assessment of industrial food production chains and therefore, it can be excluded from the analysis.

\section{Consequences for the design of industrial food production chains}

\section{Archetypes of industrial food production chains}

The categorization of industrial food production chains in conceptual archetypes is valuable for the development of sustainable system design. In these archetypes, food processes are seen as thermodynamic engines that deliver safe, nutritious, palatable, and sustainable food products. Quoting Špicar [26]:

"understanding the system archetypes helps making the correct decisions because it allows the users to see beyond the apparent behaviour and leads them to understand the system in its entirety."

Industrial food production chains can be categorized in three main archetypes illustrated in Figure 4: a) linear chains, b) side-stream-recycling chains, and c) network chains. Linear chains are described mainly by combined material exergy streams that flow throughout the chain in a linear manner until the very last step of consumption. Side-stream-recycling chains are described by closed loops that reuse side-streams at any part of their enclosed system boundaries, mainly for their own benefit. Network chains can be seen as branched chains with multiple input flows that first converge towards central nodes of the system (i.e. processes where most of exergy streams flow through), and then diverge to other sides. They can involve also other sectors, pointing towards the direction of bio-refinery and industrial symbiosis. 
- The linear chain. An example is the conventional bread production chain (Chapter 3). In such a chain, all components are collected and processed, and through a sequence of steps, a product (portfolio) is created. Along the chain, side streams are generated, which are typically wasted, or used for low-value purposes. This chain type can be very efficient in terms of the production of the main product (portfolio), provided the amount of material (and energy) lost in the side stream remains very limited. Generally however, in these chains the focus is usually on the product to produce, and not on the complete conversion of the raw materials into high-value products.

- The side-stream-recycling chain. An example is the sourdough bread production chain, with the waste bread from the supermarkets collected, fermented, and re-processed into sourdough bread (Chapter 3). Such a chain is a typical case where one cannot avoid the generation of side streams. Another example is the case of industrial mushroom production where the spent compost is much larger than the actual food product of the chain (Chapter 4). A logical approach is then to use these side streams of such a chain as part of its own raw materials, thus lowering the net use of raw materials. It has been shown that both the exergetic and the economic performance of the whole system can be improved considerably when all side-streams of industrial mushroom production are recycled and reused completely [27]. In some cases, however, the amount of exergy involved in the recycling can be high, possibly even higher than the exergy content of the side streams would justify. Moreover, the overall exergy efficiency of the food production chain might also be reduced if part of the recycled waste stream (e.g. wasted bread) is used to create higher amounts of a competing "exergy-dilute" product (e.g. sourdough) rather than the actual "exergy-rich" product of chain (e.g. sourdough bread). These types of chains can be encountered when the (more) complete conversion of the raw materials into end product(s) is more important. 
- The network chain. This chain extends its system boundaries to include additional stakeholders (which can be related to other sectors). If production of side streams cannot be avoided, and there is no option to reuse on-site the side streams (e.g., after conversion or upgrading), then one may transfer the side streams to other actors, who may use it for the production of very different things (e.g. use of champost for energy [28] or fertilizer purposes [29]). It has been shown that the exergetic optimization of industrial bread and mushroom production comes at the expense of a decreased economic profit [30] [27]. This indicates that at some point, (sub)optimization of a single food production chain does not make sense anymore and optimization has to be done in a wider system. While this interconnectivity may yield better overall exergetic performance, one also becomes more dependent on other actors, and therefore this enhanced efficiency can impact negatively on the resilience against external disturbances (e.g. an unforeseen factor that might cause the whole network structure to shift its "optimum structure”).

Currently, many food products consist of a number of ingredients, all of which might have their own production chains. Therefore, one could argue that the food production system is on a high level already a network, and therefore, highly efficient. However, many of these ingredients are highly processed and refined which leads to additional exergy expenditure, since on a smaller scale the processes used for this refining are generally linear.

Perhaps complete refinement of ingredients is unnecessary, and sustainable solutions for obtaining "good quality" food products might lie in the better use of "sidestreams" (i.e. new raw materials/ingredients) that are obtained "earlier" in the network. If individual food production chains are seen as sub-systems of a larger network, then they do not necessarily have to be highly specialized on delivering a very limited number of extensively processed food products, but they could rather focus on delivering all of their minimally processed (portfolio) side-streams to other actors in the chain maximally. 
Obviously, wide system boundaries and the inclusion of multiple actors are aspects that increase the complexity of the analysis considerably. Besides, a complex network will probably require investments in technologies that are not exergyintensive for recycling and reusing side-streams efficiently. Nevertheless, rethinking the design of food production chains as networks seems to be a very reasonable option for ensuring an exergy-efficient supply of food products. 

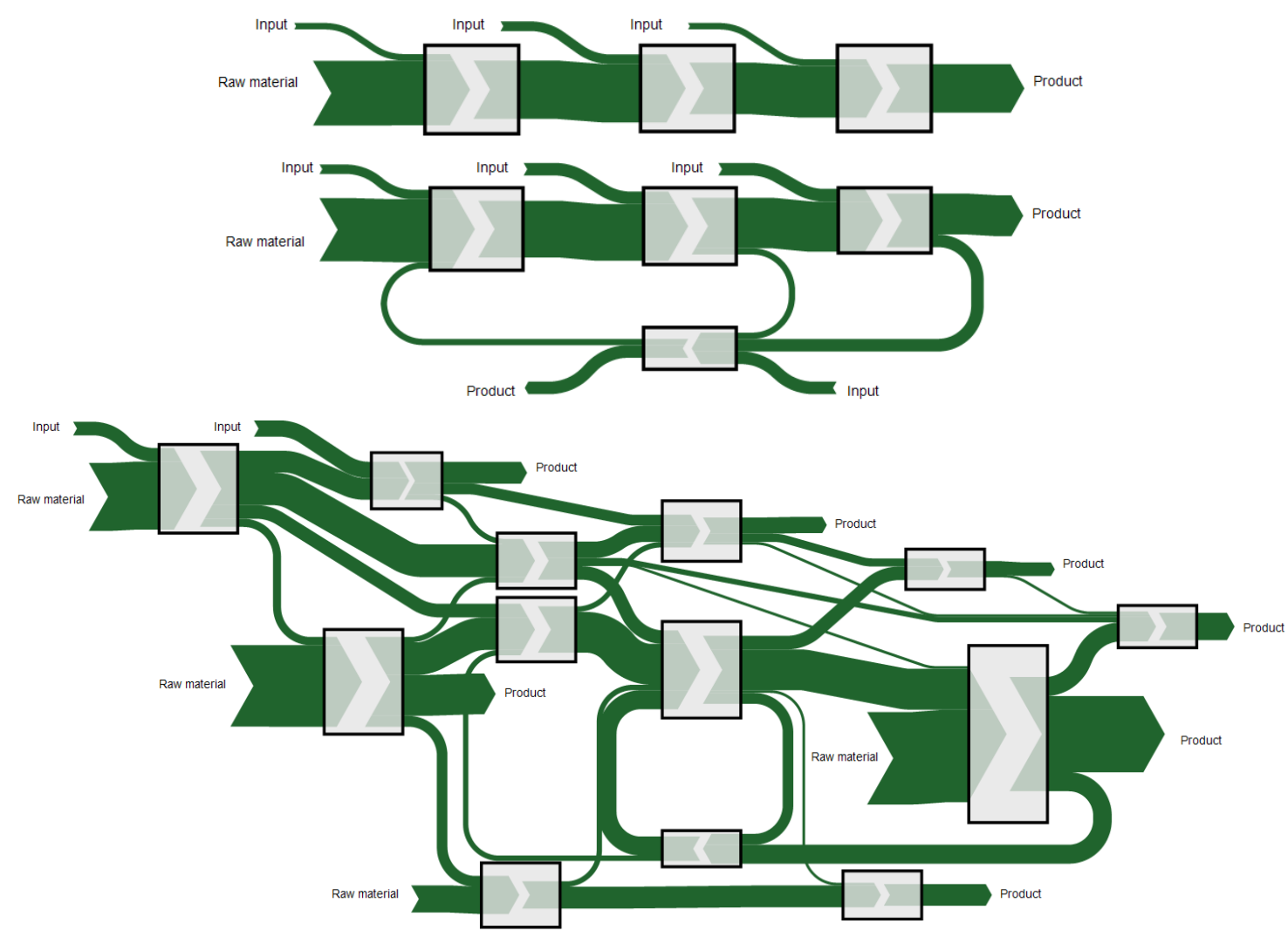

Figure 4. Conceptual archetypes of industrial food production chains: top: the linear chain, middle: the recycling-side-stream chain, bottom: the network chain. 


\section{Adapting insights from systems ecology}

Entropy production (i.e. exergy destruction) does not necessarily have a negative impact on the environment because it merely indicates the degradation of driving forces [31]. This seems to be a rather counter-intuitive argument that could invite someone to ask: "if exergy destruction does not negatively affect the environment then why should we bother using exergy analysis?'. However, exergy destruction quantifies an unavoidable cost of running a process e.g. for converting one form of exergy into another. Always, a certain amount of exergy has to be invested to operate any process, leading to a certain amount of destroyed exergy. In the case where the process is suboptimal, additional exergy is wasted unnecessarily, and thus, the total exergy losses also increase unnecessarily.

A brief look on how ecosystems work could shed more light on clarifying the previous counter-intuitive statement regarding the production of "non-harmful" entropy. Following a systems ecology approach, it is theorized that ecosystems selforganize, grow, and develop by adopting configurations that allow for maximum exergy flux and for maximum exergy storage $[32,33]$. They do so by minimizing their specific dissipation rather than maximizing their total dissipation [34]. In this way they maximize exergy storage faster, particularly: a) by maximizing the exergy input, b) by maximizing the exergy retention time, and c) by maximizing the internal exergy recycling [34].

Additionally, the self-organization of ecosystems lies on the interplay between two complementary aspects: efficiency (specialization in a certain task) and resilience (through redundancy of connections in their network) [35]. Following this reasoning, exergy utilization (i.e. storage and consumption) is theorised to occur naturally in ecosystems, and particularly the way exergy is flowing, is preserved, and is destroyed seems to matter for their self-organization and health. Ecosystem health can be assessed by using the concept of eco-exergy and structural exergy, because these indicators consider complexity. For example: "a kilogram of grass has lower eco-exergy than a kilogram of lion, although their physical and chemical 
exergy storage might be identical" [36]. Regarding industrial ecosystems it has been shown that firms with low interconnectedness for exchanging material and energy flows with each other, are much more resilient (i.e. able to maintain eco-efficient exergy flows under disruptions) than highly connected and inter-dependent firms [37].

Perhaps by understanding nature's exergy flux management, and by measuring complexity by using the concept of eco-exergy, insights could be reached (through analogies) for the sustainable design of industrial food production networks. It could be hypothesized that industrial food production chains that are designed for maximum utilization of all exergy flows in a broader network of sufficient complexity (i.e. to have flexibility and avoid "rigid inter-dependency"), will be highly resilient exergy-wise.

\section{Guidelines for the design of sustainable food production chains}

Sustainability should be intrinsically designed into industrial food production chains rather than specified afterwards. General rules for the design of sustainable systems (ranging from chemical processes to buildings) have been formulated by Denbigh [38], by Leites et al. [39], by Schmidt [40], and by Stremke et al. [41] which could also apply for the design of sustainable industrial food production chains. Therefore, by summarizing the main finding of this thesis (considering the already existing design rules), the following guidelines are proposed to be adopted by the food industry to design sustainable food production chains exergy-wise:

- Avoid the generation of waste streams, particularly material (chemical exergy) streams (chain architecture 1: linear). Exergy losses later in the chain are more severe than losses in the beginning of the chain.

- When the avoidance of waste streams is not possible then consider them as side-streams by either recycling or reusing them, i.e. by closing all material loops of the chain (chain architecture 2: recycling). Choose for internal recycling only when this can be done via a small exergetic investment. 
- If internal recycling is too costly, then external cascading is recommended (chain architecture 3: network). This is valid both for material and immaterial exergy streams. Material cascading involves the use of side streams for another process; immaterial cascading involves the use of physical exergy in other processes by matching the necessary exergy requirements.

- In a network chain, saturate all nodes with just the minimum exergy required and make sure that all exergy outflows are utilized maximally, and are not wasted.

- From a set of given processes, select one that is slowest, i.e. reduces the dissipation of resource quality.

- In each process identify the main driving forces that are relevant, and match their size to what is minimally required to achieve the process in the given process time, i.e. distribute the driving forces in such a way that the amount of exergy that is destroyed is as close as possible to the unavoidable amount of exergy destruction.

- If high driving forces are used for only a very small part of the process, then cascade any remaining gradients to another process to improve the overall resource efficiency.

- Whenever possible, make use of renewable energy sources. 


\section{Towards a sustainable food industry}

The main focus of today's food industry is the demand-driven production of an abundance of cost-effective (cheap) food products rather than the efficient conversion and the complete use of raw materials and energy, and their proper management throughout the complete food production chain [42-46]. This modus operandi leads to large amounts of food (materials) being wasted, material sidestreams discarded, water and energy consumed, and land used to no purpose [22, 47]. It is indisputable that the sustainable production and supply of food on a global scale will be one of the main challenges to be faced in the coming years [48].

With this thesis we showed that the application of exergy analysis as a sustainability assessment tool of industrial food production chains is feasible and can provide useful information for the efficient use of natural resources. The use of exergy destruction as a criterion for estimating the depletion of natural resources has already been proposed (e.g. [49, 50]). A number of authors argued that exergy destruction should be used in policy making for sustainable development $[51,52]$, while others recommended exergy wastage taxation through the active participation of governments $[53,54]$. An entropy added tax (EAT) was already proposed by Hirs in the early 90s [55]. In such a system, the involved stakeholders in the food production chain would be taxed for exergy-inefficient processing and exergy wastage practices, while the consumers would have to face taxation according to the cumulative exergy spent for producing the delivered food products or services. The allocation of exergy use to specific products is however very difficult in a strongly networked economy. Moreover, passing an exergy-based tax on consumers would be difficult, because it would depend on how the concept of exergy is communicated and on whether it would be accepted by the society as an objective benchmark indicator. Nevertheless, consumers would still have the option of comparing exergysustainable food products in such a system, and this "license to consume exergy" would form an incentive for companies to improve their environmental performance. The importance of understanding resource efficiency in terms of exergy and not solely of economics has been stressed by Robert Ayres [31]: "It is 
not the finiteness of resource stocks, but the fragility of self-organized natural cycles that we have to fear. Unfortunately, the services provided by these cycles are part of the global commons. They are priceless, yet "free". Markets play no role in the allocation of these resources". The main hurdle to be overcome for the adoption of exergy analysis as an assessment tool by the food industry, still seems to be the communication of its usefulness and of the results.

The implementation of exergy safeguarding practices in the food industry is not an infeasible task. Some encouraging practical applications exist, which could inspire the adoption of the exergy concept as a mandatory requirement for the sustainable design of industrial food production chains. For example, a dairy processing plant was assessed by exergy analysis to reduce the thermodynamic inefficiencies in the system [56].

In another case, a heat (thermal exergy) integration framework that comprised of four main steps (i.e. process zoning and data extraction, zonal analysis, intra-zonal integration, and inter-zonal integration) was developed and applied successfully on a confectionary factory [57]. These studies demonstrate the feasibility of monitoring, collecting, and assessing data by using the concept of exergy, as well as of designing exergy-efficient systems.

It should be stressed that any modifications on the configuration of the complete food production chain should be done with caution. Industrial scale intensification might also lead to negative results by integrating processes without considering the potential effects on the environment. For example, integrated bioenergy production from peach nectar residues was shown to minimize the environmental impact when the energy produced was utilized directly on site, and was considered as a byproduct that did not compete with the actual food product, therefore, not disturbing the soil nutrient cycles through unsustainable biomass removal rates [58].

Of course, the implementation of any exergy preservation program should extend to all directions. It should not only focus on rendering the food industry more sustainable but also on educating policy makers, retailers, consumers, and all other 
stakeholders involved in the chain, to learn how to value high quality exergy appropriately. Some authors stress the importance of multi-stakeholder collaboration for achieving target objectives that go beyond production interests [59]. Other authors propose a reverse-engineering decision making approach for designing food products that is based on expert knowledge modelling which is not yet possible to be automated [60].

Exergy resource use and consumption, could be used in policies that do not stress only food waste (chemical exergy) reduction management, but exergy loss reduction practices in general. Strong incentives, increased awareness, and support by governments and international organizations could facilitate the adoption of exergy preservation programmes by the food industry. The use of exergetic indicators could prove useful in building up databases for monitoring the exergy performance of industrial food production chains, and for formulating evidence-based policies that mandate exergy efficiency targets.

A resilient society that will be self-sufficient, and autonomous in feeding itself without disrupting the environment, could be achieved by learning how to balance between the efficient and effective use of natural resources. This thesis showed that exergy can be an important and practical means to this end.

\section{References}

[1] Dincer I, Cengel Y. Energy, Entropy and Exergy Concepts and Their Roles in Thermal Engineering. Entropy. 2001;3(3):116-49.

[2] Gaudreau K. Sustainability assessment of energy systems. Ontario, Canada: University of Waterloo, 2013.

[3] Morris DR, Szargut J. Standard chemical exergy of some elements and compounds on the planet earth. Energy. 1986;11(8):733-55.

[4] Szargut J. Chemical exergies of the elements. Applied Energy. 1989;32(4):26986. 
[5] Rivero R, Garfias M. Standard chemical exergy of elements updated. Energy. 2006;31(15):3310-26.

[6] Ayres RU, Ayres LW, Martinás K. Eco-thermodynamics: exergy and life cycle analysis. In: Centre for the Management fo Environmental Resources I, editor. Fontainebleau, France1996.

[7] Dewulf J, Bösch ME, Meester BD, Vorst GVd, Langenhove HV, Hellweg S, et al. Cumulative Exergy Extraction from the Natural Environment (CEENE): a comprehensive Life Cycle Impact Assessment method for resource accounting. Environmental Science \& Technology. 2007;41(24):8477-83.

[8] Zisopoulos FK, Becerra Ramírez HA, van der Goot AJ, Boom RM. A resource efficiency assessment of the industrial mushroom production chain: the influence of data variability. Journal of Cleaner Production. 2016;126:394-408.

[9] Song G, Shen L, Xiao J. Estimating specific chemical exergy of biomass from basic analysis data. Industrial \& Engineering Chemistry Research. 2011;50:9758-66.

[10] Zhang Y, Ghaly AE, Li B. Determination of the exergy of four wheat straws. American Journal of Biochemistry and Biotechnology. 2013;9(3):338-47.

[11] Hernández Suárez M, Rodríguez Rodríguez EM, Díaz Romero C. Chemical composition of tomato (Lycopersicon esculentum) from Tenerife, the Canary Islands. Food Chemistry. 2008;106(3):1046-56.

[12] Szargut J, Morris DR, Steward FR. Exergy analysis of thermal, chemical and metallurgical processes. Berlin: Springer Verlag.

[13] Alvarado S, Iribarne J. Minimum energy requirements in industrial processes: An application of exergy analysis. Energy. 1990;15(11):1023-8.

[14] Huang W, Wang J, Dai X, Li M, Harder MK. More than financial investment is needed: food waste recycling pilots in Shanghai, China. Journal of Cleaner Production. 2014;67(0):107-16. 
[15] Papargyropoulou E, Lozano R, K. Steinberger J, Wright N, Ujang Zb. The food waste hierarchy as a framework for the management of food surplus and food waste. Journal of Cleaner Production. 2014;76(0):106-15.

[16] Senthilkumar K, Mollier A, Delmas M, Pellerin S, Nesme T. Phosphorus recovery and recycling from waste: An appraisal based on a French case study. Resources, Conservation and Recycling. 2014;87(0):97-108.

[17] Mirabella N, Castellani V, Sala S. Current options for the valorization of food manufacturing waste: a review. Journal of Cleaner Production. 2014;65(0):28-41.

[18] Daniel JJ, Rosen MA. Exergetic environmental assessment of life cycle emissions for various automobiles and fuels. Exergy, An International Journal. 2002;2(4):283-94.

[19] Rosen MA, Dincer I. ON EXERGY AND ENVIRONMENTAL IMPACT. International Journal of Energy Research. 1997;21(7):643-54.

[20] Gaudreau K, Roydon AF, Murphy S. The tenuous use of exergy as a measure of resource value or waste impact. Sustainability. 2009;1:1444-63.

[21] Rijksdienst voor Ondernemend Nederland. Gross energy requirement values. 2015.

[22] Gustavsson J, Cederberg C, Sonesson U, Otterdijk Rv, Meybeck A. Global food losses and food waste - Extent, causes and prevention. Food and Agriculture Organization of the United Nations; 2011. p. 37.

[23] Mulder J, Van Der Kooi HJ, Arons J, Dewulf JP. Alternative routes for ethanol production from renewable resources. Conference Alternative routes for ethanol production from renewable resources, Enschede, The Netherlands.

[24] Pol H. Innovation in the Dutch wheat supply chain : a study into the ways of increasing the utilization of Dutch wheat in bread production by means of supply chain innovatio: University of Twente, 2007. 
[25] FAO. http://faostat.fao.org/. 2016.

[26] Špicar R. System Dynamics Archetypes in Capacity Planning. Procedia Engineering. 2014;69(0):1350-5.

[27] Banasik A, Kanellopoulos A, Claassen GDH, Bloemhof-Ruwaard J, van der Vorst JGAJ. Closing loops in agricultural supply chains using multi-objective optimization: a case study of an industrial mushroom supply chain. (submitted).

[28] Finney KN, Ryu C, Sharifi VN, Swithenbank J. The reuse of spent mushroom compost and coal tailings for energy recovery: Comparison of thermal treatment technologies. Bioresource Technology. 2009;100(1):310-5.

[29] Oei PT. The alternative uses of spent mushroom compost. In: Oei P, editor. Productschap Tuinbouw. Tiel, The Netherlands2007.

[30] Banasik A, Kanellopoulos A, Claassen GDH, Bloemhof-Ruwaard J, van der Vorst JGAJ. Assessing alternative production options for eco-efficient food supply chains using multi-objective optimization. (submitted).

[31] Ayres RU. Eco-thermodynamics: economics and the second law. Ecological Economics. 1998;26(2):189-209.

[32] Jørgensen SE, Bendoricchio G. Fundamentals of Ecological Modelling, 3rd Edition. Amsterdam, The Netherlands2001.

[33] Silow EA, Mokry AV. Exergy as a Tool for Ecosystem Health Assessment. Entropy. 2010;12(4):902-25.

[34] Fath BD, Patten BC, Choi JS. Complementarity of Ecological Goal Functions. Journal of Theoretical Biology. 2001;208(4):493-506.

[35] Bodini A, Bondavalli C, Allesina S. Cities as ecosystems: Growth, development and implications for sustainability. Ecological Modelling. 2012;245(0):185-98. 
[36] Burkhard B, Fath BD, Müller F. Adapting the adaptive cycle: Hypotheses on the development of ecosystem properties and services. Ecological Modelling. 2011;222(16):2878-90.

[37] Zhu J, Ruth M. Exploring the resilience of industrial ecosystems. Journal of Environmental Management. 2013;122(0):65-75.

[38] Denbigh KG. The second-law efficiency of chemical processes. Chemical Engineering Science. 1956;6(1):1-9.

[39] Leites IL, Sama DA, Lior N. The theory and practice of energy saving in the chemical industry: some methods for reducing thermodynamic irreversibility in chemical technology processes. Energy. 2003;28(1):55-97.

[40] Schmidt D. Low exergy systems for high-performance buildings and communities. Energy and Buildings. 2009;41(3):331-6.

[41] Stremke S, van Den Dobbelsteen A, Koh J. Exergy landscapes: exploration of second-law thinking towards sustainable landscape design. Int $\mathrm{J}$ Exergy. $2011 ; 8(2): 148-74$.

[42] Roy P, Orikasa T, Nakamura N, Shiina T. Environmental Sustainability in Food Processing. Sustainable Food Processing: John Wiley \& Sons, Ltd; 2013. p. 39-62.

[43] Verma M. Food Wastage-Energy Wasted. Energy Use in Global Food Production: Springer International Publishing; 2015. p. 23-6.

[44] Verma M. Energy Intensity and Efficiency in Food Production. Energy Use in Global Food Production: Springer International Publishing; 2015. p. 27-33.

[45] Hall GM, Howe J. Energy from waste and the food processing industry. Process Safety and Environmental Protection. 2012;90(3):203-12. 
[46] Notarnicola B, Hayashi K, Curran MA, Huisingh D. Progress in working towards a more sustainable agri-food industry. Journal of Cleaner Production. $2012 ; 28(0): 1-8$.

[47] Kummu M, de Moel H, Porkka M, Siebert S, Varis O, Ward PJ. Lost food, wasted resources: Global food supply chain losses and their impacts on freshwater, cropland, and fertiliser use. Science of The Total Environment. 2012;438(0):477-89.

[48] Ohlsson T. Chapter 43 - Sustainability and Food Production. In: Motarjemi Y, Lelieveld H, editors. Food Safety Management. San Diego: Academic Press; 2014. p. $1085-97$.

[49] Cornelissen RL. Thermodynamics and sustainable development. Enschede, The Netherlands: University of Twente, 1997.

[50] Edwin C. Exergy: less heat, more light. Physics World. 2015;28(12):10.

[51] Dincer I. The role of exergy in energy policy making. Energy Policy. 2002;30(2):137-49.

[52] Rosen MA, Dincer I, Kanoglu M. Role of exergy in increasing efficiency and sustainability and reducing environmental impact. Energy Policy. 2008;36(1):12837.

[53] Wall G. Exergy, ecology and democracy - concepts of a vital society or a proposal for an exergy tax. 2nd European Congress on Economics and Management of Energy in Industry. Estoril, Portugal1994.

[54] Horne JP. Climate change and economic growth enigma: An investment suggestion from Wall Street. Environmental Innovation and Societal Transitions. 2013;9(0):26-32.

[55] Hirs G. Exergy loss: A basis for energy taxing In: Energy Efficiency in Process Technology, Pilavachi PA editor. Elsevier Applid Science, 1993, p. 1241-1253. 
[56] Jafaryani Jokandan M, Aghbashlo M, Mohtasebi SS. Comprehensive exergy analysis of an industrial-scale yogurt production plant. Energy. 2015;93, Part 2:1832-51.

[57] Miah JH, Griffiths A, McNeill R, Poonaji I, Martin R, Yang A, et al. Heat integration in processes with diverse production lines: A comprehensive framework and an application in food industry. Applied Energy. 2014;132(0):452-64.

[58] De Menna F, Vittuari M, Molari G. Impact evaluation of integrated foodbioenergy systems: A comparative LCA of peach nectar. Biomass and Bioenergy. 2015;73(0):48-61.

[59] Halloran A, Clement J, Kornum N, Bucatariu C, Magid J. Addressing food waste reduction in Denmark. Food Policy. 2014;49, Part 1(0):294-301.

[60] Thomopoulos R, Croitoru M, Tamani N. Decision support for agri-food chains: A reverse engineering argumentation-based approach. Ecological Informatics. (0). 


\section{Summary}

In this thesis the concept of exergy is applied to assess the environmental performance of industrial food production chains and processes in terms of resource efficiency. Exergy is an objective metric to assess resource efficiency because it is based on the first and second law of thermodynamics, and it quantifies the available work that can be extracted from a stream or a process in relation to a selected environment of reference.

The objective of the work reported in this thesis is to identify overarching principles that can lead to general rules in the form of guidelines for the sustainable design of industrial food production chains, firstly, by pinpointing the exergy-inefficient locations, and secondly, by understanding the reasons for these inefficiencies.

Chapter 2 presents a literature review focused on the use of exergetic indicators in assessing the sustainability of industrial food production chains and processes. Exergy analysis has been applied extensively in the energy and the construction sectors, its potential, however, has not been fully exploited within the food industry yet. The use of various exergy-based indicators is summarized and their physical meaning is discussed. Drying processes are the most frequently studied processes due to the high energy requirements of water evaporation. The chapter finally discusses additional aspects and challenges in assessing the thermodynamic performance of industrial food production chains and processes with exergy analysis, as well as potential future trends.

Chapter 3 demonstrates the use of exergy analysis in assessing the sustainability of an industrial bread production chain. Conventional bread production (with bread wasted at the retailer) is compared to par-baking (where bread waste is avoided by baking on demand), and to a fermented breadcrumb technology (where the bread waste is reworked into a new product of equally good quality). The results show that closing mass balances should be the first priority in improving the resource efficiency of a food production chain because unused material side-streams translate into considerable amounts of chemical exergy wasted. Furthermore, recycling of 
material streams for forming new products can also improve the efficiency of the chain but only as long as it comes at reasonable additional exergy cost for reprocessing.

Chapter 4 introduces Critical Exergy loss Points (CEPs) as a criterion for identification of the locations within the food production chain where most of the exergy losses occur, and for assessment of potential chain modifications for the improvement of its thermodynamic performance. As a case study, the resource efficiency of an industrial mushroom production chain was assessed: the two main CEPs in this chain are the first phase of composting process and the final steaming of the spent compost. The actual food product (mushrooms) of this food production chain is much smaller in terms of mass than the side-stream generated (spent compost), suggesting recycling of the latter. Assessment of the theoretical recycling of this spent compost as a new raw material showed that the exergetic performance of this chain could be improved considerably. These results demonstrate that decisions regarding chain improvement should be based on the nature and size of the exergy losses (which can be either physical or chemical exergy). Additionally, it was shown that variability in data can lead to both quantitatively and qualitatively different outcomes; not only were different values for the selected indicators obtained, in addition a different number of CEPs was identified.

Chapter 5 explores exergy assessment for understanding the exergy losses associated with the fundamentals of a particular single process step. As a case study the exergetic requirements of a spray drying process were investigated, to understand the consequences of increasing processing rates on the resource efficiency of the process. A conventional drying model was used to describe the impact of utilizing air of different qualities on the thermodynamic performance of a conceptual convective drying process of a lactose solution. The higher the quality of the air, i.e. the more its temperature and moisture content deviate from the environment of reference, the more exergy it has. A high quality is however necessary, since the drying times in a spray drying process have to be short. This implies that outlet air, which still might have high quality, should be cascaded to 
other processes to improve the overall resource efficiency. The thermal and chemical exergy of the air and the food product are the most relevant forms of exergy to consider in a natural convective drying process while the effects of the kinetic, potential, and surface tension exergy can be neglected. It was shown that the use of large driving forces (i.e. warm and dry air) is better than the use of smaller ones (i.e. cold and moist) in terms of exergy destruction, and that slower processing is better than fast drying exergy-wise. Additionally, the influence of the selection of the environment of reference was assessed, and it was found that it does not affect the results. This study demonstrates the usefulness of the exergy concept for assessing the real efficiency of resource use in food processes.

Chapter 6 is a general discussion that summarizes the main findings of the cases studied and the generalizations based on those case studies. Industrial food production chains are characterised into three different archetypes, and general guidelines for their sustainable design are formulated. Additional aspects related to the use of exergy such as the allocation of a value to waste streams, the impact of system boundaries, and the influence of the environment of reference, are also critically discussed. Finally, a few thoughts related to the use of exergy in policy related aspects are presented. 


\section{Acknowledgements}

With these last words I am finalizing my thesis. I have to admit that it is a peculiar feeling because in some way it signifies an end to a "chapter in my life" but also a start to new one. In retrospect, I think that I could have done more things, and perhaps in a different way. I have heard before that self-criticism is a "normal process" for everyone who engages in research, however, I have never imagined that I would feel it so intensively, especially during the last year. In fact, the more I read through my thesis the more I feel that it is far from complete, and that there is plenty of room for criticism which, of course, is always welcome if not necessary in science. My wish and hope is that this work will contribute a grain of knowledge that is useful both to science and to society. Even though some of the people that I will acknowledge did not contribute content-wise in this thesis, they did change me in one way or another, and without them perhaps this work might have not been pleasant, finished on time, or even finished at all.

I dedicate this thesis especially to my father, to my sister Christina and her husband Anestis, and to my brother Thanos, for always supporting and loving me, and of course, to my mother who I am sure she would be very proud.

I am particularly grateful to Professor Remko Boom for giving me the opportunity to do a $\mathrm{PhD}$ in the exciting field of exergy, for allowing me to express my wild philosophical endeavors without constraining me at any single moment, and who always supported me in all my research choices, but without forgetting to challenge me in a constructive way so that I could see the bigger picture. Moreover, I would like to thank Professor Tiny van Boekel for his valuable comments during the kickoff meeting of the project, and who together with Professor Remko Boom provided the initial foundations of this very interesting work package.

Next, I would like to thank Professor Atze Jan van der Goot for his supervision, for all the types of interesting discussions we had, but also for his impressive less-than24-hours-paper-delivery-policy. Many thanks also to Francisco Rossier-Miranda for his supervision during the first months of my $\mathrm{PhD}$. 
It was a pleasure to be part of the TIFN team of Toine Timmermans. Friso van Assema is simply the coolest and most straightforward project leader ever and he certainly deserves a big "thank you" for giving me the chance to be part of this team. I really enjoyed working with the people from the Operations Research and Logistics department of Wageningen University who participated in this project: Frits Claassen, Jacqueline Bloemhof-Ruwaard, and Jack van der Vorst. Aleksander Banasik, always inspired me with his pragmatic view on basically everything, and Argyris Kanellopoulos was always very polite, positive, and supportive even though he wasn't my direct supervisor. Also many thanks to Jan Broeze from the Food and Bio-based Research group for always finding time to critically discuss my research. I also would like to thank Caroline van der Horst, Peter Weegels, and Marcel Peeters for the amazing collaboration we had, and for the valuable insights they provided in the actual practices of the industrial world.

My former students Sanne Moejes, Anne van der Ploeg, Henry Becerra Ramírez, Josephine Ecklu, Birte Schepers, Jose Jimenez Gutierrez, Huixuan Zhao, Jose Rueda Seidel, and Ian Made Supriyatna, certainly deserve compliments for all their contributions in my research, and I thank them for helping me become a better supervisor.

I am also very happy to have met Jue Wang and Feifei Gao, and I am grateful to them for understanding, and supporting me in similar "battles in life"!

There is no doubt that the whole Food Process Engineering department is a great group to be part of, full of nice people. Laura van Donkelaar thank you for always charging me with positivity, Marta Rodriguez-Illera and Nicolas Hardt for all the extropic discussions we had, Jaap Dijkshoorn for being a great host in your house in Leeuwenborgh :P, Meinou and Kelly for the nice lunch breaks together, Angelica Tamayo Tenorio for the random candy surprises on my desk, Sami Sahin for the "hints \& tips" during the final steps of the PhD, Victor Qui for the short trips to the cinema, Ekaraj Paudel for the random and full-of-wisdom chats, Ali for all the 
Maxwell-Stefan related spontaneous discussions, and Lu Zhang for designing the beautiful cover of this thesis!

I do not forget to thank all my favorite technicians who supported me with all the labwork throughout this thesis: Maurice Strubel (I still owe you a box of stroopwafels from my MSc thesis times), Martin de Wit (for enduring all my questions for declaring expenses and my mistakes in filling in the time-sheet), Jos Sewalt (for helping me with the DVS that I never used), and Jarno (for our joint quest to find the universal white rabbit that hides somewhere within the journey itself rather than in some particular location in the Cosmos).

It was a pleasure to share the office with Marlies Geerts and Mauricio Opazo Navarette who I thank for transforming a simple room into a cozy place for posterhanging, and for the spontaneous chats about all kinds of both relevant and irrelevant stuff.

Here, I would also like to thank Anja Janssen for her subtle, and highly appreciated support throughout my time in the FPE department during both my MSc thesis and my PhD time. Next on the list is Hans Tramper, who I have to admit I don't know very well personally, but just the fact that he showed support during some very difficult times of my $\mathrm{PhD}$, triggered a high level of respect from my side.

Also many thanks to Joao Gouveia and Anika Oppermann for the great vibes! $:$

A special place in my acknowledgements list belongs to my friends back in Greece (but also dispersed in other parts of the world): Ikaros Tsantekidis, Ilias Lalagkas, Ladikos Schmidt, Dimitris Stergiadis, Christos and Sotiris Mastrogiannidis, Lina Mpompou and Kostas Perifanopoulos, Yannis Patras, Asteris Chatzikas, Christos Stamatopoulos, Vasilis Voulgaris and Sofia Mimikou, and Giannis Stefanou who always welcomed me in the most enthusiastic ways.

Finally, I am extremely grateful to Thomas Kockmeyer for being always on my side through this academic journey, and for withstanding me even when I was my most difficult self. 


\section{About the author}

Filippos K. Zisopoulos, son of Parmenion Zisopoulos and Varvara Zisopoulou, was born in Thessaloniki in Greece on the $2^{\text {nd }}$ of December 1983. He obtained a BSc in Food Technology from the Alexandrian Technological Educational Institute of Thessaloniki in Greece. His BSc thesis aimed at understanding the inhibition of enzymatic browning of osmotically dehydrated Granny Smith apple slices. His internship as a quality control technologist took

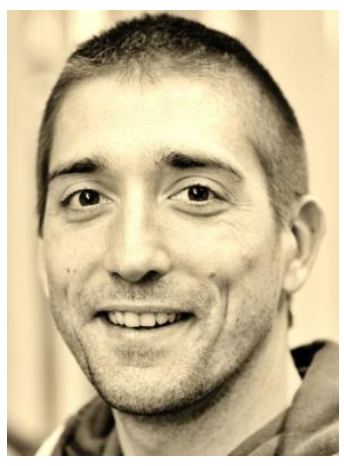
place at Entente Ltd., a pet-food canning industry in Portugal, under a Leonardo da Vinci fund. After fulfilling his military service as a quartermaster of food supplies, he worked on a short project on new product development at PAMI S.A., a company active in the treatment and standardization of dry nuts and confectionary production in Thessaloniki, Greece. He continued studying at Wageningen University in the Netherlands where he obtained an MSc in Food Technology and specialized further on the biotechnological aspects of food processing. For his MSc thesis he studied the kinetic behaviour of different galactosidase isoforms, he explored the theory of molecular crowding on understanding the effect of different sugars on the activity of the enzymes, and he assessed the exergetic performance of the commercial galactooligosaccharide production process. He finalized his studies with an internship at Cereal Partners Worldwide in Orbe, Switzerland on understanding cocoa powder properties. He continued working as a doctorate candidate at the Food Process Engineering (FPE) department of Wageningen University researching the sustainable design of industrial food production chains, a topic which was within the project "Valorization of Raw Materials and Process Efficiency" of the Top Institute of Food and Nutrition, a public-private organization on precompetitive research in food and nutrition in the Netherlands. Currently, he works as a post-doc at the FPE department, assisting in the development of an online course that deals with the assessment and the sustainable design of food processes and food production chains. 


\section{List of publications}

Warmerdam A., Zisopoulos F.K., Boom R.M., Janssen A.E.M. (2013). Kinetic characterization of galacto-oligosaccharide (GOS) synthesis by three commercially important $\beta$-galactosidases. Biotechnology Progress. 30(1):38-47.

Zisopoulos F.K., Rossier-Miranda F.J., van der Goot A.J., Boom R.M. (2015). The use of exergetic indicators in the food industry - A review. Critical Reviews in Food Science and Nutrition.

Zisopoulos F.K., Moejes S.N., Rossier-Miranda F.J., van der Goot A.J., Boom R.M. (2015). Exergetic comparison of food waste valorization in industrial bread production. Energy. 82(0): 640-649.

Zisopoulos F.K., Becerra Ramírez H.A., van der Goot A.J, Boom R.M. (2016). A resource efficiency assessment of the industrial mushroom production chain: the influence of data variability. Journal of Cleaner Production. 126: 394-408.

Zisopoulos F.K., van der Goot A.J., Boom R.M. Thermodynamic efficiency analysis of a conceptual drying process - Towards resource efficiency use in the food industry. (submitted).

Van Donkelaar L.H.G., Mostert J., Zisopoulos F.K., Boom R.M., van der Goot A.J. The use of enzymes for beer brewing: thermodynamic comparison on resource use. (submitted).

Zisopoulos F.K., van der Goot A.J., Boom R.M. Industrial food production chains as thermodynamic archetypes. (in preparation).

Zisopoulos F.K. Rodriguez-Illera M., Hardt N., van der Goot A.J., Boom R.M., Methodological aspects of exergy analysis in assessing the sustainability of industrial food production chains and processes. (in preparation). 


\section{Overview of completed training activities}

\begin{tabular}{|c|c|}
\hline Discipline specific activities & \\
\hline \multicolumn{2}{|l|}{ Courses } \\
\hline Long Harvest and Wasted Food in Wageningen (NL) & 2012 \\
\hline Fundamentals and Practice of Process Intensification in Delft (NL) & 2013 \\
\hline Mushroom Masterclass in Moerdijk (NL) & 2013 \\
\hline Advanced Thermodynamics in Delft (NL) & 2014 \\
\hline Design of Experiments in Wageningen (NL) & 2014 \\
\hline Multivariate Analysis for Food Data/sciences in Wageningen (NL) & 2014 \\
\hline Process Economics and Cost Engineering in Eindhoven (NL) & 2016 \\
\hline \multicolumn{2}{|l|}{ Conferences and Workshops } \\
\hline 2nd TIFN Annual Conference in Amsterdam ${ }^{1}$ (NL) & 2013 \\
\hline 9th European Congress of Chemical Engineers in the Hague ${ }^{2}$ (NL) & 2013 \\
\hline $14^{\text {th }}$ NPS Conference in Utrecht ${ }^{1}(\mathrm{NL})$ & 2014 \\
\hline $\mathrm{PhD}$ Council Conference in Wageningen ${ }^{2}(\mathrm{NL})$ & 2015 \\
\hline $4^{\text {th }}$ TIFN Annual Conference in Vlaardingen ${ }^{2}(\mathrm{NL})$ & 2015 \\
\hline $12^{\text {th }}$ International Congress on Engineering and Food in Quebec ${ }^{2}(\mathrm{CA})$ & 2015 \\
\hline $4^{\text {th }}$ International Exergy, Life Cycle Assessment \& Sustainability Workshop in Nisyros ${ }^{2}$ (GR) & 2015 \\
\hline $29^{\text {th }}$ EFFoST International Conference in Athens ${ }^{2}$ (GR) & 2015 \\
\hline Nederlandse Werkgroep Drogen in Wageningen ${ }^{2}$ (NL) & 2016 \\
\hline $10^{\text {th }}$ European Workshop on Food Engineering \& Technology in Uzwil ${ }^{2}(\mathrm{CH})$ & 2016 \\
\hline Estafette-bijeenkomst PPS CARVE en TIFN in $\operatorname{Veghel}^{2}$ (NL) & 2016 \\
\hline \multicolumn{2}{|l|}{ General courses } \\
\hline How to Give and Receive Feedback in Wageningen (NL) & 2012 \\
\hline TIFN IP workshop in Wageningen (NL) & 2012 \\
\hline PhD Week in Baarlo (NL) & 2012 \\
\hline Information Literacy Including Endnote Introduction in Wageningen (NL) & 2013 \\
\hline Teaching and Supervising Thesis Students in Wageningen (NL) & 2013 \\
\hline Lecturing in Wageningen (NL) & 2013 \\
\hline Techniques for Writing and Presenting a Scientific Paper in Wageningen (NL) & 2013 \\
\hline Project and Time Management in Wageningen (NL) & 2013 \\
\hline Communication with the Media and the General Public in Wageningen (NL) & 2013 \\
\hline Competence Assessment in Wageningen (NL) & 2013 \\
\hline Career Orientation in Wageningen (NL) & 2015 \\
\hline \multicolumn{2}{|l|}{ Optional activities } \\
\hline Scientific PhD Excursion to Chile and Brazil & 2014 \\
\hline Food Process Engineering Group Meetings & 2012-2016 \\
\hline TIFN Project Meetings & 2012-2016 \\
\hline
\end{tabular}

${ }^{1}$ Poster

${ }^{2}$ Oral presentation 
This thesis was within the project "Valorization of raw materials and process efficiency" and under the Top Institute of Food and Nutrition, a public-private partnership on precompetitive research in food and nutrition.

Printed by Gildeprint.

Cover by Lu Zhang. 